\title{
Serotonin and behavior: animal studies applying the method of acute tryptophan depletion
}

Citation for published version (APA):

Lieben, C. K. J. (2004). Serotonin and behavior: animal studies applying the method of acute tryptophan depletion. [Doctoral Thesis, Maastricht University]. Maastricht University. https://doi.org/10.26481/dis.20041223cl

Document status and date:

Published: 01/01/2004

DOI:

10.26481/dis.20041223cl

Document Version:

Publisher's PDF, also known as Version of record

\section{Please check the document version of this publication:}

- A submitted manuscript is the version of the article upon submission and before peer-review. There can be important differences between the submitted version and the official published version of record.

People interested in the research are advised to contact the author for the final version of the publication, or visit the DOI to the publisher's website.

- The final author version and the galley proof are versions of the publication after peer review.

- The final published version features the final layout of the paper including the volume, issue and page numbers.

Link to publication

\footnotetext{
General rights rights.

- You may freely distribute the URL identifying the publication in the public portal. please follow below link for the End User Agreement:

www.umlib.nl/taverne-license

Take down policy

If you believe that this document breaches copyright please contact us at:

repository@maastrichtuniversity.nl

providing details and we will investigate your claim.
}

Copyright and moral rights for the publications made accessible in the public portal are retained by the authors and/or other copyright owners and it is a condition of accessing publications that users recognise and abide by the legal requirements associated with these

- Users may download and print one copy of any publication from the public portal for the purpose of private study or research.

- You may not further distribute the material or use it for any profit-making activity or commercial gain

If the publication is distributed under the terms of Article $25 \mathrm{fa}$ of the Dutch Copyright Act, indicated by the "Taverne" license above, 


\section{Serotonin and behavior:}

animal studies applying the method of acute tryptophan depletion 
Cindy K.J. Lieben, Maastricht 2004

Serotonin and behavior:

animal studies applying the method of acute tryptophan depletion

Thesis with summary in English and Dutch

ISBN: 9090189157

Author: Cindy K.J. Lieben

Cover picture: Christine Vandenameele

Layout: Christine Vandenameele

Productions: Baillien \& Maris 


\title{
Serotonin and behavior:
}

\author{
animal studies applying the method of acute \\ tryptophan depletion
}

\section{PROEFSCHRIFT}

ter verkrijging van de graad van doctor aan de Universiteit Maastricht,

op gezag van de Rector Magnificus, Prof. mr. G.P.M.F. Mols, volgens het besluit van het College van Decanen, in het openbaar te verdedigen op donderdag 23 december 2004 om 12.00 uur

door

\section{Cindy Kathleen Josefa Lieben}

Geboren op 3 oktober 1975 te Genk. 
Promotor

Prof. dr. H.W.M. Steinbusch

\section{Co-promotores}

Dr. A. Biokland

Dr. N.E.P. Deutz

\section{Beoordelingscommissie}

Prof. dr. E.J.L. Griez (voorzitter)

Prof. dr. B.B. Olivier (Universiteit Utrecht)

Prof. dr. W.J. Riedel

Prof. dr. W. Saris

Prof. dr. B.H.C. Westerink (Rijksuniversiteit Groningen)

The publication of this thesis was financially supported by Roche Pharmaceuticals and PB Gelatins. 


\section{Contents}

Chapter I General introduction

Chapter 2 Anxiogenic and depressive-like effects, but no cognitive deficits after repeated moderate tryptophan depletion in the rat

Chapter 3 Methodological aspect of a tryptophan-free protein69 carbohydrate mixture on plasma tryptophan levels in the rat

Chapter 4 Acute tryptophan and serotonin depletion using an optimized tryptophan-free protein-carbohydrate mixture in the adult rat

Chapter 5 Acute tryptophan depletion induced by a gelatin95 based mixture impairs object memory but not affective behavior and spatial learning in the rat

Chapter $6 \quad$ 5,7-DHT lesion of the dorsal raphe nucleus impairs object recognition but not affective behavior and corticosterone response to stressor in the rat

Chapter 7 Dose related effects of acute tryplophan depletion on object discrimination in the rat

Chapter 8 Cognition-enhancing effects of the selective 5-HT, receptor antagonist R04368554 in cholinergic and serotonergic models of memory deficiency in the rat

Chapler 9 General discussion

Summary

Samenvatting

Appendix

Effects of an acute tryptophan depletion on the

kynurenine pathway

Dankwoord

Curriculum Vitae

Publications 



\section{CHAPTER}

1 
The identification of serotonin can be traced back to the middle of the last century. Dr. Erspamer found a substance in gastric mucosa that exerted a contractile effect on vascular and other smooth muscles and called it enteramine (Whitaker-Azmitia, 1999). In 1948, Page, Rapport and Green isolated and characterized a new substance they named serotonin which name is given because it originates from blood 'serum' and has a 'tonic' effect upon cardiovascular muscles. Although enteramine and serotonin were discovered independently from each other, they were later found to be identical. After this finding, the name serotonin was exclusively used. Shortly thereafter, the chemical structure was finally determined to be 5-hydroxytryptamine (5-HT) and identified as a indoleamine. It was in 1951 that synthetic serotonin was first made available for research.

High 5-HT concentrations are located in mucous membranes of the gastrointestinal tract $(-90 \%$ of the total body content of $5-\mathrm{HT})$, in blood platelets $(\sim 8-10 \%)$ and in the central nervous system $(-1-2 \%)$ of numerous vertebrates (Twarog and Page, 1953). The discovery of the 5-HT neurotransmitter in the mammalian brain was a major breakthrough for research in biological psychiatry.

Over the last half century, the importance of the role of 5-HT has been demonstrated in biological and psychological functions such as sleep, anxiety, aggression, cognition and impulsivity. Based on this, 5-HT has been implicated in the pathogenesis of psychiatric illnesses such as depression, eating disorders, migraine, anxiety disorders, schizophrenia, developmental disorders, alcoholism, aging and neurodegenerative disorders. Consequently, many currently used drug treatments of these disorders act by modulating serotonergic function.

Animal studies have generated extensive information regarding the possible involvement of $5-\mathrm{HT}$ in these disorders and various paradoxical experimental findings suggest a very complex role of 5-HT (irrespective of its interaction with other transmitter systems) in the occurrence of neuropsychiatric dysfunctions. Therefore, investigation of the precise role 5-HT metabolism in these behavioral dysfunctions may be useful for the discovery of novel serotonergic psychrotropic drugs. 


\section{The serotonergic system}

\section{The synthesis of central 5-HT}

5-hydroxytryptamine (5-HT; serotonin) is synthesized from the essential amino acid L-tryptophan (TRP), indicating that TRP is not produced by the body but must be consumed with food.

TRP shares its transporter-carrier with other amino acids to cross the blood-brain barrier. Therefore competition between TRP and these other large neutral amino acids (i.e. LNAA; tyrosine, leucine, isoleucine, valine and phenylalanine) determines the uptake and consequently the availability of TRP in the brain.

In the first step of the synthesis in the brain, TRP is hydroxylated by the rate limiting enzyme TRP monooxygenase (TRP hydroxylase; TH) into 5-hydroxytryptophan (5-HTP: see Fig. 1). Changes in TH activity can influence the synthesis of 5-HT following a parallel working mechanism (Boadle-Biber, 1993). Subsequently 5-HTP is transported to the axonal nerve terminals where the final step of the 5-HT synthesis takes place via aromatic amino acid decarboxylase ( $A A D C$ ) (Feldman et al., 1997) and, 5-HTP is rapidly decarboxylated into 5-HT.

\section{Pathways}

Serotonergic neurons are compactly clustered together in the midline raphe nuclei that extend caudally from the midbrain to the medulla, consisting of seven distinct nuclei (Azmitia and Segal, 1978; Steinbusch, 1981). These neurons receive input from several brain structures, e.g., substantia nigra, locus coeruleus, hypothalamus and limbic areas (Steinbusch and Nieuwenhuys, 1983: Jacobs and Azmitia, 1992). Compared with the total number of neurons in the brain, the total number of 5-HT neurons is small. Nevertheless, the serotonergic cell bodies send out the most wide branching projections throughout the entire central nervous system. Both the dorsal 
raphe nucleus (DRN) and the medial raphe nucleus (MRN) are considered to be the most important of all raphe nuclei. The innervation from the DRN is generally more spread out over the different parts of the brain than the MRN pathways (Tork, 1990; Boadle-Biber, 1993). These two major 5-HTcontaining cell groups distribute to essential non-overlapping regions (DRN: striatum, amygdala) or in complementary parts of the same structure (e.g. septum and hypothalamus) (Vertes, 1991; Vertes et al., 1999) which can contribute to the distinct regulation of many behavioral and physiological systems.

\section{Synapse}

After synthesis, 5-HT is stored in vesicles located in the nerve terminal. Upon neuronal stimulation, 5-HT is released into the synaptic cleft and transported to the post-synaptic nerve terminal where it attaches to 5-HT receptors. Once the signal is transmitted, the reuptake of 5-HT in the pre-synaptic nerve terminal results in a further release of the transmitter. 5- Ht can also be catalyzed into the inactive metabolite 5-hydroxyindolacetic acid (5-HIAA) by the mitochondrial enzyme monoamine oxidase-A (MAO-A). It is then diffused out of the nerve cell and cleared from the brain via a probenecidsensitive acid transport mechanism (Feldman et al., 1997).

\section{Receptor types}

The heterogeneity of 5-HT receptors has recently become clear. Currently, a variety of 16, molecularly and functionally distinct, 5-HT receptor types have been identified. These were assigned into seven main 5 -HT receptor families (i.e. 5-HT, to 5-HT, (for review see: Feldman et al., 1997; Cryan and Leonard, 2000): Naughton et al., 2000). Over the last few decades, researchers have performed numerous studies to map the location of 5-HT receptor subtypes. These receptors mediate many different physiological and behavioral processes (see Table 1: Berendsen et al., 1996: Feldman et al., 1997). The 5-HT, family is particularly well studied. This family of receptors is further divided into five different subtypes. $5-\mathrm{HT}_{\mathrm{A}}$ receptors are located on either the presynatpical or the postsynaptical membrane of the neuron. When located presynaptically, they act as somatodendritic receptors and have an autoinhibitory function (i.e. reducing the firing rate of 5-HT signal transmission when stimulated). However, when located postsynaptically, the receptors initiate an excitatory effect on 5-HT upon activation (Boadle-Biber, 1993). 5-HT 14 receptors are, amongst others, involved in motor activity, mood. cognition and temperature regulation (Meneses, 1999). Other 5-HT recepiors located pre- or postsynaptically are the $5-\mathrm{HT}_{1 \mathrm{~B}}$ and the $5-\mathrm{HT}_{10}$ 
Table 1: Overview of the 5-HT receptor subtypes and their involvement in physiological and neuropsychological functions.

\begin{tabular}{|c|c|c|}
\hline 5-HT receptor & location & function \\
\hline 5-HT1A & $\begin{array}{l}\text { presynaptic } \\
\text { (DRN \& MRN) }\end{array}$ & $\begin{array}{l}\text { thermoregulation } \\
\text { anxiety } \\
\text { sexual behavior }\end{array}$ \\
\hline 5-HT1A & $\begin{array}{l}\text { hippocampus } \\
\text { lateral septum } \\
\text { amygdala } \\
\text { cortical limbic area } \\
\text { frontal cortex } \\
\text { entorhinal cortex. } \\
\text { brain stem } \\
\text { spinal cord }\end{array}$ & $\begin{array}{l}\text { depressed mood } \\
\text { aggression } \\
\text { cardiovascular function } \\
\text { learling/memory } \\
\text { muscle spasm } \\
\text { tremor } \\
\text { ataxia } \\
\text { delinum }\end{array}$ \\
\hline 5-HT1B/1D & $\begin{array}{l}\text { substantia nigra } \\
\text { globus pallidus } \\
\text { superior collicuts } \\
\text { caudate putamen } \\
\text { central gray area } \\
\text { nucieus accumbens }\end{array}$ & $\begin{array}{l}\text { locomotion } \\
\text { thermoregulation } \\
\text { anxiety } \\
\text { depression } \\
\text { migraine } \\
\text { inflamation } \\
\text { vasodillatation }\end{array}$ \\
\hline 5-HT1E & $\begin{array}{l}\text { caudate putamen } \\
\text { basal ganglia } \\
\text { amygdala } \\
\text { hippocampus }\end{array}$ & \\
\hline 5-HT1F & $\begin{array}{l}\text { cortex } \\
\text { dorsal raphe nucleus }\end{array}$ & \\
\hline 5-HT2A & $\begin{array}{l}\text { peripheral nervous system } \\
\text { basal ganglia } \\
\text { olfactory nuclei } \\
\text { brainstem } \\
\text { neocortex }\end{array}$ & $\begin{array}{l}\text { endocrine response } \\
\text { motor control } \\
\text { obsession and compulsion } \\
\text { sleep } \\
\text { psychosis/schizophrenia } \\
\text { emotion } \\
\text { cognition }\end{array}$ \\
\hline 5-HT2B & $\begin{array}{l}\text { peripheral nervous system } \\
\text { imbic system }\end{array}$ & $\begin{array}{l}\text { intestinal function } \\
\text { panic and anxiety } \\
\text { migraine }\end{array}$ \\
\hline $5-\mathrm{HT} 2 \mathrm{C}$ & $\begin{array}{l}\text { substantia nigra } \\
\text { globus pallidus } \\
\text { cerebral cortex } \\
\text { olfactory tubercles }\end{array}$ & $\begin{array}{l}\text { locomotion } \\
\text { migraine } \\
\text { hypophagia }\end{array}$ \\
\hline 5-HT3 & $\begin{array}{l}\text { peripheral nervous system } \\
\text { enthorinal cortex } \\
\text { amygdala } \\
\text { brainstem } \\
\text { frontal cortex } \\
\text { hippocampus }\end{array}$ & $\begin{array}{l}\text { nausea/vomitting } \\
\text { eating } \\
\text { intestinal movement } \\
\text { anxiety } \\
\text { learling/memory } \\
\text { withdrawal symptoms after drug abuse }\end{array}$ \\
\hline 5-HT4 & $\begin{array}{l}\text { peripheral nervous system } \\
\text { heart } \\
\text { globus pallidus } \\
\text { striatum } \\
\text { nucleus accumbens } \\
\text { sustantia nigra } \\
\text { limbic structures }\end{array}$ & $\begin{array}{l}\text { eating } \\
\text { intestinal function } \\
\text { control of visto-motor activity } \\
\text { emotion/mood } \\
\text { learning/memory }\end{array}$ \\
\hline 5-HT5 & $\begin{array}{l}\text { cortex } \\
\text { hippocampus. } \\
\text { olfactory bulb } \\
\text { cerebellum }\end{array}$ & $\begin{array}{l}\text { molor control } \\
\text { feeding } \\
\text { anxiety } \\
\text { emotion/mood }\end{array}$ \\
\hline
\end{tabular}




\begin{tabular}{|c|c|c|}
\hline 5-HT6 & $\begin{array}{l}\text { limbic structures } \\
\text { cortex }\end{array}$ & $\begin{array}{l}\text { psychose } \\
\text { emotion/mood } \\
\text { learning/memory }\end{array}$ \\
\hline 5-HT7 & & $\begin{array}{l}\text { neuroendocrine functions } \\
\text { emotion/mood } \\
\text { learning/memory }\end{array}$ \\
\hline
\end{tabular}

receptors. These are located in the peripheral nervous system and are involved in affective functions (Moret and Briley, 2000). 5-HT receptors such as 5-HT 1 and 5-HT 1 are functionally not well defined yet.

Post-synaptic 5- $\mathrm{HT}_{2}$ receptors are assumed to play a role in regulation of mood, anxiety and body temperature, but also in sexual behavior, sleep, obsessions and compulsions, eating behavior, hallucinations, psychosis and panic attacks. 5-HT, receptors are involved in nausea, vomiting, appetite and gastrointestinal motility and have been proposed to be involved in mood, anxiety and cognition (Naughton et al., 2000). 5- $\mathrm{HT}_{4}$ receptors located in the striatum and basal ganglia are mostly involved in motor functions while those located in the limbic system can be more related to synaptic plasticity, memory processes and emotional functions The 5-HT. 5-HT, and 5-HT, receptors are the most recently discovered receptor types and the neuropharmacology of these receptors is not fully understood. They are considered to be associated with affective function, motor control and processes of learning and memory. For example, the $5-\mathrm{HT}_{b}$ receptor was found to be located in the hippocampus and cortex (Ruat et al.. 1993). It's function is assumed to be involved in the control of the cholinergic neurotransmission and $5-\mathrm{HT}_{6}$-related drugs have investigated in models for schizophrenia and cognition (Bourson et al., 1995; Russell and Dias, 2002).

\section{Methods for studying 5-HT function in animals}

In order to develop highly efficient ligands to reverse specific dysfunctions in diseases where 5-HT plays a prominent role, such as depression or Alzheimer's disease, it is of great importance to better understand the role of this transmitter in the etiology of these disease. In order to study the role of 5-HT in behavior, receptor specific drugs (agonists or antagonists) can be used. An alternative way to study the function of 5-HT is to deplete 5-HT in the brain. In animal studies, different methods can be applied to accomplish a substantially reduction in 5-HT levels/transmission. 


\section{5,7-dihydroxytryptamine $(5,7-D H T)$}

Administration of the neurotoxin 5,7-DHT selectively decreases serotonergic activity. It can be administrated in the raphe nuclei to destroy serotonergic neurons. Furthermore, ascending 5-HT projections to different brain areas are reduced by injections of 5,7-DHT intracerebroventricularly (ICV) or in selected brain structures.

\section{Tryptophan hydroxylase (TH) inhibitors}

A reduction in 5-HT synthesis can be established by administration of p-chlorophenylalanine (PCPA) or p-ethynylphenylalanine (p-EDA). These inhibitors of TH are often applied to block this rate-limiting step in the 5-HT synthesis (Dringenberg et al., 1995; Zimmer et al., 2002).

\section{Amphetamine derivates}

Administration of amphetamine derivates has neurotoxic effects on the 5-HT metabolism, thereby inducing long-lasting 5-HT depletion. The p-chloroamphetamine (PCA) is a halogenated amphetamine which induces a sustained

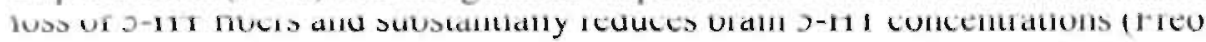
et al., 1991: Harro et al., 2001). Administration of 3,4-methylenedioxymethamphetamine (MDMA; ecstasy) can severely damage central 5-HT neurons, especially after repeated exposures (Green et al., 1995; O'Shea et al., 1998). Even in humans, extensive use of MDMA has revealed distinct changes in the metabolism of tryptophan and a decrease in 5-HT transporter binding (McCann et al., 1998; Curran and Verheyden, 2003). Nevertheless, the function of both amphetamine-related substances is rather heterogeneous. A single injection of PCA or MDMA increases the levels of 5-HT, while after a longer interval, a higher dose or repeated administration, they will have a neurotoxic effect on 5-HT neurons (Santucci et al., 1996; White et al., 1996).

\section{5-HT receptor ligands}

Through binding to a specific receptor, serotonergic drugs can activate or inhibit the transmission of a signal through the membrane of an subsequent neuron. These drugs can increase transmitter release (e.g. presynaptic antagonists, postsynaptic agonists) or block the reuptake of 5-HT (e.g. selective serotonin reuptake inhibitors; SSRIs), or modulate serotonergic activity by blocking the 5-HT release (e.g. presynaptic agonists or postsynaptic antagonists). However, the effect of these compounds is sometimes ambiguous. Paradoxical effects of the same ligand on behavioral functioning 
seem to be related to differences in methodology applied in these experiments. For instance, dosage of the drug, route of administration (peripheral or central, per os or intraperitoneal), number of treatments (single or repeated) or strain/species differences (mice versus rat) all seem to be important factors that may underlie these differences.

\section{Knockout mice}

Instead of using 5-HT subtype selective drugs, there is the option to use genetically modified mice lacking selective receptor subtypes. To advance our understanding in the pharmacological role of the 5-HT metabolism and individual 5-HT receptors, knockout models have been developed. At present, knockout models exist for the 5 -HT reuptake transporter, the $5-\mathrm{HT}_{1 \mathrm{~A}}$ or the $5-\mathrm{HT}_{1 \mathrm{H}}$ receptor subtypes in mice (Zhuang et al., 1999).

\section{Acute TRP depletion}

In contrast to interventions with drugs, which induce long-lasting effects on line 5-HT system, the idea to develop a method that could acutely reduce this neurotransmitter system and could be applied across species without having permanent and intrusive consequences has become very appealing. The method of acute TRP depletion emerged from the hypothesis that a reduction in plasma TRP levels may lower central 5-HT levels. In humans, treatment of a TRP-free amino acid mixture has frequently demonstrated to rapidly (5-6 hours after administration) reduce plasma TRP levels by about $70-90 \%$ (Young et al., 1985; Moja et al., 1988). Over the last decennia, the method of acute TRP depletion has shown to be a reliable and specific way to reduce 5-HT synthesis (Jagannathan and Venitz, 1997; Nishizawa et al., 1997; Williams et al., 1999) and to investigate the function of 5-HT in a noninvasive and reversible mamer in both humans and animals (for review see: Bel and Artigas, 1996: Reilly et al., 1997: Moore et al., 2000).

\section{Advantages disadvantages of models}

It needs to be noted that ali of the different methods as described above have been established to investigate the role of 5-HT and each method has its own advantages and disadvantages. The models can induce different effects on 5-HT activity. Among others, this can be determined by the exact location where a treatment affects the 5-HT synthesis (e.g. PCPA inhibits the TH while 5,7-DHT destroys neurons). Moreover, lowering plasma TRP level induces an acute and temporary effect on the 5-HT metabolism while the neurotoxic effect of 5,7-DHT results in a chronic termination of 5-HT neurons. 
Besides, these models do not always show comparable effects on the 5-HT system (e.g. treatment of MDMA also affects the dopaminergic system and genetically removing the 5- $\mathrm{HT}_{14}$ receptors during the development of mice also affects the GABA-ergic system). Therefore, compensation mechanisms (e.g. feedback or receptor desensitization) within neurotransmitter systems can occur in particular models. Consequently, it is reasonable to assume that the use of different models to mediate a 5-HT depletion results in different functional effects. Therefore, selection of a method to study the role of 5-HT mainly depends on the study objective.

\section{Affective and cognitive processes}

\section{Anxiety}

In order to asses the effect of anxiety-related agents, it is important to distinguish the different types of anxiety syndromes for which animal experimental situations could serve as a model of anxiety (Shekhar ei al., 2001). The generalized anxiety disorder is characterized by excessive and uncontrollable worries about life events and is accompanied by symptoms of motor tension, autonomic reactivity or hypervigilance. Similar physiological symptoms also occur in panic disorders which are characterized by unexpected panic attacks without any apparent relationship to external circumstances. Phobias take place when the patient displays an irrational and excessive fear to a particular item (e.g. snakes or spiders) or to a very defined situation (e.g. heights or closed spaces). Patients with obsessive-compulsive disorder undergo intrusive and recurrent distressing thoughts (obsessions), which are usually followed by repetitive, ritualistic behaviurs (compulsions) aimed to alleviate obsessions. Post-traumatic stress disorders develop after experiencing or witnessing a traumatic event (e.g. life-threatening situation or assault). This may lead to lasting symptoms including re-experiencing the trauma, avoidance behavior and/or numbing of emotions.

Most of the syndromes can also be distinguished by gender (panic, posttraumatic stress and generalized anxiety disorder are more prevalent in females) or by treatment response (benzodiazepines are more effective in treating generalized anxiety disorder when compared to its effects on phobias and panic attacks whereas SSRIs are effective against most anxiety disorders). 
From the neuroanatomical perspective of anxiety, the amygdala, the periaqueductal gray (PAG), the hippocampus, the locus coeruleus and the neocortex are all involved in anxiety and the GABAergic and the 5-HTergic systems play a prominent role in these brain areas. (Charney et al., 1990).

Animal models that are intended to reflect anxiety in rodents, are generally not distinguished by the same criteria as in humans. Most behavioral paradigms used in animals include conflict tests, exploration tests or, tests to examine the response to stressful situations. The various animal models of anxiety can be roughly classified into two types of models (Griebel, 1995).

\section{Models based on unconditional responses}

Unconditioned models of anxiety are largely based on spontaneous, instinctive behavior. The approach-avoidance paradigm, for example, is based on the conflict between two instinctive behaviors exhibited by most animals i.e., the tendency to explore novel environments and the avoidance of open spaces. (e.g. the open field test and the elevated plus-maze test or elevated zero-maze test). Anxious rats also tend to avoid a very bright light (e.g. the light-dark exploration test) and exhíbl ieduced soufal autivity (c.g. sowial interaction test). Although rodents do not require explicit physical punishment to avoid events, some unconditioned models of anxiety apply procedures of punishment (e.g. ultrasonic vocalizations and stress-induced hyperthermia) to elicit measurable autonomic responses such as blood pressure, heart rate, adrenal stress responses and defecation.

\section{Models based on conditional responses}

These models are based on the animal's conditioned responses to stressful and aversive events. Frequently used tests are the Geller-Seifter conflict test, the Vogel lick-suppression test and classical fear conditioning tests such as the fear-potentiated startle reflex and the conditioned emotional response test. In these tests, the environmental cues are paired with aversive events and the degree of inhibition is used as a measure of anxiety. Although models for anxiety are in abundance, there is no accepted guideline regarding which models are the best predictor for which specific anxiety-related disorders as seen in humans.

Ethanol, barbiturates and benzodiazepines are known to be the most common classic anxiolytics and most of the preceding models of anxiety are diminished by benzodiazepines (e.g. diazepam and chlordiazepoxide) Benzodiazepines reduce the turnover of catecholamines and indolamine (i.e. 
5-HT) in the brain (Corrodi et al., 1971). These findings led to the hypothesis that the release of 5-HT is associated with anxiety-like behavior. This hypothesis was largely supported by the observation that activation of the 5-HT system suppressed punished behavior (Graeff and Silveira Filho, 1978). Moreover, 5-HT reduction and 5-HT receptor antagonists increased punished behaviors (Tye et al., 1977). Therefore these 5-HT receptor antagonists were considered as an alternative to benzodiazepine anxiolytics.

An alternative theory on how 5-HT was involved in anxiety was proposed by Deakin and Graeff (1991) which mainly concentrates on the anxiety-related functions of the amygdala and the PAG (Deakin and Graeff, 1991). Perceptual input from the environment is assimilated in the amygdala and the degree of threat is then transmitted to the PAG which will induce the animal to respond in a appropriate, defensive way. According to this 'dual hypothesis', a different kind of 5-HT input is given in these structures. It was stated that by stimulating the amygdala, 5-HT facilitates a conditional 'fight/flight' defense strategy when an animal is exposed to a proximate threat. In contrast, the defense strategy is inhibited when the threat is more distal thereby decreasing detection level by predator and increasing the survival value. This unconditional defense strategv is attained bv a 5-HT inhibitorv innut to the PAG. To test this dual 5-HT fear hypothesis by Graeff, a new animal model of anxiety was developed (i.e. the elevated T-maze). However, testing the function of 5-HT led to rather inconsistent findings (Graeff et al., 1997).

Several findings are accounted for by the classic hypothesis suggesting that a decrease in 5-HT synthesis can be associated with anxiolytic behavior. The treatment with PCPA has been reported to decrease anxiety in $70 \%$ of the studies (Griebel, 1995). Treatment with 5,7-DHT produced anxiolytic effects in the social interaction test (Clarke and File, 1982) or anticonflict effects in the Vogel test (Soderpalm and Engel, 1991). The anxiolytic effects after a 5,7-DHT treatment in the elevated plus maze (Briley et al., 1990), could not be confirmed by other studies (Thomas et al., 2000; Andrade and Graeff, 2001; Rex et al., 2003). It could be argued that the discrepancy in these behavioral effects are due to the variance in location of administration (ICV versus DRN or MRN).

However, Hall et al. (1999) demonstrated a significant increase in anxietylike behavior in the elevated plus-maze when rats were ICV treated with 5,7-DHT. However, these findings were at a relatively low dose of the treatment and disappeared at a more severe serotonergic lesion effect (Hall et al., 1999). Their suggestion that these anxiogenic behaviors might specifically appear at a moderate decrease in 5-HT concentrations was further 
supported by treatment with PCA, showing that at a $20 \%$ decline of 5-HT levels the animals displayed a lower social activity (Harro et al., 2001). This illustrates that variability of 5-HT function in anxiety-related behavior can be attributed to a number of factors, including experimental paradigms, administration routes, doses used, species differences, the sex of the animals or the environment in which a test is conducted.

Although a single high dose of MDMA resulted in decreased anxiety-related behavior (Morley and McGregor, 2000), it was found that long-term treatment of MDMA induces an increase in anxiety-like behavior (Morley et al., 2001; Gurtman et al., 2002) Nevertheless, opposite findings are also reported in other studies where the long-term use of MDMA induced anxiolytic behavior (Mechan et al., 2002).

Another finding which seems to conflict with the classic theory is that chronic treatment with antidepressant drugs also relives anxiety. Yel, the anxiolytic effect of this drug regimen is likely to be caused by an increase, rather than a reduction of 5-HT neurotransmission (Charney et al., 1990). Nevertheless, occurrence of anxiolytic behavior mediated by inhibition of 5-HT receptors may depend on the selective receptor subtype when tested in a certain paradigm (e.g. social interaction) (Kennett, 1992).

The 5-HT $1 A-5-\mathrm{HT}_{1 \mathrm{~B}}, 5-\mathrm{HT}_{2 \mathrm{~A} Z \mathrm{C}}$ and $5-\mathrm{HT}_{3}$ receptors are considered to be the most prominent 5-HT receptor subtypes involved in anxiety (Griebel, 1995). Iligh densities of $5-\mathrm{HT}_{1 \wedge}$ receptors in the amygdala and hippocampus, and high densities of 5- $\mathrm{HT}_{2}$ receptors in the locus coeruleus and cortex, suggest that these receptors are involved in the etiology of anxiety and fear (Charney et al., 1990).

It was found that experimental variations (e.g. species or strain differences) ean have profound effect on the degree to which 5-HT ligands affect behavioral measures of exploration or anxiety. For example, test-specific effects of 5-HT different emotional states (Griebel, 1995; Griebel et al., 2000). This indicates that although that 5-HTergic activity is believed to play a prominent role in fear/anxiety, little evidence is available as to how exactly 5 -HT is related to anxiety.

\section{Depression}

Depression can be defined as a cluster of symptoms with psychological, physical, behavioral and vegetative features. The core symptoms of depression are loss of interest or pleasure (anhedonia) and depressed mood which can be combined with secondary symptoms including negative 
thinking, diluted social interaction, loss of energy, disturbance of sleep or appetite. There are severe risk factors involved in depression such as gender, age, personality, genetic predisposition and negative (stressful) life events (e.g. parental deprivation, physical abuse).

Exposure to stress (acute or chronic) is sometimes expressed in an abnormal, excessive activation of the hypothalamic-pituitary-adrenal (HPA) axis (Nestler et al., 2002a). Severe stress or inhibitory activation from the hippocampus stimulate neurons in the paraventricular nucleus of the hypothalamus to secrete corticotropin-releasing factor (CRF). Next, CRF stimulates release of adrenocorticotropin ( $\mathrm{ACTH}$ ) from the anterior pituitary. $\mathrm{ACTH}$ then stimulates release of corticosterone (cortisol in humans) from the adrenal cortex. Although there are striking parallels between stress response, depressive symptoms and administration of CRF or corticosterone, it is still unknown how exactly HPA abnormalities are related to the onset of depression.

In respect of brain structures involved in the etiology of depression, it is suggested that the neocortex and hippocampus may mediate cognitive processes (memory impairment, negative feelings) while the ventral striatum and the amygdala are more involved in emotional aspects (anhedonia, anxiety, motivation). Neurovegetative symptoms (sleep, appetite, energy, sex) are linked to the hypothalamus (Nestler et al., 2002a). Abnormalities in the neuronal circuitry between these interacting structures underlie the complexity and the variety of depressive symptoms. Hence, animal models are mostly based on particular aspects (behavioral and physiological) of depression.

\section{Olfactory bulbeclomy.}

Rats can be brought to a depressive-like state by surgically removing the olfactory bulbs, thereby disrupting the limbic-hypothatamic axis. Subsequently, the rats display a hyperactive response and aggressive behavior (Kelly et al., 1997; Harkin et al., 2003).

\section{Selective breeding}

Based on behavioral differences between strains, the model of selective breeding is used to generate animals with depressive-like phenotypes. Special strains of rats are selected for their sensitivity to abnormal avoidance in the shuttle box (Roman high- and low-avoidance strains; see: Brush, 1991), for hypercortisolaemia and for a blunted response to dexamethasone-induced suppression of corticosterone secretion (Fawn Hooded, see: Owens and 
Nemeroff, 1991) or for their hypothermic response to cholinergic agonists (i.e. Flinders Sensitive Line, see: Overstreet, 1993). The latter also shows a. number of depressive-like symptoms such as serotonergic hypersensitivity, increased REM sleep, reduced locomotor activity and immobile behavior in. the forced swimming test.

\section{Stress-induced models}

Since depressive episodes are frequently precipitated by exposure to severe acute stress or chronic low-grade stress (Kessler, 1997), the majority of animal models of depression are typically generated by exposure of animals to stressor of various kinds (for reviews see: Cryan et al., 2002; Nestler et al., 2002b; Willner and Mitchell, 2002). In the model of chronic variable stress (CVS: Katz, 1982) or chronic mild stress (CMS: Papp et al., 1996; Willner, 1997), rats are exposed over a period of several weeks to a variety of uncontrollable stressors. Both models differ in selection of stressors and timing of their presentation. For example, exhibiting shock-inducing stressors to the mother during pregnancy induces prenatal stress. A neonatal stress model can be mediated through maternal separation thereby isolating weaning rats from their mothers. This induces elevated activity of the HPA axis and a frustrated or helpless state that continues for a long period. This results in behavioral deficits which are similar to depressive symptoms as seen in humans (Maccari et al.. 2003; Matthews and Robbins, 2003).

The forced swimming test (FST), also known as the Porsolt swim test, is among the most widely used models for screening antidepressant drugs. Treaiment with most antidepressants increases the latency to immobility and decreases the amount of immobility time reflecting a lowering of behavioral despair when exposed to an inescapable situation (Porsolt, 1979; Detke and Lucki, 1996). A variant in mice is the tail-suspension test in which the animals are suspended by their tail and the amount of time that they struggle is reported as a parameter indicating the state of depression. Also similar are the tests where animals are tightly restrained for a period or where an inescapable electric shock is submitted to the animal. Animals showing more active and resistant behavior are considered to display a less depressive--iike state. The model of learned helplessness involves an animal's response to stress and is based on the notion that repeated experience of failure induces a belief that the person is incapable of succeeding and is helpless when facing the problems of life. Such a state can experimentally be induced by repeatedly administering large, unavoidable electric shocks. When later given the opportunity to escape from these shocks, animals show a deficit in escape learning (Willner, 1990). 
An increasing number of studies are using these models (e.g. forced swimming test, learned helplessness) as a confirmation of 'depressive-like' state of the animals, induced by prior treatments.

Patients with depression often have a feeling of reduced energy and are therefore less active and less sensitive to reward. Based on this dysfunctional reward mechanism, the method of self-stimulation used to test the effort an animal is willing to make in order to collect a reward. Another test used to assess the (in)sensitivity of the animal to rewards is the sucrose preference test. This is based on the phenomenon of anhedonia, representing the inability to experience pleasure (Papp et al., 1996; D'Aquila et al., 1997). An improvement in performance indicates the effectiveness of a drug treatment to reverse the depressive state of the animal.

Years before research on genetic determinants of depression was started, one of the first theories stated that depression was related to a deficiency of monoamine neurotransmitters (notably NE and 5-HT; monoamine hypothesis). Abnormalities in these monoamine transmitter systems were linked to symptoms of depression (c.g. changes in appetite, mood, sexual functions, sleep and circadian rhythms (Meltzer, 1989). It is the role of 5-HT in both the pathogenesis of depression and in the mechanism of action of antidepressants that has received most attention over the years.

A decrease in 5-HT uptake was found in the peripheral and central nervous system of unmedicated depressed patients and post-mortum brain tissues of depressed patients have demonstrated reduced 5-HT activity. This indicates that a dysfunction in 5-HT metabolism might be considered as an important factor in the etiology of depression (Mann, 1999; Stockmeier, 2003). Furthermore, a change in the transporter binding has been reported together with a change in the densities of 5-HT receptors (Owens and Nemeroff, 1994; Stockmeier, 2003). It has been hypothesized that depressed mood is accompanied by down-regulation of postsynaptic 5-HT ${ }_{1 \mathrm{~A}}$ receptors and upregulation of 5- $\mathrm{HT}_{2}$ receptors (Maes and Meltzer, 1995; van Praag, 1996). The reduction in 5-HIAA concentrations that was found in the cerebrospinal fluid of depressed patients and suicide victims also contributed to this 5-HT hypothesis of depression (van Praag et al., 1970; Asberg et al., 1976). More recently, in vivo brain imaging techniques (e.g. PET, SPECT, MRI and fMRI) have made it possible to target structural and neurochemical alternation within the brain. An altered 5-HT uptake was found across the blood-brain barrier in depressed patients (Agren et al., 1991; Cryan and Leonard, 2000). 
Furthermore, in humans, extensive use of MDMA, which is believed to reduce 5-HT, has also been associated with depressive symptoms (McGuire, 2000; Parrott et al., 2000).

To examine the role of 5-HT in depression, numerous studies have been performed using different treatments to deplete central 5-HT concentrations and led to ambiguous results. One of the first animal models that pharmacologically induced a depressive-like state by depleting central levels of monoamines (including 5-HT) is treatment with reserpine (Coppen, 1967). The treatment of 5,7-DHT did not affect immobile behavior in the FST (Perfumi et al., 2001). However, animal models, such as CMS and PCA, induced depressive-like behavior (i.e. reduced immobility time in the FST) without having a significant effect on the sucrose consumption (Harro et al., 2001). In contrast, anhedonic symptoms were found when the rats were exposed to a CMS paradigm (Moreau et al., 1992) or when female rats were bulbectomized (Stock et al., 2000). And although treatment of PCPA did not cause behavioral changes in the FST (Harkin et al., 2003), it has been reported to suppress the antidepressive-like behavior of the SSRI fluoxetine in the FST (Page et al., 1999). Furthermore, studies with 'knockout' mice of the $5 . \mathrm{H}_{1 \mathrm{~T}}$ receptor type have shown antidepressive-like behavioral responses (i.e. reduced immobility) in the FST and TST (Ramboz et al., 1998; Gardier and Bourin, 2001; Overstreet et al., 2003).

Much of our understanding of the relationship between depression and 5-HT has evolved from the tremendous effort that has been made to develop new antidepressant medications utilizing in vitro and in vivo models. Various drugs that have been developed to relieve depressive symptoms are based on the facilitation of the 5-HT neurotransmitter (for review see: Blier and de Montigny, 1994: De Vry, 1995; Moller and Volz, 1996). Administration of tricyclic antidepressants (TCAs) inhibits the reuptake of NE and/or 5-HT and enhances the sensitivity of postsynaptic $5-H T_{1 A}$ receptors. Treatment with monoamine oxidase inhibitors (MAOIs), SSRIs and 5-HT agonists increase synaptic levels of 5-HT by enhancing the amount of 5-HT to be released, by lowering the degree of reuptake and by enhancing the tonic activity of postsynaptic 5-HT receptors, respectively (Blier and De Montigny, 1999). Recently, development of SSRIs is stimulated because SSRIs have less drawbacks and side effects compared to the older TCA medication. Moreover; the development of new antidepressants focuses on a combination strategy utilizing treatment with SSRIs together with drugs acting on specific 5-HT receptor subtypes (e.g. 5- $\mathrm{HT}_{1 \mathrm{~A}}$ agonists, 5-HT $1 \mathrm{H}$ antagonists) to overcome 
problems regarding the treatment of depression (delayed onset of action and non-responding) (Cryan and Leonard, 2000; Blier, 2001). Although their function is not very conclusive, there has been some evidence suggesting the involvement of the 5- $\mathrm{HT}_{2 \mathrm{Ax}}$ and 5- $\mathrm{HT}_{3}$ receptors in depression.

Although these findings highlight the significance of 5- HT in the pathophysiology of depression, certain 5-HT agents failed to display antidepressive effects, indicating that other factors, besides 5-HT, might also be involved in the neurobiology of depression. Molecular and cellular research has demonstrated potential targets mediating antidepressive response including other neurotransmitter receptors (e.g. adrenergic, glutamatergic receptors), change in immune activity (e.g. cytokine production), intracellular second messenger generating systems and proteins involved in neurotrophic cascades (e.g. cAMP-dependent protein kinase (PKA), mitogen-activated protein (MAP) kinase cascade) (Nestler et al., 2002a). For example, the use of cortisol or CRF antagonists are momentarily under investigation as novel antidepressant treatments

\section{Cognition}

Cognition is a very dynamic process consisting of both non-mnemonic and mnemonic factors. In order to acquire information or recollect it from the brain, cognitive performance depends on non-mnemonic factors such as our emotional, motivational (arousal) or attentional state. Altention refers to those processes of perception which actively select the particular stimulus of interest from the environment. One can distinguish between types of attention. The sustained attention (vigilance) refers to a continuous allocation of processing information for the detection of unpredictable events. In a state of selective (focused) attention, a subject has to focus on one dimension while ignoring the rest which points out the necessity to simultaneously monitor different perceptual dimensions.

Furthermore, it is important to distinguish the different stages of mnemonic: information processing. When exposed to the sample, the presented information needs to be transformed into a mental representation (process of encoding/acquisition), after which the information needs to be maintained over a delay until it can be stored into the memory (process of consolidation) from which the information can be later recollected for adequate action or performance (process of retrieval). This latter process of retrieving information can be either by recall or recognition. 
Memory is generally thought to be composed of multiple independent processes rather than a single unitary one. Atkinson \& Shiffrin have developed a model for human memory processes consisting of three phases. The sensory memory contains incoming information for a fraction of a second. Information is then transferred into the short-term memory, also often referred to as the working memory. At this stage valuable information is temporarily retained and processed before permanently stored in the longterm memory. The latter can further be subdivided into different forms of memory. Procedural memory is automatic and pertains to information about procedures and skills (Steckler and Muir, 1996). This includes habituation, sensitization and simple classical conditioning. Declarative memory is effortful and refers to information processing about facts (semanic memory: give an example of a bird) or time-place (episodic memory: when did you last see a pelican) events. This implies processes at 'higher' levels.

\section{Paradigms on working/ reference memory}

Even though learning and memory processes in rodents also consist of encoding, consolidation and retrieval processes, in preclinical research, a somewhat different definition is used of subdivided memory processes. It is important to realize this difference when comparing studies of rodent and human working memory. Most animal studies refer to Olton's definition when assessing working memory (Olton. 1979) referring to the requirement of trial-specific information for accurate performance (e.g. the number of places already visited within a particular trial). As this definition of working memory can refer to the full duration of a trial, which can last for minutes, it may be regarded as a form of long-term memory (more specific episodic memory) and clearly different from the 'working memory' concept by Baddeley. On the other hand, the reference memory forms more general information which retains it's validity over many trials, usually for the entire experiment fe.g. fixed location for food reward) and therefore does not contain the same kind of temporal component as working memory. However, it may also be categorized into a long-term memory process, but since it depends on more specific facts one could refer to semantic memory. Tasks such as the radial maze and the cone field can be applied to discriminate between working and reference memory (Olton, 1979; van der Staay et al.. 1989).

\section{Paradigms on discrimination memory.}

There are also tests based on the concurrent discrimination paradigm which is comprised of a sample stage, followed by a delay interval and a comparison 
stage and assesses the ability to discriminate items of different familiarity or relative recency (i.e. recognition). Performance is usually expressed as a function of the delay interval (the higher the delay, the more difficult it becomes to recollect and discriminate the sample). Examples are the delayed (non-)matching to sample test, the T-maze test and the object recognition test (see Fig. 2). Since the tests developed on this paradigm are mostly one-trial tests where the animal must remember the sample stimulus throughout the delay (retention) interval, it has been suggested that they assess the performance dependent on working memory (Ennaceur and Delacour, 1988). Although these are mainly non-spatial orientated memory tasks, there also is the option to add a spatial component to it (e.g. delayed (non-) matching to position and spatial recognition test) (Jakala et al., 1993; Mumby et al., 2002).

\section{Paradigms on spatial memory}

The Morris water maze test is probably the most used behavioral test to map spatial orientation in rats (Morris et al., 1982). By using a platform (located at a fixed position in a water tank) and visual cues in the environment, the animals learn to navigate to the appropriate position in space. The Morris water maze test is typically designed to asses performance on reference memory. However, the same test has been adapted to a different version that enables the researcher to investigate working memory processes.

\section{Avoidance paradigms}

Furthermore, fear-motivated avoidance paradigms (e.g. passive avoidance test) have been frequently employed in order to asses the retention effects of cognition-enhancing drugs. Although it has been argued that factors such as motivation and impulsivity may confound the information processing, this task can be classified under procedural memory (Steckler and Muir, 1996)
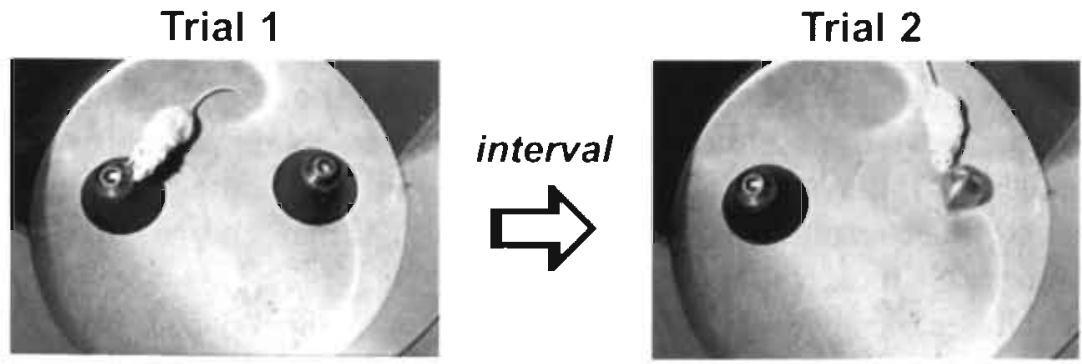

Fig.2: The object recognition test. In the sample stage (Trial 1), two identical objects are presented for exploration. During a delay interval, one familiar object form Trial 1 is replaced with a novel object. Based on the exploration times for each object (familiar and novel) in Trial 2, the discrimination index states the performance in recognition memory 
Generally, central brain structures such as the prefrontal cortex, sensory association areas, rhinal cortices, hippocampus and thalamus are considered to be most prominent areas underlying learning and memory functions. The glutamatergic and the cholinergic systems are highly involved in the mediation of memory processes. Nevertheless, it is believed that the involvement of distinct transmitter activity, transferring an adequate signal to specific structures, is required in the various phases (e.g. consolidation or retrieval) and functions (e.g. spatial versus non-spatial) of memory formation in order to correctly perform a test (Prickaerts et al., 2002; Myhrer, 2003).

The occurrence of several memory problems have frequently been seen in non-psychiatric aging people and patients suffering with Alzheimer's disease. It is exactly in this population that signs of a deregulated 5-HT system have been found (e.g. decrement in the 5-HT release or decrease in the numbers of 5-HT receptors (Cross, 1990; Meneses, 1998)). This indicates that an abnormal 5-HT system may be associated to learning or memory disorders. However, great controversy exist concerning these subjects (McEntee and Crook, 1991). Nevertheless, besides psychological problems related to mood (e.g. anxiety, hostility, impulsivity), the use of MDMA (ecstasy) has been linked to several attentional and memory deficits which persist from months to years after abstinence and are probably due to abnormities in serotonergic functioning (Morgan, 2000; Reneman et al., 2000; Gouzoulis-Mayfrank et al., 2003). In contrast, acute treatment with a SSRI in healthy subjects had no effect on immediate recall but showed enhanced long-term memory performance, indicating that augmentation of 5-HT is associated with increased memory consolidation (Harmer et al., 2002). Even though it has been suggested that SSRIs could have primarily antidepressant effects rather than cognitive enhancing effects, some SSRIs improve memory functions in aging subjects and in patients with Alzheimer's disease (Hasbroucq et al., 1997: Meltzer et al., 1998).

Until now, most of the animal experiments on the role of 5-HT in learning and memory processes have used lesions and pharmacological approaches to reduce the 5-HT system. However, with regard to learning and memory processes, their results are far from consistent (Altman and Normile, 1988; McEntee and Crook, 1991; Meneses, 1998).

Although treatment with 5,7-DHT does not seem to affect performance in the radial arm maze (Asin et al., 1985). PCPA treated rats had deficits in spatial learning and memory when tested in the radial arm maze (Mazer et al., 1997). Inconsistent findings have also been reported for performance in the Morris 
water maze test. Some studies showed that an almost complete 5-HT depletion, induced by treatment of 5,7-DHT, PCPA or PCA, did not affect performance in spatial memory (Richter-Levin and Segal, 1989; Riekkinen et al., 1991; Jakala et al., 1992; Santucci et al., 1995, while others found impaired performance in Morris water maze test \{Carli, 1992 \#432). treatment with 5,7-DHT. PCPA or PCA did not affect spatial working memory in the delayed non-matching to position task (Jakala et al., 1993; Ruotsalainen et al., 1998), nor did it change acquisition and retention processes as testesed in the passive avoidance paradigm (Sirvio et al., 1994; Santucci et al., 1996). However the study of Santucci demonstrated that excessive 5-HT concentrations disturbed performance in the passive avoidance test. This suggested that 5 -HT can regulate cognitive function albeit through increased concentrations in stead of a depletion.

Even the use of MDMA showed astonishing memory deficit especially related to the long-term factors of working memory (Frederick and Paule, 1997). Moreover, treatment with the SSRI fluoxetine reversed the impaired learning effect induced by aging (Meneses, 1998) and treatment with scopolamine (a cholinergic antagonist: see Meneses and Hong, 1997).

Although the relationship between 5-HT neurotransmission and cognitive function is not completely clear, most data suggest that learning and memory processes can be mediated through the 5-HT system, possibly through interacting with other neurotransmitters (e.g. ACh) (Steckler and Sahgal, 1995 ) or by mediating its action via specific receptor subtypes (Meneses, 1999: Buhot et al., 2000). For example, 5-HT: antagonists (ondansetron) have been shown to possess cognitive enhancing propertics in a number of animals test (Barnes et al., 1992) and treatment with a 5-HT agonist resulted in a cognitive-enhancing eflect for object recognition (Moser et al., 2002). However, most of the 5-HT antagonists also have effects on other neurotransmitter systems, which probably is related to the observed discrepancies. Additionally, methodological variance, such as differences in experimental design, test applicatinn, timing of treatment makes it sometimes hard to interpret the results and is often the cause of inconsistent findings. 


\section{Effects of acute tryptophan depletion on 5-HT synthesis, affective and cognitive behavior}

The intake of $50-100 \mathrm{~g}$ of a TRP-lacking amino acid mixture typically leads to a $75-90 \%$ reduction in plasma TRP levels within 4 to 6 hours in healthy subjects (Young et al., 1985; Smith et al., 1987; Moja et al., 1988; Ellenbogen et al., 1996; Jagannathan and Venitz, 1997) as in remitted depressed patients (Delgado et al., 1990) and in subjects with a family history of depression (Benkelfat et al., 1994: Klaassen et al., 1999b). These findings show a good reliability of the method to induce a substantial lowering in plasma TRP levels across subject populations. Since the effects of this treatment on 5-HT levels in the brain can not be investigated in humans, the ratio of TRP/LLNAA in plasma is considered as one of the best indicators of central 5-HT concentration (Fernstrom and Wurtman, 1997). Nevertheless, the efficacy of the method on 5-HT synthesis has further been confirmed by reduced 5-HIAA concentrations in the cerebrospinal fluid (CSF) of humans (Carpenter et al., 1998; Williams et al., 1999). In rats, the method of TRP

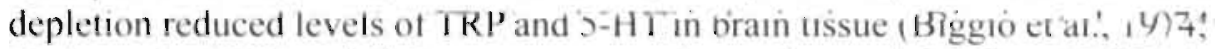
Moja et al., 1989) and dialysate concentrations of central 5-HT and 5-HIAA (Bel and Artigas, 1996; Stancampiano et al., 1997b).

In order to investigate the role of 5-HT on neuropsychological functions, the method of acute TRP depletion should be specific. The biochemical effects have to be solely related to the 5-HT system and not to metabolic functions of other amino acids or neurotransmitters. Conforming results have been found in humans, where the treatment did not affect peripheral levels of lysine (Klaassen et al., 1999a). Furthermore it was found that the levels of tyrosine and catecholamine in TRP depleted monkey remained unchanged (Young et al. 1989).

Since a deregulation in the 5-HT metabolism primarily occurs in depressed patients, it was hypothesized that a decrease in plasma TRP concentrations may cause a change in neuropsychological functions associated with depression (e.g. affective and cognitive behavior). However, conflicting findings have been found, showing a lowering of mood in normal subjects when receiving a TRP-free mixture (Young et al.. 1985: Klaassen et al.. 1999a), whereas other studies could not replicate this change of mood, especially not in healthy male subjects (Schmitt et al., 2000). Nevertheless, there are indications that occurrence of certain risk factors of depression (e.g. recurrent episodes, gender, prior treatment with SSRI's) can be considered as 
independent predictors of the sensitivity to mood effects when depleting TRP levels (Booij et al., 2002). Symptoms of a more depressed mood were clearly found in female subjects compared to male subjects (Ellenbogen et al., 1996). This gender-dependent effect may be related to the finding that women displayed a more pronounced reduction in 5-HT synthesis after ATD (Nishizawa et al., 1997: Smith et al., 1999). Mood effects after TRP depletion were also demonstrated in remitted depressed patients (Delgado et al., 1990; Spillmann et al., 2001), subjects with positive family history of affective disorder (Benkelfat et al., 1994; Klaassen et al., 1999b; Sobczak et al., 2002) and in unmedicated depressed patients (Delgado et al., 1994).

Cognitive disorders are frequently found in depressed patients, ranging from poor performance in immediate and delayed recall and recognition memory (Ilsley et al., 1995) to impaired performance in information processing tasks (Tarbuck and Paykel, 1995). Antidepressant treatment often improves these cognitive dysfunctions, supporting the importance of 5-HT in processes of learning and memory. Induction of an acute TRP depletion has also been found to impair learning functions in normal subjects (Park et al., 1994; Riedel et al., 1999: Cassaday et al., 2003). Park et al. (1994) reported impairment in learning functions concerning spatial locations of abstract and paired association learning. Riedel et al. (1999) reported that an acule TRP depletion did not affect short-term memory performance but induced an impairment in long-term memory (processes of consolidation and retrieval). The recall and recognition of learned words was impaired from a delay of 30 min to $18 \mathrm{~h}$ when the to-be learned words were presented at the lime TRP was low (i.e. $6 \mathrm{~h}$ after intake). However, this was not the case when words had to be learned afterward, when TRP levels were back to normal (i.e. 24 h after intake), nor when the words had to be learned before the TRP-free amino acids mixture was administrated. This supported the theory that TRP depletion impairs consolidation of newly learned words (Riedel et al., 1999; Schmitt et al., 2000). Furthermore, the factor of first-degree relatives of depression or bipolar disorders was independent of the TRP depletioninduced impairment in delayed word recall (Riedel et al., 1999; Klaassen et al., 2002; Sobczak et al., 2002). Moreover, Klaassen and colleagues (2002) found that the TRP depletion induced an impairment on delayed recall of words depended on the affective content of the words (i.e. the recall of neutral and positive words were impaired, this in contrast to negative words). These results are in agreement with the clinical symptom of depression, i.e., patients often show impaired memory and are more likely to store or recall information that is congruent with their mood state (Blaney, 1986). 
In spite of the different compositions of mixtures or diets that have been used in animal studies to induce the TRP depletion (i.e. varying from a mixture containing LNAA's to a mixture integrated of different amino acids with or without additional substances such as oil, sucrose, protein or vitamins), the method of acute TRP depletion is also shown to be applicable in rodents resulting in a reduced 5-HT synthesis (Biggio et al., 1974; Gessa et al., 1974; Moja et al., 1989; Stancampiano et al., 1997b), and increased sensitivity of 5-HT 1 A and 5- $\mathrm{HT}_{2 \mathrm{C}}$ receptors (Franklin et al., 1999). Nevertheless, this procedure has only been used in a few studies to investigate the effects of reduced 5-HT concentrations on behavior. A modest reduction of hippocampal 5-HT and 5-HIAA concentrations (23\% and $38 \%$, respectively) induced by a TRP-lacking mixture did not affect the rat's performance in response inhibition, spontaneous locomotor activity or analgesia (Brown et al., 1998). However, the reduction in plasma TRP levels was not measured and it was reasoned that the lack of behavioral effects could be explained by insufficient reduction in 5-HT neural activity. In another study, it was demonstrated that, in spite of a diminished 5-HT release, the treatment with a TRP-free diet did not affect cognitive processes (Stancampiano et al., 1997a). The TRP depleted rats performed the cognitive test as good as control rats thereby showing no distinction between groups in retentional and spatial memory functions (passive avoidance test and radial arm maze, respectively). However, the same research group noticed an increase in sexual mounting behavior in rats, $6 \mathrm{~h}$ after administration of the TRP-free diet (Fadda et al., $2000)$.

\section{Aim and outline of the thesis}

The 5-HT system is very dynamic and complex. Abnormalities in the 5-HT system have also been detected in a variety of psychiatric dysfunctions (eating disorders, depression, cognition and impulsive behavior) and of neturological disorders (e.g. Alzheimer's disease, Parkinson's disease). In order to gain a greater insight into the role of 5-HT on behavior, the aim of the experiments in this thesis was to investigate affective and cognitive consequences of reduced central 5-HT concentrations by means of using the method of acute TRP depletion to substantially reduce plasma TRP and central 5-HT levels in rats. In this manner, the function of reduced 5-HT synthesis could be examined in animal models of anxiety. depression and cognition. 
To improve the validity of this method, we aimed to lower plasma TRP levels to a similar extent as previously found in humans. The initial experiment was conducted in adult male rats that were treated with a TRPfree amino acid mixture, using the same composition as applied in human studies (Chapter 2). Mood-related and cognitive behavior was examined after treatment and the corticosterone response to a stress-induced condition was determined. Based on the inconsistency found in the extent of plasma TRP levels (i.e. moderate depletion in rats) when compared to humans, we tried to develop an alternative method to substantially reduce plasma TRP in rats. Chapter 3 presents an experiment discussing methodological issues concerning the use of a gelatin-based protein-carbohydrate mixture.

Chapter 4 gives an elaborate and detailed biochemical description of the peripheral effects of this gelatin-based protein-carbohydrate mixture on the amino acid levels. Additionally, the selectivity of this treatment was determined by measuring central concentrations of 5-HT and DA and both their metabolites, 5-HIAA and DOPAC, respectively. The next experiment (Chapter 5) focuses on the functional effects of this newly developed mixture that substantially reduced plasma TRP levels in adult male rats. To compare the effects of this acute TRP depletion with a more chronic manner of depleting the 5-HT system, the treatment with the neurotoxin 5,7-DHT was selected to destroy 5-HT cell bodies in the dorsal raphe in the rat (Chapter 6). The effects of a 5-HT lesion were similar to those previously found after an acute TRP depletion, indicating that the impairment in object recognition after substantially reducing plasma TRP levels was presumably 5-HT related. Furthermore, we investigated whether this treatment could be used to deplete plasma TRP levels in a dose-dependent manner by varying the amount of protein added to the mixture (Chapter 7 ). This expcriment was designed to investigate the relationship between object recognition and the degree of TRP depletion. Finally in Chapter 8, together with a 24-h delay and a treatment with scopolamine, the TRP-free protein-carbohydrate mixture was used as an animal model of memory deficiency to examine the potential cognitive enhancing effect of a 5-HT 6 antagonist (Ro4368554) on object recognition. Further characterization of this drug was achieved by comparing it's effects with those of metrifonate, a cholinergic-mediated drug known to improve memory functions. The final chapter gives an overview of the studies presented in this thesis and provides a general conclusion on basis of the data obtained. Moreover, the effects of the biochemical TRP-free protein-carbohydrate mixture were investigated in another TRP-dependent pathway, i.e., the synthesis of kynurenine (Appendix 1). 


\section{References}

Agren, H., Reibring, I., Hartvig, P., Tedroff, J., Bjurling, P., Hornfeldt, K., Andersson, Y.. Lundqvist, H, and Langstrom, B. (1991) Low brain uptake of L-[1!C]5-hydroxytryptophan in major depression: a positron emission tomography study on patients and healthy volunteers. Acta Psychiatr Scand, 83: 449.55.

Altman, H.J. and Normile, H.J. (1988) What is the nature of the role of the serotonergic nervous system in learning and memory: prospects for development of an effective treatment strategy for senile dementia. Neurobiol Aging, 9:627-38.

Andrade, T.C. and Ciraelf, F.C. (2001) Effect of electrolytic and neurotoxic lesions of the median raphe nucleus on anxicty and stress. Pharmacol Biochem Behav 70: 1-14.

Asherg, M., Thoren, P. Traskman, L., Bertilsson. I. and Ringberger, V. (1976) "Serotonin depression"-a biochemical subgroup within the affective disorders? Science 191: 478-80.

Asin, K.E., Wirtshafter, D. and Fibiger, H.C. (1985) Electrolytic, hut not 5.7-dihydrosytryptamine, lesions of the nucleus medianus raphe impair acquisition of a radial mase task. Behaw. Neural Biol. 44: 415-24.

A/mitia, F.C. and Segal. M. (1978) An autorạdiographic analysis of the differential ascending prigections of the dersal and median raphe nuclei it the rat I Comp Neuro! 179:64t-67.

Barnes, J.M. Barnes, N.M and Cooper, S.J. (1992) Bchav wural pharmacology of 5-HT3 receptor ligands. Neturose Btobehav Rev: 16: !07-13.

Bel. N. and Artigas. F. (1996) Reduction of serotonergic function in rat bram by tryptophan depletion: eflects in control and fluvosaminetreated rats. I Neurochem. 67: 669-76.

Benkelfar, C.. Ellenbogen, M.A.s Dean, P., Palmour, R.M and Young, S.N. (1994) Moodlowering effect of tryprophan depletion. Enhaneed susceptibility in young men at genetic risk for major aflectue disorders. Anch Gen Prochiatn: $51: 6 \times 7-07$.

Berendsen, H.H., Kester, R. (.. Peeters, B.W and
Broekkamp, C.L. (1996) Modulation of 5-HT receptor subrype-mediated behaviours by corticosterone. Eur J Pharmacol. 308: 103-11.

Biggio, G., Fadda, F., Fanni, P., Tagliamonte, A. and Gessa, G.L. (1974) Rapid depletion of serum tryptophan, brain tryptophan, serotonin and 5 hydroxyindoletic acid by a tryptophan-free dict. Life Sciences. 14:1321-1329.

Blaney, P.H. (1986) Affect and memory: a review. Prychol Bull. 99: 229-46.

Blier, P. (2001) Possible neurobiological mechanisms underlying faster onset of antidepressant action. J Clin Psychiatry: 62 Suppl 4: 7-11.

Blier. P. and de Montigny, C. (1994) Current advances and trends in the treatment of depression. Trends Pharmacol Sci 15:220-6.

Blicr, P. and De Montigny, C. (1999) Serotonin and drug-induced therapeutic responses in major depression, obsessive-compulsive and panic disorders, Neuropsychopharmacology: 2I Suppl 1: S91-8.

Boadle-Biber, M.C. (1993) Regulation of serotonin synthesis. Prog Biophys Mol Biol. 60: 1-15.

Booij, L... Van der Does, W., Benkelfat, C.. Bremnẹ, J.D., Cowẹn, P.J., Favạ, M. Gillin, C.. Leyton, M., Moore, P., Smith. K.A. and Van der Kloot, W.A. (2002) Predictors of mood response to acute: tryptophan depletion. A reanalysis. Neuropsichopharmacologv: 27:852-61.

Bourson, A. Borroni. E., Austin. R.H., Monsma, F.J. Jr, and Sleight, A.J. (1995) Determination of the role of the $5-\mathrm{ht}_{\mathrm{e}}$ receptor in the rat brain: a study using antisense oligonueleotides. J Pharmacol Exp Ther. 274: 173-80.

Briley, M., Chopin, P. and Moret. C. (1990) Effect of serotonergic lesion on "anxious" behaviour measured in the elevarẹt plus-maze tẹs in the rat. Psichopharmacology (Berl). 101: 187-91.

Brown, C.M. Fletcher, P.J and Coscina, D.V. (1998) Acute amino acid loads that deplete brain serotonin fail to alter behavior. Pharmacol Buchem Bechas 59 115-21 
Brush. F.R. (|99|) Genetuc determunants of individual differences in avoidance learning: behavioral and endocrine characteristics. Experientia. 47: 1039.50.

Buhot, M.C., Martin, S. and Segu, L. (2000) Role of serotonin in memory impairment. Ann Med 32 : 210-21.

Carpenter, J.S. Andrykowskı. MA. Wilson, J. Hall, L.A., Rayens, M.K.. Sachs, B. and Cunningham, L.L. (1998) Psychometrics for two short forms of the Center for Epidemiologic Studies-Depression Scale. Issues Ment Health Nurs 19: 481-94.

Cassaday, H.J. Norman. C.. Sholliam. C.S. Vincent, C. and Marsden, C.A. (2003) Intraventricular 5,7-dihydroxytryptamıne lesions disrupt acquisition of working memory task rules but not performance once learned. Prog Neuro. psuchopharmacol Bial Psuchiarn. 27: 147-56.

Charney, D.S., Woods, S.W. Krystal, J.H. and Heninger, G.R. (1990) Serotonin function and human anxiety disorders. Ann N Y Acad Sci. 600: 558-72; discussion 572-3.

Clarke, A. and File, S.E. (1982) Selective neurotoxin lesions of the lateral septum: changes in social and aggressive behaviours. Phormacol Biochem Behon: 17: 623-8.

Coppen, A. (1967) The biochemistry of affective disorders. Br.J Psychiany. 113: 1237-64.

Corrodi, H.. Fuxe, K., Lidbrink, P. and Olson, L. (1971) Minor tranquillizers, stress and central catecholamine neurons. Brain Res. 29:1-16.

Cross, A.J. (1990) Serotonin in Alzhemer-type dementia and other dementing illnesses. Amn $N Y$ Acad Sci. 600: 405-15; discussion 415-7.

Cryan, J.F. and Leonard, B.E. (2000) 5-HT1 A and beyond: the role of serotonin and its receptors in depression and the antidepressant response. Hum Psychopharmacol 15: 113-135.

Cryan. J.F., Markou, A. and Lucki, I. (2002) Assessing antidepressant activity in rodents: recent developments and future needs. Trends Pharmacol Sci. $23: 238-45$.
Curran, H.V. and Verheyden. S.I. (2003) Altered response to tryptophan supplementation after longterm abstention from MDMA (ecstasy) is highly correlated with human memory function. Psuchopharmacolingy (Berl) 169: 91-103

D'Aquila, P.S, Newton, J, and Willner, P. (1997) Diurnal varation in the effect of chronic mild stress on sucrose intake and preference. Phosiol Behan: $62: 421-6$

De Vry. J. (I995) 5-HT(IA) receptor agonists: Recent developments and controversial issues. Psuchopharmacologv: 121: 1-26.

Deakin, J.W.F. and Gract, F.G (1991) 5-11T and mechanusms of defence. I Psuchopharmacol 5: 305-315.

Delgado, P.L.. Chamey, D.S. Price, L.H. Aghajanian, GK., Landis, H and Heninger, GR. (1990) Serotonin function and the mechanism of antidepressant action. Reversal of antudepressantinduced remission by rapid depletion of plasma tryptophan. Arch-Gen-Psychiatry 47:411-8

Delgado, P.L., Price, L.H., Miller, H.L., Salomon, R.M., Aghajanian, G.K.., Heninger, G.R. and Charney, D.S. (J994) Serotonin and the neurobiolingy of depression. Effects of tryptophan depletion in drog-tree depressed patients. Arch Gen Prochialm. 51: 865-74.

Detke, MJ and Lucki, I. (1996) Detection of serotonergic and noradrenergic antidepressants in the rat forced swimming test: the effects of water depth. Beha Brain Res. 73: 43-6.

Dringenberg, H.C.. Hargreaves, E.L., Baker, G.B., Cooley. R.K. and Vanderwol1. C.II. (1995) p-chtorophenylalanine-indaced serotonin depletion: reduction: in exploratory locomotion but no obvious: sensory-motor deficits. Behav Brain Res. 6x: $229-37$

Ellenbogen, M.A.. Young. S.N., Dean. P., Palmour, R.M. and Benkelfat, C. (1996) Mood response to acate tryptophan depletion in healthy volunteers: sex differences and temporal stability. Neurapsychopharmacology. 15: 465-74.

Ennaceur. A. and Delacour, 1. (1988) A new onetrial test for neurobiological' studies of memory in rats. 1: Behavioral data. Behav Brain Res. 31:47-59. 
Fadda, F., Cocco, S. and Stancampiano, R. (2000) A physiological method to selectively decrease brain serotonin release. Brain Res Brain Res Protoc. 5: 219-22.

Feldman, R.S., Meyer, J.S. and Quenzer, L.F. (1997) Principles of Neuropsychopharmacology. Sunderland, Massachusetls: Sinauer Associates Inc.

Fernstrom, J.D. and Wurtman, R.J. (1997) Brain serotonin content: physiological regulation by plasma neutral amino acids. Ohes Res. 5; 377-80.

Franklin, M., Craven, R.D., Dowling. B., Campling. G. Ellsott, J.M. and Cowen, P.J. (1999) Eflect of a long-term low tryptophan diet on the prolactin responses to the $5-\mathrm{HT}_{1 \mathrm{~A}}$ and $5-\mathrm{HT}_{\mathrm{X}}$ agonists, 8-OH-DPAT and $\mathrm{mC}$ CP in the male rat. $f$ Psychopharmacol 13:58-63.

Frederick, D.L. and Paule, M.G. (1997) Effects of MDMA on complex brain function in laboratory animals. Neurasci Biohehav Rev 21:67-78.

Freo, U., Larson, D.M.. Tolliver, T., Rapoport, S.I. and Soncrant, T.T. ( $\mid 99$ |) Parachloroamphetamine selectively alters regional cerebral metabolic responses to the serotonergic agonist metachlorophenylpiperazine in rats. Brain Res 544: 17-25.

Gardier, A.M. and Bourin, M. (2001) Appropriate use of "knockout" mice as models of depression or models of testing the efficacy of antidepressants. Psychopharmacology (Berl). 153: 393-4.

Gessa, G.L., Biggio, G, Fadda, F., Corsini, GiU. and Tagliamonte. A. (1974) Effect of the oral administration of tryptophan-free amino acid mixtures on serum tryptophan, brain tryptophan and serotonin metabolism. J Neurochem. 22: 869-70.

Gouzoulis-Mayfrank, E. Thimm, B., Rezk, M.. Hensen, Gi and Daumann, J. (2003) Memory imparment suggests hippocampal dysfunction in abstunent ecstasy users. Prog Neuropsychopharmacol Biol Psichiary: 27: 819-27.

Gracfl, F.G. and Silveira Filho, N.G. (1978) Behavioral inhibition induced by electrical stimulation of the median raphe nucleus of the rat. Phosiol Behas: 21:477-84.

Giraefl, F.G. Viana. M.B. and Mora. P.O. (1997) Dual role of 5-HT in defense and anxiety. Neurosel Brobchav Rev: 21: 791-9
Green, A.R., Cross, A.J. and Goodwin, G.M. (1995) Review of the pharmacology and clinical pharmacology of 3,4-methylenedioxymethamphetamine (MDMA or "Ecstasy"). Psychopharma-cology (Berl). 119: 247-60.

Griebel, G. (1995) 5-Hydroxytryptamine-interacting drugs in animal models of anxiety disorders: more than 30 years of research. Pharmacol Ther 65: 319-95.

Griebel, G., Rodgers, R.J., Perrault, G. and Sanger, D.J. (2000) The effects of compounds varying in selectivity as $5-\mathrm{HT}_{11}$, receptor antagonists in three rat models of anxiety. Neunopharmacology. 39 : 1848-57.

Gurtman, C.G., Morley, K.C.. Li, K.M., Hunt, G.E. and McGregor, I.S. (2002) Increased anxiety in rats after 3.4-methylenedioxymethamphetamine: association with serotonin depletion. Eur J Pharmacol. 446: $89-96$

Hall, F.S., Devries, A.C., Fong, G.W., Huang, S. and Pert. A. (1999) Effects of 5,7-dihydroxytryptamine depletion of tissue serotonin levels on extracellular serotonin in the striatum assessed with in vivo microdialysis: relationship to behavior. Synapse. 33: 16-25

Harkin, A., Connor, T.J., Walsh, M., St John, N. and Kelly, J.P. (2003) Serotonergic mediation of the antidepressant-like effects of nitric oxide synthase inhibitors. Neuropharmacology: 44: 616-23.

Harmer, C.J., Bhagwagar, Z., Cowen, P.J. and Goodwin. GM. (2002) Acute administration of citalopram facilitates memory consolidation in healthy volunteers. Psychopharmacology (Berl). 163: $106-10$.

Harro, J., Tonissaar. M. Eller, M.. Kask, A. and Oreland, L. (200! ! Chronic varable stress and partial 5-HT denervation by parachloroamphetamine treatment in the rat: effects on behavior and monoamme neurochemistry. Brain Res. 899: 227-39.

Hasbroucq. T., Rihet. P., Blin, O. and Possamai. C.A. (1997) Serotonin and human information processing: fluvoxamine can improve reaction time performance. Neurosct lett 229: 204-8.

Ilsley. JE. Moffoot, A.P. and O'Carroll, R.E. (1995) An analysis of memory dysfunction in major depression. J Affect Dssond 35:1-9 
Jacobs, B.L. and Azmita, EC. (1992) Structure and function of the brain serotonin system. Physiol Rev: 72: 165-229.

Jagannathan, V, and Venity, J. (1997) Pharmacokinetics and CNS pharmacodynamics of the 5-HTIA agonist buspirone in humans followtng acute L-tryptophan depletion challenge. Methods Find Exp Clin Pharmacol 19:351-62.

Jakala, P., Sirvio, J., Riekkinen, P., Jr. and Riekkinen, P.J., Sr. (1993) Effects of p-chlorophenylalanine and methysergide on the performance of a working memory task. Pharmacol Biochem Behav: 44; $411-8$.

Jakala, P. Sirvio, J., Rickkmen, P. Jr. Valjakka, A and Riekkinen, P. (1992) The effects of alaproclate and p-chlorophenylalanine on cued navigation performance in rats. I Neural Transm Park Dis Dement Sect, 4: 43-52.

Katz. R.J. (1982) Animal model of depression: pharmacological sensitivity of a hedonic deficit. Pharmacol Biochem Behav 16: 965-8.

Kelly, J.P., Wrynn, A.S and Leonard, B.E. (1997) The olfactory bulbectomized $r a t$ as a model of depression: an update. Phamacol Ther 74:299-316.

Kennet. G.A. (1992) 5-HTIC receptor antagonists have anxiolytic-like actions in the rat social interaction model. Psychopharmacology (Berl). 107: $379-84$.

Kessler, R.C. (1997) The effects of stressful life events on depression. Amm Rev Psychol. 48: 191. 214.

Klaassen, T., Riedel, W.J., Deut, N.E and Van Praag, H.M. (2002) Mood congruent memory bias induced by tryptophan depletion. Fsychol Med. 32: 167-72.

Klaassen, T. Ricdel, W.J., Deuts, N.E., van Someren, A and van Praag. H.M. (1999a) Specificity of the tryptephan depletion method. Psychopharmacology (Berl). 141: 279-86.

Klaassen, T., Riedet. W.J., Honig, A., Van Someren, A., Deutz, N.E.P. and Van Praag, H.M. (1999b) Mood effects of 24-hour tryptophan depletion in healthy first degree relatives of patients with affective disorders. Biological Psychiatr: 46: 489-497.
Maccarı, S., Darnaudery, M., Morley-Fletcher, S. Zuena, A.R., Cinque, C. and Van Reeth, O. (2003) Prenatal stress and long-term consequences: implications of glucocorticoid homones. Neumest Biobehav Rev 27: 119-27.

Maes, M. and Meltzer, H.Y, (1995) The serotonin hypothesis of major depression. In F. E Bloom and D. J. Kupfer (Eds.). Psychopharma. cology. The Fourth Generation of Progress (pp. 933-944). New York: Raven Press.

Mann, J.J. (1999). Role of the serotonerge system in the pathogenesis of major depression and suicidal bchavior. Neuropsuchopharmacology, 21 995-105S.

Matthews, K. and Robbins, T.W (2003) Larly experience as a determunant of adult behavioural responses to reward: the effects of repeated maternal separation in the rat. Neurosci Biobehav Rev. 27:45-55,

Mazer, C., Muneyyire, J., Taheny, K., Raso, N. Borella, A and Whitaker-A/miria, P. (1997) Serolonin depletion during synaplogeness leads 10 decreased synaptic density and learning deficits in the adult rat: a possible model of neurodevelopmental disorders with cognitive deficits. Brain Res. 760: $68-73$

McCann, U.D., Smabo, Z., Scheflel, U., Bannals, R.F. and Ricaurte, G.A. (1998) Positron emission tomographic evidence of toxic effect of MDMIA ("Ecstasy") on bain serotonin neurons in human beings. Lancet. 352: 1433-7.

McEntee, W.J. and Crook, T.H. (1991) Serotonin. memory, and the aging brain. Psachopharmatologe. 103: 143-4

McGuire, P. $\{2000)$ Long term psychiatric and cognitive effects of MDMA use. Toxicol Lett. [12-113: 153-6.

Mechan, A.G., Moran, P.M., Elliot, M., Young. A.J., Joseph, M.H. and Green, R. (2002) A siudy of the effect of a single neurotoxic dose of 3,4-methylenedioxymethamphetamine (MDMA; "ecstasy") on the subsequent long-term behaviour of rats in the plus maze and open field. Psychopharmacology (Berl). 159: 167-75.

Meltzer, C.C., Smith, Ci, DeKosky, S.T., Pollock, B.G. Mathis, C.A. Moore, R.Y., Kupfer, D.J. and Reynolds, C.F., 3rd. (1998) Serotonin in aging. 
late-life depression, and Alzheimer's discase: the emerging role of functional imaging. Neumopsychopharmacology. 18: 407-30.

Meltzer, H. (1989) Serotonergic dysfunction in depression. Br J Psychiary Suppl 155 (Suppl 8): 25-31.

Meneses, A. (1998) Physiological, pathophysiological and therapeutic roles of 5-HT systems in learning and memory. Rev Neurosci. 9: 275-89.

Meneses, A. (1999) 5-HT system and cognition. Neurosei Biobehav Rev: 23: 1111-25.

Meneses, A. and Hong. E. (1997) A pharmacological analysis of serotonergic receptors: effects of their activation of blockade in learning. Prong Neuroprychopharmacol Biol Psychatr: 21:273-96

Moja, E.A., Cipolla, P., Castoldi, D, and Tofanctt, O. (1989) Dose-response decrease in plasma tryptophan and in brain tryptophan and serotonin after tryptophan-free amino acid mixtures in rats. Life Sct 44: $971-6$.

Moja, E.A., StofI, D.M., Gessa, Gi ... Castoldi, D.. Assereto, R. and Tofanetti, O. (1988) Decrease in plasma tryptophan after tryptophan-free amino acid mixtures in man. Life $S_{C l}$ 42: 1551-6.

Moller, HI. and Voľ, H.P. (1996) Drug treatment of depression in the 1990s. An overview of achevements and future possibilities. Drugs. 52: $625-38$

Moore, P., Landolt. H.P., Seifritz. E., Clark. C.. Bhatt, T., Kelsoc, J.. Rapaport, M. and Gillın. J.C. (2000) Cluncal and physiological consequences of rapid tryptophan depletion. Neturopsichopharmacologv: 23:601-22

Moreau, J.L.. Jenck, F. Martin, J.R.. Mortas, P. and Hacfely. W.E. (1902) Antidepressant treatment prevents chronic unpredictable mild stress-induced anhedonia as assessed by ventral tegmentum selfstimulation hehavior in rats. Eur Veuroprichopharmocol. 2: 43-9

Moret. C. and Briley, M. (2000) The possible role of 5-HT, $17 \mathrm{~m}$ recepton in psychiatric disorders and ther potential as a target for therapy. Eur . Pharmacol' 404: 1-12

Morgan. M.J. (2000) Festasy (MDMA): a review of its possible persistent psychological effects.
Psychopharmacologv (Berl). 152: 230-48.

Morley, K.C., Gallate, J.E., Hunt, G.E., Mallet, P.E. and McGregor, 1.S. (2001) Increased anxiety and impaired memory in rats 3 months after administration of 3,4-methylenedioxymethamphetamine ("ecstasy"). Eur J Pharmacol. 433: 91-9.

Morley, K.C. and McGiregor, I.S. (2000) (+/-)-3, 4-methylenedioxymethamphetamine (MDMA. 'Ecstasy') increases social interaction in rats. Eur J Pharmacol. 408:41-9.

Morris, R.G., Garrud, P., Rawlins, J.N. and O'Keefe, J. (1982) Place navigation impaired in rats with hippocampal lesions. Nature. 297: 681-3.

Moser, P.C., Bergis, O.E., Jegham, S., Lochead, A., Duconseille, E., Terranova, J.P., Caille, D., BerqueBestel, I., Lezouale'h, F., Fischmeister, R., Dumuis, A., Bockacr, J., George, P., Soubrie, P. and Scatton, B. (2002) SL65.0155, a novel 5-hydroxytryptamine(4) receptor partial agonist with potent cognition-enhancing properties. I Pharmacal Exp Ther 302:731-41.

Mumby, D.G., Gaskin, S., Glenn, M.J., Schramek, T.E. and Lehmann, H. (2002) Hippocampal damage and exploratory preferences in rats: memory for objects, places, and contexts. Learn Mem. 9: 49.57.

Myhrer, T. (2003) Neurotransmitter systems involved in learning and memory in the rat: a metaanalysis based on studies of four behavioral tasks. Brain Res Brain Res Rev: 4!: 26.8-87.

Naughton, M., Mulrooney, J.B. and Leonard, B.E. (2000) A review of the role of serotonin receptors in psychiatric disorders. Hum Psichopharmacol 15: $397-415$

Nesiler. F.J., Barrot, M., Dileone, R.J., Fisch, A.J., Gold. S.J. and Monteggia. L.M. (2002a) Neurobiology of depression. Neumon. 34: 13-25.

Nestler. E.J., Gould, E., Manjı. H., Buncan, M. Duman, R.S., Greshenfeld, H.K. Hen, R., Koester, S., Lederhendler, I., Meancy, M. Robbuns, T., Winshy. L. and Zalcman. S. (2002b) Preclinical models: status of basic research in depression. Biol Psuchiatry: 52:503-28.

Nishizawa. S. Benkelfat. C., Young. S.N. Leyton. M. Mrengera, S., de Montigny, C . Blier, P and Diksie. M. (1997) Differences berween males and 
females in rates of serotonin synthesis in human brain. Proc Natl Acad Sci US.A. 94: 5308-13.

Olton. D.S. (1979) Mazes, maps, and memory. Am Psuchol, 34; 583-96.

OrShea. E., Granados, R., Estehan, B., Colado, M.I. and Gireen, A.R. (1998) The relationship between the degree of neurodegeneration of rat brain 5-HT nerve terminals and the dose and frequency of administration of MDMA ('ecstasy'). Neuropharmacology: 37:919-26.

Overstreet, D.H. (1993). The Flinders sensitive line rats: a genetic animal model of depression. Neumosct Biobehav Rev: 17:51-68.

Overstreet, D.H. Commissaris, R. C.. De La Garza, R., 2nd. File, S.E., Knapp. D.J. and Seiden, I..S. (2003) Involvement of 5-HTIA receptors in animal tests of anxiety and depression: evidence from genetic models. Siress. 6:101-10

Owens, M.J and Nemeroff. C.B. (I991) Physiology and pharmacology of corticotropmreleasing factor. Pharmucol Rev: 43: 425-73.

Owens, M.J. and Nemeroft, C.B. (1994) Role of serotonin in the pathophysiology of depression: focus on the serotonin transporter. Clin Chem 40: 288-95.

Page. M.E., Detke, M.J., Dalvi, A., Kirby, L.G. and Lucki, I. (1999) Serolonergic mediation of the effects of lluoxetine. but not desipramine, in the rat forced swimming iest. Psichopharmacology (Berl). 147: 102-7.

Papp. M.. Moryl, E. and Willner, P. (1996) Pharmacological validation of the chronic mild stress model of depression. Eur J Fharmacol. 296: 129-36.

Park, S.B., Coull, J.T., McShane, R.H.. Young. A.H., Sahakian. B.J., Robbins, T.W. and Cowen, P.J. (1994) Tryptophan Depletion in Normal Volunteers Produces Selective Impairments in Leaming and Memory. Neuropharmacology. 33: $575-588$

Parrott. A.C.. Sisk, E. and Turner. J.I. (2000) Psychobiological problems in heavy 'ecstasy' (MDMA) polydrug users. Drug Alcohol Depend. 60: $105-10$.

Perfumi. M.. Panocka, 1., Ciccocioppo, R., Vitali. D.. Froldi. R. and Massi. M. (2001) Effects of a methanolic extract and a byperform-ennched $\mathrm{CO}_{2}$ extract of Hypericum perforatum on alcohol intake in rats, Alcohol Alcohol 36: 100.206

Porsolt, R.D. (1979) Animal model of depresston. Biomedicine. 30: 139.40.

Prickaerts, J., de Vente, J., Honig. W.. Stembusch. H.W and Blokland, A. (2002) cGiMP, but not CAMP, in rat hippocampus is involved in carly stages of object memory consolidation. Eur J Pharmacol 436: 83.7.

Ramboz, S., Oosting, R., Amara, D A., Kung, H.F. Blier, P., Mendelsohn, M. Mann, J.J., Brunner, D. and Hen, R. (1998) Serotonu receptor IA knockout: an animal model of anxiety-related disorder Proc Natl Acad Sci U S A 95-14476-81.

Reilly, J.G, McTavish, S.F.B. and Young, A.H. (1997) Rapid depletion of plasma tryptophan: a review of studies and experimental methodology. Journal Of Psuchopharmacology 11:381-392.

Reneman, L. Booy, J. Schmand, B, van den Brink. W. and Gunning. B. (2000) Memory disturhances in "Eestasy" users are correlated with an altered brain serotonin neurotransmission. Psychopharmacology (Berl). 148: 322-4.

Rex, A., Thomas, H., Hormagl, H., Voits, M. and Fink, H. (2003) Bethavioural and microdialysis study after neurotoxic lesion of the dorsal raphe nucleas in rats. Pharmacol Biochem Bithe 74: $587-93$.

Richter-Levin, G and Segal, M. (1989) Spatial performance is severely imparted in rats with combined reduction of serotonergic and cholinergic transmission. Brain Res. 477: 404-7.

Riedel. W.I. K.laassen. T., Deutz, N.E.. van Somerco, A. and van Praag. H.M. (I999) Tryptophan depletion in normal volunteers preduees selective impairment in memory consolidation. Psychopharmacology (Berl). 141:362-9.

Riekkinen, P.. Ir., Sirvio, J.. Vạjakka, A., Mietinen, R. and Rickkinco, P. (1991) Phamacological consequences of cholinergic plus serotonergic manipulations. Brain Res. 552: 23-6.

Ruat, M. Traiffort, E., Arrang, J.M., TardivelLacombe, J., Diaz, J., Leurs, R. and Schwart, J.C. (1993), A novel rat serotonin $\left(5-\mathrm{HT}_{6}\right)$ receptor: molecular cloning. localization and stimulation of 
cAMP accumulation. Biochem Biophys Res Commun. 193: 268-76.

Ruotsalainen, S., Miettinen, R., MacDonald, E., Riekkinen, M. and Sirvio, J. (1998) The role of the. dorsal raphe-serotonergic system and cholinergic receptors in the modulation of working memory. Neurosci Biohehav Rev 22: 21-31.

Russell, M.G. and Dias, R. (2002) Memories are made of this (perhaps): a review of serotonin 5 . $\mathrm{HT}(6)$ receptor ligands and their biological functions. Curr Top Med Chem 2: 643-54

Santucci, A.C., Knott, P.J. and. Haroutunian, V. (1996) Excessive serotonin release, not depletion. leads to memory impairments in rats. Eur $d$ Pharmacal. 295: 7-17.

Santucei, A.C., Moody, E. and Demetriades, J. (1995) Effects of scopolamine on spatial working memory in rats pretreated with. the serotonergic depleter p-chloroamphetamine. Neurohiol Learn Mem 63: 286-90.

Schmit, J.A., Jorissen, B.L., Sobezak, S., van Boxtel, M.P. Hogervorst, E., Deutz, N.E. and Riedel, W. 3. (2000) Tryptophan depletion impairs memory consolidation but improves focussed attention in healthy young volunteers. Journal of Psychopharmacology. 14:21-29.

Shekhar, A. MeCann, U.D., Meaney, M.J.. Blanchand, D.C., Davis, M., Frey, K.A., Liberzon, I., Overall, K.1.. Shear, M.K., Tecott, L.H. and, Winsky, 1. (2001) Summary of a National Institute of Mental Health workshop: developing animal. models of anxiety disorders. Pswchopharmacology (Berl) 157:327-39

Sirvio, J., Riekkinen, P.. Jr., Jakala, P. and Rickkinen, P.J. (1994) Experimental studies on the role of scrotonin in cognition. Prog Neurobiol. 43: 363-79

Smith, K.A. Morris, J.S., Friston, K.J., Cowen, P.J. and Dolan, R.J. (1999) Brain mechanisms associated with depressive relapse and associated cognitive. impairment following acute tryptophan depletion. British fournal of Pswchatr: 174:525-529.

Smith, S.E., PihI. R.O. Young. S.N. and Ervin. F.R. (1987) A test of possible cognitive and environmental influences on the mood lowering effect. of tryptophan depletion in normal males. Powhopharmacologe (Berl). 91:451-7.
Sobczak, S., Riedel, W.J., Booij, I., Aan Het Rot, M., Deutz, N.E. and Honig. A. (2002) Cognition following acute tryptophan depletion: difference between first-degree relatives of bipolar disorder patients and matched healthy control volunteers. Psychol Med. 32: 503-15.

Soderpalm. B. and Engel. J.A. (1991) Involvement of the GABAA/benzodiazepine chloride ionophore receptor complex in the 5,7-DHT Induced anticonflict effect. Life Sci. 49; 139-53.

Spillmann, M.K., Van der Does, A.J., Rankin, M.A., Vuolo, R.D., Alpert, J.E., Nierenberg, A.A., Rosenbaum, J.F., Hayden, D.. Schoenfeld, D. and Fava, M. (2001) Tryptophan depletion in SSR!recovered depressed outpatients. Psychopharmacology (Berl) 155: 123-7.

Stancampiano, R.. Cocco, S., Melis, F., Cugusi, C., Sarais, L. and Fadda, F. (1997a) The decrease of serotonin release induced by a tryptophan-free amino acid diet does not affect spatial and passive avoidance leaming. Brain Res. 762: 269-74.

Stancampianu, R., Melis, F., Sarais, L., Coceo, S., Cugusi. C and Fadda, F. (1997b) Acute administration of a tryptophan-free amino acid mixture decreases 5-HT release in rat hippocampus in vivo. Am of Phusiol. 272: $\mathrm{R} 991-4$.

Steckler, T and Muir, J.L. (1996) Measursment of cognitive function: relating rodent performance with human minds. Brain Res Cogn Brain Res: 3 : 299-308.

Steckler, T. and Sahgal, A. (1995) The role of serotonergic-cholinergic interactions in the mediation of cognitive behaviour. Behavioural Brain Research. 67: 165-199.

Steinbusch, H.W. (1981) Distribution of serotenin-immunoreactivity in the central nervous system of the rat-cell bodies and terminals. Neuroscience, 6: 557-618.

Steinbusch, H.W.M. and Nieuwenhuys, R. (1983) The raphe nuclei of the rat brainstem: a cytoarchitectonic and immunohistochemical study. Chemical Veuroanatomy (pp. 131-207). New York: Raven Press.

Stock, H.S.. Ford, K. and Wilson, M.A. (2000) Gender and gonadal hormone eflects in the offactory bulbecromy animal model of depression. Pharmacol Biochem Behav 67: 183-91. 
Stockmeier, C.A. (2003) Involvement of serotonun in depression: evidence from postmortem and imaging studies of serotonin receptors and the serotonin transporter. J Psychiatr Res. 37: 357-73.

Tarbuck, A.F. and Paykel. E.S. (1995) Effects of major depression on the cognitive function of younger and older subjects. Psuchol Med. 25:285-95

Thomas, H., Fink, H., Sohr, T.R. and Voits, M (2000) Lesion of the median raphe nucleus; a combined behavioral and microdialysis study in rats Pharmacol Biochem Behav 65: 15-21.

Tork, I. (1990) Anatomy of the serotonergic system. Ann N Y Acad Sci. 600: 9-34: discussion 34-5.

Twarog, B.M. and Page, 1.H. (1953) Serotonin content of some mammalian tissues, and urine and a method for its determination. Am I Physiol 175 157-61.

Tye, N.C., Everitt, B.J. and Iversen, S.D. (1977) 5Hydroxytryptamine and punishment. Nature. 268: $741-3$.

van der Siaay, F.J., Raaijmakers, W.G, Lammers. A.J. and Tonnaer, I.A. (1989) Selective fimbria lesions impair acquisition of working and reference memory of rats in a complex spatial discrimination task. Behar Brain Res. 32: 151-61.

van Praag. H.M. (1996) Serotonin-related, anxiety/aggression-driven, stressor-precipitated depression. A psycho-biological hypothesis. Eur Psuchiatry: 11: $57-67$.

van Prag. H.M. Kor̂, J. and Puite, J. $(1970) 5$ Hydroxyindoleacetic acid levels in the cerebrospinal fluid of depressive patients treated with probenecid Name. 225: 1259-60.

Vertes, R.P. (199!) A PHA-L analysis of ascending projections of the dorsal raphe nucleus in the rat. $f$ Comp Netirol. 313: 643-68.

Vertes, R.P., Fortin. W.J. and Crane, A.M. (1999) Projections of the median raphe nucleus in the rat. $J$ Comp Neurol. 407: 555-82.
Whitaker-Ammina, P.M. (1999) The discovery of scrotonin and its role in neuroscience. Neurypsichopharmucology: 21 Suppl 1: S2-8.

White, S.R., Obradovic, T., Imel, K.M. and Wheaton, M.J. (1996) The effects of methylenedroxymethamphetamune (MDMA, "Eestasy") on monoaminergic neurotransmission in the central nervous system. Prog Neurotiol 49: 455-79.

Williams, W.A., Shoaf, S.E., Hommer, D., Rawlings, R' and Linnoila. M. (1999) Effects of acute tryptophan depletion on plasma. and cerebrospinal flud tryptophan and 5-hydroxyindoleacetic acid in normal voluntecrs. I Neurochem. 72: 1641-7.

Williner, P. ( 1990$)$ Animal models of depression: an overview. Pharmacol Ther 45: 425-55.

Willner, P. (1997) Validity, reliability and utility of the chronic mild stress model of depression: a 10 year review and evaluation. Psichopharmacologe. (Berl). 134: 319-29.

Willner, P. and Mitchell, P.J. (2002) The validity of animal models of predisposition to depression. Bchar Phamacol. 13: 169-88.

Young, S.N., Frvin, F.R., Pihl, R.O. and Fimn, P. (1989) Biochemical aspects of tryptophan depletion in primates. Psychopharmacology (Ber/). 98: 508.11 .

Young. S.N., Smith, S.E., Piht, R.O. and Ervin. F.R. (1985) Tryplophan depletion causes a rapid lowering of mood in nommal males. Pychopharmacology, 87: 173-7.

Zhuang, X., Gross, C., Santarelli, L.. Compan, V., Trillat. A.C. and Hen, R. (1999) Altered emotional states in knockout mice lacking 5 -HT/A of 5 HTIB receptors. Neuropsychopharmacology. 21: 52S-60S.

Zimmer, L., Lusen, A., Giacomelli, F. and Pujol. J.F. (2002) Short- and long-term effects of pethynylphenylalanine on brain serotonin levels. Neurochem Res. 27: 269-75. 


\section{Abbreviations}

5,7-DHT
5-HIAA
5 -HT
5 -HTP
AADC
ACh
AChEi
CSF
CTX
DA

DOPAC

DRN

FST

HCET

HIP

HPA

HPLC

ICV

KYN

KYNA

LNAA

LTP

MAO-A

MDMA

MRN

MTF

MWET

NE

NO

NOS

OF

ORT

PAG

P-EDA

PCA

PCPA

QUINA

SPT 5,7-dihydroxytryptamine

5-hydroxyindolacetic acid

5-hydroxytryptamine; serotonin

5-hydroxytryptophan

aromatic amino acid decarboxylase

acetylcholine

acetylcholinesterase Inhibitor

cerebrospinal fluid

cortex

dopamine

3,4-dihydroxyphenylacetic acid

dorsal raphe nucleus

forced swimming test

home cage emergence test

hippocampus

hypothalamic-pituitary-adrenal

high-performance liquid chromatrography

intracerebroventricular

kynurenine

kynurenine acid

large neutral amino acids

long term potentiation

monoamine oxidase- $A$

methylenedioxymethamphetamine

medial raphe nucleus

metrifonate

Morris water escape test

norepinephrine

nitric oxide

nitric oxide synthase

open field

object recognition test

periaqueductal gray

p-ethynylphenylalanine

p-chloroamphetamine

p-chlorophenylalanine

quinolinic acid

sucrose preference test 
SSRI

STR

TCA

TH

TRP

TYR selective 5-HT re-uptake inhibitor

striatum

tricyclic antidepressant

tryptophan hydroxylase

tryptophan

tyrosine 



\section{CHAPTER}

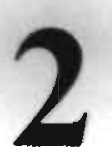

\section{Anxiogenic and}

depressive-like effects,

but no cognitive deficits

after repeated moderate

tryptophan depletion in the rat

A. Blokland, C.K.J. Lieben and N.E.P. Deutz.

Published in: Journal of Psycopharmacology 2002; 16(1):27-37 


\section{Abstract}

The tryptophan (TRP) depletion method has been used' as a tool to investigate the effects of acute lowered serotonin levels in the brain. In the present study the effects of this treatment were investigated in rat models of anxiety (i.e. open field test, home cage emergence test), depression (i.e. forced swimming test, sucrose preference test), and cognition (i.e. spatial discrimination learning, sustained attention). It was found that the repeated TRP depletion increased anxiety-related behaviour in the open field test and increased the immobility in the forced swimming test. The other behavioural tests did not reveal effects of treatment. TRP levels were decreased in plasma $(34 \%)$ and hippocampus (33\%) but not in the cortex. Stress-induced corticosterone levels were not affected after TRP depletion. The present findings indicate that repeated moderate TRP depletion leads to anxiogenic and depressivelike behaviour in the rat and corroborates the notion of the involvement of serotonin in these behaviours.

\section{Introduction}

Serotonin (5-HT) has been assumed to play an important role in various aspects of behaviour and it has been suggested that lowered central 5-HT levels underlie various kinds of psychiatric diseases (Meltzer and Lowy. 1987; Brown and Van Praag, 1991). Although neuroanatomical, neurophysiological and behavioural studies support the concept of the involvement of 5-HT in the development and treatment of anxiety. the specific nature of the involvement of 5-HT, and its receptors, in affective disorders remains to be defined. One method that has been developed in order to investigate the functions of 5-HT experimentally is the acute tryptophan (TRP) depletion method (Biggio et al., 1974; Gessa et al., 1974; Moore et al., 2000). Briefly, an amino acid mixture without TRP is administered to subjects which subsequently leads to a reversible decline in the ratio of plasma TRP/large neutral amino acids with a maximum decrease after $5-7 \mathrm{~h}$. Animal studies have shown that these peripheral changes are paralleled by lowered central TRP and 5-HT concentrations (see Reilly et al., 1997: Moore et al.. 2000).

Human studies using this treatment have found a $80 \%$ decrease in plasma TRP which was concomitant with a lowered mood state (Young et al., 1985). although it should be mentioned that this can more reliably be found in patients who recovered from depression than in healthy volunteers (see Reilly 
et al., 1997: Klaassen et al., 1999). More recently, different studies have shown that TRP depletion also affected cognitive functions in healthy volunteers (Park et al., 1994: Coull et al., 1995), and it has been suggested that this treatment has a specific effect on memory consolidation (Riedel et al., 1999: Schmitt et al., 2000). Surprisingly, this treatment was also found to improve aspects of attention (Coull et al., 1995; Schmitt et al., 2000).

Although the acute TRP depletion method could be an interesting tool for animal studies, only a few animal studies have examined the behavioural effects of this method. One study in which the effects of this treatment were tested in rats did not reveal any behavioural effects (Brown et al., 1998). In this study 5 -HT levels were reduced by about $25 \%$ in the hippocampus. This modest effect of amino acid loading stands in contrast with previous data (Biggio et al., 1974; Gessa et al., 1974), but corroborates a more recent microdialysis study in which a drop of about $50 \%$ in cortical 5-HIAA but not 5-HT was found in non-fasted rats (Bel and Artigas, 1996).

In the present study, we examined the behavioural effects of the amino acid mixture that has been used in human studies. We tested the effects of this treatment in animal models of anxiety, depression and cognition in rats. Special care was taken with respect to restriction of food intake and the selection of the treatment-test interval in order to maximize the reduction in TRP levels (see Bel and Artigas, 1996; Brown et al., 1998). Further, peripheral and central (i.e. hippocampus and cortex) TRP levels were measured to determine the level of TRP depletion and to relate the decline in blood to that in brain. A second biological parameter that was measured in this study was the resting- and stress-induced corticosterone level.

\section{Methods and materials}

\section{Animals}

All experimental procedures were approved by the local ethical committee of the Maastricht University for animal experiments and met governmental guidelines. Subjects were twenty four-month-old male Wistar (Charles River, NL) rats, weighing between 339 and $429 \mathrm{~g}$ at their arrival. The rats were housed two per cage in standard Makrolon cages on sawdust bedding in an air-conditioned room $\left(20^{\circ} \mathrm{C}\right)$. They were kept under a reversed 12/12-h light/dark cycle. The lights went on from 06.00 to $18.00 \mathrm{~h}$. A radio, which was playing softly, provided background noise. Unless specifically indicated the 
rats had free access to food and water.

The rats were matched for body weight and assigned to either the TRP+ group $(n=10)$ or the TRP- group $(n=10)$. The assignment of the rats to a treatment group was independent of cage. The TRP + group was given the amino acid mixture containing TRP whereas the TRP- rats were given the TRP deficient mixture. This grouping remained constant over the whole experiment.

\section{Treatment}

The amino acid mixtures consisted of fifteen/sixteen amino acids and was similar to that used in previous human and animal studies (e.g. Young et al., 1985; Bel and Artigas, 1996; Brown et al., 1998; Riedel et al., 1999).

Table 1: Order and duration of the different behavioural experiments. The last column indicates whether the rats received treatment, the number indicates the number of days treatment was given

\begin{tabular}{|c|c|c|}
\hline Week & Tesi & Treatment \\
\hline 1 & Arriva! and handling & no treatment \\
\hline 2 & Open Field Test & 4 \\
\hline $3-6$ & Spalial Cone Field Test, training & no treatment. \\
\hline $7 \cdot 8$ & Spatial Cone Field Test; treatment & 5 \\
\hline 9 & Forced Swimming Test & 3 \\
\hline 10 & Home Cage Emergence Test & 2 \\
\hline 11 & Sucrose Preference Test & 3 \\
\hline 12 & Sucrose Preference Test & 3 \\
\hline $13-17$ & Sustained attention: training & no treatment: \\
\hline 18 & Sustained attention: treatment & 2 \\
\hline 19 & & no treatment! \\
\hline 20 & $\begin{array}{l}\text { Blood sampling and stress condition } \\
\text { (corticosterone) }\end{array}$ & 1 \\
\hline 21 & Blood sampling and decapitation & 1 \\
\hline
\end{tabular}


Per $6.8 \mathrm{~g}$ the following amount of amino acid was used: $0.367 \mathrm{~g} \mathrm{L-Alanine,}$ $0.327 \mathrm{~g}$ L-Arginine, $0.180 \mathrm{~g}$ L-Cysteine, 0.213. g Glycine, $0.213 \mathrm{~g}$ L-Histidine, $0.533 \mathrm{~g} \mathrm{L-Isoleucine,} 0.9 \mathrm{~g}$ L-Leucine, $0.733 \mathrm{~g}$ L-Lysine, $0.2 \mathrm{~g}$ L-Methionine, $0.380 \mathrm{~g}$ L-Phenylalanine, $0.813 \mathrm{~g} \mathrm{L-Proline,} 0.460 \mathrm{~g} \mathrm{L-Serine,}$ $0.460 \mathrm{~g} \mathrm{~L}$-Threonine, $0.460 \mathrm{~g} \mathrm{~L}$-Tyrosine and $0.593 \mathrm{~g} \mathrm{L-Valine.} \mathrm{The} \mathrm{TRP+}$ mixture contained the same amount of amino acid plus an absolute amount of $0.153 \mathrm{~g} \mathrm{~L}$-TRP. Each day of testing, between $8.30 \mathrm{~h}$ and $11.30 \mathrm{~h}$, the animals were orally injected with the TRP- or TRP + mixture $(5 \mathrm{~g} / \mathrm{kg}$ in a volume of $10 \mathrm{ml} / \mathrm{kg}$ ). Behavioural testing was conducted $5 \mathrm{~h}$ after drug administration. At the end of each testing day the animals received their daily food ration (about $10 \mathrm{~g}$ ). All rats were fasted during a period of approximately $14 \mathrm{~h}$ before and also during the periods of treatment and testing. Food deprivation was applied to prevent the intake of TRP via the food. In the cognitive tests food intake was more restricted to reduce their weight to $85 \%$ of their free feeding weight. Therefore, it might be possible that the TRP levels were even more reduced in these tests.

An overview of the order of testing and the number of times the rats were treated with the amino acid mixture is given in Table 1.

\section{Behavior}

\section{Open field test}

Testing was conducted in a square, clear Plexiglas box $(100 \mathrm{~cm} \times 100 \mathrm{~cm} \times$ $30 \mathrm{~cm}$ ), with an open top and a dark floor. The arena of the open field (OF) was subdivided in nine zones: 'corner' zones (four squares each $16 \mathrm{~cm} \times 16$ $\mathrm{cm}$ ), 'wall' (four rectangles each $16 \mathrm{~cm} \times 64 \mathrm{~cm}$, and 'center' (one square 64 $\mathrm{cm} \times 64 \mathrm{~cm}$ ). The $\mathrm{OF}$ was placed on the floor of a experimental room. A camera was installed at wo and a half meters above the center of the field. Immediately after a rat was placed in the center of the OF, the movements and position of the animals were recorded and registered automatically by a computerized system (EthoVision). The illumination of the room was reduced to $60 \mathrm{Lux}$ on the floor of the apparatus. Testing was carried out on four consecutive days. Each session lasted five min. OF behaviour was tested between $13.30 \mathrm{~h}$ and $17.00 \mathrm{~h}$.

The data of the OF test were aggregated over the four days to enhance reliability (Ossenkopp and Mazmanian, 1985). Three aggregated variables are reported: The mean time spent in the corner squares of the OF, the mean distance moved, and the mean frequency of rearing and leaning (i.e. rearing but making contact with the fore paws against the wall) in the entire 
apparatus. We have shown in previous studies that the aggregated scores in the open field test yield results comparable to those in other test models of anxiety, like the 'plus maze', 'light-dark box', 'punished drinking' (comparable to the Vogel's test) (see Blokland et al., 1992; van der Staay and Blokland, 1996).

\section{Home cage emergence test}

In the home cage emergence test (HCET), the home cage was placed in the arena of the open field and the lid of the home cage was removed (Schoemaker and Smits, 1994; Prickaerts et al., 1996). During the testing of one rat the other rat was placed in another cage. A grid was placed over the edge of the home cage to make it easier for the rats to leave the home cage The test room was darkened, providing very dim illumination ( $\sim 5$ Lux $)$ on the floor of the apparatus. A stopwatch was used to measure the latency to leave the cage. The experimenter measured the time it took for the rat to climb out of its cage into the open field. A criterion was set to determine the escape time. The two hind legs had to be over the edges of the cage. If the rat did not emerge from its home cage within ten min, the session was ended, the home cage was closed again and the rat was given a score of $600 \mathrm{~s}$. This test was carried out on two consecutive days.

\section{Forced swimming test}

Four cylindrical glass tanks (40 cm tall $\times 17 \mathrm{~cm}$ in diameter) of $23{ }^{\circ} \mathrm{C}$ water, lilled to a depth of $30 \mathrm{~cm}$, were used in this test. When the animals were placed in the water, their movements were video taped to allow behavioural assessment later on. The rats were tested on three successive days in 5 min test sessions five hours after treatment.

The behavioural variable was 'immobility' which was defined as follows: making no movements or only making those movements that were necessary to keep the nose above the water. It was allowed to move the forepaws or support themselves by pressing their paws against the wall of the cylinder. Active climbing and swimming along the wall were not scored as immobility.

\section{Sucrose preference test}

For the sucrose preference test (SPT), the animals were housed individually. First, the animals were trained to drink a $1 \%$ sucrose solution, by exposing them to sucrose instead of water during $1 \mathrm{~h}$. When testing the treatment effects, a 19-h period of food and water deprivation was applied. After 
testing, the rats were given about $10 \mathrm{~g}$ of food and they had free access to water during $1 \mathrm{~h}$. Five hours after treatment with the mixture, each animal was presented simultaneously with two bottles in the home cage, one containing a $1 \%$ sucrose $(40 \mathrm{ml})$, the other containing standard tap water $(40 \mathrm{ml})$. Waterand sucrose intake was measured by weighing the pre-weighed bottles after 1 h. The position of the two bottles (right/left) was varied over days so that preference to position was prevented. The total intake and ratio ((sucrosewater)/total intake) were measured for each test trial that was given over a period of two weeks.

\section{The spatial cone field task}

The cone field apparatus was a dodecagonal field with 16 cones (diameter top: $7.8 \mathrm{~cm}$; bottom diameter: $18 \mathrm{~cm}$; height: $14 \mathrm{~cm}$ ) in it (van der Staay et al., 1990b). The $45 \mathrm{~cm}$ high side walls were made of transparent Plexiglas. The floor consisted of stainless steel. Four start boxes were connected to the cone field; guillotine doors could be operated by the experimenter. A food cup (diameter: $3.3 \mathrm{~cm}$; depth: $2.9 \mathrm{~cm}$ ) was placed in the top of each cone. To prevent localization of the baited cones by odor cues, all cones contained six food pellets that could not be reached by the rat. In each baited cone, an additional 45-mg food pellet was placed on top of the inaccessible pellets as a reward that could be reached and consumed. The cone field was situated in an experimental room that was illuminated by fluorescent red tubes and one light bulb (10 Lux on the floor of the apparatus). Extra-maze cues consisted of one door, a window (covered by a black curtain), a sink, and two tables, on one of which was a computer and interface. The experimenter sat in a chair in front of the cone lield. She was present and visible throughout the behavioural testing.

The rats were familiarized with the cone field in 450-sec trials on consecutive days. All cones contained one 45-mg food pellet during the habituation trials. Additional pellets were scattered on the floor of the apparatus. A different start box was used on each of these adaptation sessions. At this point, the weight of the animals was gradually reduced by $4-6 \mathrm{~g}$ per day until they reached $85 \%$ of their free feeding weight.

A trial was started by placing the rat in the start box. The guillotine door was then opened immediately. As soon as the rat had entered the cone field, the door $w$ as closed. Whenever the rat touched the top of a cone, it closed an electrical circuit between the collar and the floor and activated a counter. This was scored automatically as a cone visit. Only contacts preceded by a visit to another cone were scored (excepting the first cone visit). Infrared photocells 
detected whether a rat poked its nose into the top of the cone. A persona computer collected the data and controlled the duration of the trials. A tria was terminated when the rat had found and consumed all four food pellets o when $450 \mathrm{~s}$ had elapsed, whichever occurred first. The animal was put bacl into its home cage between trials. After the cone field was cleaned with damp sponge, and the cones had been re-baited, the next trial was started.

As soon as a rat reached criterion performance (i.e. it collected ten or mor food pellets in one adaptation trial) training started. Now only four cones o a fixed set contained one food pellet each. All rats were trained with masse trials to a total of 20 trials. Within a series of daily trials, the starting positio was determined by random permutations of the numbers 1 to 4 . As man trials as possible were given within $15 \mathrm{~min}$. After the twenty training trial were completed, the treatment period was started. During the next 50 trials the rats were again treated with a mixture of amino acids (TRP+ or TRP$5 \mathrm{~h}$ prior testing. The procedure of the cone field remained the same. Eac trial with less than three collected rewards was not counted and the rat wa given an extra trial. Testing was continued until in total seventy correct trial



The following behavioural parameters were evaluated: working memory, (number of rewarded visits/number of all visits to the baited set of cones); reference memory, (number of all visits to the baited set of cones/number of visits to all cones); mean inter-visit interval, (time between the first and last visit in a trial/ (number of visits-1)); sequence of reinforced visits, this measure reflects the variability of the spatial pattern of obtaining rewards (van der Staay, 1999). If rats visit the rewarded cones in a random order from trial to trial this measure will approximate the value 1.72; first choice latency; session duration ( $\max 450 \mathrm{~s}$ ).

\section{Spatial sustained visual attention test}

Visual attention performance was tested in ten identical conditioning chambers $(40 \times 30 \times 33 \mathrm{~cm})$. The ceiling of the Skinner boxes contained a light that illuminated the conditioning chamber during the experiments. The left and right sidewalls served as control panels and included manipulanda and discriminanda. A recess $(5 \times 5 \mathrm{~cm})$ was built into the left side panel $2.5 \mathrm{~cm}$ above the grid floor and contained a food tray, into which a pellet dispenser delivered $45-\mathrm{mg}$ food pellets (Bioserve). Two retractable stainless steel levers ( $4 \mathrm{~cm}$ wide) projected $2 \mathrm{~cm}$ into the conditioning chamber and located $6 \mathrm{~cm}$ from both sides of the recess. $12 \mathrm{~cm}$ above the grid floor. The conditioning chambers were enclosed in sound-attenuating housing. An 
exhaust fan produced background noise. A personal computer controlled the experimental equipment and collected the data. In this test the rats were food deprived to about $85 \%$ of their free feeding weight.

After the rats had acquired the lever press response, they were subjected to a visual discrimination task. Before the two levers were presented, a light stimulus was presented at random, either on the left or on the right position in the box. Whenever the rat pressed a lever, both levers were retracted and the stimulus light went off. Responses on the lever on the side of the stimulus were rewarded with a food pellet, whereas a response to the other lever (incorrect response) resulted in a time out period of $5 \mathrm{~s}$. After this time-out, the next trial was initiated after an ITI of another $5 \mathrm{~s}$. The ITI and time-out were each set at $5 \mathrm{~s}$ and kept constant during the training. In each session there were 40 rewards to be earned in a maximum duration of $20 \mathrm{~min}$. Training was commenced until the rats showed a stable performance in the condition in which there were three possible stimulus durations (i.e. 3,1 or $0.3 \mathrm{~s}$ ), which were given randomly. During this stage of training the levers were inserted $1 \mathrm{~s}$ after the stimulus was extinguished. If the rat failed to respond to the lever within $3 \mathrm{~s}$ (scored as an omission), the levers were retracted and a time out period of $5 \mathrm{~s}$ followed. When the rats showed a stable performance in this condition, the effects of treatment were assessed.

The following parameters were used to evaluate the performance in this task: percentage correct, omissions, latency. The signal detection measure index $\mathrm{Y}$ (=|Percentage correct left - Percentage correct right $\mid /$ Percentage correct left + Percentage correct right) was also evaluated to examine possible treatment effects on the response bias (Sahgal, 1987).

\section{Biochemistry}

Corticosterone levels

The effects of TRP depletion on resting- and stress-induced corticosterone levels were determined in blood. For resting levels blood samples were taken $5 \mathrm{~h}$ after treatment. After $30 \mathrm{~min}$, during which the rats were placed in a novel cage containing water (depth $5 \mathrm{~cm}$, approximately $35^{\circ} \mathrm{C}$ ), again blood samples were taken from the rat. Blood sampling, resting and stress-induced, took place between 15:00-16:00 for all animals. The rats were taken out of their cages and wrapped in a towel to fixate the rat. This method allows withdrawal of small amounts of blood without disturbing the rat either behaviourally or physiologically (Fluttert et al., 2000). After the tail was held in warm water $\left(25^{\circ} \mathrm{C}\right)$ for $1 \mathrm{~min}$, an incision was made in the tail and venous 
blood $(300 \mu \mathrm{l})$ was collected into heparin tubes and kept cold on ice. Thirty min after the rats were held in the cages this procedure was repeated. At this time point corticosterone levels usually reach peak values (De Boer et al. 1990).

After centrifugation of the plasma samples $(4000 \times \mathrm{g}$ for $15 \mathrm{~min}$ a $4{ }^{\circ} \mathrm{C}$ ), the serum was removed and stored at $-80^{\circ} \mathrm{C}$ until corticosterone assay For the determination of the plasma corticosterone concentrations, $50 \mu \mathrm{lo}$ serum sample was extracted with $3 \mathrm{ml}$ of dichloromethane. This combination was mixed by vortex for one minute. The corticosterone was measured directly on $1 \mathrm{ml}$ dried dichloromethane and extracted by radioimmunoassay

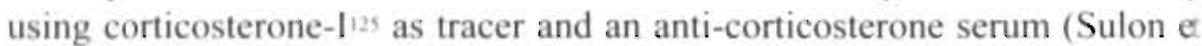
al., 1978). The radioimmunological reaction was performed overnight a $4{ }^{\circ} \mathrm{C}$ and bound and unbound steroid was separated using a second antibody system.

\section{TRP concentrations, peripheral}

The blood was collected according to the same procedure as in the blood sampling for corticosterone concentrations, $5 \mathrm{~h}$ after treatment administration and prior to decapitation. Blood $(300 \mu \mathrm{l})$ was collected in sodium heparin tubes. The blood samples were immediately placed on ice after collection and then centrifuged $\left(4000 \times \mathrm{g}\right.$ for $15 \mathrm{~min}$ at $4^{\circ} \mathrm{C}$ ). Subsequently, $100 \mu \mathrm{l}$ plasma was mixed with $4 \mathrm{mg}$ sulfosalicyl acid and frozen in liquid nitrogen. The samples were stored at $-80^{\circ} \mathrm{C}$ until quantitative amino acid analysis by highperformance liquid chromatography (van Eijk et al., 1993). In addition to total plasma concentrations of TRP and twenty-two other amino acids (e.g. five essential amino acids (see below), glutamate, arginine), the ratio of TRP/LLNAAs was determined. The values of $\Sigma$ LNAA were calculated by taking the sum of the five essential amino acids (tyrosine, phenylalanine, leucine, isoleucine and valine).

\section{TRP concentrations, central}

Five hours after the treatment the rats were decapitated. The head was immersed in liquid nitrogen for $8 \mathrm{~s}$. The entire hippocampus and the cortex (except the frontal cortex) were dissected at $4{ }^{\circ} \mathrm{C}$ and stored at $-80^{\circ} \mathrm{C}$. The brain structures were pulverized and about $100 \mu \mathrm{g}$ was mixed with $250 \mathrm{ml} 5 \%$ sulfosalicyl acid and homogenized with a mini-beat beater. Subsequently, the samples were immersed in liquid nitrogen and stored at $-80{ }^{\circ} \mathrm{C}$ until quantitative amino acid analysis (see above). 


\section{Statistical analysis}

All variables were analysed using parametric statistics (i.e. two-tailed t-test or analysis of variance). Where appropriate a repeated measures analysis was used. In the home cage emergence test the data were not normally distributed since some rats remained in the home cage for the entire observation period. These data were transformed to rank scores and subjected to parametric analysis. In the cone field task the mean performance was calculated per ten trials and used for statistical analysis. Since the rats were given twenty acquisition trials before treatment started, treatment effects were evaluated for the third to seventh block of ten trials. In the sustained visual attention task the performance of two sessions were collapsed for statistical analysis.

\section{Results}

\section{Body weight}

The body weight of the rats did not differ at the start of the experiment [mean (SEM): TRP+, 374 (8.0) g; TRP- 375 (8.1) g]. Also, at the end of the experiment the body weight of the rats of both groups did not differ [mean (SEM): TRP+, 461 (12.6) g; TRP- 461 (9.9) g]. During the study the body weight of rats increased similarly in both groups [Treatment $x$ Weeks: $F(14,252)=1.14$, n.s.].

\section{Behavior}

\section{Open field test}

One rat from the TRP-group had to be removed from the statistical analysis, because it did not move in all trials. In Fig. I the data of the open field are depicted. The TRP- treated rats spent more time in the corner squares $[t(17)=2.45, p<0.05$; Fig. $1 \mathrm{~A}]$, and less time in the wall zones $[t(17)=2.62$, $p<0.05]$, than the TRP + group. Compared to the TRP+ group, the rats with a TRP depletion were less active in the open field as indicated by the total distance moved $[t(17)=2.32, p<0.05$; see Fig. IB]. Further, the TRP-group tended to make less rearings than the TRP + group $[r(17)=1.97,0.05<p<0.1]$. There was a strong negative correlation between the time in the corner and the tolal distance moved $[r=-0.76, p<0.01$; Fig. 2]. 
(A)

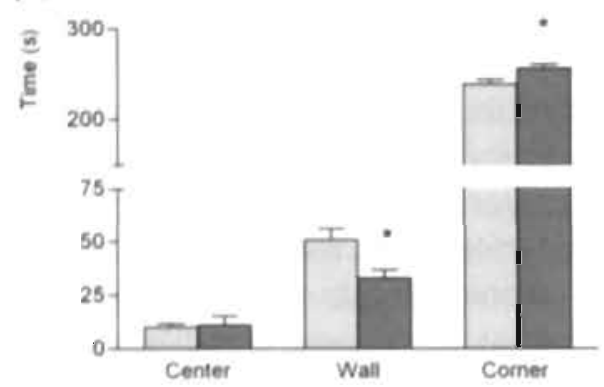

(B)

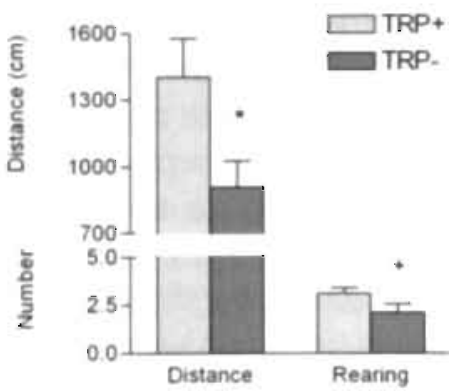

Fig. 1: Effects of TRP depletion on open field behaviour. A) Time spent in the different areas of the open field, and B) total distance moved and the number of rearings in the open field. Data represent aggregated data of four $5 \mathrm{~min}$ sessions. Values are mean(SEM) of rats receiving the amino acid mixture with TRP (TRP+) or without TRP (TRP-). ${ }^{+}=0.05<p<0.10$; * $p<0.05$

Fig. 2. Individual scores of rats of the TRP. and TRP-group for total distance moved versus time spent in the comer squares. Both measures were correlated $[r=-0.76, p<0.05]$. Lower activity and more time spent in the corner squares (i.e. lower right area of plot), indicate a higher level of anxiety.

\section{Home cage emergence test}

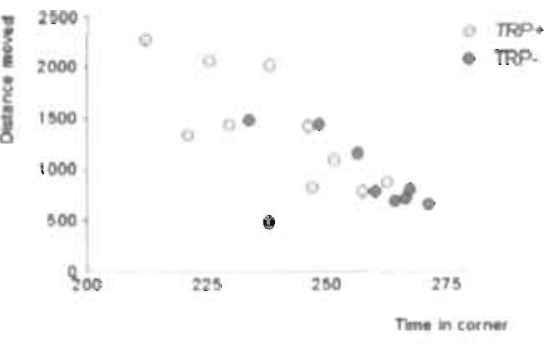

()n the first trial three rats of TRP-group and one rat of the TRP+ group did not leave their home-cage within $10 \mathrm{~min}$. On the second trial, all rats left the home cage within $5 \mathrm{~min}$. Over the two trials no treatment effects were observed [Treatment $x$ Trial: $F_{\mathrm{s}}<0.63, \mathrm{n}$.s; data not shown].

\section{Forced swimming test}

As can be seen in Fig. 3, the TRP-rats were immobile for longer during the three trials when compared to the TRP+ rats [Treatment: $F(1,18)=5.28$, $p<0.05]$. Over the three days there was reduction in immobility $[F(2,36)=$ $3.77, p<0.05]$. Although the performance seemed to diverge between both groups this was not confirmed statistically [Treatment $\mathrm{x}$ Trial: $F(2,36)=1.01$, n.s.]. 


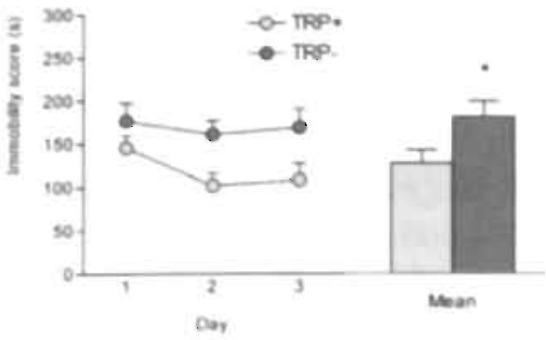

Fig. 3: Effects of TRP depletion on the immobility score (per day and mean of three days) in the forced swimming test on three successive days Values are mean (SEM) of rats receiving the amino acid mixture with TRP $(T R P+)$ or without TRP (TRP-) * $p<0.05$

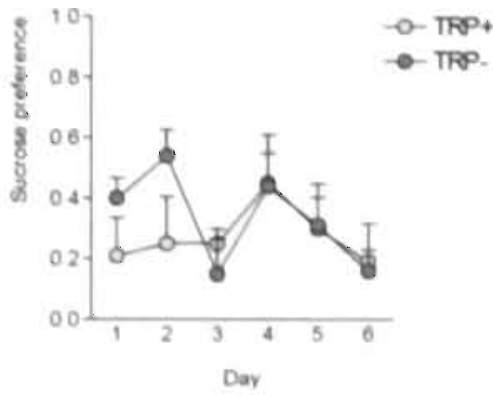

Fig. 4 Performance of rats receiving the amino acid mixture with TRP (TRP+) or without TRP (TRP.) in the sucrose preference test on six days Values are mean (SEM) of rats receiving the arnino acid mixture with TRP (TRP+) or without TRP (TRP-)

\section{Sucrose preference test}

No treatment effects were found during this test [Treatment: $F_{\mathbf{s}}<1.17$, n.s.; Fig. 4), although a tendency occurred for a differential development of the preference in both groups (Treatment $\mathrm{x}$ Trial: $F(2,36)=2.20,0.05<p<0.10$ ]. The preference did not change over the six trials $[F(2,36)=0.75$, n.s.].

\section{Spatial cone field test}

Two rats did not reach the criterion to enter the acquisition training. The data of the cone field task are shown in Fig. 5. The performance of the TRP- and TRP + group on all measures did not differ on the first two blocks of 10 trials [Treatment $x$ Block: $F_{\mathrm{S}}<2.34$, n.s.]. However, the performance of the rats changed over the first two trial blocks, i.e., an improvement in memory performance and a decrease in latency measures [Block: $F \mathrm{~s}>15.74, p<0.05]$.

\section{Working memory (block 3-7)}

The working memory performance was further improved over the last five blocks $[F(4,64)=7.01, p<0.05$; see Fig. $5 \mathrm{~A}]$. There was no indication that the TRP- treatment affected the performance [Treatment $\times$ Block: $F$ 's $<1.31$, n.s.]. 


\section{Reference memory (block 3-7)}

TRP- treatment did not affect the reference memory performance (Treatment x Block: $F$ s $<0.91$, n.s.; see Fig. 5B], although ar improvement of performance was observed $[F(4,64)=51.15, p<0.01]$.

\section{Inter-visit interval (block 3-7)}

There was no further change in the speed in which the rats visited the cone: [Block: $F(4,64)=0.47$, n.s.; see Fig. $5 \mathrm{C}$ ]. Also, no treatment effects wert found during this phase of acquisition [Treatment $x$ Block: $F \mathrm{~s}<1.30$, n.s.].

\section{First choice latency (block 3-7: data not shown)}

There was a further reduction in the time the rats used to make the first visi [Block: $F(4,64)=2.78, p<0.05]$. However, treatment did not affect the performance on this measure [Treatment $x$ Block: $F$ S $<1.93$, n.s.].

(A)

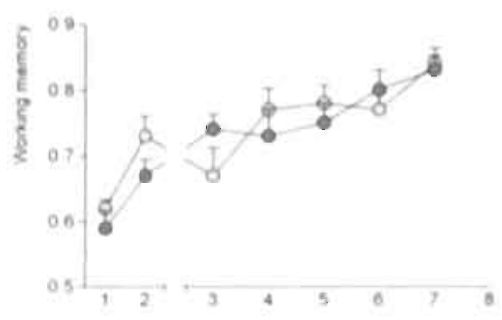

(C)

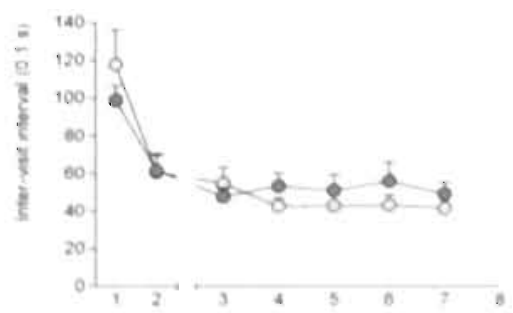

(B)

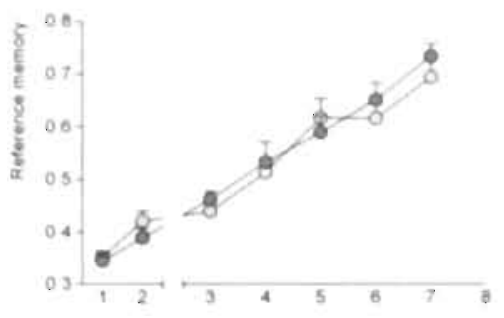

(D)

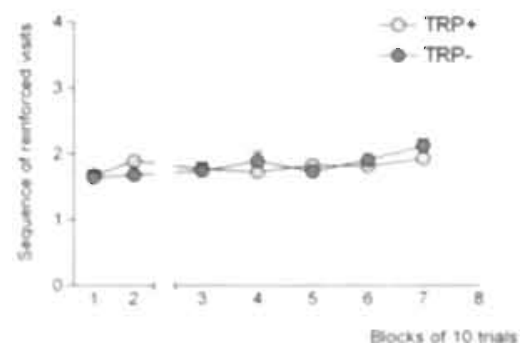

Fig. 5. Effects of TRP depletion in a cone field spatial discrimination task. (A) working memory, ratio measure of revisits to baited: cones, (B) reference memory, ratio measure of visits to non-baited cones, (C) mean inter-vișit interval, and (D) sequence of reinforced vișits (dashed line indicates chance level). Data are mean (SEM) of ten trials of rats receiving the amino acid mixture with TRP (TRP+) or without TRP (TRP-) 


\section{Choice correspondence of reinforced visits (block 1-7)}

Statistical analysis revealed an increase in the choice correspondence over the first two blocks $[F(1,16)=4.53, p<0.05$; see Fig. 5D], and a further increase over the last five blocks of training $[F(4,64)=2.63, p<0.05]$. Except for a tendency that the TRP- rats had a lower choice correspondence than the TRP+ rats during the last five trial blocks $[F(1,16)=3.33,0.05<p<0.1]$, no treatment effects were evident [Treatment $x$ Block: $F \mathrm{~s}<2.34$, n.s.]. The performance of both groups did not deviate from the value 1.72 , indicating that the sequence of visiting the baited cones was random.

\section{Spatial visual attention task}

\section{Choice accuracy}

As expected, the duration of the stimulus presentation affected the accuracy performance of the rats $[F(2,36)=106.13, p<0.01 ;$ Fig. 6A $]$. Treatment did not affect the accuracy performance in any condition [Treatment $x$ Duration: $F$ s $<$ 2.41, n.s.].

\section{Omissions}

The proportion of errors of omissions was not aflected by the stimulus duration $[F(2,36)=1.71$, n.s.; Fig. 6B]. Comparison between the TRP+ and the TRP-group, indicated that the treatment did not affect the scores of omissions [Treatment $\mathrm{x}$ Duration: $F<0.99$, n.s.].

\section{Response latency}

It was found that the rats responded faster when the stimulus duration was longer $[F(2,36)=110.09, p<0.01$; Fig. $6 \mathrm{C}]$. No treatment effects in response latencies across the conditions were found [Treatment $\mathrm{x}$ Duration: $F<1.15$, n.s.].

$\underline{\text { Index } Y}$

With decreasing stimulus duration the index $Y$ increased in both groups [Stimulus duration: $F(2,36)=32.54, p<0.01]$. The measure index $Y$ across the different stimulus durations was different for both treatment groups [Treatment $x$ Stimulus duration: $F(2,36)=6.49, p<0.01 ;$ Fig. 6D]. This was most evident at the shortest stimulus duration condition, where the value of index $Y$ was higher in the TRP-group. 
(A)

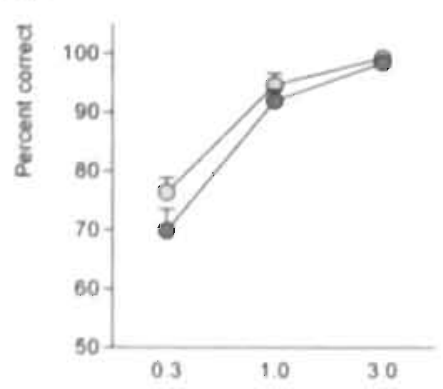

(C)

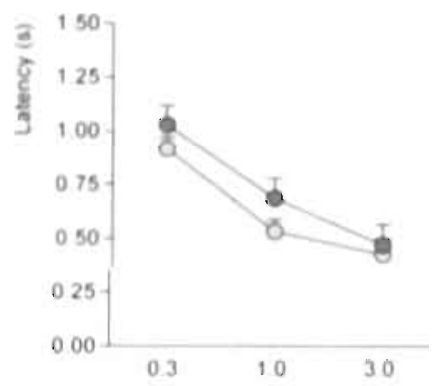

(B)

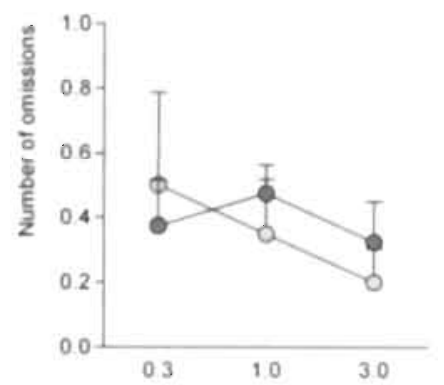

(D)

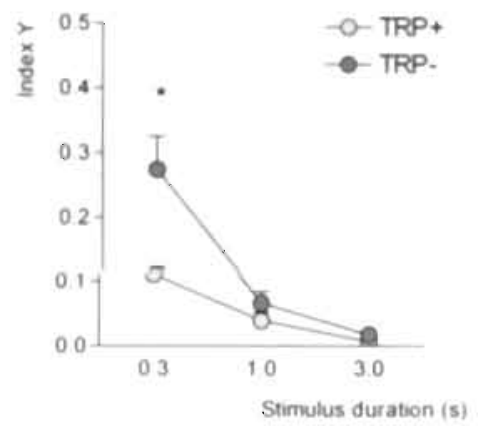

Fig. 6: Effects of TRP depletion on the performance in a spatial sustained visual attention test. (A) percent correct responses, (B) number of omissions, (C) latency to press the lever after insertion into the chamber, and (D) index $Y$, a signal detection derived measure for response bias. Data are mean (SEM) of two sessions of 60 trials of rats receiving the amino acid mixture with TRP $($ TRP +$)$ or without TRP (TRP-) $* p<0.05$

\section{Biochemistry}

Corticosterone levels

When the two groups were compared to each other, no difference could be found in the increasing amount of corticosterone concentrations in the blood $[F(1,18)=0.01, \mathrm{n} . \mathrm{s}$.$] . The stress condition dramatically raised the level of$ corticosterone in both treatment groups $[F(1,18)=469.31, p<0.01$; Table 2] Treatment did not affect the resting and stress-induced corticosterone level [Treatment x Time: $F \mathrm{~s}<0.77, \mathrm{n} . \mathrm{s}$.$] .$ 
Table 2: 'Resting' and 'stress-induced' corticosterone levels ( $\mathrm{ng} / \mathrm{ml}$ ) in plasma in TRP+ and TRP. rats, 5 and $5.5 \mathrm{~h}$ after administration of the amino acid mixture, respectively.

The last row indicates the mean difference score (stress-induced-resting. per subject). There were no differences between groups. Entries are mean (SEM)

\begin{tabular}{lcc} 
& \multicolumn{2}{c}{ Group } \\
& TRP+ & TRP. \\
\hline Resting & $585(57)$ & $516(38)$ \\
Stress-induced & $2123(102)$ & $2183(62)$ \\
Response & $1538(130)$ & $1667(70)$
\end{tabular}

\section{TRP concentration, peripheral}

Five hours after amino acid loading, the plasma TRP concentrations were lower $(34 \%)$ in the TRP- rats than the TRP + rats $[r(18)=5.01, p<0.01$; Table 3]. When considering the TRP to $\Sigma$ LNAA ratio a somewhat higher reduction $(38 \%)$ could be found $[t(18)=4.41, \mathrm{p}<0.01]$. There was a tendency that the plasma tyrosine concentrations tended to be higher $(17 \%)$ in the TRP-group $[t(18)=1.80,0.05<p<0.10]$.

Table 3: Peripheral ( $\mu \mathrm{mol} / \mathrm{l}) \mathrm{l}$ and central (i.e. cortex, hippocampus; $\mu \mathrm{mol} / \mathrm{kg}$ wet weight) amino acid concentrations in TRP+ and TRP-groups $5 \mathrm{~h}$ after administration of the amino acid mixture.

\begin{tabular}{|c|c|c|c|c|c|c|c|c|c|}
\hline & \multicolumn{3}{|c|}{ PLASMA } & \multicolumn{3}{|c|}{ CORTEX } & \multicolumn{3}{|c|}{ HIPPOCAMPUS } \\
\hline & TRP+ & TRP. & $\%$ & TRP+ & TRP. & $\%$ & TRP+ & TRP. & $\%$ \\
\hline TRP & 119 & 79 & $-34^{* *}$ & 12 & 11 & -14 & 16 & 11 & $-33^{*}$ \\
\hline TRP/ILNAA & 0.152 & 0.094 & $-38^{* *}$ & 0.062 & 0.043 & $-31^{* *}$ & 0.069 & 0.02 & $-39^{* * *}$ \\
\hline GLU & 62 & 57 & -8 & 7671 & 7792 & 2 & 9189 & 8091 & -12 \\
\hline$A S N$ & 47 & 44 & -5 & ND & ND & . & ND & ND & -- \\
\hline SER & 382 & 398 & 4 & 1134 & 1321 & 16 & 1244 & 1207 & -3 \\
\hline GLN & 981 & 975 & -1 & 3425 & 3811 & 11 & 3897 & 3946 & 1 \\
\hline HIS & 18 & 19 & 14 & 646 & 757 & 17 & 964 & 942 & 2 \\
\hline GL.Y & 453 & 456 & 1 & 555 & 678 & $22^{*}$ & 606 & 612 & 1 \\
\hline THR & 370 & 413 & 12 & 611 & 705 & 15 & 600 & 582 & -3 \\
\hline CIT & 95 & 93 & -2 & 52.2 & 63 & 21 & 57 & 55 & -4 \\
\hline ALA & 161 & 168 & 4 & 503 & 623 & 24 & 775 & 771 & 0 \\
\hline TAU & 426 & 491 & $15+$ & 3957 & 4471 & 13 & 4927 & 4927 & 0 \\
\hline ARG & 394 & 351 & -11 & 1011 & 1235 & $22+$ & 1405 & 1400 & 0 \\
\hline AAB & 20 & 19 & 4 & 20 & 23 & 12 & 25 & 27 & 9 \\
\hline TYR & 77 & 90 & $17+$ & 45 & 65 & $43^{* *}$ & 53 & 56 & 7 \\
\hline VAL & 308 & 352 & 14 & 87 & 104 & 20 & 105 & 111 & 6 \\
\hline MET & 73 & 71 & -3 & ND & ND & $\ldots$ & ND & ND & - \\
\hline ILE & 133 & 134 & 0 & ND & ND & .. & ND & ND & -. \\
\hline PHE & 74 & 77 & 5 & 24 & 30 & 24 & 25 & 27 & 7 \\
\hline LEU & 198 & 212 & 7 & 60 & 70 & 17 & 64 & 65 & 2 \\
\hline ORN & 63 & 63 & 0 & 32 & 47 & $47^{*}$ & 32 & 34 & 7 \\
\hline LYS & 482 & 522 & 8 & 187 & 243 & 30 & 190 & 207 & 9 \\
\hline
\end{tabular}


Plasma TRP levels were also related to five essential large neutral amino acids (LNAAs: tyrosine. phenylalanine, leucine, isoleucine and valine). The central LNAA values consisted of four essential amino acids (tyrosine, phenylalanine, leucine and valine). TRP: tryptophan; GLU: glutamate: ASN aspargagine, SER serine; GLN glutamine: HIS: histidine; GLY: glycine; THR: threonine: CIT: citruline; ALA alanine; TAU: taurine; ARG: arginine; aAB: amino butyric acid; TYR: tyrosine, VAL: valine; MET: methionine: ILE: isoleucine: PHE: phenylalanine: LEU: leucine; ORN ornithine; LYS: Iysine. ND: not determined. Entries are means and percentages. ${ }^{+}: 0.05<p<0.10$ $\because p<0.05 ; \cdots p<0.01$

\section{TRP concentration, central}

Due to technical problems data of five rats were lost (per group: TRP-, 2; $T R P+, 3)$. Five hours after treatment, hippocampal TRP concentrations were lower $(33 \%)$ in the TRP- rats $[t(13)=4.36, p<0.05$; Table 3]. Tyrosine concentrations in the hippocampus were similar in both treatment groups $[t(13)=0.67, \mathrm{n} . \mathrm{s}$.]. The TRP to $\Sigma$ LNAA ratio indicated a somewhat higher reduction $[39 \% ; t(13)=3.56, p<0.01]$. Although the mean cortical TRP concentration was lower $(14 \%)$ in the TRP-group, this was not confirmed statistically $[t(13)=1,12, n . s$.$] . The cortical tyrosine concentrations were$ higher $(44 \%)$ in the TRP-group $[t(13)=4.23, p<0.05]$. As a consequence the TRP to ELNAA ratio was lower in the TRP- group $[31 \% ; t(13)=2.57$, $p<0.05]$. No changes were observed in GLU and GLY concentrations.

\section{Discussion}

The aim of the present study was to investigate the effects of repeated TRP (lepletion in models of anxiety, depression and cognition. In accordance with previous studies an amino acid loading, the same that has been used in various human studies, leads to a moderate decrease in TRP levels in the rat (Bel and Artigas, 1996; Brown et al., 1998). In contrast to an 80 to $90 \%$ decrease in plasma level in man, the decrease in plasma TRP levels in the rat were less than $40 \%$. Although the reduction in TRP in the present study was less pronounced when compared to humans, the behavioural data indicated that this treatment affected the behaviour of the rats in different tests.

It was found that the repeated TRP depletion increased anxiety-related behaviour in the open field, i.e., the rats were less active and spent more time in the corner areas of the apparatus (van der Staay et al.. 1990a). The correlation between these two measures in both groups (see Fig. 2) clearly demonstrated the shift in the TRP-group on the anxiety continuum, i.e., less activity and more time in safe areas. In the forced swimming test the TRP depletion increased the immobility of the rats indicating a higher despair in 
these rats. The latter finding is in agreement with the notion that lowered 5-HT levels are associated with depression-related symptoms (Meltzer and Lowy, 1987: Brown and Van Praag, 1991).

On the other hand various studies have shown that low 5-HT levels are associated with a decrease in anxiety levels. In a review paper on the role of 5-HT in different animal models of anxiety, it was stated that the available data were most consistent with the notion that 5-HT activity enhances anxiety, although it should be noted that this relation was more evident from unconditioned models of anxiety (Griebel, 1995). However, the effects of lowering 5-HT levels on exploratory behaviour have been a matter of debate. Thus, although both para-chlorophenylalanine (PCPA) and 5.7-DHT lesions appear to decrease behavioural activity in unfamiliar environments, there are some apparent differences (see Dringenberg et al., 1995; Hall et al., 1999). PCPA treatment induced a dose-dependent decrease in open field activity in rats, whereby the highest dose most dramatically reduced the activity measures. On the other hand, it has been shown that moderate 5-HT depletions increased anxiety-related behaviour whereas greater 5-HT depletions did not affect the behavioural activity in a plus maze (Hall et al., 1999). The acute TRP depletion model differs from these models since this treatment leads to an acute and reversible lowering of 5-HT. The findings of the present study are in agreement with the data of the 5,7-DHT model since in both models moderate 5-HT depletions were found to induce anxietyrelated behaviour. Although treatment with PCPA and 5,7-DHT are both neurotoxic models there appears to be dissociation with respect to 5-HT depletion and behavioural activity in a new environment. Nevertheless, these previous studies and the present data indicate that lower 5-HT levels lead to more anxiety-related behaviours in this type of task.

Repeated TRP depletion did not affect the performance in the home cage emergence test and the sucrose preference test, which are also assumed to measure anxiety-and depressive-like behaviours in the rat (e.g. Papp et al., 1996; Prickaerts et al., 1996). However, it has been suggested that these tests may assess different aspects of anxiety/depression-related behaviours (Prickaerts et al,, 1996), and may indicate that TRP depletion only afiects specific aspects of anxiety/depression. An alternative explanation for these different effects could be that the open field and forced swimming test were more sensitive to a modest decrease in TRP concentrations than the home cage emergence and the sucrose preference test.

It could be argued that a general decrease in bchavioural activity underlies the observed changes in the open field and the forced swimming test. However. 
the finding that the activity-related measures in the cone field task and te attention task did not differ between the TRP+ and TRP-group (see belo') do not support this idea.

In the present study we did not apply a design that is regularly used in humn studies, e.g., crossover design. In our tests the same group of rats wee frequently subjected to the TRP+/TRP- treatment. The tests used in our stuy require multiple testing to obtain valid indices of anxiety, depression ad cognition. This aspect prevents the use of designs that are used in humn studies. On the other hand, the behaviour of the TRP- rats were always testd under the same conditions suggesting that group differences were related $O$ low 5-HT levels.

The cognitive performance of the rats, as assessed by spatial discriminatin learning and sustained attention, was not affected by the TRP depletion. Te claim that TRP depletion impairs (verbal) memory consolidation (Riedel st al., 1999; Schmitt et al., 2000) was the underlying hypothesis that ths treatment may impair the performance in the cone field task. Since we did nt observe a treatment effect in this task it is likely that impairment $n$

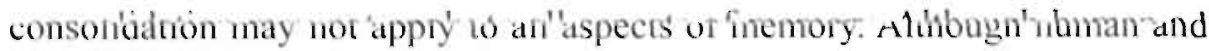
animal models of memory may not always reflect similar neurobiological mechanisms, a previous study using the TRP depletion in man revealed no effects of this treatment in tests assessing spatial memory (Park et al., 1994). More relevant, a recent animal study also reported a lack of an effect of TRP depletion on radial maze learning (Stancampiano et al., 1997). However, it cannot be excluded that more dramatic reductions in TRP could have impaired the performance in the cone field task.

The finding that the TRP depletion did not improve the performance in the attention task does not corroborate previous findings in humans (Schmitt et al., 2000). However, it should be noted that in humans lowered TRP levels did not improve divided attention, but only focussed attention. The task used in the present study could be considered as a divided/sustained attention task (see Bushnell, 1998), which could explain this apparent discrepancy.

Although no ireatment effects were observed on the accuracy performance in the sustained attention task, there was a clear increase in the response bias at the shortest stimulus presentation, where the attentional demand was the highest. This increased response bias, as calculated with the measure index $\mathrm{Y}$, indicates that the rats responded to one side in this condition. Taking into account that both groups did not differ on the accuracy performance and the stimulus durations were randomly chosen during a session. it must be assumed that if the stimulus was not detected the TRP depleted rats 
responded to a preferred side. At present no ready explanation could be offered for this finding, although these data suggest that the TRP- rats were less sensitive to the stimulus.

The repeated testing of the rats in the successive tasks (see Table 1), could have affected the performance from one test to the other. Thus, the performance in the forced swimming test may have been different if the rats had been subjected to this test first. However, both the TRP+ and TRP-group were subjected to the same series of tests, assuming that the effects of repeated testing were controlled for. On the other hand, it cannot be excluded that this successive testing could have interfered with treatment effects. This can only be tested if naîve rats are used for each individual test.

To our knowledge, only one study has previously investigated the effects of acute TRP depletion on behaviour in the rat (Brown et al., 1998). In contrast to our findings this study revealed no treatment effects in tests which are sensitive to 5-HT treatments, i.e., locomotor activity, DRL responding. Although no behavioural changes were observed, 5-HT concentrations were decreased by $23 \%$ in the hippocampus and $31 \%$ in the frontal cortex. However, there were no changes in the 5-HIAA/5-HT ratio, suggesting no substantial effects of this treatment on the 5-HT turnover. However, since TRP depletion leads to lower 5-HT and a decrease in 5-HT release ( $\mathrm{Bel}$ and Artigas, 1996), the ratio may not provide a good measure for the decrease in 5-HT neurotransmission.

In the present study we only measured the TRP concentrations to directly compare the peripheral with central TRP concentrations. Although we did not measure the 5 -HT content in the brain, previous studies have indicated that TRP values in blood and brain strongly correlate with central 5-HT and 5-HIAA levels (Gessa et al., 1974; Moja et al., 1989). One explanation for the different results from the study of Brown et al. (1998) and our study could be related to the finding that the effects of serotonergic treatment are strain-dependent (Emery et al., 1980; Zhou et al., 1996; Lopez-Rubalcava and Lucki, 2000), or to strain differences in behaviour (Chaouloff et al., 1995; Andrews, 1996; van der Staay and Blokland, 1996).

An interesting feature of the TRP levels in the brain was that the decrease in hippocampal TRP was greater than the decrease in the cortex. This regional variation in the effects of TRP depletion corroborates earlier studies in which this method was applied (Bel and Artigas, 1996; Brown et al., 1998). Differences in 5-HT turnover in these regions or region-specific effects of TRP depletion could possibly underlie these differences. 
In the present study we also examined the effects of amino acid load on other amino acids in plasma and brain. These levels were not significantly affected in plasma and hippocampus. In contrast, tyrosine, glycine and ornithine levels were increased in the cortex. This increase in cortical tyrosine was responsible for the decrease in the TRP/LNAA ratio since the absolute TEP values were not affected in this region. It should also be noted that in the cortex all amino acids tended to be higher in the TRP. group when compared with the TRP+ group. In the hippocampus and plasma the decrease in TRP appeared to be specific. This suggests that amino acid concentrations were unequally affected in brain regions, which might be related to regioral differences in protein degradation in these postabsorptive rats. Thus, it could be speculated that a higher protein degradation in the cortex results in increased amino acid production, including TRP and tyrosine. On the basis of the amino acid data it can be concluded that, apart from the increased tyrosine levels in the cortex, the treatment appears to specifically affect TRP. On the other hand, dopaminergic neurotransmission appears to be independent of the availability of tyrosine (see Buyukuysal and Mogol, 2000), suggesting that higher tyrosine levels did not affect dopamine levels (Westerink and De Vries. 1991).

In depressive patients a dysregulation of the HPA axis does occur which results in higher resting levels of cortisol (e.g., Aberg-Wistedt et al., 1998; McAllister-Williams et al., 1998). Here it was found that resting and stressinduced corticosterone levels were not affected after repeated TRP depletion. Other studies have shown that a decreased availability of TRP decreases the corticosterone response (Kennett and Joseph, 1981; Joseph and Kennett, 1983). Since these latter findings were obtained using the restraint stress model, it could be argued that the type of stressor may mediate the effects of TRP on the stress response.

On the one hand this indicates that repeated acute lowering of TRP does not affect the HPA axis, at least with respect to the 5-HT receptor (Fuller, 1996; Franklin et al., 1999). On the other hand, it has been shown that a TRP deficient diet leads to a supersensitivity of $5-\mathrm{HT}_{2}$ receptors, whereas the $5-\mathrm{HT}_{\text {iA }}$ receptors were only modestly and transiently affected (Franklin et al., 1999). It must be noted that the treatment used in the present study leads to a moderate decrease in TRP levels for about $4 \mathrm{~h}$, whereas in the abovementioned studies a long lasting ( $>1$ week) lowering of TRP was established. However, although we did not find an effect of decreased TRP levels on the corticosterone levels, it cannot be excluded that the repeated amino acid mixture treatment induced long lasting changes in the 5-HT system. In a previous behavioural study the effects of TRP depletion was 
evaluated in groups that consisted of previously treated and non-treated rats (Brown et al., 1998). Since the degree of 5-HT depletion was very comparable with our findings, and the newly formed groups were very homogeneous, further suggests that repeated treatment does not have longlasting effects on the 5-HT system.

To summarize, administration of an amino acid load without TRP, in a composition that has been used for human studies, lowers the TRP/LNAA ratio by about $38 \%$ in rats. Despite this modest repeated decline in TRP levels we observed an increased anxiety- (i.e. open field) and depressive-like (i.e. forced swimming) behaviour. The same treatment did not affect the behaviour in a home cage emergence test and the sucrose preference suggesting that the effects of lowered TRP levels are behaviour/task specific. Further, cognitive performance, spatial working- and reference memory and sustained attention, were not affected by repeated TRP depletion. These data support the notion that moderately lower 5-HT levels are related to specific aspects of behaviour in animal models of anxiety and depression in the rat.

\section{Acknowledgments}

We would like to thank Dr. J. Sulon (University of Liege, Belgium) for the determination of plasma corticosterone. The research of Arjan Blokland was made possible by the Royal Netherlands Academy of Arts and Sciences.

\section{References}

Aberg-Wistedt, A., Hasselmark, L., StainMalmgren, R., Aperia, B. Kjellman, B.F. and Mathe. A.A. (1998) Serotonergic 'vulnerability' in affective diserder: a study of the tryptophan depletion test and relationships between peripheral and central serotonin indexes in citalopramresponders. Acta Psithialr Scand 97: 374-80.

Andrews, J.S. (1996) Possible confounding influence of strain, age and gender on cognitive performance in rats. Brain Res Cogn Brain Res. 3: 251-67.

Bel, N, and Artigas. F. (1996) Reduction of serotonergic function in rat brain by tryptophan depletion: effects in control and fuvoxaminetreated rats. I Nearochem. 67: 669-76.
Biggio, C., Fadda, F. Fanni. P., Tagliamonte, $A$. and Gessa, G.L. (1974.) Rapid depletion of serum tryptophan, brain tryptophan. serolonin and 5 hydroxyindolegic acid by a tryptophan-fiec dict. life Sesences, 14: 1321-1329.

Blokland, A., Prickacrts, J and Raajmakers, W. (1992) Reduced level of arixiety in afult Lewis rat after chronic ethanol consumption. Phasiol Behan: 51: $245-8$.

Brown, C.M., Fetcher, P.J. and (ascind. D.V. (1908) Acute amino acid loads that deplete hrain serotonin fall to alter behavior. Phamacol Brohem Behar. 59: 115-2.1

Brown. S.1. and Van Praag, HM. (1991) The role of serotonin in psychiatric disorders. New York: Brunner/Mazel Publishers. 
Bushnell, PJ. (1998) Behavioral approaches to the assessment of attention in animals. Psychopharmacology (Berl), 138:23!-59.

Buyukuysal, R.L. and Mogol, E. (2000) Synthesis and release of dopamine in rat striatal slices: requirement for exogenous tyrosine in the medium. Neurochem Res. 25: 533-40.

Chaouloff, F., Kulikov, A., Sarrieau, A., Castanon. N. and Mormede. P. (1995) Male Fischer 344 and Lewis rats display differences in locomotor reactivity, but not in anxiety-related behaviours: relationship with the hippocampal serotonergic system. Brain Res. 693: 169-78.

Coull, J.T., Sahakian, B.J., Middleton, H.C. Young, A.H., Park, S.B., McShane, R.H., Cowen. P.J. and Robbins, T.W. (1995) Differential effects of clonidine, haloperidol, diazepam and tryptophan depletion on focused attention and attentional scarch. Psychopharmacology. 121: 222-230.

De Boer, S.F., Koopmans, S.J., Slangen, J.L. and Van der Gugten. J (1990) Plasma catecholamine. corticosterone and glucose responses to repeated stress in rals: effect of interstressor interval length. Phrsiol Behas: 47: 1117-24.

Dringenberg, H.C. Hargreaves, E.L., Baker, G. B.. Cooley, R.K. and Vanderwolf, C.H. (1995) p-chlorophenylalanine-induced serotonin depletion: reduction in exploratory locomotion but no obvious sensory-motor deficits. Behav Brain Res $68: 229-37$.

Emery, D., Engel. J. and Larsson. K. (1980) Rat strain differences in brain monoamine metabolism following para-chlorophenylalanine treatment. Pharmacol Biochem Behas: 12:311-2

Fluttert, M. Dalm, S. and Gitzl, M.S. (2000) A refined method for sequential blood sampling by tail incision in rats. Lab Anum. $34: 372-8$.

Franklin, M., Craven, R.D., Dowling, B. Campling, G. Flliott, J.M. and Cowen, P.J. (1999) Effect of a Iong-term fow tryptophan diet on the prolactin responses to the $5-\mathrm{HT} 1 \mathrm{~A}$ and $5-\mathrm{HT} 2 \mathrm{C}$ agonists, 8-OH-DPAT and mCPP in the male rat. $J$ Psvchopharmacol. 13:58-63.

Fuller, R.W. (1996) Serotonun receptors involved in regulation of pituitary-adrenocortical function in rats, Behav Brain Res. 73:215-9.
Gessa, G.L., Biggio, G. Fadda, F., Corsini, Gil. and Tagliamonte. A. (1974) Effect of the oral administration of tryptophan-free amino acid mixtures on serum tryptophan, brain tryptophan and serotonin metabolism. J Neurochem. 22: 869-70.

Griebel. G (1995) 5-Hydroxycryptamineinteracting drugs in animal models of anxicty disorders: more than 30 years of research Pharmacol Ther. 65: 319-95.

Hall, F.S., Devries, A.C., Fong, G.W., Huang, S and Pert. A. (1999) Effects of 5,7-dihydroxytryptamine depletion of tissue serotonin levels on extracellular serotonin in the striatum assessed with in vivo miçrodialysis: relationship io behavior Synapse. 33: 16-25.

Joseph, M.H. and Kennett, G.A. (1983) Corticosteroid response to stress depends upon increased tryptophan availability. Psychopharmacology (Berl). 79: 79-81.

Kennett, G.A. and Joseph. M.H. ([98.) The functional importance of increased brain tryptophan in the serotonergic response to restraint stress. Neuropharmacology: 20: 39-43.

Klaassen, T., Riedel, W.J., Honig, A., Van Someren, A.. Deutz. N.E.P. and Van Praag, H.M. (1999) Mood effects of 24-hour tryptop̣han depletion in healthy first degree relatives of patients with affective disorders. Biological Psychiatry. 46: 489-497.

Loper-Rubalcava, C. and Lucki, I. (2000) Strain differences in the behaviora! effects of antidepressant drugs in the rat forced swimming test. Neumopschopharmacofogu. 22: 191-9.

McAllister-Williams, R.H.. Ferrier; I.N and Young. A.H. (1998) Mood and neuropsychological function in depression : the role of corticosteroids and serotonin. Psuchological medicine. 28: 573-584.

Meltzer. H.Y and Lowy. M.T. (1987) The serotonin hypothesis of depression. In Meltzer. H. Y. (eds), Psychopharmacology the thind generation of progress. New York: Rasen Press.

Moja. E.A. Cipolla. P. Castoldi, D. and Tofanetti. O. (1989) Dose-response decrease in plasma tryptophan and in brain tryptophan and serotonin after tryptophan-free amino acid mistures in rats. Life Sct 44: $971-6$ 
Moore, P. Landolt. H.P. Seifritz, E., Clark, C. Bhatti. T. Kelsoe, J., Rapaport, M. and Gillin, J.C. (2000) Clinical and physiological consequences of rapid tryptophan deplection. Neuropsychopharmacology, 23: 601-22

Ossenkopp, K.P. and Mazmanian, D.S. (1985) The measurement and integration of behavioral variables: aggegation and complexity as important issues. Neurobehan Toxicol Teratol 7:95-100

Papp, M., Moryl, E. and Willner, P. (I996) Pharmacological validation of the chronic mild stress model of depression. Eur J Pharmacol. 296 $129-36$

Park, S.B., Coull, J.T., McShane, R.H.. Young. A.H. Sahakian, B.J., Robbins, T.W and Cowen. P. (1994) Tryptophan Depletion in Normal Volunteers Produces Selective Impairments in learning and Memory. Neumpharmacology. 33: $575-588$.

Prickaerts, J., Raaijmakers, W. and Blokland, A. (1996) Effects of myocardial infarction and captopril therapy on anxicty-related behaviors in the rat. Physiol Behaw 60: 43-50.

Reilly, J.G. McTavish, S.F.B. and Young, A.H (1997) Rapid depletion of plasma tryptophan: a review of studies and experimental methodology. Journal Of Psychopharmacology: 11: 381-392.

Riedel, W.J., Klaassen, T., Deutz, N.E., van Someren, A. and van Praag, H.M. (1999) Tryptophan depletion in normal volunteers produces selective impairment in memory consolidation. Psuchophamacology (Berl). 141: 362-9.

Sahgal. A. (1987) Some limitations of indices derived from signal detection theory: evaluation of an alternative index for measuring bias in memory tasks. Prichopharmacologi (Berl) 91: 517-20.

Sehmitl, J.A., Jorissen, B.L.. Sobczak, S., van Boxtel. M.P., Hogervorst. E., Deut. N.E. and Riedel, W.I. (2000) Tryptophan depletion impairs memory consolidation but improves focussed atterition in healthy young volunteers. Journal of Prychopharmacolog: 14:21-29.

Schoemaker, R.G. and Smits, J.F. (1994) Behavioral changes following chronic myocardial infarction in rats. Physiol Behav: 56: 585-9.
Stancampiano, R., Cocco, S., Melis, F., Cugusi, C.. Sarais, L. and Fadda. F. (1997) The decrease of serotonin release induced by a tryptophan-free amino acid diet does not affect spatial and passive avoidance learning. Brain Res. 762:269-74.

Sulon, J., Demey-Ponsart, L., Beauduin, P. and Sodoyez, J.C. (1978) Radiommunoassay of corticosterone, cortisol and cortisone: their application to human cord and maternal plasma, I Sienoid Biochem. 9: 671-6.

van der Staay, F.J. (1999) Spatial working memory and reference memory of Brown Norway and WAG rats in a holeboard discrimmation task. Neunbiol learn Mem 71: 113-25

van der. Staay, FJ. and Blokland, A. (1996) Behavioral differences berween outhred Wistar, inbred Fischer 344, brown Norway, and hybrid Fischer $344 \times$ brown Norway rats. Physel Behas $60: 97-109$

van der Staay, F.J., Kerbusch, S, and Raajmakers, W. (1990a) Genctic correlations in validating emotionality. Behar Genet. 20: 51-62.

van der Staay, F.J., Kreching, B., Blokland, A. and Raaijmakers. W. (1990b) The cone field: a spatial discrimination task for the automatic and simultaneous assessment of working and reference memory in rats. J Neurosci Merhods. 31: 13-22.

van Eijk, H.M., Rooyakkers, D.R. and Deut, N.F. (1993) Rapid routine determination of amino acids in plasma by high-performance liquid chromatography with a $2-3$ microns Spherisorb ODS II column. J Chromatogs: 620: 143-8.

Westerink, B.H. and De Vries, J.B. (1991) Effect of precursor landing on the synthesis rate and release of dopamine and serotonin in the striatum: a microdialys is study in conscious rats. J Neurochem. 56 : $228-33$.

Young, S.N., Smith, S.F., Pihl, RO and Ervin. F.R. (1985) Trypuphan depletion causes a rapid lowering of mood in nomal males. Pushopharmocologi. 87: 173-7.

Zhou, D. Schreinert, M., Pily, J. and Huether, (; (1996) Rat strain differences in the vulnerability of serotonergic nerve endings to neurotoxic damage by p-chloroamphetamine, I Neroul Transm. 103: $1381-95$. 



\section{CHAPTER}



\section{Methodological aspect of}

a tryptophan-free protein-carbohydrate mixture on plasma tryptophan levels in the rat.

C.K.J. Lieben, A. Blokland and N.E.P. Deutz. 


\section{Abstract}

The tryptophan (TRP) depletion method is based on a nutritional diet wich lowers the levels of TRP; the precursor of 5-hydroxytyptamine (5IT: serotonin) and has been described as a valid manner to reduce the synthsis of 5-HT in a very early stage. Treatment with a TRP-free amino acid mixure substantially reduces plasma TRP levels in humans. However, in rats, he same mixture only leads to moderate reduction in TRP levels.

In this study we investigated the effects of a TRP-free protein-carbohydnte mixture on the plasma TRP levels in rats. This method was used in differnt ways by varying the amount of administrations, and the effects wre compared to rats treated with saline.

In rats treated with the TRP-free protein-carbohydrate mixture, plasma RP levels were substantially lowered within 2 hours. Multiple injections of his mixture further reduced plasma TRP levels and the TRP/LLNAA rtio showing depletions of $62 \%$ and $73 \%$ within $4 \mathrm{~h}$ afier the first administratitis. Compared to the single injection, multiple administration of this mixire prolonged the depletion to an extent comparable to humans. Since plana TRP levels increased back to resting level within several hours, the effects of this gelatin-like mixture are reversible. The plasma TRP levels of rats treated with a TRP-enriched protein-carbohydrate mixture were comparable to those of saline-treated rats and both remained stable over time.

In conclusion, the TRP-free protein-carbohydrate mixture induces a substantial depletion in plasma TRP levels and the duration of depletion depends on the number of injections. The effects the mixture can be balanced for plasma TRP by adding TRP to the mixture. It is concluded that the present method provides an improvement for depleting TRP in rats and that it consists of an efficient tool to substantially reduce plasma TRP levels within several hours after treatment

\section{Introduction}

A dysfunction in 5-HT manifests in psychopathological disorders, such as aggression, impulsivity and anxiety disorders (Sanchez and Meier, 1997; Evenden, 1999: Placidi et al., 2001), and in major psychiatric diseases such as Alzheimer's and Parkinson's (Sandyk, 1992: Meltzer et al.. 1998). The importance of serotonin (5-hydroxytryptamine; 5-HT) is mostly brought forward in respect of depression. A decrease in plasma tryptophan (TRP; 
5-HT precursor) levels and in CSF 5HIAA (5-HT metabolite) levels was found in depressed patients (van Praag et al., 1970; Cowen et al., 1989). Abnormalities in 5-HT function have been linked to depressive symptoms such as a decrease in mood, sexual function and sleep (Meltzer and Lowy, 1987). Moreover, the fact that that chronic treatment with anti-depressants, e.g. selective serotonin reuptake inhibitors (SSRI's), suppresses panic- and depressive-like symptoms (Blier and de Montigny, 1994; Moller and Volz, 1996) and improves memory performances (Harmer et al., 2002), further supports the prominent role of 5-HT in various neuropsychological functions. Reducing the 5-HT synthesis improves our insight on the regulation of 5-HT in functional behavior which consequently attributes to the development of more selective treatments.

One frequently used method for inducing a lesion of the 5-11T system consists of injecting animals centrally with a neurotoxic substance (e,g. 5,7-dihydroxytryptamine; 5,7-DHT). Another manner to irreversibly disrupt the normal distribution of $5-\mathrm{HT}$, is the use of pharmacological treatments, such as p-chlorophenylalanine (PCPA) and MDMA ('ecstasy'). In preclinical studies, all three methods have been related to affective and/or cognitive changes (Harrison et al., 1997; Mazer et al., 1997; Morley et al., 2001), with the exception of long-term users of MDMA, these methods can ethically not be applied in humans. Another method consists of TRP depletion.

The method of TRP depletion can be induced by a nutritional treatment with an amino acid mixture lacking TRP. Administration of such a mixture reduces the availability of TRP and results in an acute lowering of plasma TRP levels. Prevention of the 5-HT precursor from entering the brain, consequenlly reduces central concentrations of $5-\mathrm{HT}$. This method has the advantage that the effects on plasma TRP are non-intrusive and reversible and can be applied in humans as well as in animals. Treatment with a TRP-free amino acids mixture has frequently been shown to substantially reduce plasma TRP levels by $80-90^{\circ} \%$ in humans within several hours after treatment (Reilly et al., 1997; Bell et al., 2001). However, in rodents, the same treatment results in less pronounced effects on plasma TRP levels (Moja et al., 1989; Brown et al., 1998). In a previous study we found that administration of a TRP-free amino acid mixture moderately (38\%) reduced plasma TRP levels (Blokland et al., 2002). This differentiation in the degree of depletion impeded an inter-species comparison on functional effects of the same treatment. Therefore, we wanted to develop a method which would result in a more substantial TRP depletion, and which would be comparable to the depletion found in humans. 
Only then, we would be able to compare the role of 5-HT in neuropsychological functions across species. This would enable us to use potential drug treatments.

In the present study we induced a substantial TRP depletion in rats using a gelatin hydrolysate derived from the selective hydrolysis of collagen protein. It is known for its unique gel-forming ability, its high protein content, and for its lack of TRP (Djagny et al., 2001). The main idea behind using this gelatin-like protein mixture is that it does no longer consist of a combination of a few selective amino acids, but it comprises of a broad range of amino acids which are chained into peptides, and therefore this mixture is very similar to a standard diet. Intake of this mixture presumably keeps the metabolic functions stable or even incites to an increase since the animals are given a boost of different kinds of amino acids to be broken down by protein synthesis. We thereby mimic a normal nutritional condition, except for the TRP levels. Amongst the different nutritional fractions of the protein are the large neutral amino acids (LNAA: tyrosine, leucine, valine, phenylalanine and isoleucine) which are sharing the same transporter carrier together with TRP. The lack of TRP in this protein will stimulate the competition in favor of the LNAAs thereby enhancing a better uptake of the LNAAs into the bloodstream and consequently into the central nervous system. It is therefore speculated that the administration of this gelatin-like protein mixture depletes plasma TRP levels. Moreover, carbohydrates, in the form of maltodextrine, are added to the mixture to promote the protein synthesis and the degree of amino acid uptake into the bloodstream. Carbohydrates also provide the body with a sufficient amount of caloric values. One would speculate that the effects of this gelatin-like, protein-carbohydrate mixture would be most prominent at the time that it is ingested by the stomach and gets into the bloodstream.

In summary, we hypothesized that our TRP-free, protein-carbohydrate mixture substantially reduces plasma TRP levels in adult male rats. To establish a optimal treatment condition which can be used for further studies, the administration of this TRP-free protein-carbohydrate mixture was varied in number, and the effects on plasma TRP levels were evaluated over time. Furthermore: the results were compared to a saline group and a group of rats administrated with a similar mixture enriched with TRP to investigate whether the depletion on plasma TRP levels could be balanced. 


\section{Materials and methods}

\section{Animals}

Experiments were carried out using four-month old adult male Wistar rats (Charles River, The Netherlands), weighing maximally $500 \mathrm{~g}$. The rats were individually housed in standard Makrolon cages on sawdust bedding in an airconditioned room $\left( \pm 20^{\circ} \mathrm{C}\right)$. The rats had free access to standard rat chow (Hopefarms, The Netherlands) and tap water. They were kept under a reversed 12/12 h light/dark cycle (lights off from 06.00 to $18.00 \mathrm{~h}$ ). A radio, which was playing softly, provided background noise. All experimental procedures were approved by the institutional ethical commiftee for the use of experimental animals of the Maastricht University according to governmental guidelines.

\section{Drug and chemicals}

The Gelatin hydrolysate (Solugel $\mathrm{P}^{*}$ ) was purchased from PB Gelatins (Tessenderio, Belgium). Maltodextrine was obtained from the Amylumgroup (Koog aan de Zaan, The Netherlands). L-tryptophan, L-tyrosine and L-norvaline were from Sigma (Zwijndrecht, The Netherlands). Potassiumchloride $(\mathrm{KCl})$, calciumchloride-dihydrate $\left(\mathrm{CaCl}_{2}, 2 \mathrm{H}_{2} \mathrm{O}\right)$ and 5-sulfosalicylic acid dihydrate were purchased from Merck (Darmstadt, Germany).

\section{Treatment}

For two wicks preceding the experiment, the rats were daily handled and hahiruated to oral injections with normal tap water $(10 \mathrm{ml} / \mathrm{kg})$. Rats were randomly assigned to one of four experimental groups ( $n=6 /$ group). Before each experimental day, food was removed $14 \mathrm{~h}$ before treatment to minimize TRP uptake from food. Rats were treated orally with saline, or a proteincarbohydrate mixture (see Table I for composition) containing additional TRP $(\mathrm{TRP}+)$ or lacking TRP (TRP-1). Every group of animals received one oral administration of the mixture contained $4 \mathrm{~g}$ Solugel $\mathrm{P} / \mathrm{kg}$ and $2 \mathrm{~g}$ Maltodextrine $/ \mathrm{kg}$ and this was given in a volume $10 \mathrm{ml} / \mathrm{kg}$. Except for the fourth group where the TRP-lacking mixture was given three times with an interval of $1 \mathrm{~h}$ between injections (i.e. TRP-3 group). The amount of TRP added to the mixture of the TRP+ group was set at $0.28 \%$ of the total protein. This is similar to the amount of TRP normally found in standard diet for rats. At all times, the animals had free access to water. 
Table 1: Composition of the nutritional TRP-free proteincarbohydrate mixture $(\mathrm{g})$

\begin{tabular}{l|c} 
Protein (Solugel P) in $100 \mathrm{ml}$ tap water & 100 \\
Carbohyđrate (Maltodextrine) in $80 \mathrm{ml}$ tap water & 50 \\
$\mathrm{KCl}$ & 0.094 \\
$\mathrm{CaCl}_{2}-2 \mathrm{H}_{2} \mathrm{O}$. & 2.32 \\
L-tryptophan (TRP- group) & 0 \\
L-tryptophan (TRP+ group) & 0.28
\end{tabular}

\section{Collection of blood samples}

Blood samples were taken at resting values (i.e. 20 min before the first. treatment) and repeated at 100,220 and $340 \mathrm{~min}$ after the first injection. Blood sampling was done via a tail-incision method (Fluttert et al., 2000). Promptly after collection of blood into heparin coated tubes (Microvette ${ }^{x}$ CB 300, Sarstedt, Germany), the samples were kept on ice. After centrifugation of the blood samples (at $4{ }^{\circ} \mathrm{C}$ for $15 \mathrm{~min}$ at $3000 \mathrm{~g}$ in a Hettich EBA 12 centrifuge), plasma was deproteinised with cups containing dry 5-sulfosalicylic acid $(6 \mathrm{mg} / 100 \mu \mathrm{l}$ plasma) and the protein was spun down. Samples were frozen in liquid nitrogen and stored at $-80^{\circ} \mathrm{C}$. Before analysis, samples were thawed at $4{ }^{\circ} \mathrm{C}$, vortex-mixed vigorously and centrifuged at $50,000 \times \mathrm{g}$ in a Hereaus Model Biogufe Stratos for $10 \mathrm{~min}$ at $4^{\circ} \mathrm{C}$. From the clear supernatant $20 \mu \mathrm{l}$ was mixed with $1960 \mu \mathrm{l}$ water and $20 \mu \mathrm{l}$ norvaline and stored in the cooled $\left(7^{\circ} \mathrm{C}\right.$ ) sample compartment until analysis (van Eijk et al., 1993).

The levels of plasma amino acids ( $\mu$ mol/l) were determined using a fully automated high-performance liquid chromatography (HPLC) system after precolumn derivatization with o-phthaldialdeliyde (OPA)(van Eijk et al., 1993). OPA-AA derivales of the amino acids were quantified with fluorescence.

\section{Statistical analysis}

The concentrations of plasma amino acids were determined for each treatment and time condition separately. The extent of reduction (expressed in absolute values and in percentage decline from resting values) was calculated for the total plasma TRP concentrations and for the ratio of TRP/ ILNAA. Data were first submitted to a normality test (KolmogorovSmimov) and were expressed as (means \pm SEM). Extreme values were excluded form the statistical analysis. Differences in plasma amino acids concentrations were analyzed with a one-way ANOVA, with main factor 
'Treatment' and repeated measure 'Time'. Differences were regarded as statistically significant if $p<0.05$. To further characterize the effects of the treatment over Time within each group, a post-hoc Bonferroni analysis $(p<0.05)$ was performed.

\section{Results}

The levels of plasma TRP differed between groups $[F(3,18)=17.27, p<0.01]$ and changed over time $[F(3,57)=27.07, p<0.01]$. Post-hoc analysis showed that the TRP levels in both the TRP-, and the TRP-, group were lowered when compared to the saline and TRP + group $[F(9.54)=14.31, p<0.01]$. Plasma TRP levels did not change over time in the saline and the TRP+ group. Compared to resting levels, a more substantial decrease in plasma TRP levels was found in the TRP-, group (43\%; see Fig. I) and the TRP-, group $(58 \%)$, two hours after administration. However, as from that moment, plasma TRP levels of the TRP-, group started to increase and reached normal levels $6 \mathrm{~h}$ after administration. Furthermore, the effects multiple administrations of the TRP-lacking mixture on plasma TRP levels are more prolonged and a reduction of $44 \%$ still occurred $6 \mathrm{~h}$ after the first administration.

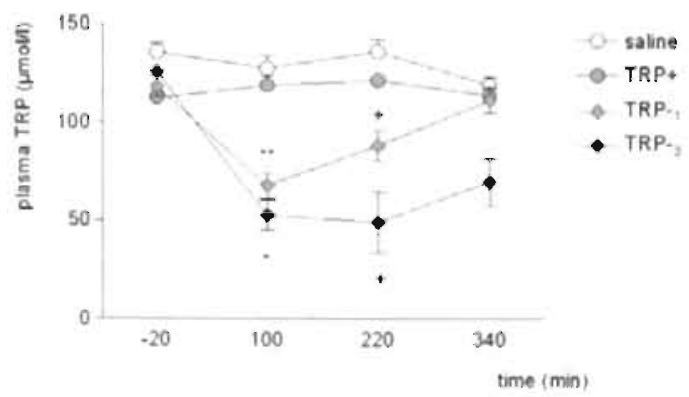

Fig. 1: Plasma TRP levels at rest (i.e. $20 \mathrm{~min}$ belore), 100,220 and $340 \mathrm{~min}$ after the first administration was given. Entries are means \pm SEM The effects on TRP levels at 100, 220 and $340 \mathrm{~min}$ after treatment, are compared to resting levels within each group

$\because 0.05<p<0.10$.

$* p<0.05$ :

$* 0<0.01$

Treatment of the TRP-lacking mixture also affected the ratio of TRP/ $L L N A A$ $[F(3,15)=22.24, p<0.01]$. The decrease in TRP $/ \Sigma L N A A$ over time $[F(3,45)=$ $37.31, p<0.01]$ depended on the treatment $[F(9.45)=21.51, p<0.01]$. The saline and TRP + group showed similar values of TRP/LLNAA over time, except for the latest point where the ratio was reduced in the saline group. Treatment of the TRP-lacking mixture reduced TRP/ $L$ LNAA values over time in both TRP-, and TRP-, group (see Fig. 2). Similar to plasma TRP leveis, multiple administrations of the TRP-lacking mixture decreased TRP/ LLNAA values within $2 \mathrm{~h}$ in both TRP-, and TRP-; group (i.e. $48 \%$ and $65 \%$, 
respectively). Within a $4 \mathrm{~h}$ interval, the depletion in TRP/ $\Sigma$ LNAA was even more substantial $(73 \%)$ when three administrations of the TRP-lacking mxture were given. Less than $6 \mathrm{~h}$ after administration, the reduction in TRP/ILNAA was completely reversed in the TRP-, group, while at the sane time, the depletion was still highly pronounced $(54 \%)$ in the TRP- ${ }_{3}$ group.

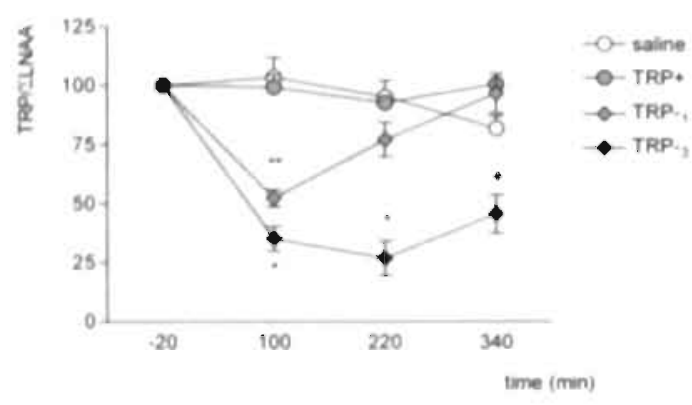

Fig. 2: Values of the ratio TRP/LLNAA at rest (i.e. $20 \mathrm{~min}$ before), 100, 220 and $340 \mathrm{~min}$ after the first adminisration. Entries are means \pm SEM the treatment effects are expressed in percentage decrease and the effects on the TRP/LLNAA ratio at 100, 220 and $340 \mathrm{~min}$ after treatment, are compared to resting levels wihin each group.

$\because 0.05<p<0.10$

$\because p<0.05$

$\because p<0.01$

\section{Discussion}

A treatment inducing similar biochemical effects in both rodents and humans is considered to be valuable for comparing functional treatment effects across species. Application of the TRP depletion method in humans and rats, has shown to result in conflicting degrees of plasma TRP reduction (i.e. substantial in humans and moderate in rats), hence limiting the use of the TRP-free amino acids mixture as a tool to investigate the role of 5-HT in functional disorders. A gelatin-like protein-carbohydrate mixture was created as an alternative method of depleting TRP levels, and the aim of the present study was to examine the effects of this mixture on plasma TRP levels in adult rats. More specifically, we evaluated the effects of different methodological conditions (i.e. frequency of injection) on the degree of TRP depletion.

Our data confirm the hypothesis that administration of a TRP-free proteincarbohydrate mixture induces a substantial depletion of plasma TRP levels within several hours in adult male rats. A single administration of the TRPfree, protein-carbohydrate mixiure reduced plasma TRP levels by $43 \%$ within $2 \mathrm{~h}$ after treatment after which levels increased back to normal. Within $6 \mathrm{~h}$ after treatment, plasma TRP levels had returned to resting levels and to the levels of the saline and TRP+ group. This finding demonstrates that, similar to the TRP-free amino acid mixture, the effect of this TRP-free 
protein-carbohydrate mixture is reversible over time, thereby inducing an acute effect on plasma TRP levels. At the time where the rats of the TRP-3 group were injected already twice with the mixture (i.e. 2-h delay), plasma TRP levels were reduced by $58 \%$. This effect was maintained over time when the third administration. was given, which finally resulted in a $62 \%$ decrease in plasma TRP levels within $4 \mathrm{~h}$ after the first administration was given. From that point on the levels started to increase but the effects in this condition were clearly more substantial and more prolonged over time.

In human studies, the ratio of TRP/LLNAA is often calculated to estimate treatment effects on brain 5-HT levels (Fernstrom 1981; Klaasen 1999). Compared to plasma TRP levels, the parameter TRP/ LLNAA is considered to be a better estimator for central 5-HT levels since this ratio also reflects the competition between TRP and LNAAs. Nevertheless, our data show a similar decrease in plasma TRP/SLNAA, compared to the plasma TRP levels, after administration of the TRP-free protein-carbohydrate mixture. Therefore, we could not confirm the ratio to be a better predictor for central 5-HT levels.

However, irrespective of parameter, the depletion effects were more pronounced after multiple administration of this TRP-lacking mixture, and more importantly, multiple administrations of this TRP-free proteincarbohydrate mixture depleted TRP/ LNAA values in adult rats to a comparable extent as previously found in human studies using a TRP-free amino acid mixture.

To balance the depletion effect, TRP was added to this protein-carbohydrate mixture with an amount of $0.28 \%$ of total protein used. Proportionally, this was about the same as found in standard rat chow. It was demonstrated that the plasma TRP levels of the TRP-enriched group were similar to those of the saline treated animals, and plasma TRP levels of both groups remained statble over time. Consequently, these data suggest that the TRP depletion can be prevented by adding TRP to the mixture.

It's worthwhile considering that administration of this protein-carbohydrate. mixture may nonspecifically influence other metabolic processes. While plasma TRP levels decreased over time, the concentration of other amino acids probably increase due to the boost of protein intake. Furthermore, the triple administration was not only labor-intensive, but we also had the impression that it was hard to swallow for the animals since this resulted in a final volume of about $15 \mathrm{ml}$ to be ingested by each animal. Therefore, it would be desirable to reduce the number of administration to two, hereby 
using an interval of $90 \mathrm{~min}$ between injections. Finally, to determine the selectivity of this treatment, we also intend to determine central levels of the amino acids and 5-HT in a next study.

We believe this TRP-free protein-carbohydrate mixture to be a more appropriate method to induce a substantial plasma TR.P reduction in rats. Subsequently, if shown that administrating this mixture to humans would result in similar TRP depletion we would have an out-standing method to evaluate the role of 5-HT on functional behavior across species.

\section{References}

Bell, C., Abrams, J. and Nutt, D. (2001) Tryptophan depletion and its implications for psychiatry. $\mathrm{Br} J$ Psychatry. 178: 399-405.

Blier, P, and de Montigny, C, (1994) Current advances and trends in the treatment of depression. Thends Pharmacol Sci 15:220-6.

Blokland, A., Lieben, C. and Deut, N.E. (2002) Anxingenic and depressive-like effects, but no cognitive deficits, after repeated moderate tryptophan depletion in the rat. J Psychopharmacol. 16 : $39-49$

Brown. C.M., Fletcher, P.J. and Coscina, D.V. (1998) Acule amino acid loads that deplete brain serotonn fail to alter behavior. Pharmacol Biochem Beha:, 59: 115-21.

Cowen, PI, Parry-Billings, M. and Newsholme, E.A. (1989) Decreased plasma tiyptophan levels in major depression Ifffect Disond 16:27-31.

Djagny, V.B., Wang, Z and Xu, S. (2001) Gielatin: a valuable protein for food and pharmaceutical induslies: review. (rit Rev Foed Sci Nurr. 41:481-92.

Evenden. J. (1999) Impulsivity: a discussion of clinical and experimental findings. I Psychopharmacol. 13: 180-92.

Fluttert, M., Dalm, S. and Oitzl, M.S. (2000) A retined method for sequentia! blood sampling by tail incision in rats. Lah Anim. 34:372-8.

Harmer, C.J. Bhagwagar, Z. Cowen, P.J. and Goodwin. GM. (2002) Acute administration of citalopram facilitates memory consolidation in healthy volunteers. Psychopharmacology (Berl) 163: 106-10.

Harrison, A.A., Everitt, B.J. and Robbins, 'T.W (1997) Doubly dissociable effects of median- and dorsal-raphe lesions on the performance of the fvechoice serial reaction time test of attention in ats beriav bran kies. $89: 155-49$.

Mazer, C.. Muneyyirci. J., Tahery. K... Raio, N., Borella, A. and Whitaker-Azmitia, P. (1997) Serotonin depletion during synaptogenesis leads to decreased synaptic density and leaming delicits in the adult rat: a possible model of neurodevelopmental disorders with cognitive deficits. Brain Res. 760: 68-73.

Meltzer, C.C.. Smith, G., DeKosky, S.T., Pollock. B.G., Mathis, C.A., Moore, R.Y., Kupfer, D.J. and Reynolds, C.F., 3rd. (1998) Serotonin in aging, late-life depression, and Alzheimer's disease: the emerging role of functional imaging. Neuropsychepharmacology, 18: 407-30.

Melter. H.Y. and Lowy. M.T. (1987) The serotonin hypothesis of depression. In Meltzer. H. Y. (eds), Psychopharmacologv: the third generation of progness. New York: Raven Press.

Moja, E.A.. Cipolla, P.. Castoldi. D. and Tofanetti, O. ( $(989)$ Dose-response decrease in plasma tryptophan and in brain tryptophan and serotonin after tryptophan-free amino acid mixtures in rats. Life Sc7. 44: $971-6$.

Moller, H.J. and Volz, H.P. (1996) Drug treatment of depression in the $1900 \mathrm{~h}$. An overview of achieve. ments and future possibilities. Drags, 52:625-38. 
Morley, K.C. Gallate, J.E., Hunt, G.E, Mallet, P.E. and McGregor, I.S. (200I) Increased anxiety and impaired memory in rats 3 months after administration of 3.4-methylenedioxymethamphetamine ("ecstasy"), Eur J Pharmacol. 433: 91-9.

Placidi, G.P., Oquendo, M.A., Malone, K.M., Huang, Y.Y.. Ellis, S.P. and Mann, J.J. (2001) Aggressivity, suicide attempts, and depression: relationship to cerebrospinal fluid monoamine metabolite levels. Biol Psychiatry: 50: 783-91.

Reilly, J.G. MeTavish, S.F.B. and Young, A.H. (1997) Rapid depletion of plasma tryptophan: a review of studies and experimental. methodology. Journal Of Psychopharmacology: 11: 381-392.

Sanchez, C. and Meier, E. (1997) Behavioral profiles of SSRIs in animal models of depression, anx. iety and aggression. Are they all alike? Psychopharmacology (Berl). 129: 197-205.

Sandyk, R. (1992) L-tryptophan in neuropsychiatric disorders: a. review, Int J Neumosci. 67: 127-44.

van Eijk, H.M., Rooyakkers, D.R. and Deutz, N.E. ( 1993$)$ Rapid routine determination of amino acids in plasma by high-performance liquid chromatography with a 2-3 microns Spherisorb ODS II column. J Chnomatogr. 620: 143-8.

van Praag. H.M., Korf. J. and Puite, J. (1970) 5. Hydroxyindoleacetic acid levels in the ecrebrospinal fluid of depressive patients treated with probenecid. Nature. 225: 1259-60. 



\section{CHAPTER}

\section{4}

\section{Acute tryptophan and}

serotonin depletion using an optimized tryptophanfree protein-carbohydrate mixture in the adult rat.

C.K.J. Lieben, A. Blokland, B. Westerink and N.E.P. Deutz. Published in: Neurchemistry International 2004; 44(1):9-16 


\section{Abstract}

In contrast to humans, a tryptophan (TRP)-free amino acid mixture only leads to moderate depletion in plasma TRP levels in adult rats. In this study ve evaluated the effects of an acute administration of a TRP-free protencarbohydrate nutritional mixture in adult male Wistar rats. Plasma amino acid levels were examined 2 and $4 \mathrm{~h}$ starting after the first administration. Furthermore, the concentrations of amino acid, serotonin (5-HT), dopamine (DA) and their metabolite (5-HIAA and DOPAC, respectively) were measured within the striatum, hippocampus and cortex. In the TRP depleted animals, the TRP/ $\Sigma L N A A$ ratio (LNAA: large neutral amino acids) was substantial decreased at 2 and $4 \mathrm{~h}$ after the first administration of the oral administration (by $71 \%$ and $78 \%$, respectively). Four hours after treatment central TRP and 5-HT concentrations were decreased by $50 \%$. Both peripheal and central TRP levels returned to basal values in the group treated wth the nutritional mixture supplemented with TRP. Surprisingly, tyrosine levils were also reduced after oral administration of the protein-carbohydrate mx-

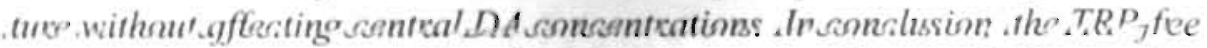
protein-carbohydrate nutritional mixture appears to be an efficient tool to substantially reduce plasma and central TRP levels in adult rat.

\section{Introduction}

One of the regulating factors of serotonin (5-HT) synthesis is the availability of its precursor L-tryptophan (TRP), an essential amino acid found in most living species and plants. Specific mixtures deficient in TRP can be used as a tool to evaluate the metabolism and functions of 5-HT within the central nervous system of humans and animals (Young, 1993; Reilly et al., 1997; Moore et al.. 2000).

In this regard, mixtures of amino acids lacking TRP have been used to substantially lower plasma TRP and central 5-HT levels in humans (Young et al., 1985; Delgado et al., 1989; Williams et al., 1999) and in juvenile rats (Biggio et al., 1974: Gessa et al., 1974; Moja et al.. 1989). We believe that age may have an important influence on the effects of TRP deficient mixtures. Recent animal studies show less pronounced $(\sim 35 \%)$ reductions in plasma TRP levels when a TRP-free amino acid mixture was given to adult rats (Moja et al., 1989; Brown et al., 1998; Blokland et al., 2002). 
In the present study, we investigate a alternative approach to substantially lower plasma TRP and central 5-HT levels in adult male Wistar rats. By using a gelatin hydrolysate in combination with carbohydrate, we tried to induce acute and substantial reduction of plasma TRP levels. Using this gelatinbased protein, the nutritional mixture no longer consists of individual amino acids. Nevertheless, except for the deficiency of TRP, this gelatin-based protein comprises the entire range of amino acids in the form of peptides, as seen in normal food. The efficacy of the gelatin-based protein-carbohydrate mixture was determined by measuring plasma amino acids $4 \mathrm{~h}$ after oral administration. Subsequently, central levels of amino acids, 5-HT, 5-hydroxyindolacetic acid (5-HIAA) were determined within the striatum (STR), hippocampus (HIP) and cortex (CTX). Dopamine (DA) and 3,4-dihydroxyphenylacetic acid (DOPAC) were assayed to evaluate the selectivity of the treatment.

\section{Materials and methods}

\section{Animals}

Experiments were carried out using four-month old adult male Wistar rats (Charles River, The Netherlands), weighing about $450 \mathrm{~g}$. The rats were individually housed in standard Makrolon cages on sawdust bedding in an airconditioned room $\left( \pm 20^{\circ} \mathrm{C}\right)$. The rats had free access to standard rat chow (Hopefarms, The Netherlands) and water. They were kept under a reversed $12 / 12 \mathrm{~h} \mathrm{light/dark}$ cycle (lights off from 06.00 to $18.00 \mathrm{~h}$ ). A radio, which was playing softly, provided background noise. All experimental procedures were approved by the institutional ethical committee for the use of experimental animals of the Maastricht University according to governmental guidelines.

\section{Drug and chemicals}

The Gelatin hydrolysate (Solugel $\mathrm{P}^{*}$ ) was purchased from PB Gelatins (Tessenderlo, Belgium; see Table I for amino acid composition). Maltodextrine was obtained from the Amylumgroup (Koog aan de Zaan, The Netherlands). L-tryptophan, L-tyrosine and L-norvaline were from Sigma (Zwijndrecht, The Netherlands). Potassiumchloride ( $\mathrm{KCl}$ ), calciumchloridedihydrate $\left(\mathrm{CaCl}_{2}, 2 \mathrm{H}_{2} \mathrm{O}\right)$ and 5-sulfosalicylic acid dihydrate were purchased from Merck (Darmstadi, Germany). 
Table 1: Composition of the nutritional mixture and determination of the amino acids conter of the gelatin-based protein $(g)$

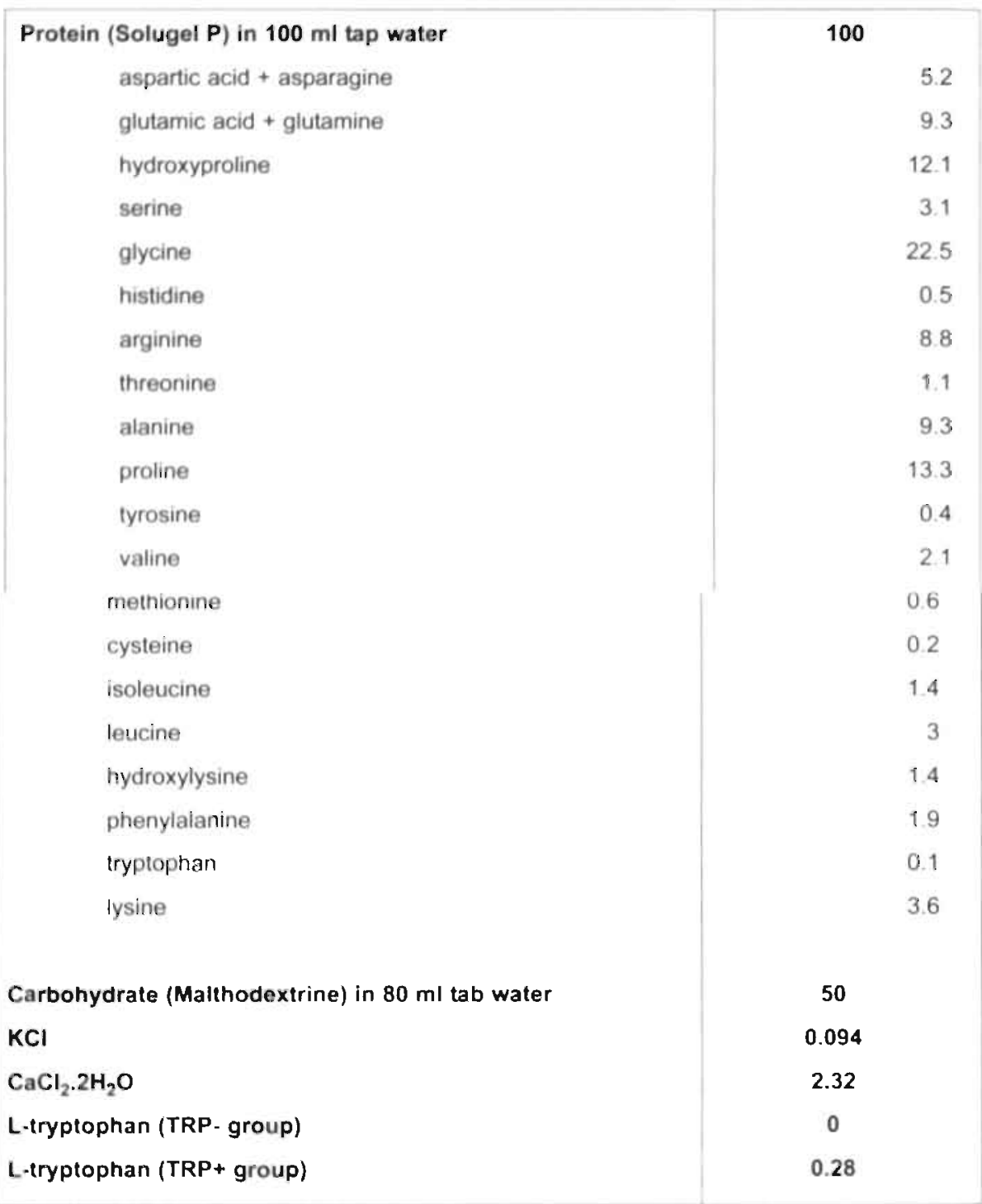

The composition of the nutritional mixture used in this experiment is described in bold. The amino acid spectrum (\%). of the Solugel $\mathrm{P}^{*}$ protein was obtained from PB Gelatins, Tessenderlo, Belgium 


\section{Treatment}

Rats were randomly assigned to one of the three experimental groups ( $n=8 /$ group). They were treated orally with saline, or a protein-carbohydrate mixture containing additional TRP (TRP+, $0.28 \%$ TRP of total protein) or one lacking TRP (TRF-). The composition of the nutritional mixture is shown in Table 1.

For two weeks preceding the experiment, the rats were handled and habituated to oral injections with normal tap water $(10 \mathrm{ml} / \mathrm{kg})$. Food was removed $14 \mathrm{~h}$ before treatment to minimize TRP uptake from food. Al all times, the animals had free access to water. On the experimental day, the animals were orally infused twice, with an interval of $90 \mathrm{~min}$. Each administration contained $4.0 \mathrm{~g}$ Solugel $\mathrm{P} / \mathrm{kg}$ and $2.0 \mathrm{~g}$. Malthodextrine $\mathrm{kg}$ and was given in a volume $10 \mathrm{ml} / \mathrm{kg}$.

\section{Collection of blood samples}

Blood samples were taken at resting values (i.e. $10 \mathrm{~min}$ before the first. treatment) and repeated at 2 and $4 \mathrm{~h}$ after the first injection. Blood sampling was done via a tail-incision method (Fluttert et al., 2000). Promptly after collection of blood into heparin coated tubes (Microvette* CB 300, Sarstedt, Germany), the samples were kept on ice. After centrifugation of the blood samples (at $4{ }^{\circ} \mathrm{C}$ for $15 \mathrm{~min}$ at $3000 \mathrm{~g}$ in a Hettich EBA 12 centrifuge), plasma was deproteinised with cups containing dry 5-sulfosalicylic acid $(6 \mathrm{mg} / 100 \mu \mathrm{l}$ plasma) and the protein was spun down. Samples were frozen in liquid nitrogen and stored at $-80^{\circ} \mathrm{C}$. Before analysis, samples were thawed at $4{ }^{\circ} \mathrm{C}$, vortex-mixed vigorously and centrifuged at $50,000 \mathrm{~g}$ in a Hereaus Model Biogufe Stratos for $10 \mathrm{~min}$ at $4{ }^{\circ} \mathrm{C}$. From the clear supernatant $20 \mu \mathrm{l}$ was mixed with $1960 \mu \mathrm{l}$ water and $20 \mu \mathrm{l}$ norvaline and stored in the cooled $\left(7^{\circ} \mathrm{C}\right.$ ) sample compartment until analysis (van Eijk et al., 1993).

\section{Collection of brain samples}

Four hours after the first administration, the rats were decapitated. The head was immersed in liquid nitrogen for $5 \mathrm{~s}$. The brain was removed and the entire STR, HIP and CTX were rapidly dissected bilaterally at $4^{\circ} \mathrm{C}$ and stored at $80^{\circ} \mathrm{C}$. Before analysis, the frozen brain structures were pulverized in a pre-frozen morter. The tissue was transferred to a pre-weighed vail, containing $0.3 \mathrm{~g}$ of glass beads ( $1.0 \mathrm{~mm}$ diameter) and $400 \mu \mathrm{l}$ of an ice-cold $10 \%$ 5 -sulfosalicylic acid solution. The vails were weighed again and the tissue samples were homogenized in a mini-bead beater (Biospec products, Bartlesville, USA) set at a low speed for $30 \mathrm{~s}$ (Hopkins, 1991). The tissue: 
samples were frozen in liquid nitrogen and stored at $-80{ }^{\circ} \mathrm{C}$. Further processing was similar to the blood sample preparation.

\section{Biochemical analysis}

Plasma and brain amino acids were determined using a fully automated highperformance liquid chromatography (HPLC) system after precolumn derivatization with o-phthaldialdehyde (OPA) (van Eijk et al., 1993). OPA-AA derivates of the amino acids were quantified with fluorescence. The concentrations of the plasma and central amino acids were expressed as $\mu \mathrm{mol} / \mathrm{l}$ and $\mathrm{ng} / \mathrm{mg}$ tissue weight, respectively. The concentrations of 5-HT, 5-HIAA, DA and DOPAC in the brain samples were quantified by HPLC with electrochemical detection (Westerink and De Vries, 1991).

\section{Statistical analysis}

The extent of reduction (expressed in absolute values and in percentage decline from resting values) was calculated for the total plasma TRP concentrations and for the ratio of TRP/ LLNAA (LNAA; large neutral amino acids, i.e., tyrosine, phenylalanine, leucine, isoleucine and valine). To study differences in these peripheral levels and ratios over time, a repeated measures analysis (GLM) was used. The central concentrations of TRP, 5-HT, 5-HIAA, TYR, DA and DOPAC were determined for each structure separately. A multifactor analysis of variance was performed to investigate the effects of Treatment and/or Structure. For each structure, between group effects were studied after using a one-way ANOVA. To further characterize the differences between groups a post-hoc Bonferroni analysis $(p<0.05)$ was performed.

\section{Results}

\section{Plasma concentrations}

Although, at resting state, the concentrations of most the amino acids were equal beiween the groups (see Table 2), differences in concentrations were found in other amino acids levels for which we have no clear explanation. Over time, the protein-carbohydrate nutritional mixture increased the levels of numerous amino acids (e,g. serine, glycine, arginine and ornitine). On the other hand, the amino acid levels of the saline-treated group declined slightly over time. 
Table 2: Absolute plasma amino acid (AA) concentrations $(\mu \mathrm{mol} / \mathrm{l})$ at resting levels $(\mathrm{t}-10)$ and two (1120) and four (1240) hours after the first oral administration (mean \pm SEM) in animal treated with either saline or a protein-carbohydrate nutritional mixture containing TRP (TRP+) or not (TRP.).

\begin{tabular}{|c|c|c|c|c|c|c|}
\hline & \multicolumn{2}{|c|}{ Resting level } & \multicolumn{2}{|c|}{1120} & \multicolumn{2}{|c|}{1240} \\
\hline$\overline{A A}$ & \begin{tabular}{|l|} 
Saline \\
TRPt \\
\end{tabular} & TRP. & $\begin{array}{l}\text { Saline } \\
\text { TRP+ }\end{array}$ & TRP. & $\begin{array}{l}\text { Salline } \\
\text { TRP+ }\end{array}$ & TRP. \\
\hline$\overline{G L U}$ & \begin{tabular}{|l|}
$176 \pm 91$ \\
$115 \pm 11$ \\
\end{tabular} & $142 \pm 11$ & $\begin{array}{l}130 \pm 8 \\
103 \pm 7\end{array}$ & $156 \pm 18$ & $\begin{array}{l}128 \pm 11 \\
108 \pm 8\end{array}$ & $132 \pm 15$ \\
\hline ASN & $\begin{array}{l}51 \pm 1 \\
55 \pm 1\end{array}$ & $55 \pm 2$ & $\begin{array}{l}41 \pm 1 \\
33 \pm 0.8 \quad \cdots\end{array}$ & $32 \pm 1 \quad \cdots$ & $\begin{array}{ll}46 \pm 2 \\
25 \pm 0.7\end{array}$ & $27 \pm 1 \quad \cdots$ \\
\hline SER & $\begin{array}{l}305 \pm 6 \\
317 \pm 8\end{array}$ & $315 \pm 7$ & $\begin{array}{l}252 \pm 9 \\
401 \pm 14 \cdots\end{array}$ & $420 \pm 11 \cdots$ & $\begin{array}{|ll|}256 \pm 13 & \\
442 \pm 29 & \cdots\end{array}$ & $413 \pm 14 \cdots$ \\
\hline GLN & $\begin{array}{l}772 \pm 11 \\
775 \pm 12\end{array}$ & $765 \pm 15$ & $\begin{array}{l}721 \pm 21 \\
681 \pm 21\end{array}$ & $737 \pm 9$ & $\begin{array}{l}804 \pm 20 \\
612 \pm 17\end{array}$ & $662 \pm 25 \cdots$ \\
\hline HIS & $\begin{array}{l}80 \pm 1 \\
82 \pm 2\end{array}$ & $80 \pm 3$ & $\begin{array}{l}75 \pm 2 \\
80 \pm 1\end{array}$ & $82 \pm 1$ & $\begin{array}{l}80 \pm 2 \\
74 \pm 2\end{array}$ & $73 \pm 2$ \\
\hline GLY & $\begin{array}{l}438 \pm 9 \\
447 \pm 12\end{array}$ & $415 \pm 13$ & $\begin{array}{l}369 \pm 13 \\
984 \pm 27 \cdots\end{array}$ & $1184 \pm 45^{\cdots} \cdots / m$ & $\left.\begin{array}{l}372 \pm 14 \\
1153 \pm 40\end{array}\right]$ & $1118 \pm 49 \cdots$ \\
\hline THR. & $\begin{array}{l}289 \pm 15 \\
310 \pm 17\end{array}$ & $288 \pm 11$ & $\begin{array}{l}242 \pm 16 \\
262 \pm 15\end{array}$ & $274 \pm 11$ & $\begin{array}{l}241 \pm 20 \\
240 \pm 8\end{array}$ & $250 \pm 8$ \\
\hline $\mathrm{CIT}$ & $\begin{array}{l}70 \pm 3 \\
67 \pm 1\end{array}$ & $64 \pm 2$ & $\begin{array}{l}66 \pm 3 \\
72 \pm 2\end{array}$ & $79 \pm 2$ & $\begin{array}{l}62 \pm 3 \\
91 \pm 2\end{array}$ & $90 \pm 3 \quad \cdots$ \\
\hline ARG & $\begin{array}{l}188 \pm 6 \\
189 \pm 9\end{array}$ & $182 \pm 9$ & $\frac{128 \pm 5}{288 \pm 15}$ & $312 \pm 18 \cdots$ & \begin{tabular}{|l}
$128 \pm 8$ \\
$210 \pm 7$
\end{tabular} & $220 \pm 11 \cdots$ \\
\hline ALA & $\begin{array}{l}429 \pm 20 \\
366 \pm 17\end{array}$ & $378 \pm 18$ & $\mid \frac{320 \pm 13}{549 \pm 15}$ & $584 \pm 26 \ldots *$ & $\mid \begin{array}{l}337 \pm 25 \\
453 \pm 16\end{array}$ & $422 \pm 21$ \\
\hline TAU & \begin{tabular}{|l|}
$306 \pm 27$ \\
$371 \pm 29$ \\
\end{tabular} & $353 \pm 56$ & $\begin{array}{l}215 \pm 23 \\
233 \pm 19\end{array}$ & $249 \pm 34$ & $\frac{179 \pm 21}{201 \pm 13}$ & $231 \pm 31$ \\
\hline MET & $\begin{array}{l}80 \pm 3 \\
76 \pm 2\end{array}$ & $73 \pm 2$ & $\begin{array}{l}65 \pm 2 \\
76 \pm 2\end{array}$ & $78 \pm 2$ & $\begin{array}{l}65 \pm 3 \\
62 \pm 1\end{array}$ & $61 \pm 2$ \\
\hline ORN & $\begin{array}{l}54 \pm 2 \\
46 \pm 2\end{array}$ & $49 \pm 2$ & $\frac{49 \pm 3}{160 \pm 9}$ & $178 \pm 6$ & $\mid \begin{array}{l}46 \pm 2 \\
131 \pm 8\end{array}$ & $136 \pm 13^{* * *}$ \\
\hline LYS & $\begin{array}{l}387 \pm 8 \\
433 \pm 12\end{array}$ & $434 \pm 15$ & $\begin{array}{l}326 \pm 15 \\
474 \pm 20\end{array}$ & $490 \pm 14$ & $\frac{330 \pm 23}{407 \pm 8}$ & $395 \pm 14$. \\
\hline ILE & $\begin{array}{l}82 \pm 2 \\
85 \pm 3\end{array}$ & $84 \pm 2$ & $\begin{array}{l}71 \pm 3 \\
87 \pm 3\end{array}$ & $94 \pm 2$ & $\begin{array}{l}75 \pm 4 \\
83 \pm 3\end{array}$ & $95 \pm 2 \quad \cdots j^{a}$ \\
\hline PHE & $\begin{array}{l}74 \pm 2 \\
72 \pm 2\end{array}$ & $66 \pm 2$ & $\begin{array}{l}67 \pm 3 \\
78 \pm 2\end{array}$ & $81 \pm 2$ & $\begin{array}{l}74 \pm 2 \\
78 \pm 1\end{array}$ & $83 \pm 2$ \\
\hline TYR & $\begin{array}{l}68 \pm 3 \\
72 \pm 4\end{array}$ & $76 \pm 3$ & $\begin{array}{l}54 \pm 3 \\
52 \pm 2\end{array}$ & $53 \pm 2$ & $\begin{array}{l}54 \pm 4 \\
38 \pm 1\end{array}$ & $39 \pm 1$ \\
\hline LEU & $\begin{array}{l}223 \pm 7 \\
189 \pm 11\end{array}$ & $133 \pm 4 \quad \cdots \cdots$ рама & \begin{tabular}{|l}
$188 \pm 5$ \\
$197 \pm 12$
\end{tabular} & $162 \pm 3$ & $\frac{198 \pm 7}{193 \pm 11}$ & $171 \pm 5$ \\
\hline VAL & $\begin{array}{l}215 \pm 5 \\
186 \pm 4\end{array}$ & $166 \pm 5 \quad \cdots /$ & $\begin{array}{l}183 \pm 6 \\
258 \pm 4\end{array}$ & $253 \pm 8$ & \begin{tabular}{|l|}
$185 \pm 7$ \\
$252 \pm 8$
\end{tabular} & $263 \pm 12 \cdots$ \\
\hline TRP & $\begin{array}{l}110 \pm 2 \\
103 \pm 5\end{array}$ & $101 \pm 5$ & $\begin{array}{l}97 \pm 4 \\
122 \pm 3\end{array}$ & $35 \pm 3^{\cdots \cdots}$ aaa & $\frac{90 \pm 4}{109 \pm 6}$ & $25 \pm 2^{\cdots \cdots}$ \\
\hline
\end{tabular}

Significant differences in levels of AA between saline group and (TRP+ or TRP-) group are denoted with (") while differences in levels between the TRP+ and TRP. group are denoted with $\left({ }^{a}\right)$. ${ }^{*}: p<0.05, * *$ aa $: p<0.01, * *$ aas: $p<0.001$. GLU: glutamate, ASN: asparagine, SER: serine, GLN: glutamine, HIS: histidine, GLY: glycine, THR: threonine, CIT: citrulline, ARG: arginine, ALA: alanine, TAU: taurine, MET: methionine, ORN: ornithine, LYS: lysine, ILE: isoleucine, PHE: phenylalanine, TYR: tyrosine, LEU: leucine, VAL: valine, TRP. tryptophan. 
TRP levels (Table 2) and the TRP/ LLNAA. ratio (Fig. 1) of all rats decreased over time. A treatment effect was found for both parameters. Post-hoc analysis showed that the TRP levels and the TRP/LLNAA ratio in the TRPgroup were lower when compared to those of the other groups. The TRP levels of the TRP + group were higher when compared to the saline group, but this difference disappeared when calculating the TRP/ LLNAA ratio. Moreover, both TRP levels and TRP/ILNAA values in the TRP'+ group remained stable over time.

Four hours after the first administration. TYR levels were decreased in the groups treated with the protein-carbohydrate nutritional mixture (i.e. TRP+ and TRP-group; see Table 2).

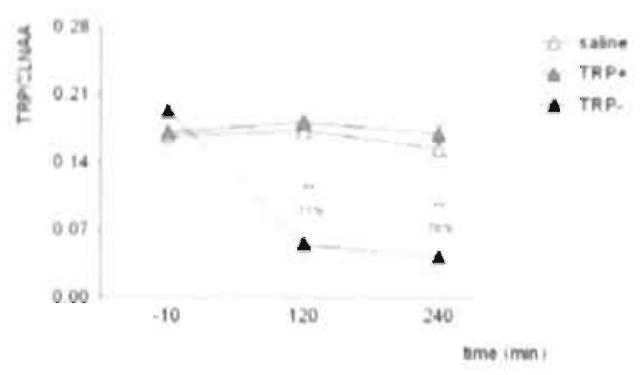

Fig. 1: Values, of the ratio TRP/ZLNAA at rest. 2 and $4 \mathrm{~h}$ after the first oral administration. Data represents mean \pm SEM with an $n=8 \mathrm{rats} / \mathrm{group}$. The effect of the different nutritional mixtures is expressed in percentage decrease at 2 and $4 \mathrm{~h}$ after first injection as compared to resting state.

\section{Central concentrations}

Treatment and structure effects were found on TRP. 5-HT and 5-HIAA levels in the brain samples. However, within each treatment, the effects were similar per structure (see Table 3). For example, the TRP-free proteincarbohydrate nutritional mixture induced a $40-45 \%$ reduction in central 5-HT levels. When comparing the TRP+ group with the saline group, no treatment effects were found in TRP and 5-HT concentrations. However, in the TRP+ group, 5-HIAA levels were reduced in the HIP and CTX.

Further, in each brain structure, concentrations of citrulline (CIT), ornitine $(O R N)$ and lysine (LYS) were substantially reduced in the TRP- group when compared with the other two groups.

Compared to the saline group, the reduction of TYR levels in TRP+ and TRPgroups was most pronounced in the STR and HIP. No treatment effects were found for the levels of DA and DOPAC concentration.

Table 3: Absolute central amino acids (AA), 5-HT, 5-HIAA, DA and DOPAC concentrations $(\mathrm{ng} / \mathrm{mg})$ in striatum, hippocampus and cortex four $\left(\mathrm{t}_{240}\right)$ hours after the first oral administration (mean \pm SEM) in animals treated with either saline or a protein-carbohydrate nutritional mixture containing TRP (TRP+) or not (TRP-). 


\begin{tabular}{|c|c|c|c|c|c|c|}
\hline & \multicolumn{2}{|c|}{ STRIATUM } & \multicolumn{2}{|c|}{ HIPPOCAMPUS } & \multicolumn{2}{|c|}{ CORTEX } \\
\hline$\overline{A A}$ & \begin{tabular}{|l} 
Saline \\
TRP+
\end{tabular} & TRP. & \begin{tabular}{|l|} 
Saline \\
TRP++
\end{tabular} & TRP. & \begin{tabular}{|l|} 
Saline \\
TRP+
\end{tabular} & |TRP. \\
\hline$\overline{G L U}$ & $\begin{array}{l}1382 \pm 48 \\
1262 \pm 26\end{array}$ & $1471 \pm 66$ & \begin{tabular}{|l|}
$995 \pm 11$ \\
$1006 \pm 28$
\end{tabular} & $1124 \pm 48$ & $\begin{array}{l}911 \pm 23 \\
855 \pm 19\end{array}$ & $924 \pm 26$ \\
\hline ASN & $\begin{array}{l}207 \pm 7 \\
200 \pm 8\end{array}$ & $189 \pm 10$ & $\begin{array}{l}152 \pm 2 \\
151 \pm 6\end{array}$ & $138 \pm 1$ & $\begin{array}{l}162 \pm 6 \\
155 \pm 8\end{array}$ & $141 \pm 7$ \\
\hline SER & $\begin{array}{l}131 \pm 4 \\
133 \pm 4\end{array}$ & $123 \pm 4$ & $\begin{array}{l}117 \pm 1 \\
125 \pm 4\end{array}$ & $114 \pm 3$ & $\begin{array}{l}119 \pm 6 \\
109 \pm 16\end{array}$ & $119 \pm 4$ \\
\hline GLN & $\begin{array}{l}846 \pm 28 \\
842 \pm 17\end{array}$ & $833 \pm 12$ & $\begin{array}{l}698 \pm 9 \\
750 \pm 17\end{array}$ & $700 \pm 20$ & $\frac{823 \pm 35}{819 \pm 29}$ & $808 \pm 27$ \\
\hline HIS & $\begin{array}{l}26 \pm 1 \\
19 \pm 1\end{array}$ & $22 \pm 1$ & $\begin{array}{l}20 \pm 1 \\
17 \pm 1\end{array}$ & $17 \pm 1$ & $\begin{array}{l}20 \pm 1 \\
14 \pm 2\end{array}$ & $20 \pm 1$ \\
\hline GLY & $\begin{array}{l}95 \pm 4 \\
95 \pm 3\end{array}$ & $81 \pm 4$ & $\begin{array}{l}88 \pm 1 \\
96 \pm 3\end{array}$ & $102 \pm 18$ & $\begin{array}{l}69 \pm 3 \\
74 \pm 2\end{array}$ & $61 \pm 16$ \\
\hline THR & $\begin{array}{l}222 \pm 3 \\
220 \pm 5\end{array}$ & $226 \pm 7$ & $\begin{array}{l}158 \pm 4 \\
163 \pm 4\end{array}$ & $151 \pm 5$ & $\begin{array}{l}164 \pm 7 \\
162 \pm 4\end{array}$ & $145 \pm 3$ \\
\hline CIT & $\begin{array}{l}20 \pm 3 \\
15 \pm 3\end{array}$ & $4 \pm 1$ & $\begin{array}{l}22 \pm 2 \\
15 \pm 1\end{array}$ & $5 \pm 1 \quad \cdots$ pas & $\begin{array}{l}17 \pm 3 \\
16 \pm 1\end{array}$ & $4 \pm 1 \quad \cdots$ pan \\
\hline ARG & $\begin{array}{l}27 \pm 2 \\
29 \pm 1\end{array}$ & $28 \pm 1$ & $\begin{array}{l}17 \pm 1 \\
17 \pm 1\end{array}$ & $17 \pm 1$ & $\begin{array}{l}18 \pm 1 \\
21 \pm 1\end{array}$ & $22 \pm 1$ \\
\hline ALA & $\begin{array}{l}71 \pm 3 \\
64 \pm 1\end{array}$ & $64 \pm 3$ & $\begin{array}{l}81 \pm 2 \\
80 \pm 2\end{array}$ & $76 \pm 2$ & $\begin{array}{l}62 \pm 2 \\
57 \pm 1\end{array}$ & $57 \pm 2$ \\
\hline TAU & $\begin{array}{l}999 \pm 28 \\
1001 \pm 31\end{array}$ & $906 \pm 41$ & $\begin{array}{l}800 \pm 14 \\
784 \pm 29\end{array}$ & $718 \pm 14$ & $\begin{array}{l}736 \pm 17 \\
688 \pm 20\end{array}$ & $583 \pm 86$ \\
\hline MET & $\begin{array}{l}24 \pm 7 \\
31 \pm 8\end{array}$ & $32 \pm 5$ & $\begin{array}{l}25 \pm 6 \\
30 \pm 6\end{array}$ & $17 \pm 5$ & $\begin{array}{l}22 \pm 5 \\
25 \pm 6\end{array}$ & $16 \pm 5$ \\
\hline ORN & $\begin{array}{l}26 \pm 1 \\
24 \pm 1\end{array}$ & $14 \pm 2 \cdots /$ aaa & $\begin{array}{l}16 \pm 1 \\
17 \pm 1\end{array}$ & $9 \pm 1 \quad \cdots$ paa & $\begin{array}{l}26 \pm 1 \\
24 \pm 1\end{array}$ & $14 \pm 2 \cdots /$ /aa \\
\hline LYS & $\begin{array}{l}48 \pm 1 \\
46 \pm 2\end{array}$ & $36 \pm 1^{\cdots * *} /$ aa & \begin{tabular}{|l|}
$31 \pm 1$ \\
$27 \pm 1$
\end{tabular} & $22 \pm 0.3^{* \cdots *} /$ aa & $\begin{array}{l}33 \pm 1 \\
29 \pm 1\end{array}$ & $24 \pm 1 \quad \cdots / a$ \\
\hline ILE & $\begin{array}{l}10 \pm 1 \\
11 \pm 1\end{array}$ & $8 \pm 1$ & $\begin{array}{l}8 \pm 0.5 \\
8 \pm 1\end{array}$ & $6 \pm 0.4$ & $\frac{6 \pm 0.2}{6 \pm 0.3}$ & $5 \pm 0.4$ \\
\hline PHE & $\begin{array}{l}20 \pm 1 \\
18 \pm 2\end{array}$ & $15 \pm 1$ & \begin{tabular}{|l}
$14 \pm 0.3$ \\
$13 \pm 1$. \\
\end{tabular} & $10 \pm 0.9$ & $\begin{array}{l}12 \pm 0.4 \\
11 \pm 1\end{array}$ & $10 \pm 0.6$ \\
\hline TYR & $\begin{array}{l}14 \pm 0.4 \\
10 \pm 0.2\end{array}$ & $7 \pm 0.4^{* * 2}$ paa & $\frac{10 \pm 0.3}{7 \pm 0.3}$ & $10 \pm 1 \quad \cdots * / a a$ & $\begin{array}{l}9 \pm 0.4 \\
6 \pm 0.3\end{array}$ & $5 \pm 0.3 \ldots$ \\
\hline LEU & $\begin{array}{l}18 \pm 2 \\
15 \pm 1\end{array}$ & $18 \pm 4$ & $\begin{array}{l}12 \pm 1 \\
13 \pm 1\end{array}$ & $14 \pm 4$ & $\begin{array}{l}13 \pm 0.5 \\
11 \pm 0.5\end{array}$ & $15 \pm 3$ \\
\hline VAL & $\begin{array}{l}30 \pm 9 \\
17 \pm 0.3\end{array}$ & $14 \pm 1$ & $\begin{array}{l}14 \pm 0.6 \\
16 \pm 0.5\end{array}$ & $14 \pm 0.7$ & $\begin{array}{l}12 \pm 0.3 \\
14 \pm 0.5\end{array}$ & $13 \pm 0.7$ \\
\hline TRP & $\begin{array}{l}13 \pm 1 \\
11 \pm 1.4\end{array}$ & $7 \pm 0.7$ & $\begin{array}{l}8 \pm 0.4 \\
7 \pm 0.8\end{array}$ & $4 \pm 0.7 \quad * * / a$ & $\begin{array}{l}6 \pm 0.1 \\
5 \pm 0.7\end{array}$ & $4 \pm 0.6$ \\
\hline $5-\mathrm{HT}$ & $\begin{array}{l}0.11 \pm 0.01 \\
0.10 \pm 0.01\end{array}$ & $0.06 \pm 0.01 \cdots$ & $\left\{\begin{array}{l}0.05 \pm 0.001 \\
0.06 \pm 0.006\end{array}\right.$ & $0.02 \pm 0.002 * 0 a 0$ & $\begin{array}{l}0.08 \pm 0.006 \\
0.07 \pm 0.009\end{array}$ & $0.05 \pm 0.002$ \\
\hline 5-HIAA &  & $0.06 \pm 0.01^{* *}$ & {$\left[\begin{array}{l}0.08 \pm 0.001 \\
0.05 \pm 0.003\end{array}\right.$} & $0.03 \pm 0.002 \cdots /$ & $0.08 \pm 0.01$ & $0.02 \pm 0.001 \cdots$ \\
\hline DA & $\begin{array}{l}14.6 \pm \pm 0.83 \\
14.5 \pm 1.1\end{array}$ & $15.6 \pm 1.2$ & $0.04 \pm 0.003$ & $0.02 \pm 0.003$ & $1.12 \pm 0.21$ & $0.66 \pm 0.09$ \\
\hline DOPAC & $\begin{array}{l}3.57 \pm 0.61 \\
2.58 \pm 0.13\end{array}$ & $2.68 \pm 0.29$ & $0.02 \pm 0.005$ & $0.02 \pm 0.002$ & $\begin{array}{l}0.14 \pm 0.02 \\
0.09 \pm 0.02\end{array}$ & $0.1 \pm 0.01$ \\
\hline
\end{tabular}

Significant differences in levels between saline group and TRP+ or TRP-) group are denoted with (") while differences in levels between the TRP+ and the TRP-group are denoted with ( $\left.{ }^{a}\right) .{ }^{*}: p<0.05$. $\cdots$ a $p<0.01, \cdots$ aas $p<0.001$. GLU glutamate, ASN asparagine, SER: serine, GLN: glutamine, HIS: histidine, GLY: glycine, THR: threonine, CIT citrulline, ARG: arginine, ALA: alanine, TAU: taurine, MET methionine, ORN: ornithine, LYS: lysine, ILE: isoleucine. PHE: phenylalanine. TYR: tyrosine. LEU: leucine, VAL: valine, TRP: tryptophan, 5-HT. serotonin, 5-HIAA: 5-hydroxyindolacetic acid, DA. dopamine, DOPAC: 3,4-dihydroxyphenylacetic acid 


\section{Discussion}

In experimental animal studies, several methods are applied to reduce central levels of 5-HT to evaluate the function of this neurotransmitter in the central nervous system. The use of selective neurotoxins (e.g. 5,7-dihydroxytryptamine; 5,7-DHT) (Harrison et al., 1997; Hall et al., 1999) or TRP hydroxylase inhibitor (e.g. para chlorophenylalanine; PCPA) (Mazer et al, 1997) are frequently used to study the chronic effects of selective 5-HT reduction. However, these methods have permanent consequences and further, compensation may take place. In contrast, using the acute TRP depletion method, 5-HT levels are lowered in a reversible manner (Jagannathan and Venitz, 1997), allowing the effects of an acute reduction of 5-HT levels on behavior to be studied. Due to its reversible and non-intrusive eflects, this method of acute TRP depletion can be used in animals ard humans.

The aim of the present study was to achieve a substantial depletion in plasna

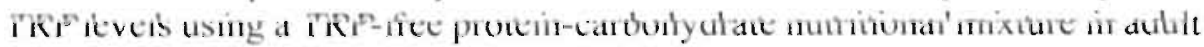
rats. The results show that plasma TRP levels were substantially lowered 2 and $4 \mathrm{~h}$ after the first ingestion $(65 \%$ and $75 \%$, respectively). Central (STR, HIP and CTX) levels of TRP and 5-HT were concomitantly reduced.

Previously, substantial plasma TRP reductions were found in juvenile rats after TRP-free amino acids mixture (Biggio et al., 1974: Gessa et ai., 1974). However, when given to adult rats, we only found a moderate TRP depletion (see also Moja et al., 1989; Brown et al., 1998; Blokland et al.. 2002). These differences can be explained by factors such as strain, sex and age of the rats. With respect to the factor age, it is known that during the developmental period there is a greater need for sufficiently available nutritional components (e.g. TRP) (Sarwar and Botting, 1999). Subsequently, due to declining metabolic functions, the rate of amino acid uptake decreases with age (Navab and Winter, 1988). Hence, it is likely that higher TRP depletions can be induced in juvenile rats. For behavioral analysis of the effect of acute TRP depletion the testing of aduit rats is preferred since most behavioral tests are validated only for adult rats (three months and older).

The composition of the TRP-free protein-carbohydrate nutritional mixture used here was different from the TRP-free amino acid mixture in several ways. First, the nutritional mixture is based on a gelatin hydrolysate derived from the selective hydrolysis of collagen protein. It is known for its unique gel-forming ability and for its lack of TRP (Djagny et al.. 2001). The product 
Solugel $\mathrm{P}^{z}$ is gelatin in an enzymatic hydrolyzed form. It is water-dispersible and has high protein content. Secondly, carbohydrate was added to the mixture as a carbohydrate mixture without protein can alter serotonergic functions (Markus et al., 1998; Dye et al., 2000) by increasing insulin concentrations. This subsequently enhances the uptake of branched chain amino acids (i.e. leucine, isoleucine and valine). The enhanced uptake into muscle tissue consequently changes the plasma ratio of amino acids and results in a rise of central TRP and 5-HT levels (Fernstrom and Wurtman, 1971: Fernstrom, 1994: Markus et al., 1998). According to this, one would suspect carbohydrate to have an undesirable control on central TRP levels. We believe that in the protein-carbohydrate nutritional mixture as used here, the presence of carbohydrate and the insulin response will enhance protein synthesis and thus lowers plasma TRP levels.

Compared to the effects of a TRP free amino acid mixture fed to adult male rats (Blokland et al., 2002), the TRP-free protein-carbohydrate nutritional mixture led to a greater depletion in plasma TRP levels. Furthermore, this depleting effect was found to be even stronger for the TRP/LLNAA ratio. In blood, TRP competes with other amino acids by sharing the same transporter system for entering the brain (Gessa et al., 1974; Fernstrom and Wurman, 1997). The TRP/ LLNAA ratio is assumed to provide an estimation of TRP uptake into the brain and consequently of central 5-HT concentrations (Fernstrom, 1981; Klaassen et al., 1999). We found that reductions in plasma TRP levels were more pronounced than central TRP and 5-11T depletion, as shown in other studies (Biggio et al., 1974; Gessa el al., 1974). Since the plasma TRP/LLNAA values usually show a higher percentage of depletion when compared to the absolute plasma TRP levels, this ratio is likely to overestimate the decrease of central 5-HT.

Moreover, we found that the TRP-free protein-carbohydrate nutritional mixture induced a similar degree of depletion as is found in human studies (Abbott et al., 1992). Four hours after treatment, concentrations of TRP and 5 -HT were reduced in several brain areas by $40-50 \%$, demonstrating the parallel mechanism of the serotonergic synthesis. Adding TRP to the mixture enhanced the TRP and 5-HT levels to basal values (as compared to the saline group), indicating that the TRP-free protein-carbohydrate nutritional mixture can be balanced for plasma TRP and central 5-HT, Nevertheless, the 5-HIAA levels of the TRP+ group were reduced in the HIP and CTX. This finding suggests that although central 5-HT levels in the TRP+ group were not affected by the protein-carbohydrate nutritional mixture, the turnover of 5-HT decreased in both the TRP+ and the TRP-groups when compared with the 
saline group. We do not have a clear explanation for this finding. Possibly, a microdialysis study may give more insight into these effects.

At resting state, the animals were food deprived and the levels of amino acids were expected to be similar between the three conditions. However, the plasma valine and leucine concentrations were lower in the TRP- and TRP+ groups when compared to the saline group and is not due to the presence of outliers or to small sample size. Besides the fact that this could be a coincidental observation, we have no reasonable explanation for this effect However, since both are members of the LNAA group, this may explain why the ratio TRP/LLNAA was somewhat higher in the rats treated with the protein-carbohydrate nutritional mixture than those in the saline group.

Another noteworthy finding was that the concentrations of CIT, ORN and LYS were substantial lowered in all brain structures of the TRP- group when compared to the other two groups. Since the amino acid levels in the TRPgroup were similar or higher than those of the saline group suggests that these changes might be specific for the TRP-treatment. Remarkably, an increase instead of a decrease was found in the plasma levels of these amino acids. It is known that arginine (ARG) is catalyzed into CIT and nitric oxide (NO) by the enzyme nitric oxide synthase (NOS) (Dawson and Dawson, 1996; Groves and Wang, 2000). Looking at our data, TRP depletion can affect CIT in the brain without affecting its precursor ARG. This could indicate that depleting TRP (and 5-HT) levels may affect NO synthesis. Clearly, further research is needed to scrutinize this surprising finding.

Furthermore, it appeared that plasma TYR levels were low in both groups treated with the protein-carbohydrate nutritional mixture. This may be related to the relative low level of TYR in the nutritional mixture. Although central TYR levels were reduced, it did not affect the DA concentrations in the brain. It is worth mentioning that, within the dopaminergic system, the TYR hydoxylase (the rate-limiting enzyme) is about $75 \%$ saturated with TYR while, within the serotonergic system. TRP hydroxylase is half saturated with TRP (Westerink and De Vries, 1991). Therefore, DA concentrations are less susceptible to variation of TYR levels.

In conclusion the use of a gelatin-based carbohydrate nutritional mixture is a viable and alternative method for inducing substantial acute TRP depletion in adult rats. This treatment can be used as a tool to examine the relationship between 5-HT. behavioral and physiological outcomes including: anxiety, depression, stress and cognition). 


\section{References}

Abbott, F.V., Etienne, P., Franklin, K. B., Morgan. M.J.s Sewitch, M.J. and Young, S.N. (1992) Acute tryptophan depletion blocks morphine analgesia in the cold-pressor test in humans. Psichopharmacology: 108: 60-6

Biggio. G. Fadda, F.. Fanni, P.. Tagliamonte. A. and Gessa, GL. ( 1974 ) Rapid depletion of serum tryptophan, brain tryptophan. serotonin and 5 hydroxyindoletic acid by a tryptophan-free diet. Life Sciences. 14: 1321-1329.

Blokland, A., Lieben, C. and Deut, N.E. (2002) Anxiogenic and depressive-like effects, but no cognituve deficits, after repeated moderate tryptophan depletion in the rat. I Psychopharmacol 16: $39-49$.

Brown, C.M., Fletcher, P.J and Coscina, D.V. (1998) Acute amino acid loads that deplete brain serotonin fail to alter behavior. Pharmacol Buchem Beha: 59: 115-21.

Dawson, V.L. and Dawson, T.M. (1996) Nitric oxide actions in neurochomistry. Neurochem lint. 29: $97-110$.

Delgado. P.L.. Chamey, D.S., Price, L.H., Landis, H. and Heninger, G.R. (1989) Neurnendocrine and behavioral effects of dietary tryptophan restriction in healthy subjects. Life $S_{c i}$. 45: 2323-32.

Djagny, V.B., Wang, Z and Xu, S. (200) Gelatin: a valuable protein for food and pharmaceutical industries: review. Crit Res. Food Sct Nim. 41: 481-92.

Dye, L.. Lluch, A. and Blundell, J.E. (2000) Macronutrients and mental performance. Nurition. 16: $1021-34$

Femsirom. J.D. (1981) Dielary precursors and brain neurotransmitter formation. Anmual Revies: of Medicine. 32: 413-425.

Fernstrom, J.D. (1994) Dictary amino acids and brain function. I Am Diet Assoc: 94: 71-7.

Fernstrom. J.D. and Wurman, R.J. (1971) Brain serotonin content: increase following ingestion of carbohydrate diet. Science. 174: 1023-5.
Fermstrom, J.D, and Wurtman, R.J. (1997) Brain serotonin content: physiological regulation by plasma neutral amino acids. Ohes Res $5: 377-80$.

Fluttert, M., Dalm, S. and Oitzl, M.S. (2000) A refined method for sequential. blood sampling by tail incision in rats. Lab Anim. 34: 372-8.

Gessa, Gi.., Biggio, G, Fadda, F., Corsmi, G.U. and Tagliamonte, A. (1974) Effect of the oral administration of tryptophan-free amuno acid mixtures on serum tryptophan, brain tryptophan and serotonin metabolism. I Neumchem. 22: 869-70.

Groves, J.T. and Wang, C.C. (2000) Nitric oxide synthase: models and mechanisms. Curr Opin Chem. Biol 4: 687-95.

Hall, E.S., Devries, A.C., Fong. G.W., Huang. S. and Pert, A. (1999) Effects of 5.7-dihydroxytryptamine depletion of ussue serotonm levels on extracellulat serotonin in the striatum assessed with in vivo microdialysis: relationship 10 behavior. Simupe. 33: 16-25.

Harrison, A.A., Everill, B.J. and Robbins, T.W. (1997) Central 5-HT depletion enhances impulsive responding without affecting the accuracy of atlentional performance: interactions with dopaminergic mechanisms. Psychopharmacology (Bcol). 133: 329. 42

Hopkins. T.R. (1991) Physical and chemical cell disruption for the recovery of iniracellular proteins. Bimproces Techol. 12:57-83.

Jagamnathan. $V$. and Venits. J. (1997) Pharmacokinetics and CNS pharmacodynamics of the 5-HT $\mathrm{A}$ agonist buspirone in humans follow ing acute L-tryptophan depletion challenge. Mothods Find Exp Cln Pharmaind 19:351.02.

Klaassen, T. Riedel, W.J., Honig, A., Van Someren, A. Deutz, N.E.P. and Van Praag, H.M. (1999) Mood effects of 24-hour tryptophan deple. tion in healthy first degree relatives of patients with antective disorders. Biological Psychiary. 46: 48\%). 497.

Markus, C.R., Panhuysen, G. Tuiten, A., Koppeschaar, H., Fekkes, D. and Peters, M.L. (1998) Does carbohydrate-rich, protein-poot food 
prevent a deterioration of mood and cognitive performanee of stress-prone subjects when subjected to a stressful task? Appetite. 31:49-65.

Mazer, C., Muneyyirci, J., Taheny, K., Raio, N. Borella, A. and Whitaker-Azmitia, P. (1997) Serotonin depletion during synaptogenesis leads to decreased synaptic density and learning deficits in the adult rat: a possible model of neurodevelopmental disorders with cognitive deficits. Brain Res. 760: $68-73$

Moja, E.A., Cipolla, P., Castoldi, D. and Tofanetti. O. (1989) Dose-response decrease in plasma tryptophan and in brain tryptophan and serotonin after tryptophan-free amino acid mixtures in rats. Life Sci. 44:971-6.

Moore, P., Landolt. H.P., Seifritz, E., Clark, C. Bhatt, I., Kelsoe, J., Rapaport, M. and Gillin, I.C. (2000) Clinical and physiological consequences of rapid tryptophan depletion. Neuropsychopharmacologv. 23: 601-22.

Navab, F, and Winter, C'.(i (1988) Effect of aging on intestinal absorption of aromatic amino acids in vitro in the ral. Am J Phwsiol 254: G631-6.

Reilly, J.G., MeTavish. S.F.B. and Young, A.H. (1997) Rapid depletion of plasma tryptophan: a revies of studies and experimental methodology. Jumal of Psychopharmacolog: 11:381-392.
Sarwar, G and Botting. H.G. (1999) Liquid concentrates are lower, in bioavailable tryptophan than powdered infant formulas, and tryptophan supplementation of formulas increases brain tryptophan and serotonin in rats. I Nutr. 129: 1692-7.

van Eijk, H.M., Rooyakkers, D.R. and Deutz, N.E. (1993) Rapid routine determination of amino acids. in plasma by high-performance liquid chromstography with a 2-3 microns Spherisorb ODS II column. J Chromatogr. 620: 143-8.

Westerink, B.H. and De Vries, J.B. (1991) Effect of precursor loading on the synthesis rate and release of dopamine and serotonin in the striatum: a microdialysis study in conscious rats. I Neurochem. 56 : 228-33.

Williams, W.A., Shoaf, S.E., Hommer, D. Rawlings, R. and Linnoila , M. (!999) Effects of acute tryptophan depletion on plasma and cerebrospinal fluid tryptophan and 5-hydroxy. indoleacetic acid in normal volunteers. I Neurochem. 72: 1641-7.

Young. S.N. (1993). The ase of diet and dietary components in the study of factors controlling affect in humans: a review. J-Psuchiary-Neumasci. 18: $235-44$

Young, S.N., Smith, S.E., Pihi, R.O. and Ervin. F.R. (1985) Tryptophan depletion causes a rapid lowering of mood in normal mates. Psychopharmacology: 87: 173-7. 


\section{CHAPTER}



\section{Acute tryptophan}

depletion induced by a gelatin-based mixture

impairs object memory

but not affective behavior and spatial learning in the rat.

C K.J. Lieben, K.I.M. van Oorsouw, N.E.P. Deutz and A. Blokland. Published in: Behavioural Brain Research 2004; 151(1-2):53-64. 


\section{Abstract}

One manner to study the role of serotonin $(5-H T)$ in behavioral functions is through nutritional manipulation of its precursor tryptophan (TRP). By. means of the method of acute TRP depletion, plasma TRP levels can be reduced in a reversible way in both humans and rats. In the present study a TRPfree protein-carbohydrate mixture was used to investigate the behavioral effects of lowering TRP and 5-HT concentrations in aduli male rats. These animals were tested in models of anxiety (open field, home cage emergence test), depression (forced swimming test) and cognition (object recognition test and Morris water escape test). The TRP-free protein-carbohydrate mixture substantially reduced the ratio TRP/ILNAA within two and four hours by 75 and $60 \%$, respectively. It was found that four hours after administration, the treatment did not affect anxiety-related behavior nor did it cause depressivelike behavior. Also, no treatment effect was found on spatial learning performance in a Morris water escape test. On the other hand, performance in an object recognition test was clearly impaired after TRP depletion. Taken together, these data suggest that acute lowered central 5-HT levels are not associated with changes in affective behavior (i.e. anxiety and depression). but do impair object memory in adult rats.

\section{Introduction}

As an essential amino acid, L-tryptophan (TRP) is the precursor of the neurotransmitter 5-hydroxy-tryptamine (serotonin, 5-HT) (Boadle-Biber, 1993). The method of nutritional TRP depletion has been frequently used as a tool to reduce systemic TRP levels and consequently central 5-HT concentrations (Biggio et al., 1974: Gessa et al., 1974; Moja et al., 1989; Fernstrom and Wurtman, 1997). Accordingly, this non-intrusive and reversible method can be applied to investigate the role of 5-HT in behavioral functions (e.g. anxiety, sleep, aggression, memory, impulsivity) in humans as well as in animals (Young, 1996: Moore et al., 2000; Bell et al., 2001).

In a previous study, we found that in adult male rats an orally ingested TRPfree amino-acid mixture induced a moderate depletion $(38 \%)$ in the plasma TRP levels (Blokland et al., 2002). In the same study it was found that this treatment induced anxiogenic and depressive-like behavior in the rats without showing profound changes on cognitive performances such as spatial learning and attention. In one other study, using the same amino acid mixture composition, also a moderate depletion of 5-HT was obtained (Brown et al., 
1998). However, no behavioral (locomotor activity, DRL20 schedule of reinforcement and paw lick latency) effects were observed. It could be argued that more substantial depletion of TRP and central 5-HT could lead to more robust effects on behavior. Moreover, human studies usually investigate behavioral effects after an $80-90 \%$ reduction in peripheral plasma TRP levels. Achieving a similar degree in plasma TRP depletion in humans and rats would allow a better inter-species comparison in behavioral effects.

Recently, we developed an alternative method to obtain a substantial reduction in plasma TRP levels in adult male rats. Using a gelatin-based-carbohydrate mixture led to a more robust reduction in plasma TRP (about $70 \%$ ) and central tissue 5-HT (about 40\%) concentrations (Lieben et al., 2004).

In the present study we examined the effects of this TRP-free protein-carbohydrate mixture on affective and cognitive behavior in adult male Wistar rats. The animals were tested in models of anxiety (open field test and home cage emergence test), depression (forced swimming test) and cognition (object recognition test; Morris water escape test). The magnitude of TRP depletion was verified by quantifying plasma amino acid concentrations.

\section{Materials and methods}

\section{Animals}

All experimental procedures were approved by the local ethical committer of the Maastricht University for animal experiments and met governmental guidelines. Subjects were twenty-four 4-month-old male Wistar rats (Charles River, the Netherlands), weighing between 315 and $395 \mathrm{~g}$ at their arrival. The rats were housed two per cage in standard Makrolon cages on sawdust bedding in an air-conditioned room $\left( \pm 20^{\circ} \mathrm{C}\right)$. The animals had free access to water. They were kept under a reversed 12/12-h light/dark cycle. The lights were on from $06.00-18.00 \mathrm{~h}$. A radio, which was playing softly, provided background noise.

\section{Drugs and chemicals}

The Gelatin hydrolysate (Solugel $C^{x}$ ) was obtained from $P B$ Gelatins (Tessenderlo, Belgium). Glucodry 200 was obtained from the Amylumgroup (Koog aan de Zaan. The Netherlands). L-tiyptophan, L-tyrosine and L-norvaline were from Sigma (Zwijndrecht, The Netherlands). Potassiumchloride (KCl), calciumchloride-dihydrate $\left(\mathrm{CaCl}_{2}, 2 \mathrm{H}_{2} \mathrm{O}\right)$ and 5 -sulfosalicylic acid dihydrate were purchased from Merck (Darmstadt, Germany). 
Table 1: Composition of mixture and determination of the amino acids in gelatin-based protein (mol).

The composition of the mixture $(g)$ used in this experiment is described in italic. The amino acid spectrum $(\%)$ of the Solugel C protein was obtained from PB Gelatins, Tessenderlo, Belgium.

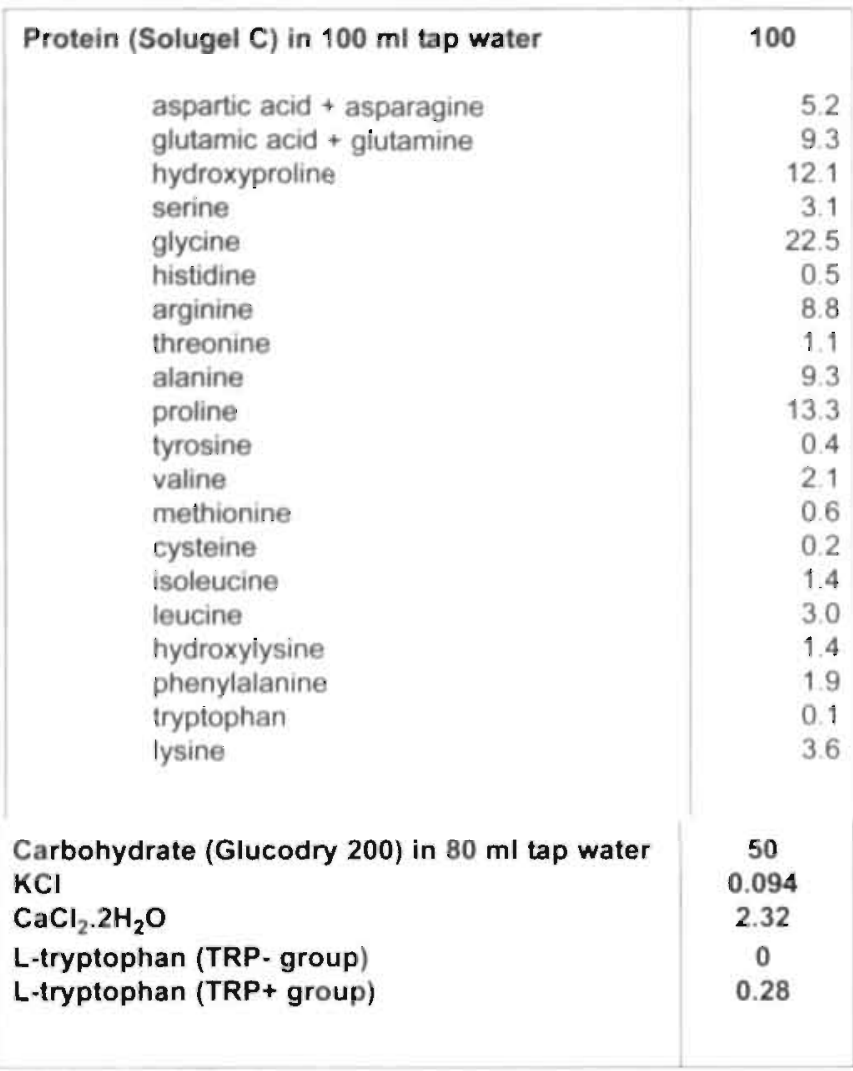

Table 2: Order and duration of the different behavioral experiments.

The last column indicates whether the rats received treatment, the number indicates the number of days treatment was given.

\begin{tabular}{|c|c|c|}
\hline \multicolumn{2}{|c|}{ Week Test } & Treatment \\
\hline 1 & arrival and handling & 0 \\
\hline 2 & handling & 2 \\
\hline 3 & forced swimming test & 3 \\
\hline 4 & open field test & 4 \\
\hline 5 & home cage emergence test. & 3 \\
\hline 6 & blood sampling & 1 \\
\hline 7 & object recognition test: training & 0 \\
\hline 8 & object recognition test training & 0 \\
\hline 9 & object recognition test: testing & 3 \\
\hline 10 & Morris water escape test & 5 \\
\hline
\end{tabular}




\section{Treatment}

During a period of two weeks preceding the experiment, the rats were handled and habituated to oral injections with normal tap water $(10 \mathrm{ml} / \mathrm{kg})$. Afterwards, they were matched for body weight and randomly assigned to one of the three experimental groups $(n=8 /$ group). They were orally treated with saline or with a protein-carbohydrate mixture containing TRP (TRP+ group, $0.28 \%$ TRP of the total protein) or one lacking TRP(TRP-group). The composition of the nutritional mixture is shown in Table 1.

The rats were fasted $14 \mathrm{~h}$ prior treatment until the testing period was completed. This was done to minimize the availability of TRP from food. On every experimental day, between $08.30 \mathrm{~h}$ and $11.30 \mathrm{~h}$, the animals were orally injected twice, with a 90 min interval. Each administration contained $4.0 \mathrm{~g}$ Solugel $\mathrm{C} / \mathrm{kg}$ and $2.0 \mathrm{~g}$ Glucodry $/ \mathrm{kg}$ of the body weight and. was given in a volume of $10 \mathrm{ml} / \mathrm{kg}$. Behavioral testing was conducted $4 \mathrm{~h}$ after the first oral administration. At the end of each testing day, the animals received their daily food ration $(-10 \mathrm{~g})$. An overview of the order of testing and the number of times the rats were treated with the mixture is given in Table 2 .

\section{Biochemistry}

For the determination of plasma amino acid levels blood samples were taken at resting values (i.e. $10 \mathrm{~min}$ before the first oral administration) and repeated at 2, 4 and $6 \mathrm{~h}$ after the first administration. Blood sampling was done via a tail-incision method (Fluttert et al., 2000). Promplly after collection of blood in a sodium heparin tubes (Microvette ${ }^{x}$ CB 300, Sarstedt, Germany), the samples were kept on ice. After centrifugation of the blood samples (at $4{ }^{\circ} \mathrm{C}$ : for $15 \mathrm{~min}$ at $3000 \mathrm{~g}$ in a Hettich EBA 12 centrifuge), plasma was deproteinized with cups containing dry 5-sulfosalicylic acid $(6 \mathrm{mg} / 100 \mu$ l plasma $)$ and the protein was spun down. Samples were frozen in liquid nitrogen and stored at $-80^{\circ} \mathrm{C}$.

Before analysis. samples were thawed at $4{ }^{\circ} \mathrm{C}$, vortex-mixed vigorously and centrifuged at $50,000 \mathrm{xg}$ in a Hereaus Model Biogufe Stratos for $10 \mathrm{~min}$ at $4^{\circ} \mathrm{C}$. From the clear supernatant $20 \mu \mathrm{l}$ was mixed with $1960 \mu \mathrm{l}$ water and $20 \mu \mathrm{l}$ norvaline and stored in the cooled $\left(7^{\circ} \mathrm{C}\right)$ sample compartment until analysis.

In addition to total plasma TRP, the concentrations of 19 other amino acids were determined with a fully automated high-performance liquid chromatrography (HPLC) system after precolumn derivatization with o-phthaldialdehyde (OPA) (van Eijk et al., 1993). OPA-AA derivates were quantified with fluorescence detection. The concentrations of the total plasma amino acids were expressed as $\mu \mathrm{mol} / \mathrm{l}$. 


\section{Behavior}

\section{Open field test}

Testing was conducted in a square, clear Plexiglas box $(100 \mathrm{~cm} \times 100 \mathrm{~cm} x$ $30 \mathrm{~cm}$ ), with an open top and a dark floor. The arena of the open field (OF) was subdivided in 'corner' (four squares each $16 \mathrm{~cm} \times 16 \mathrm{~cm}$ ), 'wall' (four rectangles each $16 \mathrm{~cm} \times 64 \mathrm{~cm}$ ) and 'center' (one square $64 \mathrm{~cm} \times 64 \mathrm{~cm}$ ) zones. The OF was placed on the floor of an experimental room. A camera was installed $2.5 \mathrm{~m}$ above the center of the field. Immediately after a rat was placed in the center of the OF, the movements and position of the animals were recorded and registered automatically by a computerized system (EthoVision. Noldus Equipment, The Netherlands). Only the total duration of rearing and leaning (i.e. rearing but making contact with the fore paws against the wall) was manually recorded. The illumination of the room was reduced to 60 Lux on the floor of the apparatus. Testing was carried out on four consecutive days. The floor of the OF was cleaned with a damp sponge after each session, which lasted $5 \mathrm{~min}$, to prevent transmission of olfactory cures. OF behavior was tested between $13.30 \mathrm{~h}$ and $17.00 \mathrm{~h}$. The data of the OF test were aggregated over four days to enhance reliability (Ossenkopp and Mazmanian, 1985). These aggregated data in the open field test strongly correlate with definitions of anxiety in other models like the plus maze and the light dark box (Blokland et al., 1992; Prickaerts et al., 1996; van der Staay and Blokland, 1996). Three dependent variables are reported: the mean time spent in each zone of the OF, the mean distance moved and the mean time of rearing and leaning in the entire apparatus.

\section{Home cage emergence test}

In the home cage emergence test (HCET), the home cage was placed in the arena of the open field and the lid of the home cage was removed (Prickaerts et al.. 1996). During the testing of one rat, the other rat was placed in another cage. A grid was placed over the edge of the cage to make it easier for the rats to leave the home cage. The test room was darkened, providing very dim illumination ( -5 Lux ) on the floor of the apparatus. A stopwatch was used to measure the latency to leave the cage. The experimenter measured the time it took for the rat to climb out of its cage into the open field. A criterion was set to determine the escape time. The two hind legs had to be over the edges of the cage. If the rat did not emerge from its home cage within $300 \mathrm{~s}$, the session was ended, the home cage was closed again and the rat was given a score of 300 . This test was carrier out on three consecutive days. 
Four cylindrical glass tanks ( $40 \mathrm{~cm}$ length $\times 17 \mathrm{~cm}$ diameter) of $23^{\circ} \mathrm{C}$ water, filled to a depth of $30 \mathrm{~cm}$, were used in this test. When the animals were placed in the water, their movements were tested in 5-min test sessions. Testing was carried out over three consecutive days. The behavioral variable 'immobility' was defined as follows: making no movements or only making those movements that were necessary to keep the nose above the waier. It was allowable for the rats to move their forepaws or support themselves by pressing their paws against the wall of the cylinder. Active climbing and swimming along the wall were not scored as immobility.

\section{Object recognition test}

The object recognition test (ORT) was performed as described in detail elsewhere (Ennaceur and Delacour, 1988; Prickaerts et al., 2002). The apparatus consisted of a circular arena, $83 \mathrm{~cm}$ in diameter. Half of the $40-\mathrm{cm}$ high wall was made of grey polyvinyl chloride, the other half of transparent polyvinyl chloride. The light intensity (20 Lux) was equal in the different parts of the apparatus. We used four different sets of objects that could not be displaced by a rat. Each object was available in triplicate. The different objects were: (1) a cone consisted of a grey polyvinyl chloride base (maximal diameter $18 \mathrm{~cm}$ ) with collar on top made of brass (tolal height $16 \mathrm{~cm}$ ), (2) a standard I I transparent glass bottle (diameter $10 \mathrm{~cm}$, height $22 \mathrm{~cm}$ ) filled with water, (3) a massive metal cube $(10 \mathrm{~cm} \times 5 \mathrm{~cm} \times 7.5 \mathrm{~cm})$ with two holes (diameter $1.9 \mathrm{~cm}$ ), and (4) a massive aluminium cube with a tapering top (13 $\mathrm{cm} \times 8 \mathrm{~cm} \times 8 \mathrm{~cm}$ ).

In the week preceding testing, the animals were adapted to the procedure, i.e., they were allowed to explore the apparatus (without any objects) twice for 3 min each day. In the three following days, the rats were trained until a stable discrimination performance was shown. A testing session comprised two trials. The duration of each trial was $3 \mathrm{~min}$. Two objects were plac $\mathrm{d}$ in a symmetrical position about $10 \mathrm{~cm}$ away from the grey wall. A rat was always placed in the apparatus facing the wall at the middle of the front (transparent) segment. During the first trial ( $\mathrm{T} 1$ ) the apparatus contained two identical objects. After the first exploration period the rat was put back in its home cage. One hour later the rat was put back in the apparatus for the second trial (T2), but now with dissimilar objects, a familiar one and a new one. The duration of exploring each object in $\mathrm{T} 1$ and $\mathrm{T} 2$ was recorded manually with a personal computer. Exploration was defined as directing the nose to the object at a distance of no more than $2 \mathrm{~cm}$ and/or touching the object with the nose. 
Sitting on the object was not considered as exploratory behavior. In order to avoid the presence of olfactory trails, the objects were always thoroughly cleaned. Moreover, each object was available in triplicate so that none of the two objects from the first trial had to be used as the familiar object in the second trial. In addition, all combinations and locations of objects were used in a balanced manner to reduce potential biases due to preferences for particular locations or objects.

After the rats were familiarized to the procedures of the task, testing with treatment began. The first trial was given $4 \mathrm{~h}$ after the first oral administration. The delay interval of $1 \mathrm{~h}$ was preferable since during this time, we expected the plasma TRP levels to remain at low level. Testing sessions were given on three consecutive days. After the rats were given food ad libitum, the animals were again tested in the ORT using a 1-h delay. Note that the animals were not treated in this fourth session with the protein-carbohydrate mixture.

The basic measures were the total exploration time of both objects during T1 and $\mathrm{T} 2, e /$ and $e 2$, respectively. We used a criterion of at least $10 \%$ above mean for a minimum exploration values to avoid possible erroneous conclusions. A discrimination index $d 2(d 2=$ (exploration new object exploration familiar object)/total exploration time during test trial) were calculated. The data of the three testing sessions were collapsed per treatment condition to enhance the reliability of the data.

\section{Morris water escape test}

The performance in the Morris water escape test (MWET; (Morris et al., 1982)) was assessed in a water tank which consisted of a circular black polyethylene tub with a slightly sloping wall (Inner dimensions: diameter at top $153 \mathrm{~cm}$, diameter at bottom $143 \mathrm{~cm}$; depth: $63 \mathrm{~cm}$ ). filled with clear tap water at a temperature of approximately $22^{\circ} \mathrm{C}$. The water tank was situated in a room illuminated by white fluorescent strip lights. Abundant extra-maze cues were provided by the furniture in the room, including desks, computer equipment, a second water tank, the presence of the experimenter, and by a radio on a shelf that was playing softly. The invisible escape platform consisted of a black polyethylene cylinder (diameter $10.8 \mathrm{~cm}$ ), submerged 1.5 $\mathrm{cm}$ below the surface of the water and was placed at a fixed position in one of the quadrants. Each rat was daily subjected to a session of four trials with a $10 \mathrm{~min}$ inter-trial interval for four consecutive days. On each trail, the rats were placed in randomly chosen starting positions (north, east, south, west). facing the wall of the tank and were trained to find the platform within $60 \mathrm{~s}$. If a rat did not find the platform within this time, it was placed on the 
platform for $3 \mathrm{~s}$ and then removed from the water tank. On the fifth session, the animals were given a probe trial to reveal whether they actually learned the position of the platform. For this purpose the platform was removed from the water tank and the behavior of the rats was monitored during $30 \mathrm{~s}$. All rats started from the same start position, opposite to the quadrant where the escape platform had been positioned during acquisition.

Registration of the behavior of the rats during all trials was automatically done by a video camera, mounted in the center above the pool, thereby using a video tracking system (EthoVision) and stored on a computer. As indices on performances in acquisition learning, the time latency (i.e. the time it took the animals to find the platform) was analyzed. In the analysis of the probe trial the time the rats spent in each quadrant was evaluated. Comparable to the other behavioral tests, $4 \mathrm{~h}$ after the first administration testing was started. Since several trials were given within every session, testing continued for 30 min, when the last trial of that session was given.

\section{Statistical analysis}

Mean total plasma amino acid concentrations, the TRP/LLNAA ratio) (LNAA; large neutral amino acids, i.e., tyrosine, phenylalanine, leucine, isoleucine and valine) and all behavioral variables were calculated for each group on four points in time. In the home cage emergence test, the data were not normally distributed since some rats remained in the home cage for the entire observation period. These data were transformed to rank scores. For all variables, treatment effects were analyzed using parametric statistics (ANOVA). In the OF and ORT, a one-factorial ANOVA was used to analyze the effects between groups. To examine interactions between Treatment and Time effects a repeated measurements analysis was used for plasma amino acid concentrations and behavioral variables in FST, HCET and MWM. To further characterize the differences between groups a post-hoc Bonferroni t-test $(p<0.05)$ was used.

\section{Results}

\section{Biochemistry}

In the majority of amino acids, the change of plasma concentrations over time was affected by treatment (see Table 3). Post-hoc analysis revealed that the levels in both groups treatment with the protein-carbohydrate mixture (i.e. 
TRP-and TRP+) differed from the saline group. Although the levels of amino acids were not affected by treatment, interaction effects were found in the levels of GLU, LEU, MET and TAU $[F \mathrm{~s}, p<0.05]$ but not in HIS an THR [ $F \mathrm{~s}$, n.s.]. The change in concentrations of ILE and LYS over time was similar for the three groups [Treatment; $F$ s, $p<0.05$ ].

TRP levels changed over the $6 \mathrm{~h}$ [Time: $F(3,45)=23.98, p<0.01]$. There was a clear treatment effect $[F(2,15)=27.87, p<0.01]$, and an interaction effect [Time $x$ Treatment: $F(6,45)=14.40, p<0.01]$. Fig. 1, shows that this effect was most prominent in the TRP-group, whereas a modest change was observed in the TRP+ and saline group. Comparing to resting levels, a reduction in TRP/LLNAA values of 70,65 and $49 \%$ was found in the TRP-group, 2,4 and $6 \mathrm{~h}$ after administration, respectively.

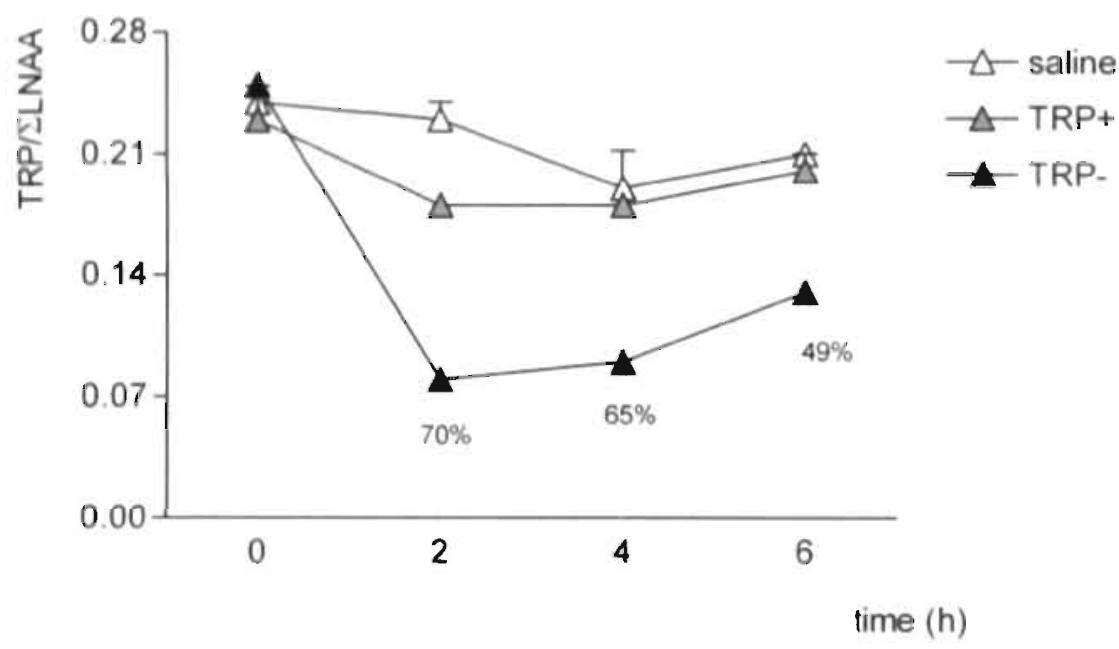

Fig. 1.: Values of the ratio TRP/LLNAA at rest, 2,4 and $6 \mathrm{~h}$ after the first oral administration of the protein-carbohydrate mixture with $(T R P+)$, without (TRP-) TRP or saline. Data represents mean + SEM with an $n=8$ rats/group. 
Table 3: Plasma AA concentrations at resting level and 2 and $4 \mathrm{~h}$ after the first injection.

\begin{tabular}{|c|c|c|c|c|c|c|c|c|c|c|c|}
\hline \multirow[b]{2}{*}{ AA } & \multicolumn{2}{|c|}{ Resting level } & \multicolumn{2}{|c|}{$\mathbf{t 1 2 0}$} & \multicolumn{2}{|c|}{240} & \multicolumn{2}{|c|}{ T360 } & \multirow[t]{2}{*}{ E్ } & \multicolumn{2}{|c|}{ 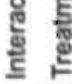 } \\
\hline & $\begin{array}{l}\text { saline } \\
\text { TRP+ }\end{array}$ & TRP- & $\begin{array}{l}\text { saline } \\
\text { TRP+ }\end{array}$ & TRP- & $\begin{array}{l}\text { saline } \\
\text { TRP+. }\end{array}$ & TRP. & $\begin{array}{l}\text { saline } \\
\text { TRP+ }\end{array}$ & TRP- & & & \\
\hline \multirow[t]{2}{*}{$\overline{\text { GLU }}$} & $129 \pm 7$ & 147 & $124 \pm 4$ & 161 & $106 \pm 3$ & $159 \pm 12$ & $118 \pm 4$ & $87 \pm$ & + & + & \\
\hline & $160 \pm 9$ & & $141 \pm 9$ & & $142 \pm 4$ & & $122 \pm 12$ & & & & \\
\hline \multirow[t]{2}{*}{ ASN } & $67 \pm 3$ & $61 \pm$ & $72 \pm 1$ & 3 & $67 \pm 2$ & 45 & $70 \pm 2$ & $42:$ & + & + & \\
\hline & $64 \pm 2$ & & $42 \pm 1$ & & $45 \pm 1$ & & $48 \pm 1$ & & & & \\
\hline \multirow[t]{2}{*}{ SER } & $288 \pm 11$ & 257 & $295 \pm 7$ & 375 & $281 \pm 7$ & 379 & $276 \pm 6$ & $406 \pm$ & + & + & \\
\hline & $284 \pm 8$ & & $417 \pm 9$ & & $429 \pm 13$ & & $468 \pm 13$ & & & & \\
\hline \multirow[t]{2}{*}{ GLN } & $721 \pm 12$ & $647 \pm 4$ & $822 \pm 12$ & $613 \pm 15$ & $799 \pm 13$ & $645 \pm 16$ & $819 \pm 15$ & $690 \pm 9$ & + & + & \\
\hline & $688 \pm 8$ & & $634 \pm 21$ & & 623 & & 23 & & & & \\
\hline \multirow[t]{2}{*}{ HIS } & $75 \pm 4$ & $76 \pm 2$ & & $66 \pm 9$ & 6 & $89 \pm 4$ & & $52:$ & + & - & - \\
\hline & $80 \pm 2$ & & 0 & & 3 & & 1 & & & & \\
\hline \multirow[t]{2}{*}{ GLY } & $427 \pm$ & $389 \pm$ & 161 & 1202 & $434 \pm 15$ & 1184 & $458 \pm 9$ & $1378 \pm 62$ & + & + & i \\
\hline & 410 & & 54 & & 52 & & \pm 20 & & & & \\
\hline \multirow[t]{2}{*}{ THR } & 256 & 225 & 24 & $233 \pm 5$ & 7 & $220 \pm$ & $247 \pm 6$ & 219 & + & - & - \\
\hline & 239 & & & & 7 & & & & & & \\
\hline \multirow[t]{2}{*}{ CIT } & $77=$ & $74 \pm 4$ & & $100 \pm 2$ & \pm 2 & $98 \pm 1$ & 4 & $105 \pm 1$ & + & + & + \\
\hline & & & & & & & & & & & \\
\hline \multirow[t]{2}{*}{ ARG } & 14 & $145 \pm 3$ & 13 & 262 & $152 \pm 16$ & $208 \pm 8$ & $130 \pm 1$ & $231 \pm 24$ & + & + & + \\
\hline & $1:$ & & & & & & & & & & \\
\hline \multirow[t]{2}{*}{ ALA } & $283 \pm 13$ & $313 \pm 12$ & $279 \pm 16$ & $417 \pm 20$ & $240 \pm 18$ & $358 \pm 14$ & $249 \pm 7$ & $307 \pm 16$ & + & + & + \\
\hline & $308 \pm 6$ & & & & $347 \pm 21$ & & $332 \pm 19$ & & & & \\
\hline \multirow[t]{2}{*}{ TAU } & $230=$ & $199 \pm 11$ & 12 & $200 \pm 10$ & \pm 21 & $303 \pm 37$ & \pm 38 & $231 \pm 15$ & + & + &  \\
\hline & 212 & & 20 & & 15 & & 27 & & & & \\
\hline \multirow[t]{2}{*}{ MET } & 69 & $50 \pm 1$ & 5 & $72 \pm 3$ & & $49 \pm 1$ & 3 & $74 t$ & + & * & - \\
\hline & 74 & & 2 & & & & & & & & \\
\hline \multirow[t]{2}{*}{ ORN } & 45 & $40 \pm 3$ & 1 & $138 \pm 6$ & $43 \pm 2$ & $103 \pm 5$ & $47 \pm 2$ & 104 & + & + & + \\
\hline & & & & & & & & & & & \\
\hline \multirow[t]{2}{*}{ LYS } & $409 \pm 14$ & $390 \pm 16$ & 17 & $458 \pm 12$ & $413 \pm 14$ & $407 \pm 17$ & 440 & $437 \pm 4$ & + & . & + \\
\hline & & & & & & & & & & & \\
\hline \multirow[t]{2}{*}{ ILE } & $89 \pm 3$ & $74 \pm 2$ & 3 & $83 \pm 2$ & 5 & $96 \pm 2$ & $113 \pm 3$ & 96 & + & - & + \\
\hline & & & & & & & & & & & \\
\hline PHE & $74 \pm$ & $68 \pm 3$ & 1 & $85 \pm 3$ & $71 \pm 5$ & $91 \pm$ & $86 \pm 2$ & 97 & + & + & + \\
\hline & & & & & & & & & & & \\
\hline TYR & $57 \pm 3$ & $52 \pm 1$ & $55 \pm 2$ & $41 \pm 1$ & $57 \pm 2$ & $37 \pm 0.4$ & $75 \pm 1$ & $46 \pm 1$ & + & + & + \\
\hline & & & & & & & & & & & \\
\hline LEU & $144 \pm 12$ & $113 \pm$ & $133 \pm 5$ & $115 \pm 15$ & $133 \pm 6$ & $154 \pm 9$ & $141 \pm 2$ & $168 \pm 9$ & + & + & $=$ \\
\hline & & & $159 \pm 11$ & & $173 \pm 11$ & & & & & & \\
\hline VAL & $166 \pm 4$ & $149 \pm 3$ & $164 \pm 6$ & $218 \pm 6 i$ & $177 \pm 6$ & $231 \pm 7$ & $182 \pm 3$ & $210 \pm 9$ & + & + & + \\
\hline & & & $230 \pm 11$ & & & & & & & & \\
\hline TRF & $120 \pm 6$ & $117 \pm 2$ & $117 \pm 5$ & $41 \pm 2$ & $102 \pm 12$ & $53 \pm 2$ & $126 \pm 4$ & $82 \pm 4$ & + & + & + \\
\hline & $105 \pm 7$ & & $109 \pm 6$ & & $110 \pm 3$ & & $123 \pm 4$ & & & & \\
\hline
\end{tabular}

Absolute plasma AA concentrations $(\mu \mathrm{mol} / \mathrm{l})$ at resting levels $\left(t_{-10}\right)$, twa $\left(t_{120}\right)$, four $\left(t_{240}\right)$ and six $\left(t_{360}\right)$ hours after the first injection (mean $\pm S E M$ ) in animal treated with saline or with a proteincarbohydrate diet with (TRP+) or without (TRP-) TRP. Treatment effects between groups, effects over time and interaction effects between Treatment and Time were denoted with $+(p<0.05)$. GLU: glutamate, ASN: asparagine. SER: serine, GLN: glutamine, HIS: histidine, GLY glycine. THR: threonine, CIT: citrulline, ARG: arginine, ALA: alanine, TAU: taurine, MET methionine. ORN ornitine, LYS:Iysine, ILE: isoleucine. PHE: phenylalanine, TYR. tyrosine, LEU: leucine, VAL: valine, TRP: tryptophan. 
Also plasma TYR levels decreased over time $[F(3,45)=43.77, p<0.01]$ Post-hoc analysis showed that TYR levels were lower in the TRP+ and the TRP- group when compared with the saline group. However, TYR level: remained stable over time in the saline group. This resulted in an interactior effect [Time x Treatment, $F(6,45)=14.00, p<0.01$ ].

\section{Behavior}

\section{Open field test}

In Fig. 2., the data of the open field are depicted. The amount of time spent it the different zones of the open field was comparable for all groups $[F(2,21)$. 1.28, n.s.]. Also, the activity was similar between groups as indicated by the total distance moved $[F(2,21)=1.30$, n.s.]. The total amount of tim vertically exploring the environment (i.e. rearing and leaning) did not diffe between groups $[F(2,21)<2.02$, n.s.; data not shown]. There was a strong neg ative correlation between the corner time and the total distance mover $[r=-0.94, p<0.01]$.

\section{Ilome cage emergence test}

No change in escape latency occurred in the animals over the trials $[F(2,42)=$ $0.00, \mathrm{n} . \mathrm{s}$.$] , nor an interaction effect was found [Trial \mathrm{x}$ Treatment: $F(2,42)=$ 0.90, n.s. J. It took all groups an equal amount of time to leave the home cage $[F(2,21)=1.91$, n.s.; data not shown $]$.

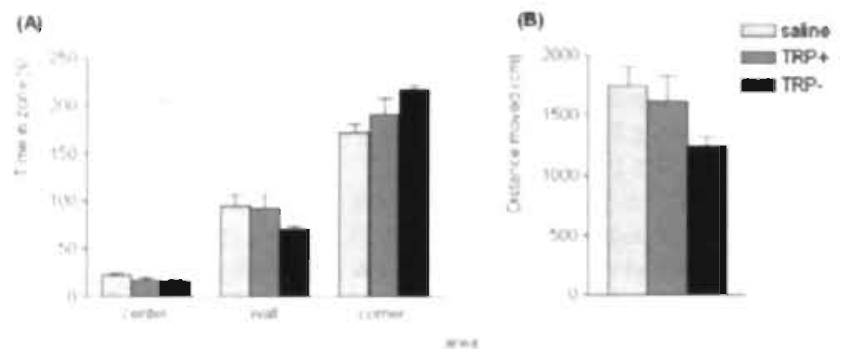

Fig. 2: Effects of TRP depletion on open field behavior. (A) Time spent in the different zones of the open field: (B) Total distance moved in the arena in the open field. Data represent aggregated data of four 5-min sessions. Values are mean + SEM of 8 rats treated with the protein-carbohydrate mixture with (TRP+), without (TRP-) TRP or saline 


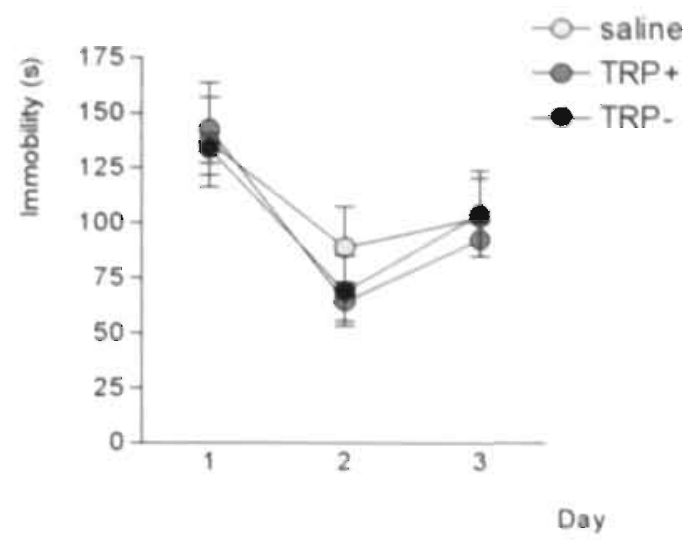

Fig. 3. Effects of TRP depletion on the immobility score in the forced swimming test on three successive days. Values are mean + SEM of 8 rats treated with the protein-carbohydrate mixture with (TRP+), without (TRP-) TRP or saline.

\section{Forced swimming test}

The scores of immobility changed over. time $[F(2,38)=19.89, p<0.01]$. Especially, after the first exposure to this inescapable situation, the rats become more active (Fig. 3.). This decrease in immobility was similar in all groups [Trial x Treatment: $F(4,38)=0.37$, n.s.] and was not affected by Treatment $[F(2,19)=0.27$, n.s. $]$.

\section{Object recognition test}

The effects of treatment on the performance in the ORT are summarized in Table 4. In general, treatment did not affect the exploration time in $\mathrm{T} 1$ or $\mathrm{T} 2$ $\lfloor F(2,67)<2.68$, n.s.]. A clear group difference was found for the discrimination index $(d 2)[F(2,67)=10.46, p<0.001$; Fig. 4A.]. Post-hoc analysis revealed that the $d 2$ scores of the TRP-group were lower when compared with the TRP+ and saline group. The TRP- treated rats did not discriminate between the novel and the known object in $\mathrm{T} 2$ after a one hour interval. In contrast, the TRP+ and saline treated animals showed a high preference to investigate the novel object.

In the additional session in which the animals were not treated, no differences were found between groups in exploration times of both $\mathrm{T} 1$ and $\mathrm{T} 2[F(2,21) \mathrm{K}$ 0.62 . n.s.]. Independent from prior treatment, the animals performed equally well on the discrimination index $(d 2)[F(2,21)=0.50$, n.s.; Fig. 4B. $]$. Rats previously treated with the TRP lacking mixture again recognized the objects sin $1 \mathrm{~h}$ before lesting. 
Table 4: Results of treatment on the measures of the object recognition test. Mean values ( \pm SEM) of the total exploration time(s) (s) during the first (e1) and second $(e 2)$ trial. In the first three sessions, the first administration of the protein-carbohydrate mixture with (TRP+) or without (TRP-) TRP or saline was given $4 \mathrm{~h}$ before testing. Performance of every treatment condition was collapsed over three session ( $A, n=24$ observations/treatment). In an additional sessions (B) the rats were not treated $(n=8)$.

\begin{tabular}{|c|c|c|c|}
\hline & Saline & TRP+ & TRP. \\
\hline \multicolumn{4}{|c|}{ (A) Treatment session } \\
\hline$\theta 1$ & $54.4(4.17)$ & $41.3(3.45)$ & $47.7(4.09)$ \\
\hline$e 2$ & $55.3(4.92)$ & $59.0(4.85)$ & $55.9(4.49)$ \\
\hline \multicolumn{4}{|c|}{ (B) Non-treatment session } \\
\hline e1 & $39.1(8.3)$ & $41.1(13.6)$ & $53.8(7.3)$ \\
\hline e2 & $66.7(9.1)$ & $58.7(5.1)$ & $66.8(5.1)$ \\
\hline
\end{tabular}

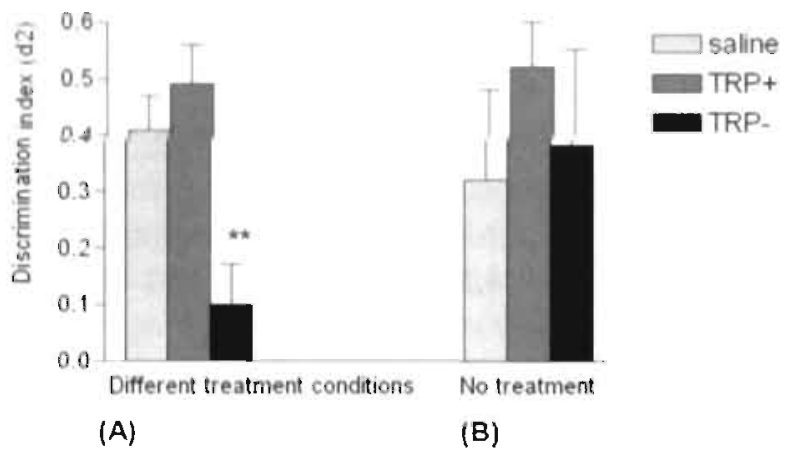

Fig. 4.: Effects of TRP depletion on the discrimination index ( $(d 2)$ in the object recognition test. (A) Treatment sessions. Values are mean of three sessions + SEM of 8 rats treated with the protein-carbohydrate mixture with (TRP+), without (TRP-) TRP or saline. (B) Control session on day four. Values are mean + SEM of 8 rats. Treatment effect on the $d 2$ measure is depicted with a double asterisk (** $p<0.01)$.

\section{Morris water escape test}

The time needed to find the platform during the acquisition of the MWET was similar for all groups $[F(2,18)=0.20$, n.s.]. All animals found the platform faster over days $[F(3,54)=121.88, p<0.001 ;$ Fig. 5.]. In the probe trial, the animals of all groups spent equal time in the zone where the platform was located during acquisition $[F(2,20)=1.70$, n.s.: Fig. 5. $]$. 


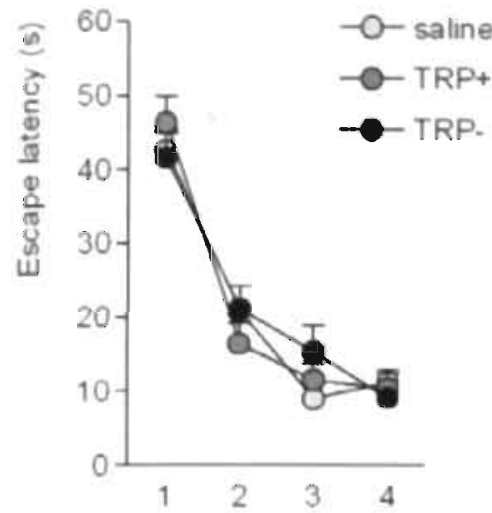

(A)

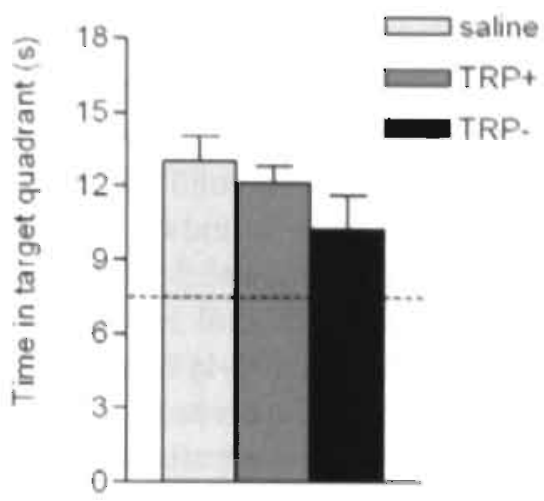

(B)

Fig. 5: Effects of TRP depletion on Morris water escape test. (A) time spent in the arena during four successive learning sessions; (B) time spent in the training quadrant (i.e. location of the escape platform) in the probe trial. Values are mean + SEM of 8 rats (reated with the protein-carbohydrate mixture with (TRP+), without (TRP-) TRP or saline. A dashed line is drawn at $7.5 \mathrm{~s}$, which indicates the time that animals would have spent in this training quadrant at chance level.

\section{Discussion}

In the present study, the effects of TRP depletion using a gelatin-based-carbohydrate mixture were examined in adult male rats tested in animal models of anxiety, depression and cognition. The TRP deficient protein-carbohydrate mixture induces a substantial reduction in plasma TRP levels. Although this treatment did not affect anxiety- and depressive related behavior, it clearly impaired object recognition. Spatial learning and memory was not affected by the acute TRP depletion.

The putative role of 5-HT in several neuropsychological functions is still a matter of debate. A serotonergic deficiency has been accepted as an underlying physiological mechanism in major depression (Meltzer, 1989; Charney, 1998). Furthermore compounds promoting the release of 5-HT induce a reverse in symptomatology related to depression. In contrast to chronic methods to reduce 5-HT concentrations (i.e. 5,7-dihydroxytryptamine (5,7-DHT) and p-chlorophenylalanine (PCPA)), the method of TRP depletion 
is regarded as a valid and acute model to investigate the function of 5-HT in both humans and animals. Frequently, a nutritional mixture composed of several amino acids, except for TRP, is applied to deplete plasma TRP levels thereby reducing 5 -HT levels. To estimate the treatment effects on central $5-\mathrm{HT}$ levels, the ratio of TRP/ $/$ LNAA is mostly calculated in human studies. Furthermore specific indications of a lowed 5-HT metabolism are found by measuring the TRP and 5-HIAA levels in central nervous fluid (Carpenter et al., 1998; Williams et al., 1999). This acute TRP depletion method was even found to affect the 5-HT synthesis and to change ERP waveforms in the posterior part of the scape (Nishizawa et al., 1997; McAllister-Williams et al., 2002). Using the same treatment in rodents can provide us with more direct central 5-HT effects. Beside lowering plasma TRP levels, the TRP lacking amino acid mixture also reduce tissue levels of 5-HT in overall brain tissue and more selective brain structures (e.g. hippocampus) in the rat (Biggio et al., 1974; Gessa et al., 1974; Moja et al., 1989; Brown et al.. 1998). A TRP depletion also lowered the extracellular levels of 5-HT in the hippocampus (Stancampiano et al., 1997b). However, Bel et al. (1996) showed that this TRP-free amino acid mixture reduced cortical levels of 5-HT dialysate in rats pretreated with a selective $5-\mathrm{HT}$ reuptake inhibitor but not in control animals (Bel and Artigas, 1996).

When using a similar amino acids mixture in adult male rats, we found plasma TRP levels to be moderately reduced $(38 \%)$. Though this treatment resulted in anxiogenic and depressive-like behavior in the rats, these results could not be generalised to clinical settings since the degree of depletion was not comparable to the substantial depletion in plasma TRP levels $(70-90 \%)$ in humans. Subsequently, we developed an alternative mixture to substantially reduce plasma TRP levels in the rat. We first investigated peripheral and central effects of the TRP-free protein-carbohydrate mixture (Lieben et al., 2004). In the present study the functional consequences of substantially reducing plasma TRP levels, by using a TRP-free protein-carbohydrate mixture, were iinvestigaled.

The biochemical data obtained with a TRP lacking protein-carbohydrate mixture showed a strong depletion in plasma TRP levels. The reduction in TRP/ $/$ LNAA ratio was most pronounced at $2 \mathrm{~h}$ after the first oral injection of the mixture was given. Although functional testing was conducted after a 4-h delay. when the TRP/LLNAA ratio was lowered by $65 \%$. In a previous study, using the same treatment, we observed a comparable reduction in plasma TRP levels. This peripheral TRP depletion was associated with a $40 \%$ reduction in 5 -HT concentrations in the different brain structures (Lieben et al., 2004). We 
assume that a comparable decrease in central tissue levels of 5-HT could be expected in the present study.

The data confirm that the method of acute TRP depletion is only transient (Jagannathan and Venitz, 1997). Plasma TRP levels started to increase back to resting level $6 \mathrm{~h}$ after the first administration of the TRP-free proteincarbohydrate mixture was given.

There were multiple reasons for using a TRP+ condition in this study. First, the only difference in the mixture composition used for the TRP-group and the TRP+ group was the presence of TRP. Thus, any dissimilarity between these groups can be attributed to the lack of TRP. Furthermore, this poinis out a more pronounced selective TRP-dependent effect than when comparing the TRP-group to the saline group. Besides this, the majority of amino acid levels decrease over time in the saline group while a general increase in concentrations was found after a protein-carbohydrate treatment. This with the exception of TYR levels, which were reduced over time in both TRP-and TRP+ group when compared to the saline group. Although this is not favorable for the selectivity of the TRP depletion treatment, this TYR reduction does not alter central dopamine levels as shown in the previous study (Lieben et al., 2004). Further, differences between TRP+ and saline were also evaluated to assess the effects of the mixture plus TRP. This was done to see whether the TRP-deficient mixture could be balanced for the reductions in plasma TRP levels and for functional changes. In this study, no differences, biochemical nor functional, were found between the TRP + group when compared to the saline group. This indicates that the TRP+ (i.e. adding TRP to the mixture) group can function as a good control treatment lor the TRP-free protein-carbohydrate mixture.

According to a classic theory, the function of 5-HT is related to the level of anxiety to which an animal is exposed (Griebel, 1996; Graeff et al., 1997). Apparently. exposing an animal to potential danger (e.g. an unfamiliar environment) results in a stimulating release of 5 -HT projected to the amygdala. Consequently, defense strategies are evoked and because the animal is then in a anxiogenic state, it will react in an appropriate way to direct danger. On the other hand, anxiety-related effects can also be measured by more conditional responds. This difference in the type of response to define anxiety-related behavior is only one factor that helps us to explain the high discrepancy in results concerning the 5-HT function on anxiety. Results can depend on the type of strain (Rex et al., 1996; Belzung, 2001) or on agerelated variability (Imhof et al., 1993; Boguszewski and Zagrodzka, 2002). Besides this. the type of test used for measuring anxiety often reflects 
different traits (e.g. exploratory behavior, conflict situation) (Griebel, 1995; File et al., 2000; Graeff, 2002). Furthermore, the method of manipulating the serotonergic system (e.g. acute or chronic) or the use of specific types of 5-HT modulating agents (receptor-specific affinities) can generate different behavioral effects (Kennett, 1992; Griebel, 1996; Andrade and Graeff, 2001; Bagdy et al., 2001). Finally, certain pharmacological compounds can have dose-dependent treatment effects on anxiety related behavior (Sanchez and Meier, 1997; Griebel et al., 2000). Hall et al. (1999) injected the neurotoxic substance 5,7-DHT centrally in rats. The moderate $(50-75 \%)$ reduction of 5 -HT levels after this treatment was related to anxiogenic effects in the open field. However, increasing the dose of this substance, thereby destroying the striatal 5-HT neurons in a greater extent $(>75 \%)$, no longer affected anxietyrelated behavior (Hall et al., 1999).

In present study, the OF test was used to measure unconditioned anxietyrelated behavior. Comparing the aggregated scores of the OF with parameters of other models of anxiety , such as the 'plus maze' and the 'light-dark box', resulted in high correlation scores and moreover, similar treatment effects were found in these dificrent tests (Blokland et al., 1992; van der Staay and Blokland, 1996). Furthermore, independent of treatment, a correlation of two behavioral aspects (i.e. the total distance moved and the time occupied in the corner squares) are replicated on frequent base in the OF, as in this experiment. Therefore it is stated that both parameters measure the same trait (i.e. emotional reactivity) (van der Staay et al., 1990). If rats experience a higher level of anxiety, they will spent more time in corner squares and will be less active or vice versa. However, in this study we found that TRP depletion did not affect anxiety-related behavior as tested in the OF (i.e. occupation time and distanced moved). In the HCET, another anxiety test based on unconditional responses, the treatment of TRP depletion did not affect explorative behavior (i.e. escape latency from home cage to explore a new environment). For further research it would be interesting to test conditional responses after depleting TRP levels.

Both the forced swimming (Porsolt) test and the learned helplessness paradigm are widely used to investigate the therapeutic potential of antidepressant compounds (Porsolt, 1979; Carpenter et al.. 1998). Consistent with clinical effects, treatment of SSRI or other 5-HT-related compounds (e.g. 5-HT1 A agonist) induce anti-depressant-like effects in rats (Schreiber and De Vry, 1993: Blier, 2001). Besides the effectiveness of these compounds and the lowering 5-HIAA levels in depressed patients, the exact relation between. 5-HT and depression is still undefined. Mood changes. as often reported by 
depressed patients, are assumed to be related to 5-HT. However, more chronic models to deplete central 5-HT levels (treatment of PCPA or 5,7-DHT) did not show consistent depressive-like symptoms. Treatment of PCPA did not affect the behavior when tested in the FST or learned helplessness (Anisman et al., 1979: Martin et al.. 1990; Cervo and Samanin. 1991; Lucki et al., 1994; Borsini and Cesana, 2001; Harkin et al., 2003). Neither did the treatment of 5,7-DHT induce depressive-like behavior in rats (Soubrie et al., 1986; Martin et al., 1990; Panocka et al., 2000; Perfumi et al., 2001). In this study, the FST was adapted to determine depressive-like behavior of the animals. Hence, we did not apply a pre-trial but exposed the treated animals successively in this test over several trials and the time of immobility was used as a reflection of behavioral despair. Our data suggest that a substantial depletion in plasma TRP levels did not affect the immobility (i.e. depressive state) of the rats.

Effects on mood after depleting TRP levels are very prominent in recovered depressed patients or people with a predispostion for depression (Delgado et al., 1990: Benkelfat et al., 1994). Reports of mood-related changes after TR.P depletion rarely appear in persons that are healthy or have a specific neurological disorder or characterisic (e.g. disease of Alzheimer, schizophrenia or neuroticism). However, in some studies depressed feelings were found when young healthy people consumed a TRP-free mixture (Ravindran et al., 1999; Luciana et al., 2001). Nevertheless, irrespective of clinical background, depleting TRP levels provoked or attenuates an impairment in cognitive functions (Stewart et al., 1998; Smith el al., 1999; Golightly et al., 200): Riedel et al., 2002; Porter et al., 2003).

The ORT was chosen to assess the effects of TRP depletion on memory performance. The selection of this test was based on a human study where TRP depletion clearly affected memory consolidation in a 15 word-learning task (Riedel et al., 1999). This specific effect of TRP depletion on memory functions was again demonstrated in other studies (Schmitt et al., 2000; Rubinsztein et al.. 2001). In these studies it has been claimed that TRP depletion impairs consolidation processes rather than acquisition and retrieval processes. Our results of the ORT corroborate this notion and show that also in rats a substantial reduction in plasma. TRP levels impairs object recognition. It should be mentioned that in our study TRP levels were low during all memory stages, (i.e. acquisition, consolidation and retrieval). Consequently, from the present data we cannot conclude that this treatment specifically affects memory consolidation in rats.

In our tests, the same group of rats were frequently subjected to the treatment. 
The tests used in this study require multiple testing to obtain valid indices of anxiety, depression and cognition. On the other hand, the behavior of the TRP- rats was always tested under the same condition suggesting that group differences were related to low 5-HT levels. To see whether multiple exposures of the same treatment have functional consequences an extra test session in the ORT was given. In this session the rats were not treated with the mixture. In this additional session, the performance on object recognition of the TRP-rats was comparable to the TRP+ and saline group. Therefore, we assume that repeated treatments the TRP-free protein carbohydrate mixture does not have prolonged effects on behavior.

The repeated testing of the rats in the successive test (Table 2) might have affected the performance from one test to the other. However, the three groups were subjected to the same series of tests, assuming that the effects of repeated testing were controlled for. On the other hand, it cannot be excluded that this successive testing could have interfered with treatment effects. This can only be tested if naïve rats are used for each individual test.

Different studies showed that manipulating the synthesis of 5-HT does not seem to have a marked effect on spatial memory functions. Neurotoxic substances (i.e. 5,7-DHT and PCPA) reduced centrai 5-HT concentrations but did not affect spatial memory functions (Richter-Levin and Segal, 1989; Riekkinen et al., 1991; Jakala et al., 1992; Lehmann et al., 2000). Also, using chronic nutritional TRP depletion method did not impair spatial learning performances in the rat (Stancampiano et al., 1997a). Even in humans, the spatial memory formation remained unchanged after a TRP-free amino acid mixture (Luciana et al, 200I). Notwithstanding the shortage of indications that lowering 5-HT would affect spatial performance, we wanted to evaluate the effect of our TRP-free protein-carbohydrate mixture in the MWET. Furthermore, part of this study was based to examine distinct effects of this treatment in two different models of cognition (i.e. ORT and MWET). Our data show that although the TRP depletion treatment impaired object recognition, it did not affect spatial learning and memory processes.

We would like to point out that spatial and object recognition was measured in different settings (e.g. higher stress conditions in the MWET). By activating the sympathetic nervous system and consequently altering metabolic functions in the rat, these stress factors can have a negative impact on the treatment effect (i.e. prolonging and reducing protein synthesis, thereby minimalizing the treatment effect of the TRP lacking mixture). Nevertheless, stress-related biases on assessing spatial memory performances can be excluded by supplying the ORT settings with a spatial feature. So, besides varying the type of object, one can also relocate the position of the 
object thereby providing a non-stressful spatial element to the test (Ennaceur et al., 1997; Mumby et al., 2002). This may be interesting aspect for further studies.

Previously we found a moderate depletion of plasma TRP levels, induced by a TRP-free amino acid mixture, to result in anxiogenic and depressive-like behavior without affecting memory performances (Blokland et al., 2002). Although a direct comparison over studies is not favorable, these results suggest the possibility that functional differences could dependent on the extent of the reduction in plasma TRP levels. However this can only be examined by using a method that can acutely lower TRP levels in different stages. Consequently, our main interest goes out to investigate whether and to what extent these behavioral disorders may be dependent to TRP and 5-HT concentrations. By manipulating the amount of protein in the mixture, the dose-dependent effects of a TRP depletion treatment on biochemical and behavioral parameters can be investigated.

In summary, although more studies using this gelatin-based protein are needed, our present findings are in line with memory impairments induced by a TRP depletion in humans without affecting mood.

\section{References}

Andrade, T.Ci and Graefi, F.G. (2001) Effect of electrolytic and neurotoxic lesions of the median raphe nucleus on anxisty and stress. Phamacel Biochem Behan: 70: 1-14.

Anisman, H., Inwin, J. and Sklar, L.S. (1979) Deficits of eseape performance following catecholamine depletion: implications for behavioral deficits induced by uncontrollable stress. Puchopharmacolog (Ber/). 64: 163-70.

Bagdy. C., Grat, M., Anheuer. Z.E., Modos, E.A. and Kantor, S. (2001) Anxiety-like effects induced by acute fluoxetine, sertraline or m-C.PP treatment are reversed by pretreatment with the $5-\mathrm{HT} 2 \mathrm{C}$ receptor antagonist SB-242084 but not the 5HTIA receptor antagonist. WAY-100635. Int J Neuropsychopharmacol. 4: 399-408.

Bel. N. and Artigas, F. (1996) Reduction of serotonergic function in rat brain by iryptophan depletion: effects in control and. fluvoxamine-treated rats. I Neurochem. 67: 669-76.
Bell, (.. Abrams, I, and Null, 1), (200)1) Tryptophan depletion and its implications for psychiaty. Br J Psychicem. 178: 399-405.

Beljung, C. (2001) The genetic basis of the pharmacological eflects of anxiolytics: a review based on rodent models. Behav Pharmacol 12:451-60.

Benkelfat, C.. E.llenbogen, M.A. Dean, P., Paimour, R.M. and Young. S.N. (1994) Mood-lowering effect of tryptophan depletion. Enhanced susceptibility in young men at genetic risk for major affective disorders. Anch Gen Psychiary. 51: 687-97.

Biggio, G., Fadda, F. Fanni, P., Tagliamonte, A. and Gessa, G.L. (1974) Rapid depletion of serum tryptophan, brain tryptophan, serotonin and 5 hydroxyindoletic acid by a tryptophan-free diet. Life Sciences. 14: 1321-1329.

Blier. P. (200I) Possible neurobiologica! mechanisms underlying faster onset of antidepressant action. I Clin Psychiatry. 62 Supn! 4: 7-1! 
Blokland, A., Lieben, C. and Deuty, N.E. (2002) Anxiogenic and depressive-like effects, but no cognitive deficits, after repeated moderate tryptophan depletion in the rat. I Psychopharmacol. 16: $39-49$.

Blokland, A., Prickaerts, J. and Raaijmakers, W. (1992) Reduced level of anxiety in adult Lewis rats after chronic ethanol consumption. Physiol Behav, 51: $245-8$.

Boadle-Biber, M.C. (1993) Regulation of serotonin synthesis. Prog Biophys Mol Biol. 60: 1-15.

Boguszewski, P and Zagrodzka, J, (2002) Emotional changes related to age in rats--a behavioral analysis. Behav Brain Res. 133: 323-32.

Borsini, F. and Cesana, R (200I) Mechanism of action of flibanserin in the learned helplessness paradigm in rats. Eur. I Pharmacol. 433; 81-9.

Brown, C.M. Fletcher, P.J. and Coscina, D.V. (1998) Acute amino acid loads that deplete brain serotonin fail to alter behavior. Pharmacol Biochem Beha: 59: 115-21.

Carpenter, J.S., Andrykowski. M.A., Wilson, J.. Hall, L.A., Rayens, M.K.. Sachs, B. and Cummingham. I.L. (1998) Psychometrics for two short forms of the Center for Epidemiologic Studies-Depression Scale. Issues Ment Health Nurs. 19: $481-94$.

Cervo, L. and Samanin. R. (1991) Effect of chronic treatment with 8-OH-DPAT in the forced swimming test requires the integrity of presy naptic serotonergic mechanisms. Parchopharmacology (Berl) 103:524-8

(barmey. DS. (1998) Monoamine dysfunction and the pathophysiology and treatment of depression. J Clin Psuchiatr: 59 Suppl 14: 11-4.

Delgade, P.1.. Chamey, D.S.. Price, L.H., Aghajanian, GiK., Landis. H. and Heninger, G.R. (1990) Serotonin function and the mechanism of antidepressant action. Reversal of antidepressant. induced remission by rapid depletion of plasma trypophan. Anch-Gen-Pswchatr: 47:411-8.

Ennaceur, A. and Delacour, J. (1988) A new onetrial test for neurobiological studies of memory in rats. 1: Bchavioral data. Behav Brain Res. 31:4759.
Ennaceur, A., Neave, N. and Aggleton, J.P. (1997) Spontaneous object recognition and object location memory in rats: the effects of lesions in the cingulate cortices, the medial prefrontal cortex, the cingulum bundle and the fornix. Exp Brain Res. 113: 509-19.

Fernstrom, J.D. and Wurtman, R.J. (1997) Brain serotonin content: physiological regulation by plasma neutral amino acids. Obes Res. 5: 377-80.

File, S.E., Kenny, P.J. and Cheeta, S. (2000) The role of the dorsal hippocampal serotonergic and cholinergic systems in the modulation of anxicty. Pharmacol Biochem Behav 66: 65-72.

Fluttert, M., DaIm, S. and Oitzl, M.S. (2000) A refined method for sequential blood sampling by tail incision in rats. Lab Anim 34: 372-8.

Gessa, Gil., Biggio, G. Faddi, F., Corsini. G.U. and Tagliamonte, A. (1974) Effect of the oral administration of tryptophan-free amino acid mixtures on serum tryptophan. brain tryptophan and serotonin metabolism. I Neurochem, 22: 869-70.

Golightly, K.I.., Lloyd. J.A., Hobson, J.E.. Gallagher. P., Mercer. G and Young. A.H. (2001) Acute iтyptophan depletion in schizophrenia. Psuchol Med 31: 75-84.

Graefl, F.G. (2002) On serotonin and experimental anxiety. Psychopharmacology (Berl). 163: 467-76.

Graeff, F.G., Viana, M.B. and Mora, P.O. (1997) Dual role of 5-HT in defense and anxiety. Neurosei Biobehav Rev: $21: 791-9$.

Griebel, G (1995), 5-Hydroxytryptamine-interacting drugs in animal models of anxiety disorders: more than 30 years of research. Pharmacol Ther. $65: 319-95$.

Griebel. G (1996) Variability in the effects of 5 HT-related compounds in experimental models of anxiety: evidence for multiple mechanisms of 5 . HT in anxiety or never ending story? Pol 2 Pharmacol 48: 129-36.

Griebel. G.. Rodgers, R.J. Perrault, Gi and Sanger. D.J. $(2000)$ The effects of compounds varying in selectuvity as $5-\mathrm{HT}(1 \mathrm{~A})$ receptor antagonists in three rat models of anxiety. Neuropharmacology: $39: 1848-57$ 
Hall, F.S., Devries, A.C., Fong. G.W., Huang, S. and Pert, A. (1999) Effects of 5,7-dihydroxytryptamine depletion of tissue serotonin levels on extracellular serotonin in the striatum assessed with in sivo microdialysis: relationship to behavior. Sinapse. 33: 16-25.

Harkin, A.. Connor, T.J., Walsh, M., St John, N. and Kelly, J.P. (2003) Serotonergic mediation of the antidepressant-like effects of nitric oxide synthase inhibitors. Neumpharmacology 44: 616-23.

Imhof, J.T., Coelho, Z.M., Schmitt, M.L., Morato, G.S and Carobrez. A.P. (1993) Influence of gender and age on performance of rats in the elevated plus maze apparatus. Behay Brain Res. 56: 177-80.

Jagannathan, V. and Venitz, J. (1997) Pharmacokinetics and CNS pharmacodynamics of the 5-HTIA agonist buspirone in humans following acute L-tryptophan depletion challenge. Methods Find Exp Clin Pharmacol 19:351-62.

Jakala, P., Sirvio, J., Riekkinen, P. Jr., Valjakka, A. and Riekkinen, P. (1992) The effects of alaproclate and p-chlorophenylalanine on cued navigation performance in rats. I Neural Transm Park Dis Dement Sect. 4: 43-52.

Kennett, G.A. (1992) 5-HTIC receptor antagenists have anxiolytic-like actions in the rat social interaction model. Psychopharmacology (Berl). 107: 379-84.

Lehmann, O., Jeltsch, H., Lehnardt, O., Pain, L., Lazarus, C. and Cassel, J.C. (2000) Combined lesions of cholinergic and semonergic neurons in the rat brain using 192 IgCiesaponin and 5.7 . dihydroxytryptamine: neurochemical and behayioural characterization. Eur $\&$ Neurosci. 12: 67-79.

Lieber, C.K., Blokland, A., Westerink, B. and Deutz, N.E. (2004) Acute tryptophan and serotonin depletion using an optimized tryptophan-free protein-carbohydrate mixture in the adult rat. Neurochem Int. 44:9-16.

Luciana, M., Burgund, E.D.. Berman, M. and Hanson, K.L. (2001) Effects of tryptophan loading on verbal, spatial and affective working memory functions in healthy adults. I Psychopharmacol. 15: $219-30$.

Lucki, I.. Singh, A. and Kreiss, D.S. (1994) Antidepressant-like behavioral effects of serotonir receptor agonists. Neumsci Bubehon Rev. 18: 85-95.

Martin, P., Beninger, R.J. Hamon, M. and Fucch. A.J. (1990) Antidepressant-like action of 8-OHDPAT, a 5-HTIA agonist, in the leamed helpless. ness paradigm: evidence for a postsynaptic mechanism. Behav Brain Res. 38: 135-44.

McAllister-Willams, R.H. Massey, A.E. and Rugg. M.D. (2002) Effects of tryptophan depletion on brain potential correlates of episodic memory retrieval. Psychopharmacologv (Berl). 160: 434-42.

Meltrer, H. (1989) Serotonergic dysfunction in depression. Br J Pswchiatry Suppl. 155 (Suppl 8): 25-3!.

Moja, E.A., Cipolla, P. Castoldı, D. and' Tofanetti, O. (1989) Dose-response decrease in plasma tryptophan and in brain tryptophan and serotonm after tryptophan-free ammo acid mixtures in rats. Life Sci. 44: $971-6$.

Moore, P., Landoli, H.P., Seifrutz, E., Clark, C.. Bhatt, T., Kelsoe, J., Rapap̧ort, M. and Gilhn, J.C. (2000) Clinical and physiological consequences of rapid tryplophan depletron. Neuropsuchopharmacolog: 23: 601:-22

Morris, R.G. Garrud, P. Rawlins, I.N and O'Keefe, 8. (1982) Place navigation impaired $\mathrm{m}$ rats with hippocampal lesions. Nanur. 297:681-3.

Mumby, D.G., Gaskin, S., Glenn, M.J., Schramek. T.E. and Lehmann, H. (2002) Hippocampal damage and exploratory preferences in rats: memory for objects, places, and contexts. Learn Mem. 9: 49-57.

Nishizawa, S. Benkelfat, C., Young, S.N., Leyton, M., Mzengeza, S., de Montigny ، C., Blier, P and Diksic, M. (1997) Differences between males, and females in rates of serotonin synthesis in human brain. Proc Natl Acad Sci US A. 94: 530x-13.

Ossenkopp, K.P. and Mazmanian. D.S. (1985). The measurement and integration of behavioral variables: aggregation and complexity as important issues. Neurobehav Toxicol Teratol, 7: 95-100

Panocka, 1., Perfumi, M., Angeletti, S., Ciccocioppo, R. and Massi, M. (2000) Effects of Hypericum perforatum extract on ethanol intake, and on behavioral despair. a search for the neurochemical systems involved. Pharmaco! Buchem Behav 66: 105-11 
Perfumi, M., Panocka, I., Ciccocioppo, R., Vitali, D., Froldi, R. and Massi, M. (200!) Effects of a methanolic extract and a hyperforin-enriched $\mathrm{CO}_{2}$ extract of Hypericum perforatum on alcohol intake in rats. Alcohol Alcohol. 36; 199-206.

Porsolt, R.D. (1979) Animal model of depression. Biomedicine. 30: 139-40.

Porter, R.J., Lunn, B.S. and O'Brien, J.T. (2003) Effects of acute tryptophan depletion on cognitive function in Alzheimer's disease and in the healthy elderly. Psychol Med 33:41-9

Prickaerts, J., Raaijmakers, W. and Blokland, A. (1996) Effects of myocardial infarction and captopril therapy on anxiety-related behaviors in the rat. Phwiol Bechaw 60: 43-50

Prickaerts, I., van Staveren, W.C., Sik, A., Markerink-van Ittersum, M. Niewohner, U., van der Staay, F I. Blokland, A and de Vente, 1. (2002) E.fects of two selective phosphodiesterase type 5 inhibitors, sildenafil and vardenafil, on object recognition memory and hippocampal cyclic (iMP levels in the rat. Neuroscience. 113:351-61.

Ravindran, A.V., Grifliths, J., Merali, Z.,Knott, V.J and Anisman, H. (1999) Influence of acute tryptophan depletion on mood and immune measures in healihy males. Psichomezuendocrinology. 24: 99113.

Rex, A., Sondern, U., Voigt, J.P., Franck, S. and Finik. 11. (1996) Sirain differences in fear-motivated behavior of rats. Pharmacol Biochem Behay. 54 : 107-11.

Richter-Levin, (i and Segal, M. (1989) Spatial porformance is severely impared in rats with combined reduction of serotonergic and cholinergic transmission, Brain Res. 477: 404-7.

Ricdel, W.J., Klaassen. T., Deut/, N.F. van Someren. A. and van Praag, H.M. (1999) Tryptophan depletion in normal volunteers produces selective imparment in memory consolidation. Pswhopharmacolog! (Berl). 141:362-9.

Riedel, W.J., Klaassen, T. and Schmitt. J.A. (2002) Tryptophan, mood, and cognitive function. Brain Behaw Immun, 16:581-9
Riekkinen, P., Jr., Sirvio, J., Valjakka, A., Miettinen, R. and Riekkinen, P. (1991) Pharmacological consequences of cholinergic plus serotonergic manipulations. Brain Res. 552: 23-6.

Rubinsztein, J.S., Rogers, R.D., Riedel, W.J. Mehta, M.A., Robbins, T.W. and Sahakian, B.J (200!) Acute dietary tryptophan depletion impairs maintenance of "affective set" and delayed visual recognition in healthy volunteers. Psychopharmacology (Berl). 154: 319-26.

Sanchez, C. and Meier, E. (1997) Behavioral profiles of SSRIs in animal models of depression, anxiety and aggression. Are they all alike? Psychopharmacology (Berl). 129: 197-205.

Schmitt, J.A., Jorissen, B.L.. Sobczak, S., van Boxtel. M.P., Hogervorst, E., Deutz, N.E. and Riedel, W.J. (2000) Tryptophan depletion impairs memory consolidation but improves focussed attention in healthy young volunteers. Joumal of Psychopharmacology. 14:21-29

Schreiber, R. and De Vry, J. (1993) Neuroanatomical basis for the antidepressant-like effects of the 5-HT(IA) receptor agonists. 8-OH-DPAT and ipsapirone in the rat forced swimming test. Behav Pharmacol. 4: 625-636.

Smith, K. A., Morris, J.S., Friston, K.J., Cowen, P.J. and Dolan. R.J. (1999) Brain mechanisms associated with depressive relapse and associated cognitive impaiment following acute tryptophan depletion. British Journal of Pstehiatrs: 174: 525-529.

Soubrie, P., Martin, P., el Mestikawy, S., Thiebot. M.H., Simon. P. and Hamon. M. (1986) The lesion of serotonergic neurons does not prevent antidepressant-indueed reversal of escape failures produced by inescapable shocks in rats. Pharmacol Biochem Behav. 25: 1-6.

Stancampiano, R., Cocco, S., Melis, F., Cugusi, C. Sarais, L. and Fadda. F. (1997a) The decrease of serotonin release induced by a tryptophan-free amino acid diet does not affect spatial and passive avoidance learning. Brain Res, 762: 269-74.

Stancampiano, R., Melis, F., Sarais, L., Cocco, S. Cugusi. C. and Fadda, F. (1997b) Acute administration of a tryptophan-frec amino acid mixture decreases 5 - HT release in rat hippocampus in vivo. Am J Physiol. 272: R991-4 




\section{CHAPTER}



\section{5,7-DHT lesion of the dorsal raphe nucleus}

impairs object recognition but not affective behavior and corticosterone response to stressor in the rat.

C K.J. Lieben, H. Steinbusch, He. Steinbusch and A. Blokland. 


\section{Abstract}

Previous studies with acute tryptophan depletion, leading to transient central 5-HT reductions, showed no effects on affective behavior but impaired object memory. In the present study the behavioral effects of a 5,7-dihydroxytryptamine $(5,7-D H T)$ lesion in the dorsal raphe were evaluated in animal models of anxiety (open field test), depression (forced swimming test), behavioral inhibition (discrete fixed interval test) and cognition (object recognition task). The corticosterone response to a stress condition was examined at several intervals after 5,7-DHT treatment.

The substantial reduction in neuronal 5-HT markers in the dorsal raphe did not affect anxiety-related, depressive-like or impulsive behavior. Compared to the sham-treated rats, the lesioned rats showed a lower response latency to obtain a reward, indicating a quick and accurate reaction to a stimulus. No differences were found in the progressive ratio test for food motivation. A marked impairment in object recognition was found. The 5,7-DHT treatment did not affect the corticosterone response to a stressful situation. Overall. these results further support the potential role of 5-HT in object memory, but failed to support the role of 5-HT in affective behavior:

\section{Introduction}

Preclinical and clinical data generally support the prominent role of serotonin (5-HT, 5-hydroxytryptamine) in the regulation of behavioral functions. although inconclusive results have also been found. Concerning the function of 5 -HT in anxiety related disorders, conflicting results were found. Some of them imply the occurrence of anxiolytic behavior at reduced 5-HT concentrations (Briley et al., 1990: Kumar et al., 1995; Artaiz et al., 1998) while others found that reducing 5-HT levels facilitated anxious behavior (Harro et al., 2001).

Evidence of serotonergic abnormalities in depressed patients is well established. Decreased concentrations of the main 5-HT metabolite 5-HIAA (5-hydroxyindoleacetic acid), altered 5-HT receptor density (Mann. 1999: Stockmeier, 2003) and a dysfunctional hypothalamic-pituitary-adrenal (HPA) axis (McAllister-Williams et al., 1998) have been found in depressed patients. A disrupted negative feedback mechanism in the HPA axis has been associated with hypercortisolaemia. With regard to depression, an interaction 
between the 5-HT system and the HPA axis has been proposed. It was found that anti-depressants can relieve the clinical symptoms of depression and can normalize the cortisol levels in depressed patients (Barden et al., 1995), indicating that enhanced transmission of 5 -HT can be associated with depression (Blier and de Montigny, 1994).

A reduced activity of the serotonergic system (i.e. the 5-HT metabolite) in impulsive suicide attempters (van Praag and Korf, 1974), suggests an inverse relationship between serotonergic activity and impulsivity. Although several paradigms have been developed to model impulsive behavior in rats (Evenden et al., 1995; Puumala et al., 1996; Harrison et al., 1997a; Evenden, 1999a), they do not always provide us with a clear picture of the 5-HT function in impulsivity. By varying the delay of reinforcement, it was found that 5-HT depleted rats responded more to the choice of small and frequent rewards in stead of larger but delayed rewards (Bizot et al., 1999; Mobini et al., 2000b). An increase in premature responses was also found in central 5-HT lesioned rats when tested in a five-choice serial reaction time test (Harrison et al., 1997a; Harrison et al., 1997b), indicating impulsive responding when substantially lowering 5-HT levels.

Further, a deficiency in the serotonergic system is also believed to be involved in the occurrence of amnesia in Korsakoff and Alzheimer patients (Meneses, 1998; Buhot et al., 2000). An improvement in memory after anti-depressant treatments also supports the involvement of 5-HT in cognitive functions (Harmer et al., 2002). However, the role of 5-HT and the mechanisms underlying the effects of serotonergic compounds on cognitive processes are not well understood, and results are sometimes inconsistent (McEntee and Crook, 1991; Steckler and Sahgal, 1995). This hampers development of a solid hypothesis on the role of 5-HT in leaming and memory processes. Recently, it was shown that depletion of 5-HT levels in the hippocampalmedial prefrontal cortex of rats increased short term as well as long term potentiation, a proposed neurophysiological substrate of learning and memory (Ohashi et al., 2003). In accordance with these finding, it was found that an increase in 5-HT release impaired memory performances (Santucci et al., 1996; Luciana et al., 2001). However, when using the method of acute tryptophan (TRP) depletion, it was shown that the reduction in 5-HT synthesis impaired recognition of words or objects in humans (Riedel et.al., 1999; Rubinsztein et al., 2001: Sobczak et al., 2002). Recently, we found that administrating rats with a TRP-free protein-carbohydrate mixture induced a deficit in object recognition, thereby leaving affective behavior intact (Lieben et al., 2004b). This impairment in object recognition seemed to be taskspecific and 5-HT related. 
Based on the results from our experiment, the present study was designed to investigate the behavioral effects of a chronic 5-HT depletion, induced by injection of the neurotoxin 5,7-dihydroxytryptamine (5,7-DHT). To increase comparison between the acute and chronic 5-HT depletion studies, we adjusted both methods to each other.

To change 5-HT levels in a very early stage of the synthesis, the rats were treated with the neurotoxin 5,7-DHT to selectively destroy 5-HT neurons in the raphe nuclei. However, there are two main regions of the raphe nuclei, the dorsal raphe and median raphe, from which fibers descend along the midline within the brainstem and mainly ascend within the medial forbrain bundel to project 5-HT thoughout widespread regions of the brain. These two major 5-HT-containing cell groups distribute to essential nonoverlapping regions or complementary parts of the same structure (e.g. septum and hypothalamus) (Vertes, 1991: Vertes et al., 1999). These different projection patterns are expected to result in a distinct regulation of behavioral and physiological functions. Acute TRP depletion decreased central 5-HT concentrations in different structures throughout the brain (e.g. striatum, hippocampus, cortex) (Lieben et al., 2004a) and the innervations from the dorsal raphe nucleus are generally spread out wider over the different parts of the brain, when compared to the innervation pattern of the median raphe (Tork, 1990). For these reasons, we choose to inject 5,7-DHT into the dorsal raphe, thereby destroying 5-HT containing neurons in this region.

The effects of chronic 5-HT depletion were assessed in different behavioral tasks. Affective functions of these rats were evaluated in animal models of anxiety (open field test), impulsivity (DFl60 test) and depression (forced swimming test). Furthermore, motivational responses were evaluated in the progressive ratio (PR10) test and the effects on cognition were assessed in an object recognition test. To examine the 5-HT-HPA axis interaction, we measured the levels of plasma corticosterone on several stages and evaluated the corticosterone response to a physiological stressor.

\section{Methods}

\section{Animals}

Twenty-four experimentally naìve male Wistar rats. (Charles River, The Netherlands) weighing 284-306 g at the time of arrival were used. Throughout the experiment. rats were maintained on a 12/12-h reversed light/dark cycle (lights on 18.00-06.00 h) and tested during the dark phase. 
between $9.00 \mathrm{~h}$. and $17.00 \mathrm{~h}$. They were individually housed in standard Makrolon cages on sawdust bedding in an air-conditioned room $\left( \pm 20^{\circ} \mathrm{C}\right)$. The rats had free access to standard laboratory chaw (Hopefarm. The Netherlands) and tap water. Except for the skinnerbox tests where the rats were fed a ratio of food $(7-10 \mathrm{~g} / \mathrm{rat}$ day). This was considered necessary to motivate performance whilst maintaining weights at approximately $90 \%$ of free feeding weight (during the weekend food was available ad libitum). A radio, which was playing softly, provided background noise. All experimental procedures were conducted in a manner approved by the local ethical committee of the Maastricht University for animal experiments and met governmental guidelines.

\section{Surgery}

A total. of 16 rats were matched for body weight and assigned to two groups. The LESION group $(n=9)$ was given an intra-raphe administration of 5.7-DHT (Sigma, Zwijndrecht, The Netherlands) and the SHAM group $(n=7)$ received a $0.9 \%$ saline injection. Desipramine (Sigma. Zwijndrecht, The Netherlands) was freshly dissolved in saline. This pretreatment was given (10 mg/kg; i.p.) 60 minutes before narcosis and was aimed to protect noradrenerigic neurons (Bjorklund et al., 1975; Azmitia and Segal, 1978). Similar to the LESION group, desipramine was also administrated to SHAM rats. The rats were anaesthetized (i.p.; $1.5 \mathrm{ml}$ ) with a combination of Nimatek $(12 \%)$. Sedamun $(8 \%)$ and $\mathrm{NaCl}(80 \%)$. They were placed into a stereotaxic frame with ear bars. All injections were made unilateral in the left hemisphere at an angle of $30^{\circ}$. The coordinates were taken with the incisor bar set at $0 \mathrm{~mm}$ below the interaural line at: AP 1.7, ML I and V 4.2. 5,7-DHT was injected $3 \mu \mathrm{g} / \mu \mathrm{l}$ in a volume of $1 \mu \mathrm{l}(0.5 \mu \mathrm{l} / \mathrm{min})$. The needle was then left in situ for a further 2 minutes after the infusion was completed. Immediately following surgery, all rats were wrapped into a paper tissue to prevent under cooling and were provided with additional palatable foods until food intake normalized and weights stabilized. After their initial postoperative reactivity subsided. rats were handled during this postoperative monitoring to prepare them for behavioral testing.

\section{Histology}

At the end of the behavioral experiments, a transcardial perfusion was performed to fixate the brains of the rats (Somogyi and Takagi, 1982). Free floating sections $(35 \mu \mathrm{m})$ were made at levels of the raphe nuclei (between $7.64 \mathrm{~mm}$ and $-8.30 \mathrm{~mm}$ from bregma, see: Paxinos and Watson, 1996) for Niss] and 5-HT staining. 


\section{Behavior}

\section{Open field test}

Testing was conducted in a square, clear Plexiglas box $(100 \mathrm{~cm} \times 100 \mathrm{~cm} \times$ $30 \mathrm{~cm}$ ), with an open top and a dark floor. The arena of the open field (OF) was subdivided in 'corner' (four squares each $16 \mathrm{~cm} \times 16 \mathrm{~cm}$ ), 'wall' (four rectangles each $16 \mathrm{~cm} \times 64 \mathrm{~cm}$ ) and 'center' (one square $64 \mathrm{~cm} \times 64 \mathrm{~cm}$ ) zones. The OF was placed on the floor of an experimental room. A camera was installed $2.5 \mathrm{~m}$ above the center of the field. Immediately after a rat was placed in the center of the OF, the movements and position of the animals were recorded and registered automatically by a computerized system (EthoVision, Noldus Equipment, The Netherlands). Only the total duration of rearing and leaning (i.e. rearing but making contact with the fore paws against the wall) was manually recorded. The illumination of the room was reduced to 60 Lux on the floor of the apparatus. Testing was carried out on four consecutive days. The floor of the OF was cleaned with a damp sponge after each session, which lasted 5 min, to prevent transmission of olfactory cures. OF behavior was tested between $13.30 \mathrm{~h}$ and $17.00 \mathrm{~h}$. The data of the OF test were aggregated over four days to enhance reliability (Ossenkopp and Mazmanian, 1985). These aggregated data in the OF test strongly correlates with definitions of anxiety in other models like the plus maze and the light dark box (Blokland et al., 1992; Prickaerts et al., 1996; van der Staay and Blokland, 1996). Three dependent variables are reported: the mean time spent in each zone of the OF, the mean distance moved and the mean time of rearing and leaning in the entire apparatus.

\section{Forced swimming test}

The forced swimming test (FST) is a well-known screening test for antidepressants in rodents (Porsolt. 1979; Cryan et al., 2002). However, in this study, the FST is used to assess effects of treatment on affective behavior (e.g. depressive-like state of the animal). Therefore, the method as described by (Lucki et al., 1994: Detke and Lucki, 1996) was modified. Four cylindrical glass tanks $\left(40 \mathrm{~cm}\right.$ length $\times 17 \mathrm{~cm}$ diameter) of $23{ }^{\circ} \mathrm{C}$ water, filled to a depth of $30 \mathrm{~cm}$, were used in this test. The animals were individually placed in the water tank and their movements were recorded for the front using a video camera in 5-min test sessions. Testing was carried out over three consecutive days. The variables were manually recorded from video footage with a personal computer that calculated the duration of every behavior. Behavioral variables included immobility, swimming and climbing. Immobility was defined as making no movements or only making those movements that were 
necessary to keep the nose above the water. It was allowable for the rats to move their forepaws or support themselves by pressing their paws against the wall of the cylinder. Swimming was scored as the animal making active swimming motions more than necessary to keep its head above the water and involved moving horizontally or crossing the water surface. Climbing consisted of the animal making active upward movements with forepaws in and out of the water directed against the walls of the cylinder.

\section{Discrete fixed interval test}

The rats were tested in six identical operant chambers (inner dimensions: $40 \mathrm{~cm} \times 30 \mathrm{~cm} \times 33 \mathrm{~cm}$ ) which were equipped with two retractable levers, and cue lights just above the levers. A food tray $(5 \mathrm{~cm} \times 5 \mathrm{~cm}$ and $2.5 \mathrm{~cm}$ above the grid floor). which was positioned equidistant between the two levers, could be accessed by pushing a hinged panel. The levers ( $4 \mathrm{~cm}$ wide) projected $2 \mathrm{~cm}$ into the conditioning chamber and were located $6 \mathrm{~cm}$ from both sides of the food tray and $12 \mathrm{~cm}$ above the grid floor. A house light and a loudspeaker were fixed in the ceiling of the conditioning chamber. The operanda and manipulanda in the chambers were controlled by a personal computer and the data were stored on disk at the end of a session.

After the rats were trained to press a lever for food reward, they were gradually trained on a discrete fixed interval (DFI60) schedule of reinforcement using an interval of $60 \mathrm{~s}$. In this test a trial was started by switching on the lever light (only one lever was used in this test). The rats had to press the lever to start the interval (see Fig. 1). After this lever press the lever light was thined off. The lever remained available during the $60 \mathrm{~s}$ interval. After the interval was ended the lever light was switched on and a lever press was rewarded with a $45 \mathrm{mg}$ food pellet (Bioserve). If a rat did not press the lever within $3 \mathrm{~s}$, a time out period of $5 \mathrm{~s}$ was given and the house light (which is on during a session) switched off. The inter-trial interval was $5 \mathrm{~s}$. The rats received 40 trials per session. Before conducting the operation the rats were trained on this procedure until the performance was stable over 3 successive sessions. Two weeks after recovery, the rats were tested again on five sessions. The following parameters were use to evaluate the performance of the rats in this test: number/percentage of responses during the FI of $60 \mathrm{~s}$ (calculated per $10 \mathrm{~s}$ ), start latency (time between onset of light and lever press to start interval), lever latency (time between end of FI and first lever press) and omissions. 


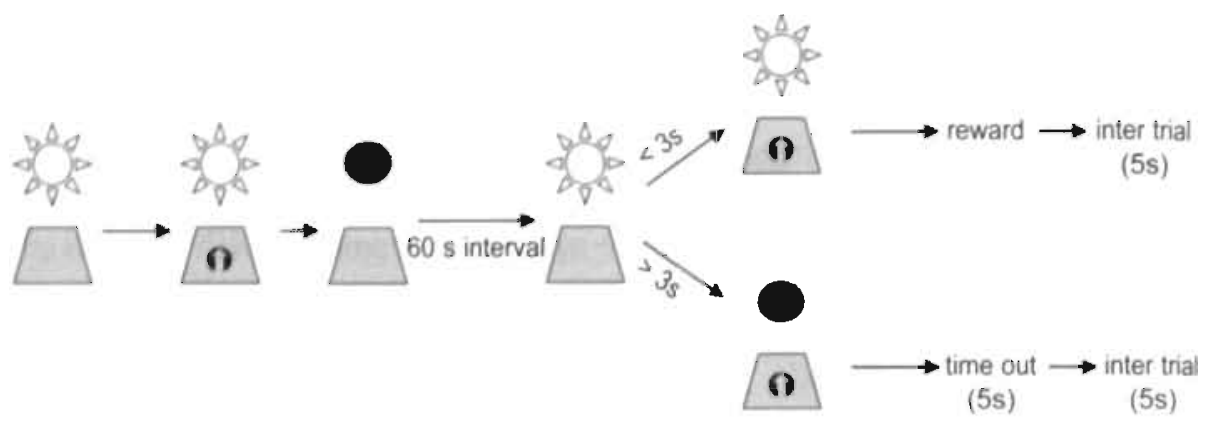

Fig. 1: Schematic representation of the procedure used in the discret fixed interval test (DF! 60)

\section{Progressive ratio test}

The rats were tested in the same operant chambers as described in DFI60. In the progressive ratio test (PRI0) the rats had to progressively increase the number of lever presses (steps of 10 lever presses) to obtain a $45 \mathrm{mg}$ food reward (Bioserve) (Hodos, 1961). For the first food pellet they had to press ten times and for the next food reward twenty times, and so forth. If a rat did not press the lever for $5 \mathrm{~min}$ the session was terminated. Three weeks after recovery, the rats were given a three daily sessions. The following parameters were use to evaluate the performance of the rats in this test: break point (number of lever presses made during a session), inter-response time (mean time between two successive lever presses).

\section{()bject recognition test}

The object recognition test (ORT) was conducted as described in detail elsewhere (Ennaceur and Delacour, 1988: Lieben et al.. 2004b). The apparatus consisted of a circular arena, $83 \mathrm{~cm}$ in diameter. Half of the $40-\mathrm{cm}$-high wall was made of grey polyvinyl chloride, the other half of transparent polyviny! chloride. The light intensity (20 Lux) was equal in the different parts of the apparatus. We used four different sets of objects that could not be displaced by a rat. Each object was available in triplicate. The different objects were (1) a cone consisted of a grey polyvinyl chloride base (maximal diameter $18 \mathrm{~cm}$ ) with collar on top made of brass (total height $16 \mathrm{~cm}$ ), (2) a standard 11 transparent glass bottle (diameter $10 \mathrm{~cm}$, height $22 \mathrm{~cm}$ ) filled with water, (3) a massive metal cube $(10 \mathrm{~cm} \times 5 \mathrm{~cm} \times 7.5 \mathrm{~cm}$ ) with two holes (diameter $1.9 \mathrm{~cm}$ ) and '4) a massive aluminum cube with a tapering top ( $13 \mathrm{~cm} \times 8 \mathrm{~cm} \times 8 \mathrm{~cm})$. In the week preceding operation. the animals were adapted to the test procedure, i.e., they were allowed to explore the apparatus (without any 
objects) twice for $3 \mathrm{~min}$. In the following days, the rats were trained until a stable discrimination performance was shown. A testing session comprised two trials. The duration of each trial was $3 \mathrm{~min}$. Two objects were placed in a symmetrical position about $10 \mathrm{~cm}$ away from the grey wall. A rat was always placed in the apparatus facing the wall at the middle of the front (transparent) segment. During the first trial (T1) the apparatus contained two identical objects. After the first exploration period the rat was put back in its home cage. One hour later the rat was put back in the apparatus for the second trial (T2), but now dissimilar objects, a familiar one and a new one. The duration. of exploring each object in $\mathrm{T} 1$ and $\mathrm{T} 2$ was recorded manually with a personal computer. Exploration was defined as directing the nose to the object at a distance of no more than $2 \mathrm{~cm}$ and/or touching the object with the nose. Sitting on the object was not considered as exploratory behavior. In order to avoid the presence of olfactory trails, the objects were always thoroughly cleaned. Moreover, each object was available in triplicate so that none of the two objects from the first trial had to be used as the novel object in the second trial. In addition, all combinations and locations of objects were used in a balanced manner to reduce potential biases due to preferences for particular locations or objects. After recovery, testing sessions were given on three consecutive days.

The basic measures were the total exploration time of both objects during T1 and $\mathrm{T} 2, e \mathrm{e}$ and $e 2$, respectively. We used a criterion of at least $10 \%$ above mean for a minimum exploration values to avoid possible erroneous conclusions. A discrimination index $(d 2=$ (exploration new object exploration familiar object)/total exploration time during test trial) were calculated. For each rat, the data of the three testing sessions were collapsed to enhance the reliability of the data.

\section{Corticosterone levels}

Peripheral corticosterone levels were determined as a physiological measure of a response to a stress condition. Immediately after the first blood sample was taken, the rat was placed in a novel cage in which the bottom was filled with water (depth $5 \mathrm{~cm}$, approximately $35^{\circ} \mathrm{C}$ ). After $30 \mathrm{~min}$, the procedure of blood sampling was repeated. It has been shown that at this time point corticosterone levels reach peak values (De Boer et al., 1990). The effects of a 5,7-DHT lesion were examined on resting- and stress-induced corticosterone concentrations in three sessions. The first session was performed several days prior to the operation. This was repeated twice, 4 and 6 week after the first session, respectively. 
Blood sampling was done by means of a tail-incision method (Fluttert et al., 2000). The rats were taken out of their cages and wrapped in a towel to fixate the rat. This method allows withdrawal of small amounts of blood without disturbing the rat either behaviorally or physiologically. An incision was made in the tail and promptly thereafter, venous blood $(300 \mu \mathrm{l})$ was collected. in a sodium heparin tubes (Microvette ${ }^{2}$ CB 300, Sarstedt, Germany). The samples were kept on ice. After centrifugation of the blood samples (at $4{ }^{\circ} \mathrm{C}$ for $15 \mathrm{~min}$ at $1500 \mathrm{~g}$ in a Hettich EBA 12 centrifuge), serum was removed, frozen in liquid nitrogen and stored at $-80{ }^{\circ} \mathrm{C}$ until the corticosterone assay. For the determination of the serum corticosterone concentrations, $50 \mu \mathrm{l}$ of serum sample was extracted with $3 \mathrm{ml}$ of dichloromethane. This combination was mixed by vortex for $\| \mathrm{min}$. The corticosterone was measured directly on $\mathrm{I} \mathrm{ml}$ dried dichloromethane and extracted by radioimmunoassay (RIA) using corticosterone-I'2s as tracer and an anti-corticosterone serum (Sulon et al., 1978). The RIA-reaction was performed overnight at $4{ }^{\circ} \mathrm{C}$. A second antibody system was used to separate bound and unbound steroid.

\section{Statistical analy'sis}

The data of the two groups of rats (SHAM and LESION) were submitted to a normality tesi (Kolmogorov-Smirnov) and extreme values were excluded from the statistical analysis. For all variables, treatment effects were analysed using parametric statistics (ANOVA). In the OF, ORT, DFI60 (i.e. latency and omission) and the PR 10 the periormance of each animal was averaged over trials before analysing the data using a one-way ANOVA (i.e. independent sample t-lest) with Treatment as a within-subject factor. In the DFI60, the number of responses made in the six $10 \mathrm{~s}$ bins was calculated. Parameters used in the FST, the number of responses in the DFI60, resting and stressinduced plasma corticosterone levels and the corticosterone response were analysed with a two-factorial (Treatment and Time) ANOVA, with repeated measures over Time or Bin. Differences were regarded as statistically significant if $p<0.05$.

\section{Results}

\section{Histology}

A typical lesion is illustrated in Fig. 2. The remaining track of a SHAM rat was histologically verified (Fig. 2A and 2B). This displays the direction of the needle entering the brain, which was correctly aimed at the target area of the dorsal raphe. 
Comparing a Nissl stained section of a LESION rat (Fig. 2E) with one of a SHAM rat (Fig. 2C), clearly illustrates the extent and the profound impact of the lesion on non-specific cellular level. Not only did the treatment result in a several loss of 5-HT neurons but also changed the morphological structure within the dorsal raphe area (Fig. 2F) compared to the sham-operated rats (Fig. 2D).

NISSL
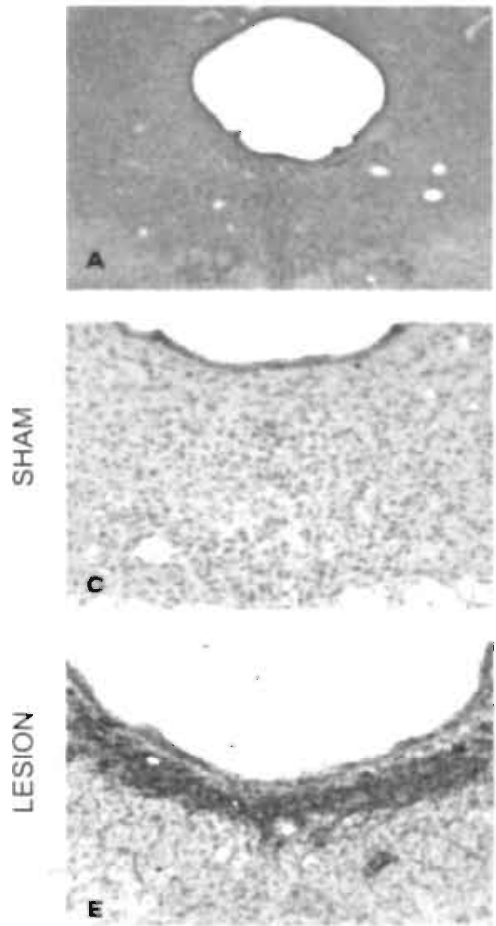

5-HT
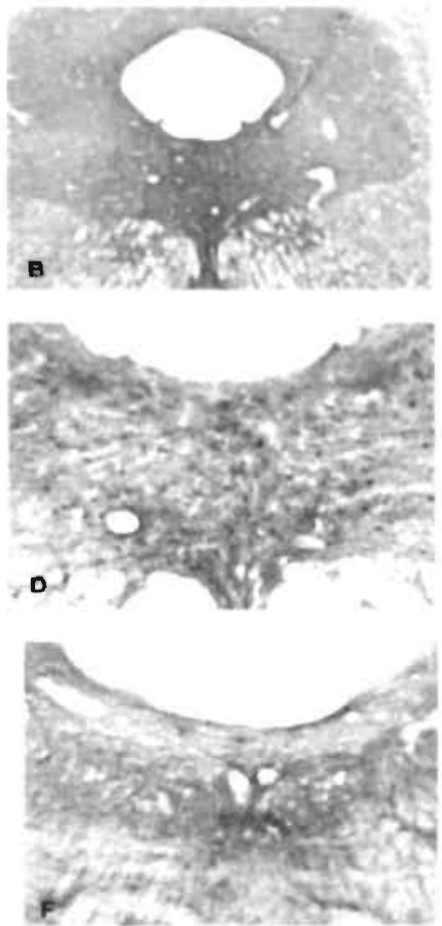

Fig. 2: Examples of Nissl ( $A, C$ and E) and 5-HT (B. D and F) stained brain sections of the dorsal raphe.

$A$ and $B$ ) illustrate the track left by the needle used for injection.

$\mathrm{C}$ and D) morphological feature and 5-HT neurons of SHAM treated rats.

E and F) morphological feature and 5-HT staining of the 5,7-DHT treated rats.

Scale bars: C. D. E and F: $-7: 80 \mathrm{~mm}$.

\section{Behavior}

Open field test

The time animals spent in the different zones of the open field was not affected by treatment $[t(13)<0.76, n$.s.; see Fig. 3] , nor was level of activity, as 
indicated by the total distance moved $[t(13)=0.23$, n.s.; see Fig. 3(insert)]. Nevertheless, the time spent in the corner correlated negatively with the total distance moved ( $r=-0.56, p<0.05$; data not shown). It was found that the frequency in which the animals vertically explored the environment (i.e. rearing and leaning) was similar between groups $[t(13)<0.87$, n.s.; data not shown].



Fig. 3: Effects of 5,7-DHT lesion on open field behavior: time spent (s) in the different zones of the open field: (insert) total distance moved. $(\mathrm{cm})$ in the arena in the open field. Data represents aggregated data of four 5 -min sessions. Values are mean (+ SEM) of SHAM and LESION rats $(n=7$ and $n=9$. respectively).

\section{Forced swimming test}

As represented in Table 1, immobility scores generally decreased over the trials $[F(2,24)=6.65, p<0.01]$. Compared to the SHAM group, the lesion did not affect immobile behavior in the LESION group $[F(1,12)=0.19$, n.s.]. Therefore, a similar decrease in immobility occurred in both groups $[F(2,24)=$ 0.40, n.s.]. The increase in mobility was accompanied by more active swimming behavior [Trial: $F(2,24)=8.52, p<0.01]$. This increase of swimming did not interact with the treatment $[F(2,24)=0.49$, n.s.]. Consequently, swimming behavior was not affected by lesion $[F(1,12)=0.03$. n.s.]. As shown in Table 1 , this increase in swimming was most pronounced after the first trial. The climbing behavior of the rats remained stable over the trials $[F(2,24)=0.07$. n.s.]. and no difference was found between groups [Treatment: $F(1,12)<1.21$, n.s.]. 
Table 1. Effects of a 5.7-DHT lesion in the forced swimming test Mean values (+ SEM) are expressed in seconds. Rats received a 5,7-DHT injection (LESION, $n=9$ ) or a sham injection (SHAM, $n=6$ ).

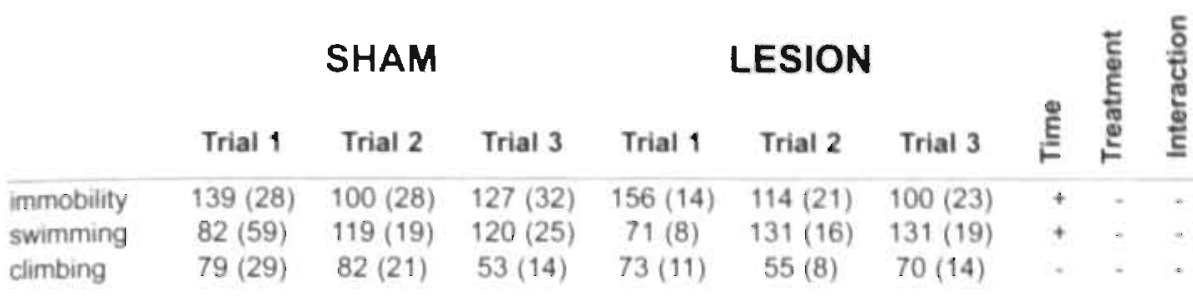

\section{Discrete fixed interval test}

There was a clear change in the distribution of responses over the six time bins $[F(5,60)=3.16, p<0.05$; see Fig. 4]. However treatment with 5,7-DHT did not affect the percentage of the responses in the $60 \mathrm{~s}$ interval $[F(1,12)=$ 0.14 . n.s.]. There was no support for a Treatment $x$ Bin interaction effect $[F(5,60)=0.92, \mathrm{n} . \mathrm{s}$. $]$. When compared to the SHAM group, the lesion rats tended to a quicker response for starting a novel trial [startlatency: $t(13)=$ $-2.15,0.05<p<0.1$; see Table 2]. The response to the light-onset after $60 \mathrm{~s}$ of leverpressing was similar in both groups [leverlatency: $t(12)=-1.6$, n.s.]. Although not statistically confirmed, there was an apparent decrease $(47 \%)$ in response latency after the $60 \mathrm{~s}$ interval in the LESION group, when compared to the SHAM group. On the other hand, this resulted in a treatment effect on the number of omissions $[t(12)=-2.88, p<0.05$; see Table 2], indicating that the lesioned rats made less omissions.

Table 2: Effects of 5.7-DHT lesion on the performance in the DFI60 task. Mean va!ves of latency times (s) and omissions (total amount) (+ SEM). Rats received a 5,7-DHT injection (LESION, $n=9$ ) or a sham injection (SHAM. $n=6$ ). Significance of difference between groups: " $0.05<p<0.1$ : " $p<0.05$

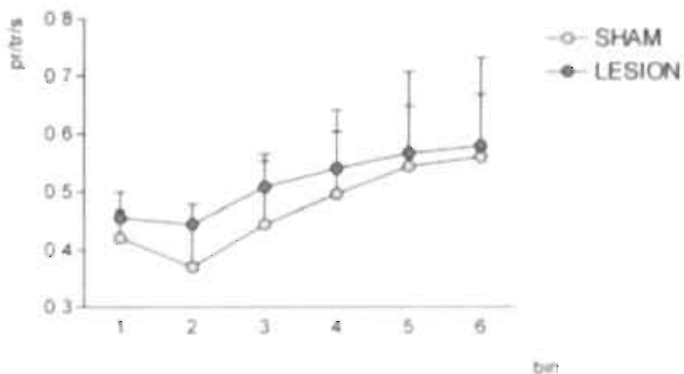

Start latency Lever latency Omissions

SHAM $\quad 14.72(1.83) \quad 0.15(0.04) \quad 1.93(0.34)$

LESION $8.68(1.93)^{:} \quad 0.08(0.02) \quad 0.78(0.24)^{n}$
Fig. 4 Performance of Wistar rats in a discrete fixed interval (60 s) task. Mean values are expressed by number of premature responses per trial per second (pr/tr/s + SEM), and plotted per $10 \mathrm{~s}$ bins. Treatment effect is depicted with asterisk (" $p<0$ 05) 


\section{Progressive ratio test}

As shown in Table 3, the break point in the PR10 test was not affected by treatment of 5,7 -DHT $[t(13)=1.39$, n.s. $]$. Also, the inter-response time was not affected by the lesion $[t(13)=-1.22$, n.s.].

Table 3: Effects of 5,7-DHT lesion on the performance in the PR10 task. Mean values of break point (s) and inter response time (s) (SEM). Rats received a 5.7-DHT injection (LESION, $n=9$ ) or a sham injection (SHAM. $n=6$ ) Significance of difference between groups: ' $0.05<p<0.1 ; " p<0.05$

\section{Break point Inter response time.}

SHAM 590(152)

LESION 798(70)

$1.23(0.26)$

\section{Treatment}

e1

e2
Table 4: The effect of the 5,7-DHT lesion on the total exploration time in the object recognition test. Mean values (SEM) of total explo. ration time (s) during the first (e1) and second trial (e2). Rats received a 5,7-DHT injection (LESION, $n=9$ ) or a sham injection (SHAM. $n=6$ ). The delay interval between the first and second trial was $1 \mathrm{~h}$.

\section{Object recognition test}

Several weeks after surgery, the treatment with 5,7-DHT did not affect the exploration time in both trials $[t(13)<-1.28$, n.s.; see Table 4]. In contrast, a treatment effect was found on the discrimination index $[d 2 ; \mathrm{t}(13)=-5.65$, $p<0.001$; see Fig. 5]. While the SHAM rats showed a high preference towards the new object which was presented one hour interval after the first trial, rats of the LESION group explored the new object and the familiar object equally indicating that they could not discriminate the new object from the object previously seen one hour before.

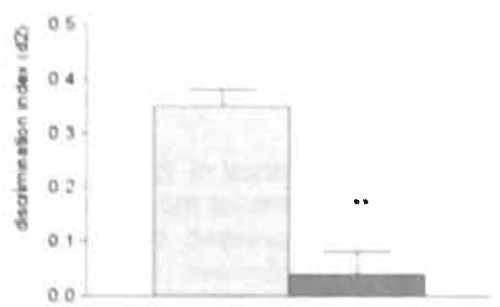

Fig. 5: Effects of a 5,7-DHT lesion on the discrimination index: $(d 2)$ in the object recognition test. Values are mean of three session (+. SEM) of sham-treated and 5,7-DHT-treated rats (SHAM, $n=7$ and LESION. $n=9$, respectively). Treatment effect on the $d 2$ measure is depicted with asterisk ( $" p<0.01)$. 


\section{Corticosterone levels}

The absolute concentrations of serum corticosterone are depicted in Table 5 . Plasma corticosterone levels changed over time in both resting and stressinduced conditions [Time; $F(2,24)>7.46, p<0.01$ ] . However, these levels of corticosterone were not affected by lesion [Treatment; $F(1,12)<0.95$, n.s.]. Consequently the statistical analysis did not support an interaction effect between Time and Treatment in the conditions where corticosterone was measured before and after exposure to a stressful event $[F(2,24)<2.37$, n.s.]. Nevertheless, exposure to the stressor showed augmentations of $70-220 \%$ in corticosterone levels.

The physiological response of serum corticosterone levels differed over time [Time: $F(2,20)=7.93, p<0.05]$. Independent of treatment $[F(1,10)<0.66, \mathrm{n} . \mathrm{s}$.]. an increase in corticosterone response occurred one month after the lesion was induced and afterwards decreased back to normal. However, this change in degree of response appeared to be equal in both groups indicating no interaction effect [Time $x$ Treatment; $F(2,20)=0.57$, n.s.].

Table 5. Resting and stress-induced corticosterone levels $(\mathrm{ng} / \mathrm{ml})$ in plasma in SHAM and LESION rats. Mean plasma corticosterone levels (ng/ml) were measured twice in every session, at resting level (rest) and after exposure to stressor (stress; warm water basin). The stressresponse was calculated as the difference score (stress-induced-resting per subject). The three sessions were given before, 4 and 6 weeks after operation, respectively. Entries are mean $(+$ SEM)

\begin{tabular}{|c|c|c|c|c|c|c|c|}
\hline & & session 1 & session 2 & session 3 & $\stackrel{\mathscr{E}}{E}$ & 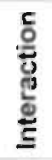 & 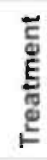 \\
\hline \multirow[t]{3}{*}{ Resting } & SHAM & $27 \div 6$ & $54+14$ & $53+7$ & & & \\
\hline & & & & & + & - & - \\
\hline & LESION & $33+4$ & $34+5$ & $55+4$ & & & \\
\hline \multirow[t]{3}{*}{ Stress-induced } & SHAM & $64 \div 6$ & $121+6$ & $89+7$ & & & \\
\hline & & & & & + & - & - \\
\hline & LESION & $70+5$ & $97+9$ & $93+7$ & & & \\
\hline \multirow[t]{3}{*}{ Response } & SHAM & $37+9$ & $68+19$ & $34+4$ & & & \\
\hline & & & & & + & - & - \\
\hline & LESION & $37+6$ & $63+10$ & $38+10$ & & & \\
\hline
\end{tabular}




\section{Discussion}

Administration of 5,7-DHT in the dorsal raphe induced a profound lesion of 5-HT neurons and a pronounced impairment in object memory. In contrast, the lesion did not affect anxiety-related, depressive- or impulsive-like behaviors.

As mentioned in the introduction, a controversy on the role of 5-HT in anxiety-related behavior exist. A number of factors may be responsible. Treatment of PCPA and 5,7-DHT are frequently applied neurotoxic models, both considered to selectively reduce 5-HT transmitter functions. However, both these 5-HT depletion models appear to reflect differences in anxietyrelated behavior (Dringenberg et al., 1995; Hall et al., 1999). Besides, the precise location of 5,7-DHT injection determines the potential effect of 5-HT activity in several projection regions in the brain. 5,7-DHT injections at different locations (e.g. lateral ventricles, cell body or specific terminal regions) results in a great diversity of functional effects (Lehmann et al., 2000; Lehmann et al., 2002a; Lehmann et al., 2002b). And even if treatment and location is similar, a variance in the volume of the neurotoxin can induce different degrees of lesion effects. The type of animal model used for measuring anxiety often reflects different traits (e.g. explorative behavior, conflict situation) (Griebel, 1995; File et al., 2000; Graeff, 2002). Due to all these potential biases, its not surprising that no clear conclusions can be drawn on the precise role of 5-HT on anxiety behavior. The dorsal raphe has been proposed to be involved in generalized anxiety and panic disorder, and that 5-HT has a dual role on the neuronal mechanism underlying anxiety and fear-related behavior. It has been stated that the ascending dorsal raphe 5-HT pathway facilitates learned fear while inhibiting unconditioned fear. (Deakin and Graefi, 1991). It was found that destroying 5-HT neurons in the dorsal raphe impaired inhibitory avoidance (i.e. anxiolytic) while facilitating one-way escape behavior (i.e. anxiogenic) when tested in the elevated plus maze (Sena et al., 2003), supporting the dual role of 5- HT in anxiety.

In the present study, the OF test was used to measure unconditional anxietyrelated behavior. Comparing the aggregated scores of the OF with parameters of other models of anxiety such as the 'plus maze' and the 'light-dark box'. resulted in high correlation scores and moreover, similar treatment effects were found in these different tests (Blokland et al., 1992; van der Staay and Blokland, 1996). Furthermore, independent of treatment, a correlation of two behavioral aspects (i.e. the time occupied in the corner squares and the total distance moved) are replicated on frequent base in the OF, as in this 
experiment. Therefore, it is stated that both parameters measure the same trait (i.e. emotional reactivity) (van der Staay et al., 1990). If rats experience a higher level of anxiety, they will spent more time in comer squares and will be less active or vice versa. However, in this study we found that treatment of 5,7-DHT did not affect anxiety-related behavior as tested in the OF.

Hall (1999) suggested that the reduction of 5-HT may have dose-dependent effects on anxiety. They found anxiogenic effects after a ventricular 5.7-DHT lesion in the OF. These effects only occurred at moderate 5-HT depletion while more severe 5-HT depletions did no longer reveal such behavior (Hall et al., 1999). It can be argued that different animal models of anxiety (elevated plus maze versus $\mathrm{OF}$ ) can generate diverse behavioral effect which ultimately represents different traits (Griebel, 1995; File et al., 2000; Graeff, 2002). However, discrepant results were also found in the elevated plus maze also frequently used as an unconditional animal models of anxiety (Griebel, 1995). It was reported that a chronic 5-HT intracerebroventricular (i.c.v.) lesion resulted in anxiolytic behavior without changing locomotor activity (Briley et al., 1990). However, recent studies show conflicting findings thereby demonstrating that the location of neuronal destruction (median raphe or dorsal raphe) did not influence the effect on anxiety-related behavior (Thomas et al., 2000; Rex et al., 2003). Furthermore, in contrast to an electrolytic induced lesion anxiety-related behavior was not affected by the treatment of 5,7-DHT (Andrade and Graeff, 2001). Although it seems that the function of 5-HT on anxiety is far from conclusive, our data support the view that a substantial reduction of 5-HT neurons in the dorsal raphe are not strongly involved in anxiety-related behavior.

Stress is assumed to induces anxious thoughts or feelings by an increase of 5-HT levels. And it was found that chronic but not acute exposure to a stress condition caused anxiogenic-like behavior in animals (Netto et al., 2002). These results implicate that perhaps a chronic in stead of an acute exposure to stress may affect the response of corticosterone levels.

As the learned helplessness paradigm, the forced swimming (Porsolt) test is also widely used to investigate the therapeutic potential of anti-depressant compounds (Porsolt, 1979; Carpenter et al., 1998). SSRIs or other 5-HTrelated compounds (e.g. 5-HT $1 \mathrm{~A}$ agonist) induced anti-depressant-like effects (e.g. lower immobility) in rats when tested in the forced swimming test (Schreiber and De Vry, 1993; Blier, 2001). However, depletion of 5-HT levels through injection of PCPA did not affect the behavior when tested in 
the FST or learned helplessness (Anisman et al., 1979; Cervo and Samanin, 1991; Borsini and Cesana, 2001; Harkin et al., 2003). Neither did the treatment of 5,7-DHT induce depressive-like behavior in rats (Soubrie et al., 1986; Martin et al., 1990; Panocka et al., 2000; Perfumi et al., 2001). To determine depressive-like behavior of the animals in stead of making them depressed to test anti-depressant drug effects, we adapted the traditional procedure of the FST. The pre-trial was omitted and by the condition of the rats was repeatedly tested throughout the treatment. Nevertheless, our findings with a 5,7-DHT lesion in the dorsal raphe are in accordance with previous findings that a substantial chronic reduction of central 5-HT concentrations did not affect the immobility and therefore did not induce a state of despair in rats treated with 5,7-DHT.

Behavioral inhibition, expresses by the amount of lever responses during a 60 $\mathrm{s}$ interval in the DFI test, was not affected by treatment with 5,7-DHT. This was not consistent with the increase in impulsive responding related to the delay of reward, previously reported in 5-HT depleted rats. (Bizot et al., 1999; Evenden, 1999b). In these studies, the effect of the serotonergic system was more relevant in time dependent factors rather than to the probability of reward (Mobini et al., 2000a). Premature responses also occurred in 5,7-DHT treated rats in the five serial choice test (Harrison et al., 1997a). Similar to our own study, it was found that lesion in the dorsal raphe increased the speed of responding and lowered the number of omission. In contrast, 5-HT depletion in the median raphe resulted mainly in premature responses and reduced latency time to collect food rewards. It was suggested that a faster food collection in deprived animals can be associated to motivation and that this function is more under control of the median raphe (Carli and Samanin, 1992). Our data supports the latter suggestion since the results of the PR 10 test showed that the motivation level was not affected by dorsal raphe lesion. It can be reasoned that the effect found was related to faster lever responding in the DFI60 task and independent of motivational processes. Moreover it has been reported that a certain amount of difference does exist between the projection areas of the median and dorsal raphe (Azmitia and Segal, 1978). While median raphe mainly projects towards media! forebrain structures (hypothalamus and hippocampus), the dorsal raphe predominately innerves the globus pallidus, nucleus accumbens and amygdala. A 5,7-DHT treatment in the dorsal raphe substantially reduced 5-HT levels in the nucleus accumbens, this in contrast to injection in the median raphe (Harrison et al.. 1997b). By reducing 5-HT levels in dorsal raphe projection areas (e.g. striatum and nucleus accumbens), the inhibitory function of 5-HT on the DA 
neurons is interrupted. This might explain the fast responding in animals, with dorsal raphe lesions.

We previously found that an acute reduction in plasma TRP levels impaired object memory in rats (Lieben et al., 2004b). To further investigate the function of 5-HT in object recognition, we decided to assess the performance of the lesioned animals in this task. To our knowledge, this is the first study to test the effects of a 5-HT lesion in the object recognition task. Our data indicated that, similar to an acute lowering in TRP levels, the 5-HT lesioned rats could no longer discriminate a novel objects from a familiar object seen only one hour before.

It has been hypothesized that the dorsal raphe receives input from the median raphe, suggesting that the output of median raphe might induce a functional compensation effect for the loss of projections coming form the dorsal raphe (Azmitia and Segal, 1978; Rex et al., 2003). This suggesi that impairment found in object recognition, induced by 5-HT lesion in the dorsal raphe, could not be compensated by its input from the median raphe and therefore assume that the impairment in object memory was characteristic for the dorsal raphe. However, the role of the median raphe on object recognition can not be fully excluded unless a similar study was conducted inducing a 5-HT lesion in the median raphe. It has recently been shown that an i.c.v. administration of 5,7-DHT impaired the acquisition of nonspatial working memory when tested in a nonmatch to sample object recognition in a Y-maze (Cassaday et al., 2003). So, although there are clear indications of 5-HT involvement in nonspatial working memory processes, the 5,7-DHT treatment generally does not affect spatial working and reference memory when tested in the Morris Water maze and in the radial maze (Murtha and Pappas, 1994: Lehmann et al., 2002b; Majlessi et al., 2003).

Indications of an overstimulated HPA axis have been which can affect memory processes. This could be caused by a change in glucocorticoid receptors which control the release of cortisol and the occurrence of hypercortisolaemia may disrupt hippocampal dependent memory functions (de Kloet et al., 1999; Jameison and Dinan, 2001). The corticosteroid response was found to be increased in olfactory bulbectomized rats, used as a model of depression (Broekkamp et al., 1986). However our data suggests that a chronic reduction of 5-HT did not affect basal plasma corticosterone levels nor did it alter the corticosterone response to a physiological stressor. 
The effects of the 5,7-DHT treatment in the dorsal raphe were histologically examined. As illustrated, severe morphological changes took place in the structure of the raphe area and the numbers of 5-HT cell bodies were substantially decreased in dorsal raphe. Unfortunately, in this study we did not investigate the effects lesion effect in projecting brain regions to see how the changes in these structures were related to behavioral functions.

Furthermore, it is likely that a compensation mechanism (e.g. collateral sprouting, increased TRP hydroxylase levels in the surviving 5-HT neurons or increased sensitivity in postsynaptical receptors) has been developed over the weeks after treatment (Azmitia and Segal, 1978; Bendotti et al., 1990; Sawynok and Reid, 1994). This might cause an underestimation of the effects on behavioral functioning. Therefore, it would be preferable to assess the behavioral effects of this treatment for each individual test. This would reduce the probability of successive testing to interfere with treatment effects. Furthermore, one has to consider that the impact of this chronic reduction of the 5-HT system may also have altered global neuronal activity and an imbalance neuronal interacting systems. Although the precise nature of these other transmitter systems (e.g. DA. Glu or ACh) still remains unclear, they may reflect a prominent contribution with regard to behavioral functioning. Nevertheless, similar effects occurred after a chronic 5-HT depletion when compared to an acute and substantial reduction in plasma TRP levels both showing a clear impairment on object recognition without inducing anxietyrelated or depressive-like behavior. Taken together, the results of the present study may indicate that central serotonerigic system do not have a primarily role in affective behavior but on the other hand. seem to play a modulatory role in processes related to the formation of object memory. 


\section{References}

Andrade, T.G and Graeff, F.G (2001) Effect of electrolytic and neurotoxic lesions of the median raphe nucleus on anxiety and stress. Pharmacol Biochem Behas 70: 1-14

Anisman. H., Irwin. J, and Sklar, L.S. (1979) Deficits of escape performance following catecholamine depletion: implications for behavioral deficits induced by uncontrollable stress. Psuchopharmacology (Berl), 64: 163-70.

Artaiz. 1. Zazpe. A. and Del Rio, J. (1998) Characterization of serotonergic mechanisms involved in the behavioural inhibition induced by 5-hydroxytryptophan in a modified light-dark test in mec. Behon Pharmocol. 9: 103-12

Azmitia, E.C and Segal, M! (1978) An autoradiographic analysis of the differential ascending projectoons of the dorsal and median raphe nucle! in the rat. I Comp Neumol. 179:641-67.

Barden, N., Reul, J.M. and Holsboer, F. (1995) Do antidepressants stabilize mood through actions on the hypothalamic-pituitary-adrenocortical system? Trends Neurosci. 18:6-11.

Bendotti, C.. Servadio, A.. Forloni, G. Angeretti. N. and Samanin. R. (1990) Increased tryptophan hydroxylase mRNA in raphe serotonergic neurons spared by 5,7-dihydroxytryptamine. Brain Res Mol Brain Res, 8: 343-8.

Bizot, J., Le Bihan, C., Puech, A.J., Hamon, M. and Thuebot, M. (1.999) Serotonin and tolerance to delay of reward in rats. Psychopharmacology (Berl) 146: 4001-12.

Bjorklund, A., Baumgarten, H. Gi and Rensch, A. (1975) 5,7-Dihydroxytryptamine: Improvement of its. selectivity for serotonin neurons in the CNS by pretreatment with desipramine. I Neurochem. 24: 833-5.

Blier. P. (2001) Possible neurobiological mechanisms underlyung faster onset of antidepressan! action. J Clin Prychiatr. 62 Suppl 4: 7-11

Bher. P. and de Montigny, C. (1994) Current advances and trends in the treatment of depression. Trends Pharmacol Sct 15: 220-6.
Blokland. A.. Prickaerts, J. and Raajmakers, W. (1992) Reduced level of anxiety in aduh Lewis rats after chronic ethanol consumption. Phstol Behav: $51: 245-8$.

Borsini. F. and Cesana, R. (2001) Mechanism of action of thibanserin in the learned helplessness paradigm in rats. Eur J Pharmacol 433: 81-9.

Briley, M., Chopin, P. and Moret, C. (1990) Effect of serotonergic lesion on "anxious" behaviour measured in the elevated plus-maze test in the rat. Psochopharmacology (Ber), 101: 187-9.

Brockkamp, C.L., O'Connor, W.T., Tonnacr, J.A., Rijk, H.W and Van Delf, A.M. (1986) Corticosterone, choline acetyltransferase and noradrenaline levels in olfactory bulbecromized rats in relation to changes, in passive avoidance acquisition and open field activity. Plnstof Behav 37 : 429-34

Carli, M. and Samanin, R. (1992) 8-Hydroxy-2. (di-n-propylamino)tetralin impairs spatial learning in a water maze: role of postsynaptic 5-HTIA receptors. Br J Pharmacal 105: 720-6.

Carpenter, J.S., Andrykowski, M.A.. Wilson, J., Hall, L.A., Kayens, M.K.. Sachs, B. and Cunningham, L.L. (1998) Psychometries for two short forms of the Center for I pidemulogic Studies-Depression Scale. Issues Ment Health Nurs. 19:481-94

Cassaday, H.J., Norman, (.., Shilliam, C.S., Vincent, C. and Marsden, (C.A. (2003) Intraventricular 5,7-dihydroxytryptamine Iesions disrupt acquisition of working memory task rules but not performance once learned. Prog Nexuropsuchopharmacol Bial Pswchiatr: 27: 147-56.

Cervo L. and Samanin. R. (1991) Effect of chronic treatment with $8-O H-D P A T$ in the foreed swimming iest rẹuies the integrity of presynaptic serotonergic mechanisms. Psychopharmacalogy (Berl) 103:524-8

Cryan, 1.F. Markou. A and Luck., I (2002) Assessing antidepressant actuvity in rodents: recent developments and future needs. Trends Pharmacol Sc1 23: 238-45. 
De Boer, S.F., Koopmans, S.J., Slangen, J.L. and Van der Gugten, J. (1990) Plasma catecholamine, corticosterone and glucose responses to repeated stress in rats: effect of interstressor interval length. Physiol Behav: 47: 1117-24.

de Kloct, E.R., Oitzl, M.S. and Joels, M. (1999) Stress and cognition: are corticosteroids good or bad guys? Trends Neurosci. 22: 422-6.

Deakin, J.W.F. and Graeff, F.Gi (1991) 5-HT and mechanisms of defence. I Psychopharmacol. 5: 305-315.

Detke, M.J. and Luckı, I. (1996) Detection of serotonergic and noradrenergic antidepressants in the rat forced swimming test: the effects of water depth. Behav Brain Res. 73: 43-6.

Dringenberg. H.C.. Hargreaves, E.L., Baker, G.B.. Cooley, R.K. and Vanderwolf. C.H. (1995) pchlorophenylalanine-induced serotonin depletion: reduction in exploratory locomotion but no obvious sensory-motor deficms. Bertan Bram Res. 68. 229-37.

Emacetir, A and Delacour, J. (1988) A new onetral test for neurobiological studies of memory in rats. 1: Behavioral data, Behav Brain Res. 31:47-59.

Evenden. J. (1999a) Impulsivity: a discussion of clinical and experimental findings, / Psychopharmacol 13: 180-92.

Evenden, J., Ryan. C. and Palejko. W. (1995) The effects of repeated treatment with 8-hydroxy-2(di-n-propslammo) tetraln (8-0H-DPAT) on the lever press responding of the a under FI and DRI schedules of food reintorcement. Pswhopharmacology $(B e r)$. 120:81-4)2

Eienden, 1.L (1999b) The pharmacology of impulswe behaviour in rats V11: the effects of serownergic agonists and antagonists on responding under a discrimination task using unreliable visua! stimuli. Prychopharmacology (Berl), 146:422-31.

File, S.E. Kenny, P. and Cheeta, S. $(2000)$ The role of the dersal hippocampal serotonergic and cholinergic systems in the modutation of anxiety. Pharmacol Biochem Behan: 66: 65-72.

Fluttert, M., Dalm, S. and Oitzl, M.S. (2000) A refined method for sequential blood sampling by tail incision in rats. Lah Anim. 34: 372-8.
Graeff, F.G. (2002) On serotonin and experimental anxiety. Psychopharmacology (Berl). 163: 467-76.

Griebel, G (1995) 5-Hydroxytryptamine-interacting drugs in animal models of anxiety disorders: more than 30 years of research. Pharmacol Ther. 65: $319-95$.

Hall, F.S., Devries, A.C., Fong. G.W., Huang, S. and Pert. A. ( I999) Effects of 5,7-dihydroxytryptamine depletion of tissue serotonin levels on extracellular serotonin in the striatum assessed with in vivo microdialysis: relationship to behavior. Synapse". 33: 16-25.

Harkin, A.. Connor, T.J., Walsh, M., St John, N. and Kelly, J.P. (2003) Serotonergic mediation of the antidepressant-like effects of nitric oxide synthase inhibitors. Neumopharmacology, 44:616-23.

Harmer, C. I. Bhagwagar, Z.. Cowen, P.J. and Goodwin. GM. (2002) Acute administration of citalopram facilitates memory consolidation in

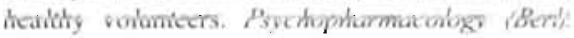
163:106-10.

Harrison, A.A., Everitt, B.J. and Robbins, T.W (1997a) Central 5.HT depletion enhances impulsive responding without affecting the accuracy of attentional performance: interactions with dopaminergic mechanisms. Psychopharmacology (Beri). 133:329-42.

Harrison, A.A., Everitt, B.J and Robbins, T.W. (1997b) Doubly dissociable effects of median- and dorsal-raphe lesions on the performance of the fivechoice serial reaction time test of attention in rats. Behav Brain Res 89: 135-49.

Harro, J., Tonissaar. M., Eller: M. Kask, A. and Oreland. L. $\{2001)$ Chronic variable stress and partial 5-HT denervation by parachloroamphetamine treatment in the rat: effects on behavior and monoamine neurochemistry. Brain Res. 899: 227-39.

Hodos, W. (1961) Progressive ratio as a measure of reward strength. Sctence. 134:943-4.

Jameison. K. and Dinan, T.G. (2001) Glucocorticoids and cognitive function: from physiology to pathophysiology. Hum Psuchopharmacol. 16: 293-302.

Kumar, K.B. Nalim, K. and Karanth. K.S. (1995) Effects of p-chlorophenylalanıne-induced depletion 
of brain serotonin on retrieval of appetitive and aversive memories. Indian J Exp Biol. 33; 837-40

Lehmann, O., Bertrand, F. Jeltsch, H., Morer. M. Lararus, C., Will, B. and Cassel, J.C. (2002a) 5,7. DHT-induced hippocampal 5-HT depletion attenuates behavioural deficits produced by $192 \mathrm{lgG}$ saporin lesions of septal cholinergic neurons in the rat. Eur J Neurasci 15; 1991-2006.

Lehmann, O., Jeltsch, H., Bertrand, F., Lazarus, C., Will, B. and Cassel, J. (2000) When injected into the fimbra-formix/cingular bundle, not in the raphe, 5.7-dihydroxytryptamine prevents amphetamue-induced hyperlocomotion. Behar Brain Res 114:213-7

Lchmann, O., Jeltsch. H., Lazarus, C., Tritschler, L., Bertrand, F. and Cassel. J.C. (2002b) Combined $192 \mathrm{IgG}$-saporin and 5,7-dihydroxytryptamine lesions in the male rat brain: a neurochemical and behavioral study. Pharmacol Biochem Behav, 72: 849.912

Lieben, C.K., Blokland, A., Westerink, B. and Deutz. N.E. (2004a) Acute tryptophan and serotonin depletion using an optimized tryptophan-free protein-carbohydrate mixture in the adult rat. Neurochem Int 44:9-16.

Lieben. C.K., Oorsouw, K., Deut, N.E. and Blokland. A. (2004b) Acute tryptophan depletion induced by a gelatin-based mixture impairs object memory but not affectuve hehavior and spatial learning in the rat. Behav Brain Res. 151: 53-64.

Luciana, M.. Burgund, E.D., Berman. M. and Hanson, K.L. (200!) Effects of tryptophan loading on verbal, spatial and affective working memory functions in healthy adults, I Psuchopharmacol. 15: $219-30$.

Lucki, I., Singh. A. and Kreiss, D.S. (1994) Antidepressant-like behavioral effects of serotonin receptor agonists. Neurusc Biobehav Rer: 18: 85-95.

Majlessi. N. Kadkhodace, M.. Parviz. M. and Naghdi.. N. (2003), Serotonin depletion in rat hippocampus attenuates L-NAME-induced spatual learning deficits, Brain Res. 963: 244-51

Mann, J. (1999) Role of the serotonergic system in the pathogenesis of major depression and suicidal behavior. Neuropsychopharmacology: 21. 995 . $105 \mathrm{~S}$.
Martin, P. Beninger, R.J., Hamon, M. and Puech. A.J. (1990) Antudepressant-like action of $8-\mathrm{OH}$ DPAT, a 5-HTIA agonist, in the learned helplessness paradigm: evidence for a postsynaptic mechanism. Behav Brain Res. 38: 135-44.

McAllister-Williams, R.H., Ferrier, I.N and Young. A.H. (1998) Mood and neuropsychological function in depression: the role of corticosteroids and scrotonin. Psuchological medicine, 28: 573. 584.

MeEntec, W.J. and (rook, T.H. (1991) Serotonin. memory, and the aging brain. Psuchopharma. cology: 103: 143-9

Mobini, S.. Chiang. T.J., Al-Ruwaitca, A.S., Ho. M.Y., Bradshaw, C.M. and Szabadi, E. (2000a) Effect of central 5-hydroxytryptamune depletion on inter-temporal choice: a quantitative analysis. Psuchopharmacologo (Berl), 149: 313-8.

Mobıni, S., Chang, TJ, Ho, M. Y. Bradshaw, C.M. and Szabadi, E (2000b) Effects of eentral 5 hydroxytryptamme depletion on sensituvity to delayed and probabilistic reinforcement. Psychopharmacology (Berl) $\quad$ 152:390-7

Murtha. S.J. and Pappas, B.A. (I994) Neurochemical, hrstopathological and mnemonic ellects of combined lesions of the medial septal and serotonin afferents to the hippocampus. Brain Res. 651 . 16-26.

Netto, S.M., Silveira, R. Coimbra, N.C.. Joca, S.R. and Guimaraes, F.S. (2002) Anxiogenic effect of median raphe nucleus lesion in stressed rats. Prog Neuropsychopharmacol Biol Psychatr: 26: 113541.

Ohashi, S., Matsumoto, M., Togashı, H., Ueno, K and Yoshioka, M. (2003) The serotonerge modulaton of synaptic plasticity in the rat hippocampomedial prefrontal cortex pathway. Neurusci lett $342: 179-82$

Ossenkopp. K.P. and Mazmanian, D.S. (1985) The measurement: and integration of behavioral vari. ables: aggregation and complexuty as important issues. Neurohehas Toxicol Teratol. 7: 95-100

Panocka, I. Perfumi, M. Angelett, S. Ciccoctoppo, R. and Massi, M. (2000) Effects of Hypericum perforatum extract on ethanol intake. and on behavioral despair: a search for the neuro- 
chemical systems involved. Pharmacol Biochem Behav. 66: 105-11.

Paxinos, $\mathrm{C}$. and Watson, C. (1996) The rat brain in stereotaxic coordinates, (compact 3rd edn ed.). San Diego: Academic Press.

Perfumi, M., Panocka, L., Ciccocioppo, R., Vitali, D. Froldi, R. and Massi, M. (2001) Effects of a methanolic extract and a hyperforin-enriched $\mathrm{CO}_{2}$ extract of Hypericum perforatum on alcohol intake in rats. Alcohol Alcohol. 36: 199-206.

Porsolt, R.D. (1979) Anımal model of depression. Biomedicine, 30: 139-40.

Prickacrts, J., Raaijmakers, W. and Blokland, A. (1996) Effects of myocardial infarction and captopril therapy on anxiety-related behaviors in the rat. Physiol Behav 60: 43-50.

Puumala, T., Ruotsalainen, S., Jakala, P., Kotvisto, E. Riekkinen, P.. Jr. and Sirvio, J. (1996) Behavioral and pharmacological studies on the validation of a new anımal model for attention deficit hyperacivity disorder. Neurobiol Learn Mem. 66 : 198-2 I!

Rex, A., Thomas, H., Hortnagl, H., Voits, M. and Fink, H. (2003) Behavioural and microdialysis sudy after neurotoxic leston of the dorsal raphe nucleus in rats. Pharmacol Biochem Behav. 74 : $5 \times 7-93$.

Riedel, W.J., Klaassen, T., Deutz. N.E., yan Someren, A. and van Praag. H.M. (1999) Tryptophan depletion in normal volunteers pro. duces selective imparment in memory consolidaAim. Psichopharmacology (Berl). 141: 362-9.

Rubinsztein, J.S., Rogers, R.D.. Riedel. W.J. Mehta, M.A., Robbins, T.W. and Sahakian, B.J (2001) Acute dietary tryptophan depletion impairs mamtenance of "aflective set" and delayed visual recognition in healthy volunteers. Pswchopharmacology $(B e r l) .154: 319-26$

Santucei, A.C.. Knott, P.J. and Haroutuman. V. (1996) Execssive serotonun release, not depletion. leads to memory imparments in rats. Eur I Pharmacol 295:7-17.

Sawynok, J. and Red, A. (1994) Spinal supersensitivity to S-HT1, 5-HT2 and 5-HT3 neceptor ago- nists following 5,7-dihydroxytryptamine. Eur J Pharmacol. 264: 249-57.

Schreiber, R. and De Vry, J. (1993) Neuroanatomical basis for the antidepressant-like effects of the 5-HT(1A) receptor agonists 8-OH-DPAT and ipsapirone in the rat forced swimming test. Behav Pharmacol. 4: 625-636.

Sena, L.M., Bueno, C., Pobbe, R.L., Andrade, T.G. Zangrossi, H. Jr. and Viana, M.B. (2003) The dorsal raphe nucleus exerts opposed control on generalized anxicty and panic-related defensive responses in racs. Behav Brain Res. 142: 125-33.

Sobczak, S., R'redel, W.J., Booij. 1., Aan Het Rot, M., Deut, N.E. and Honig, A. (2002) Cognition following acute tryptophan depletion: difference between first-degree relatives of bipolar disorder patients and matched healthy control voluntecrs. Psychol Med. 32: 503-15.

Somogyi, P. and Takagi. H. (1982) A note on the use of picric acid-paraformaldehyde-glutaraldehyde fixative for correlated light and electron microscopic immunocytochemistry. Neurosctence. 7: 1779-83.

Soubrie, P., Martin. P. el Mestikawy, S., Thiebot, M. ßl., Simon. P'. and Hamon, M. , (1986) The lesion of serotonergic neurons does not prevent antidepressant-induced reversal of escape failures produced by inescapable shocks in rats. Pharmacol Biochem Behav: 25 ; 1-6.

Steckler, T. and Sahgal. A. (1995) The role of serotonergic-cholinergic interactions in the mediation of cognitive behaviour. Behavioural Brain Reseanch. $67: 165-190$

Stockmeier, C.A. (2003) Involvement of serotonin in depression: evidence from postmortem and imaging studies, of serotonin receptors and the serotonun transporter. / Psuchatr Res. 37: $357-73$

Sulon. J., Demey-Ponsart. L. Beaudum. P. and Sodoyez, J.C. (1978) Radioimmunoassay of corticosterone, cortisol and cortisone: their application to human cord and maternal plasma. I Stemud Bioche'm. 9:671-6.

Thomas, H., Fink. H. Sohr. T.R. and Vouts. M (2000) Lesion of the median raphe nucleus a combined hehavioral and microdialysis study in rats Pharmacol Biochem Behas: 65: 15-21. 
Tork. I. (1990) Anatomy of the serotonergic system. Ann N Y Acad Sci. 600: 9-34; discussion 34-5.

van der Staay, F.J, and Blokland, A. (1996) Behavioral differences between outbred Wistar, inbred Fischer 344. brown: Norway, and hybrid Fischer $344 \mathrm{x}$ brown Norway rats. Physiol Behav. 60: $97-109$.

van der Staay, F.J., Kerbusch, S. and Raaijmakers. W. (1990) Genetic correlations in validating emotonality. Behav Genet: 20: 51-62. van Praag, H.M. and Korf, J. (1974) Serotonin metabolism in depression: clinical application of the probenecid test. Inr Pharmacopsychiatry. 9: 35-51.

Vertes, R.P. (1991) A PHA-L analysis of ascending projections of the dorsal raphe nucleus in the rat. $J$ Comp Neurol. 313: 643-68.

Vertes, R.P. Fortin, WJ. and Crane, A.M. (1999) Projections of the median raphe nucleus in the rat. $J$ Comp Neumol. 407: 555-82. 



\section{CHAPTER}

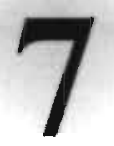

Dose related effects of acute tryptophan depletion on object discrimination in the rat.

C.K.J. Lieben, R. Schreiber, N.E.P. Deutz and A. Blokland. 


\section{Abstract}

The current study was carried out to investigate the relationship between serotonin (5-HT) and recognition memory by means of acute TRP depletion. The extent of plasma TRP depletion was accomplished by the modification of a gelatin-based protein, which was added to a carbohydrate mixture. Four hours after the first administration, we investigated the dose-dependent effects of this TRP lacking mixture on recognition memory.

Increasing the amount of the gelatin-based protein that was added to the carbohydrate mixture reduced plasma TRP levels. Especially the extent of plasma TRP/ LLNAA depletion gradually increased by raising the amount of protein. Compared to a control condition (i.e. a TRP-enriched mixture; $T R P+1$, performance in object discrimination remained stable in the conditions where the protein was absent or added in a small dose. Increasing the amount of protein tended to affect the performance in object discrimination and in the highest dose (TRP-50) condition recognition memory was impaired. These findings indicate that the performance in recognition memory is related to plasma TRP levels.

\section{Introduction}

Over recent years, increasing evidence supports the involvement of serotonin (5-hydroxytryptamine: 5-HT) in affective behavior and in cognitive processes. For example, in patients suffering from depression (Meltzer, 1989) and in long-term users of ecstasy (MDMA) (White et al., 1996: McCann et al., 1998) a reduction in central 5-HT synthesis has been found. Impaired cognitive processes in these subjects, indicated that a number of memory functions (e.g. recognition. semantic or implicit memory) might be associated with a change in 5-HT synthesis (Austin et al., 1992; llsley et al., 1995; Reneman et al. 2000). This was further supported by the acute tryptophan (TRP) depletion method (ATD) which is used to lower the synthesis of 5-HT by reducing the available amount of its precursor in plasma. Acute administration of a TRP-free amino acid mixture reduced plasma TRP levels, consequenily leading to an impairment in long-term memory functions (Riedel et al., 1999). ATD-induced cognition impairments have been found in healthy subjects and first-degree relatives of depressed patients and for verbal and non-verbal tasks (Klaassen, et al., 1999; Rubinsztein et al.. 2001; Sobczak et al., 2002). Furthermore, in healthy subjects, treatment with the selective serotonergic reuptake inhibitor citalopram improved memory performance related to long delay recall processes (Harmer et al., 2002). 
We found that a pronounced reduction in plasma TRP levels impaired recognition memory in a rat novel object recognition task (Lieben et al., 2004 b). This effect was suspected to be 5-HT related since the applied TRPfree protein-carbohydrate mixture reduced central 5-HT levels (Lieben et al., 2004a). In line with these findings, lesioning 5-HT neurons in the dorsal raphe nucleus with the neurotoxin 5,7-dihydroxytryptamine (5,7-DHT) led to an impairment, in object recognition (Lieben et al., 2003).

In the present study, we examined whether the degree of TRP depletion would correlate with the degree of impairment in recognition memory. A gelatin-like protein-carbohydrate mixture was used to induce a dose-dependent reduction of plasma TRP levels. By varying the amount of TRP-free protein in the mixture, we expected a raise in the level of most amino acids, except for TRP. As a result, the competition between TRP and large neutral amino acids (LNAAs), sharing the same transporter system for entering the central nervous system, would not be in favor for TRP. Consequently, higher amounts of this TRP-free protein would increase the degree of TRP depletion, which would eventually reduce central 5-HT concentrations. The rats' performance in an object recognition task was assessed employing different protein amounts and compared to the performance of control rats treated with a TRPenriched protein-carbohydrate mixture.

\section{Materials and methods}

\section{Animals}

The experiment was carried out with twenty-four four months old adult male Wistar rats, (Charles River, USA). The rats were individually housed in standard Makrolon cages on wood shavings in an air-conditioned room $\left(20^{\circ} \mathrm{C}\right)$. The rats had free access to food and water. They were maintained under a reversed 12/12 h light/dark cycle (lights off from 08.00 to $20.00 \mathrm{~h}$ ). All experimental procedures were conducted in a manner consistent with the local regulations (California, IUACUC).

\section{Drug and chemicals}

The Gelatin hydrolysate (Solugel $\mathrm{C}^{*}$ ) was purchased from PB Gelatins (Tessenderlo, Belgium). Glucodry 200 was obtained from the Amylumgroup, Koog aan de Zaan. The Netherlands. L-tryptophan was from Sigma (CA, USA). Sodiumchloride $(\mathrm{NaCl}, 0.9 \%$ ) was purchased from Baxter S.A., Lessines. Potassiumchloride $(\mathrm{KCl})$ and calciumchloride-dihydrate $\left(\mathrm{CaCl}_{2}, 2 \mathrm{H}_{2} \mathrm{O}\right)$ were purchased from Merck. CA, USA. 


\section{Treatment}

During the week preceding the administration of the protein-carbohydrate mixture, the rats were handled and habituated to oral injections with normal tap water $(10 \mathrm{ml} / \mathrm{kg})$. Food was removed $14 \mathrm{~h}$ before the first administration of the protein-carbohydrate mixture in order to minimize TRP uptake from food. At all times, the animals had free access to water. The rats were treated either with a protein-carbohydrate mixture containing additional TRP (TRP+, $0.28 \%$ TRP of total protein) or lacking TRP (TRP-), for further details on the composition of the mixture see (Lieben et al., 2004b).

In the TRP- condition, the amount of protein dissolved in the mixture was varied with $10 \mathrm{~g}$, ranging from 0 to 50 . Testing order of the protein dose condition was randomly chosen. All rats were treated once with each dose condition. On every test day, the animals were injected twice, using an interval of $90 \mathrm{~min}$. Independent of the protein amount, each administration contained $2 \mathrm{~g}$ Glucodry $200 / \mathrm{kg}$ and was given orally in a volume $10 \mathrm{ml} / \mathrm{kg}$.

\section{Object recognition test}

The object recognition test was performed as described in detail elsewhere (Ennaceur and Delacour, 1988; Lieben et al., 2004b). The apparatus consisted of a circular arena, $83 \mathrm{~cm}$ in diameter. Half of the $40-\mathrm{cm}$-high wall was made of grey polyvinyl chloride. the other half of transparent polyvinyl chloride. The light intensity ( 20 Lux) was equal in the different parts of the apparatus. We used four different sets of objects that could not be displaced by a rat. Each object was available in triplicate. The different objects were (1) a cone consisted of a grey polyvinyl chloride base (maximal diameter $18 \mathrm{~cm}$ ) with collar on top made of brass (total height $16 \mathrm{~cm}$ ). (2) a standard I I transparent glass bottle (diameter $10 \mathrm{~cm}$, height $22 \mathrm{~cm}$ ) filled with water, (3) a massive metal cube $(10 \mathrm{~cm} \times 5 \mathrm{~cm} \times 7.5 \mathrm{~cm})$ with two holes (diameter $1.9 \mathrm{~cm})$, and (4) a massive aluminium cube with a tapering top $(13 \mathrm{~cm} \times 8 \mathrm{~cm}$ $x \times(m)$.

In the week preceding operation, the animals were adapted to the procedure, i.e. they were allowed to explore the apparatus (without any objects) twice for 3 min each day. In the following days, the rats were trained until a stable discrimination performance was show. A testing session comprised two trials. The duration of each trial was $3 \mathrm{~min}$. Two objects were placed in a symmetrical position about $10 \mathrm{~cm}$ away from the gray wall. A rat was always placed in the apparatus facing the wall at the middle of the front (transparent) segment. During the first trial (T!) the apparatus contained two identical objects. After the first exploration period the rat was put back in its home 
cage. After a one hour interval the rat was put back in the apparatus for the second trial (T2), but now dissimilar objects, a familiar one and a new one. The duration of exploring each object in T1 and T2 was recorded manually with a personal computer. Exploration was defined as directing the nose to the object at a distance of no more than $2 \mathrm{~cm}$ and/or touching the object with the nose. Sitting on the object was not considered as exploratory behavior. In order to avoid the presence of olfactory trails, the objects were always thoroughly cleaned. Moreover, each object was available in triplicate so that none of the two objects from the first trial had to be used as the familiar object in the second trial. In addition, all combinations and locations of objects were used in a balanced manner to reduce potential biases due to preferences for particular locations or objects.

After the rats were familiarized to the procedures of the task, testing with treatment began. The first trial was given 4 h after the first oral administration. The delay interval of $1 \mathrm{~h}$ was preferable since during this time, we expected plasma TRP levels to remain low. To prevent adaptation of treatment effects on plasma TRP' levels, a delay of at least one day was build in between two testing sessions. The basic measures were the total exploration time of both objects during $\mathrm{T} 1$ and $\mathrm{T} 2$, el and e2, respectively. We used a criterion of at least $10 \%$ above mean for a minimum exploration value to avoid possible erroneous conclusions. A discrimination index $(d 2=$ (exploration new object - exploration familiar object)/total exploration time during test trial) was calculated.

\section{Plasma amino acid concentrations}

After behavioral testing, the animals were divided into two groups matched for body weight. For the determination of plasma amino acid levels, blood samples were taken from each animal once at resting levels (i.e. $20 \mathrm{~min}$ before the first administration). Different treatment conditions, defined as the administration of a protein-carbohydrate mixture in which the amount of protein in the mixture is varied, were selected (i.e. TRP+. TRP-0, TRP-10, TRP -30 and TRP-50) and were randomly given to each group ( $n=11 /$ dose condition). Blood samples were taken $4 \mathrm{~h}$ after the first administration was given. The interval between sessions was at least $24 \mathrm{~h}$.

Blood sampling was done via a tail-incision method (Fluttert et al., 2000). Promptly after collection of blood in a heparin tubes (Microvette ${ }^{*}$ CB 300 . Sarstedt. Germany), the samples were kept on ice. After centrifugation of the blood samples (at $4{ }^{\circ} \mathrm{C}$ for $15 \mathrm{~min}$ at $3000 \mathrm{xg}$ in a Hettich EBA 12 centrifuge), plasma was deproteinized with cups containing dry 5 -sulfosalicylic acid (6 $\mathrm{mg} / 100 \mu \mathrm{l}$. plasma) and the protein was spun down. Following these 
preparations, samples were frozen in liquid nitrogen and stored at $-80^{\circ} \mathrm{C}$. Before analysis, samples were thawed at $4{ }^{\circ} \mathrm{C}$, vortex-mixed vigorously and centrifuged at $50000 \mathrm{x} \mathrm{g}$ in a Hereaus Model Biogufe Stratos for $10 \mathrm{~min}$ at $4{ }^{\circ} \mathrm{C}$. From the clear supernatant $20 \mu \mathrm{l}$ was mixed with $1960 \mu \mathrm{l}$ water and $20 \mu \mathrm{l}$ norvaline and stored in the cooled $\left(7^{\circ} \mathrm{C}\right)$ sample compartment until analysis (van Eijk et al., 1993). In addition to total plasma TRP, the concentrations of LNAAs were determined with a fully automated highperformance liquid chromatography (HPLC) system after precolumn derivatization with o-phthaldialdehyde (OPA) (van Eijk et al., 1993). OPAAA derivates were quantified with fluorescence detection. The concentrations of the total plasma amino acids were expressed as $\mu \mathrm{mol} / \mathrm{l}$.

\section{Statistical analysis}

Mean exploration times in T1 and T2 were scored for each condition. Based on the explorative behavior in $\mathrm{T} 2$, the mean discrimination index $(d 2)$ was calculated for each dose condition. Mean total plasma amino acid concentrations and the mean TRP/LLNAA ratio (LNAA: large neutral amino acids, i.e., tyrosine, phenylalanine, leucine, isoleucine and valine) were measured for each condition. prior and post administration. For all variables, treatment effects were analyzed using parametric statisties (analysis of variance). To further characterize the ireatment effect on the discrimination performance, a post-hoc Dunnett analysis was performed where results of each condition were compared to those of a control group (e.g. virtual or TRP+ group) or to resting levels, significance level was set at $p<0.05$. The virtual group was constructed with a mean of zero and a SEM of 0.06 (see: Sik et al., 2003).

\section{Results}

\section{Object recognition test}

Two rats had to be removed from the statistical analysis because they did not explore the objects in all trials. The treatment of a protein-carbohydrate mixture affected the exploration times of both trials $[F(6,149)>2.86, p<0.05$; see Table 1]. Explorative behavior in $\mathrm{T} i$ was similar for every condition when compared to TRP+ condition. However in T2, post-hoc analysis revealed an increase in explorative behavior occurred after the TRP-50 dose condition compared to the TRP+ condition.

Varying the dose of protein affected, the discrimination index $[d 2 ; F(6,149)=$ 2.88, $p<0.05]$. In the TRP+ and the lower TRP-dose conditions (i.e. TP-0. 
TRP-10 and TRP-20), the rats displayed high $d 2$ values, which were different from zero, indicating a preference to investigate the novel object (see Fig. 1). Although the performance in the object discrimination of rats in the TRP-30 and the TRP-40 dose condition did not significantly differ from that of the TRP+ condition. In these dose conditions, the rats could not discriminate between the novel and the known object in the second trial and therefore performance in object recognition was similar to the virtual group. Furthermore, rats of the TRP-50 group displayed a strong decline in object discrimination when compared to the TRP+ group.

Table 1. Effects of protein-carbohydrate mixture on the exploration time in the object recognition lest Rats ( $n=24 /$ group) were administrated with the protein-carbohydrate mixture, TRP+ or TRP- (the amount of protein in the meal). 4 and 2.5 hours before the first trial. The delay interval between the first and second trial was one hour Mean values (SEM) of total exploration time (s) during the first (e1) and second trial (e2). Between session effects compared to the TRP+ condition on $e 1$ and $e 2$ are depicted with asterisks $(+0.1>p>0.05$ and * $p<0.05$ )

$\begin{array}{llllllll} & \text { TRP+ } & \text { TRP-0 } & \text { TRP-10 } & \text { TRP-20 } & \text { TRP-30 } & \text { TRP-40 } & \text { TRP-50 } \\ \text { e1 } & 27(2.8) & 24(1.6) & 29(2.4) & 33(2.2) & 24(2.2) & 24(1.7) & 28(1.6) \\ \text { e2 } & 28(1.6) & 27(2.0) & 34(2.3) & 35(2.3) & 29(1.8) & 32(1.9) & 36(2.2)\end{array}$

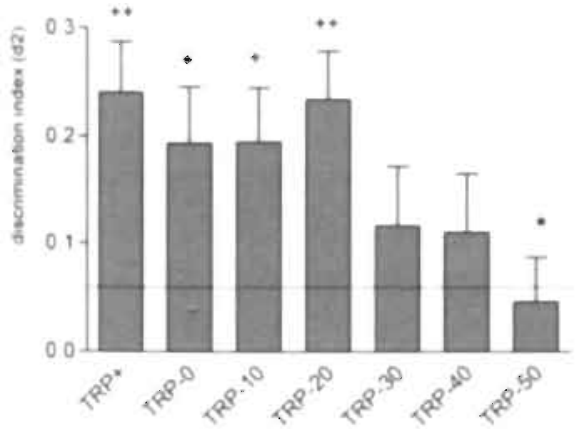

acse conglion
Fig. 1: Effects of a TRP-free, protein-carbohydrate mixture on the discrimination performance in an object recognition test in adult male rats $(n=24$ / group, mean + SEM). A $1 \mathrm{~h}$ interval was used between trials. In the control session (TRP+), rats were treated with the TRP-enriched mixture. In the TRP. condition, rats were treated with different doses of TRP-free. protein. Differences from virtual group: $+p$ $<0.05$ and $++p<0.01$. The dotted line represents the SEM-range of the virtual group (mean: 0, SEM: 0.06) Differences from TRP + group * $\rho<0.05$

\section{Plasma TRP levels.}

Administration of a protein-carbohydrate mixture significantly affected the plasma TRP levels and the TRP $/ 2 L N A A$ ratio $[F(5.73)>25.82, p<0.011$. In general, similar effects were obtained on plasma TRP levels and the TRP/LLNAA ratio, with the exception of the TRP-0 and TRP-10 dose conditions where only the plasma TRP levels were reduced. Compared to resting levels, $4 \mathrm{~h}$ after the first administration was given, plasma TRP levels 
were reduced by approximately $20 \%$ in the TRP+, TRP- 0 and TRP- 10 conditions (see Fig. 2A). A similar degree of reduction also occurred in the TRP/ $/$ LNAA ratio of the TRP+ group. However, in the TRP-0 and the TRP10 dose conditions, this ratio was comparable to those of resting condition (see Fig. 2B). In the TRP-30 dose condition, a 47\% reduction was found in both plasma TRP levels and TRP/ LLNAA ratio. The highest depletion of plasma TRP levels and the TRP/ LLNAA ratio was obtained for the TRP-50 condition ( $51 \%$ and $61 \%$, respectively).

(A)

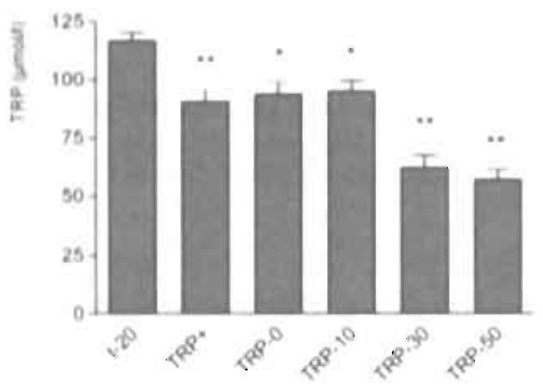

(B)

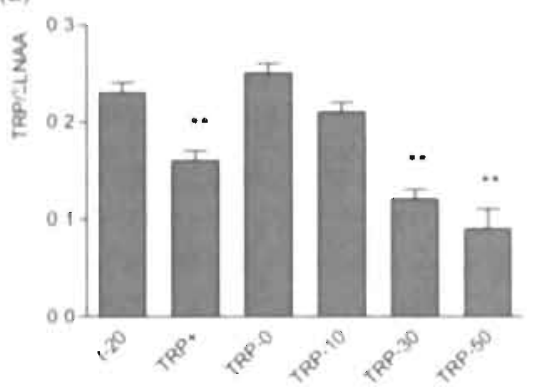

dose congtion

Fig. 2. Peripheral effects of a protein-carbohydrate mixture. Mean values (+SEM) of absolute plasma total TRP levels $(\mathrm{A}: \mu \mathrm{mol} / 1)$ and TRP/ LNAA ratio $(B)$ at resting levels $(\mathrm{t}-20)$ and $4 \mathrm{~h}$ after the first oral administration of a protein-carbohydrate mixture containing (TRP+) or lacking (TRP-) TRP. The amount of protein in the TRP. condition was varied containing 0,30 or $50 \mathrm{~g}$ of protein in the mixture. Differences from resting condition with asterisks ( $p<0.05$ and ** $p<0.01)$.

(A):

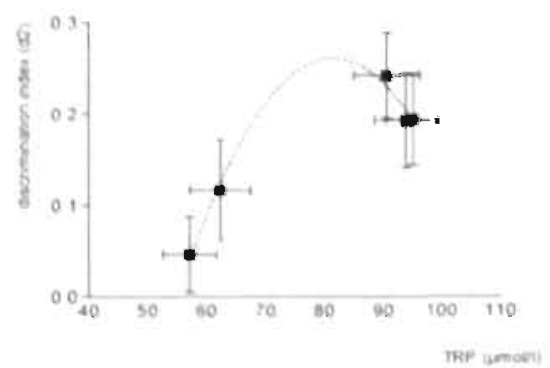

(B).

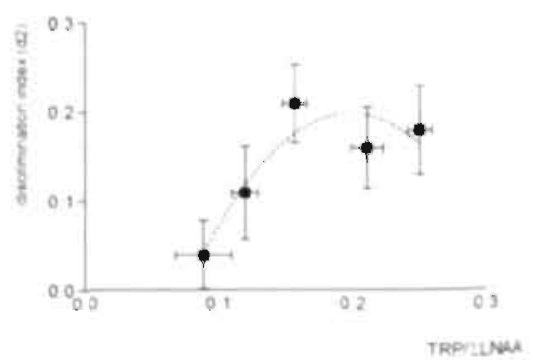

Fig. 3. The relationship between object discrimination and plasma TRP levels (A) and the TRP/ILNAA ratio (B) at $4 \mathrm{~h}$ after the first administration of a protein-carbohydrate mixture 


\section{Discussion}

The present study was carried out in order to elaborate our knowledge of the role of 5-HT on learning and memory processes. A positive correlation between plasma TRP levels (or TRP/LLNAA) and the performance in recognition memory was found (see Fig. 3). This finding indicated that a functional severity of impairment in recognition memory could be generated by the extent of plasma TRP depletion.

This experiment was initially based on a recently proposed 'threshold theory', which hypothesizes that the onset of depressive symptoms depends on 5-HT levels. The degree of TRP/ $L$ LNAA depletion would function as an indicator of depressive symptoms in remittent depressed patients treated with antidepressants. Remission would occur at a reduction of approximately $60 \%$ (Van der Does, 2001), although we previously found that a reduction of about $65^{\circ}$ in TRP/LLNAA ratio did not cause depressive-like behavior in rats (Lieben et al., 2004b). However, this level of reduction induced by a TRP-free protein-carbohydrate mixture severely impaired the rat's ability to discriminate between objects. This effect on recognition memory was presumably imputed to a reduction in 5-HT synthesis consequently leading to a reduction in 5-HT levels. This is supported by the impairment in object recognition following lesioning of 5 -HT-containing neurons in the dorsal raphe nucleus which led to the hypothesis that a direct relationship between 5-HT and recognition memory exists (Lieben et al., 2003). The objective of the present study was to investigate the dose-dependent effects of TRP-free protein-carbohydrate mixtures on object recognition.

General, similar experimental conditions were used as in previous studies. However, in the present study, a small reduction in plasma TRP levels occurred in the group treated with a TRP-enriched (TRP+) mixture. Apparently, the amount of TRP added into the mixture was not sufficient to compensate for the reduction in plasma TRP levels by the TRP-free proteincarbohydrate mixture. Differences in experimental conditions might have contributed to this effect. For example, the current experiments were performed in a laboratory where housing conditions were different and rats were not tested in the same room as where they were housed. In addition, differences in Wistar breeding strains or standard chow (e.g. containing a different amount of TRP) could have contributed to the different findings with the TRP+ groups. The reduction in plasma TRP levels was even higher for the 
TRP/LLNAA ratio. This can be induced by the increased levels of LNAAs resulting from the administration of the protein mixture, which reduced the probability for TRP to cross the blood-brain barrier even further. Nevertheless, these TRP + treated animals still performed well in the object recognition test $(d 2>0)$, suggesting that the reduction in plasma TRP levels of the control group did not affect functional behavior on object recognition.

A small reduction in plasma TRP levels was found in the TRP-0 condition in which the rats were administrated with a carbohydrate mixture. However, this protein-free carbohydrate mixture did not affect the TRP/LLNAA values. The explanation may involve the absence of the gelatin-based protein in the mixture as the lack of protein equally reduces the level of plasma TRP and of the LNAAs (data not shown). Consequently, the competition between TRP and LNAAs remains unchanged and therefore the carbohydrate-mixture might not affect central TRP/5-HT concentrations. However, carbohydrates have been shown to increase central TRP levels (Fernstrom and Wurtman, 1971: Dye et al., 2000), and it has been suggested carbohydrates can stimulate the uptake of branched chain amino acids (leucine, isoleucine and valine) into muscle tissue by an increase of insulin. Consequently, this would change the competition between TRP and the LNAAs at the level of the blood-brain barrier in favor of TRP, which therefore would eventually increase the levels of central 5-HT. But again, our data show that rats administered with the protein-free carbohydrate mixture (i.e. TRP-0 condition) displayed an intact performance in object discrimination. It appears that the small reduction of plasma TRP levels in the TRP-0 condition may have no functional relevance in our behavioral task.

Adding a small dose of the gelatin-based protein (i.e. $10 \mathrm{~g}$ ) to the carbohydrate mixture did not reduce the plasma levels of TRP and TRP/ LLNAA any further than the carbohydrate-mixiture. Nor did this TRP-10 condition affect object recognition.

However, a firther increase in the protein severely affected plasma TRP levels and TRP ILNAA values. Adding $30 \mathrm{~g}$ of protein into the mixture reduced plasma TRP levels and TRP $\Sigma L N A A$ values by $47 \%$ within $4 \mathrm{~h}$ after the first administration was given. We found that in the TRP-30 condition. rats were no longer able to discriminate a novel object from a familiar object $(d 2=0)$. A similar behavior in recognition memory was displayed in the TRP40 condition. Further inereasing the amount of this gelatin-like protein to 50 $\mathrm{g}$ affected both TRP and TRP LLNAA values by $51 \%$ and $61 \%$, respectively. The results show that in this TRP-50 condition, recognition memory was 
severely impaired indicating that the rats could no longer discriminate a novel object from a familiar one which was presented one hour before in T1.

Investigation on behavioral and physiological treatment effects of this protein-carbohydrate mixture was completed successively (i.e. first object recognition test and then blood sampling) in the same batch of rats. One has to take in account that the effect on plasma TRP levels of each dose condition was not studied at the same day as the effect of that same condition on object discrimination which might methodological confound the conclusion about the correlation between these variables. Nevertheless, in order to obtain a general indication of the relationship between TRP levels and recognition memory, we plotted the mean values of each variable on every dose condition. As illustrated in Fig. 3A and B, both the absolute plasma TRP levels and TRP/ 2 LNAA ratio showed a positive relationship with the object discrimination, indicating that performance in recognition got worse by decreasing the TRP levels and the ratio of TRP/LLNAA, both indicators of central 5-HT.

\section{References}

Austun, M.P. Ross, M., Murray, C... O'Carroll, R.E., Ebmeier. K.P. and Goodwin. GiM. (1992) Cognitive function in major depression. I Affect Disond. 25: 21-9

Dye. L.. Lluch. A and Blundell. J.E. (2000) Macronutrients and mental performance. Nutrition. 16: 1021-34

Ennaceur, A. and Delacour, J. (1988) A new onetrial test for neurobiological studies of memory in rats. 1: Behav voral data. Behon Bran Res. $31: 47-59$

Fernstrom, J.D. and. Wurtman, R.J. (I971) Brain serotonin content: increase following ingestion of carbohydrate diet. Science: 174; 1023-5

Fluttert, M. Dalm. S. and Oitzl. M.S. (2000) A refined method for sequential blood sampling by tail incision in rats. Lah fnim 34: $372-8$

Harmer. C.J., Bhagwagar, Z., Cowen. PJ and Goodwin. GM (2002) Acute adminstratıon of crtalopram facilitates memory consolidation in healthy volunteers. Psychopharmacoling (Berl). $163.106-10$.
Ilsley, J.E. Moffoot, A.P. and O'Carroll. R.! (1995) An analysis of memory dysfunction in major depression. I Affect Disord. 35: 1.9.

Klaassen, T., Riedel, WJ. Honig, A., Van Someren, A., Deutz N.E.P. and Van Praag. H.M. (1999) Mood effects of 24-hour tryptophan depletion in healthy. first degree relatives of patients with affective disorders. Bioloxical Pswchatry 46, 489-497.

Lieben, C.. Steinbusch, H and Blokland, A. (2003) Comparable effects of acute and chronic 5-HT depletion: Impaired object recognition but no effects. on forced swimming behavior in the rat. Society for Neurosctience: 835.19.

Lieben, C.K.. Blokland. A., Westerink, B and Deutz, N.E. (2004a) Acute tryptophan and serotonin depletion using an optımired tryptophan-free protein-carhohydrate mixture in the adult rat. Veurochem Int 44 :9.16,

Lieben. C.K.. Oorsouw, K.. Deut,. NE and Blokland, A (2004h). Acute tryptophan depletion induced by a gelatin-based mixture impars object memory hut not affective hehavior and spatial learnung in the rar Behas Brain Res. 151: 53-64. 
McCann, U.D., Szabo, Z.. Scheffel, U., Dannals. R.F. and Ricaurte, G.A. (1998) Positron emission tomographic evidence of toxic effect of MDMA ("Ecstasy") on brain serotonin neurons in human beings. Lancet. 352: 1433-7.

Meltzer. H. (1989) Serotonergic dysfunction in depression. Br J Psychiatry Suppl. IS5 (Suppl 8): 25-31.

Reneman, L., Booij, J', Schmand, B., van den Brink, W. and Gunning, B. (2000) Memory disturbances in "Ecstasy" users are correlated with an altered brain serotonin neurotransmission. Psychopharmacology (Berl), 148: 322-4.

Riedel, W.J., Klaassen, T., Deutz, N.E., van Someren, A. and van Praag. H.M. (1999) Tryptophan depletion in normal volunteers produces selective impairment in memory consolidation. Prychopharmacology (Berl) 141:362-9.

Rubinsztein, J.S., Rogers, R.I). Riedel, W.J.. Mehta, M.A., Robbins, I.W. and Sahakian, B.J. (2001) Acute dietary tryptophan depletion impars maintenance of "affective set" and delayed visual recognition in healthy volunteers. Pswchopharmacologu (Berl) 154:319-26.
Sik, A., van Nieuwehuyzen, P., Prickaerts, J. and Blokland, A. (2003) Performance of different. mouse strains in an object recognition task. Behar Brain Kes 147: 49-54.

Sobczak, S., Riedel, W.J., Booij, I., Aan Het Rot. M., Deutz, N.E. and Honig. A. (2002) Cognition following acute tryptophan depletion: difference between first-degree relatives of bipolar disordet patients and matched healthy control volunteers. Psychol Med. 32: 503-15.

Van der Does, A.J.W. (2001) The moodlowering effect of tryptophan depletion: possible explanarion for discrepant findings. Archives of General Psuchiatry. 58: 200-202.

van Eijk, H.M., Rooyakkers, D.R. and Deutz, N.E (1.993) Rapid routine determination of amino acids in plasma by high-performance liquid chromatography with a $2-3$ microns Spherisorb ODS II column. I Chromatogr: 620: 143-8.

White, S.R., Obradovic, T., Imel, K.M, and Wheaton, M.J. (1996) The effects of methylenedioxymethimphetamine (MDMA, "Ecstasy") on monoaminergic neurotsansmission in the central nervous system. Prog Neurobiol. 49: 455-79. 


\section{CHAPTER}



Cognition-enhancing effects of the selective 5 - $\mathrm{HT}_{6}$ receptor

antagonist $\operatorname{Ro4368554}$ in cholinergic and serotonergic models of memory deficiency in the rat

C.K.J. Lieben, A. Blokland, A. Sik, E. Sung, P. van Nieuwenhuizen, R. Schreiber.

Submitted to Neuropsychopharmacology 


\section{Abstract}

Antagonists at serotonin type $6\left(5-H T_{\alpha}\right)$ receptors show activity in models of learning and memory. Although the underlying mechanism(s) are not well understood, these effects may involve an increase in acetylcholine (ACh) levels. The present study sought to characterize the cognitive-enhancing effects of the 5-HT antagonist Ro4368554 in a rat object recognition task employing a cholinergic (scopolamine pre-treatment) and a serotonergic (tryptophan (TRP) depletion) deficient model, and compared its pattern of action with that of the acetylcholinesterase inhibitor metrifonate. Initial testing in a time-dependent forgetting task employing a 24- $h$ delay between training and testing showed that metrifonate improved object recognition (at 10 and $30 \mathrm{mg} / \mathrm{kg}$, p.o.), whereas Ro4368554 was inactive. Both, Ro4368554 and metrifonate reversed memory deficits induced by scopolamine ( 3 and 10 $m g / k g$, i.p. and $10 \mathrm{mg} / \mathrm{kg}$, p.o., respectively), and TRP depletion $(10 \mathrm{mg} / \mathrm{kg}$. i.p., and $3 \mathrm{mg} / \mathrm{kg}$, p.o., respectively). In conclusion, although Ro4368554 did

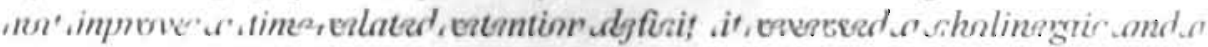
serotonergic memory deficit, suggesting that both mechanisms may be involved in the facilitation of object memory by Ro4368554 and, possibly. other 5-HT, receptor antagonists.

\section{Introduction}

The use of selective serotonin (5-hydroxytryptamine; 5-HT) agonists and antagonists has increased our understanding on the role of 5-HT receptors in processes of learning and memory. 5- $\mathrm{HT}_{1 \mathrm{~A}}, 5-\mathrm{HT}_{2}, 5-\mathrm{HT}_{3}$ (Barnes et al., 1992; Buhot et al., 2000) and. most recently, 5-HT 6 receptors were shown to be targets for cognitive-enhancing drugs (Meneses, 1999).

The 5-HT, receptor was first identified in 1993 and is localized in many brain areas. These also include brain structures associated with learning and memory processes, such as the hippocampus and the cerebral cortex (Ruat et al., 1993: Gerard et al., 1997; Roberts et al., 2002). Antagonism of 5-HT, receptors leads to an increase in the release of $\mathrm{ACh}$ (Shirazi-Southall et al.. 2002: Riemer et al., 2003), but whether this is directly caused by antagonism at these receptors is still under debate. Some evidence suggests that the cholinergic system might be activated indirectly through an increase in the excitatory amino acids aspartate and glutamate (Bourson et al., 1998; Dawson et al. 2000). 
SB271046 (Bromidge et al., 1999) and Ro046790 (Sleight et al.. 1998) were the first $5-\mathrm{HT}_{0}$ antagonists to be evaluated for their behavioral effects, and both compounds improved retention in a Morris water maze task in rats, suggesting an improvement of spatial memory (Rogers and Hagan, 2001; Woolley et al., 2001). Ro046790 enhanced non-spatial working memory in an object recognition task (Woolley et al., 2003), increased consolidation in an autoshaping task, and reversed scopolamine-induced deficits in both an autoshaping and a passive avoidance task. (Bos et al., 2001; Meneses, 2001). However, some of these effects in the autoshaping and Morris water maze task could not be replicated (Russell and Dias, 2002; Lindner et al., 2003). Although the reason is not known, poor drug properties, such as a low affinity for the $5-\mathrm{HT}_{6}$ receptor and a low penetration of the blood-brain barrier, may contribute to a higher variability in behavioral findings with both compounds.

Recently, 5HT, receptors antagonists with improved affinity and selectivity have been developed that demonstrate better penetration into the central nervous system (Russell and Dias, 2002). One of these drugs is Ro4368554, which possesses a blood-brain penetration of $80-110 \%$ (against $1 \%$ and $10 \%$ for Ro046790 and SB271046, respectively). Ex vivo findings confirmed the good brain penetration of Ro4368554, showing $50 \%$ occupancy of brain 5 - $\mathbf{H T}$. receptors at $7.8 \mathrm{mg} / \mathrm{kg}$, i.p. (Bonhaus et al., 2002). Hence, a first objective of the present studies was to test whether Ro4368554 would possess pro-cognitive activity in a rat model for recognition memory: the novel object recognition task. The initial characterization of Ro4368554 in models for learning and memory has been published in an abstract (Szczepanski et al., 2002).

A second aim of our studies was to compare the potential cognitiveenhancing effects of Ro4368554 with those of metrifonate in unimpaired animals as well as against a scopolamine deficit in the novel object recognition task. Metrifonate is a acetylcholinesterase inhibitor (AChEl) and increases ACh release in a more direct manner than $5-\mathrm{HT}_{6}$ antagonists (Cummings et al., 1998: Ringman and Cummings, 1999). Preclinical studies demonstrated that metrifonate improved age-impaired memory (spatial and non-spatial) functions (van der Staay et al., 1996a: Dachir et al., 1997: Scali et al., 1997) and scopolamine-induced impairments in water maze and passive avoidance tasks (Riekkinen et al., 1996; Itoh et al., 1997). Although treatment with metrifonate can stabilize cognitive functions in Alzheimer patients for at least six months (Becker et al., 1998), clinical development was discontinued in 2000 since some patients experienced muscle weakness in Phase III trials. We selected metrifonate for our studies since it shows a significantly better 
tolerability profile in rodents than other AChEIs such as Aricept (Blokland et al., 1995; van der Staay et al., 1996b).

Other transmitter systems, such as the noradrenergic, dopaminergic and serotonergic system, are also involved in learning and memory processes (Blokland, 1995; Robbins, 1998; Myhrer, 2003). The serotonergic system is believed to be especially relevant in mediating the acquisition processes in cognitive functions (Meneses, 1999; Myhrer, 2003), although its precise function is not fully known and studies have sometimes led to controversial findings (McEntee and Crook, 1991). Dysfunctional memory occurred after acute lowering in plasma tryptophan (TRP; precursor of 5-HT) levels (Riedel et al., 2002). The cognitive impairments after TRP depletion were found in healthy volunteers (Park et al., 1994; Riedel et al., 1999; Rubinsztein et al., 2001), as well as in patients with neurological disorders such as Alzheimer disease (Porter et al., 2003), bipolar disorders (Sobczak et al., 2002) or schizophrenia (Golightly et al., 2001).

We found that an acute and substantial reduction $(-65 \%)$ in plasma TRP levels impaired performance in an object recognition task several hours after adult rats were given a TRP-free, protein-carbohydrate mixture (Lieben et al., $2004 \mathrm{~b}$ ). These effects appeared to be selectively associated with cognitive function since anxiety-and depressive-like behavior were not affected. These data suggest that this method of acute TRP depletion could be used as model of dysfunction in object recognition. Therefore, a third aim of the present studies was to test Ro4368554 and metrifonate in a TRP depletion model of cognitive function and to compare their effects with those obtained in the time-related forgetting and scopolamine deficit studies.

\section{Materials and methods}

\section{Animals}

All experiments were conducted as described in protocols approved by the Animal Research Committee. In general, the experiments were carried out with groups of twenty-four, four-month old male Wistar rats (Charles River) except for the scopolamine (dose response study, $\mathrm{n}=18$ ) and the metrifonate study (in TRP depleted rats, $\mathrm{n}=12$ ). Rats were individually housed in standard Makrolon ${ }^{x}$ cages on a sawdust bedding in an air-conditioned room $\left( \pm 20^{\circ} \mathrm{C}\right)$. Rats had free access to food and water and were kept under a reversed 12/12 h light/dark eycle (lights off from 06.00 to $18.00 \mathrm{~h}$ ). 


\section{Drugs and chemicals}

Scopolamine hydrobromide and L-TRP were obtained from Sigma (Zwijndrecht, The Netherlands and CA, USA, respectively). Metrifonate was kindly donated by Bayer AG (Wuppertal, Germany). The selective 5-HT, antagonist Ro4368554 was provided by Roche Pharmaceuticals (Palo Alto, CA, USA). The Gelatin hydrolysate (Solugel $\mathrm{C}^{*}$ ) was purchased from PB Gelatins (Tessenderlo, Belgium). Maltodextrine was purchased from the Amylumgroup (Koog aan de Zaan, The Netherlands).

\section{Treatment}

An overview of the different experiments is given in Table 1. Over a period of two weeks preceding each experiment, the rats were handled and habituated to injections with saline $(\mathrm{NaCl}, 0.9 \% ; 1 \mathrm{ml} / \mathrm{kg}$ ). Ro4368554 was prepared daily and dissolved in saline. Administration was always given i.p. (injection volume $1 \mathrm{ml} / \mathrm{kg}$ ) 60 minutes before trial I (T1). Ro4368554 was tested at doses of $1,3,10 \mathrm{mg} / \mathrm{kg}$. Testing order of doses was determined randomly and balanced across test days. All rats were treated once with each dose condition. Metrifonate was dissolved in 0.1 M' sodium citrate buffer ( $\mathrm{pH} 5.5$ ), to prevent the non-enzymatic transformation dichlorvos in solution, on every experimental day. It was administered, p.o. in an injection volume of $1 \mathrm{ml} / \mathrm{kg}$. $30 \mathrm{~min}$ before behavioral testing. Metrifonate was tested at three different doses $(3,10$, and $30 \mathrm{mg} / \mathrm{kg}$ ), except for the acute TRP depletion experiment, where metrifonate was injected at 1,3 and $10 \mathrm{mg} / \mathrm{kg}$. Scopolamine was dissolved daily in saline and injected s.c. $(2 \mathrm{ml} / \mathrm{kg}$ ) or i.p. (1 $\mathrm{ml} / \mathrm{kg}$ ). The administration of scopolamine was $30 \mathrm{~min}$ before testing. First, a doseresponse curve of scopolamine was established $(0.03,0.1$ and $0.3 \mathrm{mg} / \mathrm{kg})$. The minimal effective dose of scopolamine was used for further drug testing.

In the TRP depletion experiment, the animals were handled and habituated to oral injections with normal tap water $(10 \mathrm{ml} / \mathrm{kg})$ and with the proteincarbohydrate mixture enriched of TRP. In the experimental condition, food was removed $14 \mathrm{~h}$ before the treatment to minimize TRP uptake from food. At all times, the animals had free access to water. The rats were treated either with a TRP lacking protein-carbohydrate mixture (TRP-) or an identical mixture containing an additional amount of TRP (TRP+). The composition of the meal is described elsewhere (Lieben et al., 2004b). On the experimental day, the animals were injected twice, using an interval of $90 \mathrm{~min}$. The first administration was given $4 \mathrm{~h}$ before $\mathrm{Tl}$. Each administration consisted of $4 \mathrm{~g}$ Solugel $\mathrm{C}$ and $2 \mathrm{~g}$ Malthodextrine in a volume of $10 \mathrm{ml} / \mathrm{kg}, \mathrm{p} . \mathrm{o}$. 
Table 1: Overview of the different behavioral experiments. The columns indicate the treatment that was given. The rows indicate the model used to induce a deficit in object recognition. For each experiment, the doses used, the route, and injection volume is given, together with the time of injection, and the number of animals.

\begin{tabular}{|c|c|c|c|}
\hline & Baseline & Rod 468554 & metrifonate. \\
\hline 24-h delay & $\begin{array}{c}1 \mathrm{~h} \text { versus } 24 \mathrm{~h} \\
n=24\end{array}$ & $\begin{array}{c}\text { 0/ 1/ } 3 / 10 \mathrm{mg} / \mathrm{kg} \\
\text { i.p. } 1 \mathrm{~m} / \mathrm{kg} \\
60 \mathrm{~min} \text { before } \mathrm{T1} \\
\mathrm{n}=24\end{array}$ & $\begin{array}{c}\text { o/ } 3 / 10 / 30 \mathrm{mg} / \mathrm{kg} \\
\text { i.p. } 1 \mathrm{ml} / \mathrm{kg} \\
30 \mathrm{~min} \text { before T1 } \\
n=24\end{array}$ \\
\hline scopolamine & $\begin{array}{c}0 / 0.03 / 0.1 / 0.3 \mathrm{mg} / \mathrm{kg} \\
\mathrm{s.c.} 2 \mathrm{~m} / \mathrm{kg} \\
30 \mathrm{~min} \text { before T1 } \\
n=24\end{array}$ & $\begin{array}{c}\text { scop-vehicle/ } 0 / 1 / 3 / 10 \mathrm{mg} / \mathrm{kg} \\
\text { scopolamine: } 0.1 \mathrm{mg} / \mathrm{kg} \\
\text { i.p. } 1 \mathrm{ml} / \mathrm{kg} \\
60 \mathrm{~min} \text { before T1 } \\
n=24\end{array}$ & $\begin{array}{c}\text { scop-vehicle/ } 0 / 3 / 10 / 30 \mathrm{mg} / \mathrm{kg} \\
\text { scopolamine: } 0.1 \mathrm{mg} / \mathrm{kg} \\
\text { i.p.: } 1 \mathrm{~m} / \mathrm{kg} \\
30 \mathrm{~min} \text { before } \mathrm{T} 1 \\
\mathrm{n}=24\end{array}$ \\
\hline
\end{tabular}

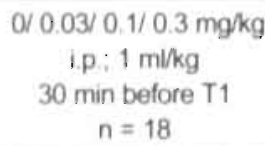

Acute TRP depletion TRP+ versus TRP.

p.o. $10 \mathrm{~m} / \mathrm{kg}$

240 and $150 \mathrm{~min}$ before $\mathrm{T} 1$

$n=24$

TRP +/ O/ $1 / 3 / 1 / 10 \mathrm{mg} / \mathrm{kg}$
TRP.
I.P: $1 \mathrm{ml} / \mathrm{kg}$
$60 \mathrm{~min}$ before $\mathrm{T} 1$

$n=24$

TRP+/ 0/ $1 / 3 \prime^{\prime} 10 \mathrm{mg} / \mathrm{kg}$
TRP.
1.P.: $1 \mathrm{~m} / \mathrm{kg}$
$30 \mathrm{~min}$ before T1

$n=12$

\section{Object recognition test}

The object recognition test (ORT) was performed as described in detail elsewhere (Ennaceur and Delacour, 1988; Lieben et al., 2004b). The apparatus consisted of a circular arena, $83 \mathrm{~cm}$ in diameter. Half of the $40-\mathrm{cm}$-high wall was made of grey polyvinyl chloride. the other half of transparent polyviny! chloride. The light intensity $(-20$ lux $)$ was equal in the different parts of the apparatus. Two objects were placed in a symmetrical position about $10 \mathrm{~cm}$ away from the grey wall. We used four different sets of objects that could not be displaced by a rat. The different objects were: 1) a cone consisted of a grey polyvinyl chloride base (maximal diameter $18 \mathrm{~cm}$ ) with collar on top made of brass (total height $16 \mathrm{~cm}$ ), 2) a standard I ! transparent glass bottle (diameter $10 \mathrm{~cm}$. height $22 \mathrm{~cm})$ filled with water, 3$)$ a massive metal cube $(10 \mathrm{~cm} \times 5$ $(\mathrm{cm} \times 7.5 \mathrm{~cm}$ ) with two holes (diameter $1.9 \mathrm{~cm}$ ), and 4) a massive aluminium cube with a tapering top $(13 \mathrm{~cm} \times 8 \mathrm{~cm} \times 8 \mathrm{~cm})$. Each object was available in triplicate.

In the first week, the animals were adapted to the procedure, i.e., they were allowed to explore the apparatus (without any objects) twice for 3 min each day. In the two following weeks, the rats were trained until they showed a stable discrimination performance (i.e. either a good object discrimination at a I-h interval or a lack of recognition at a $24-\mathrm{h}$ interval). Subsequently, drug testing began. 
A testing session comprised of two trials. The duration of each trial was 3 min. During the first trial (T1) the apparatus contained two identical objects. A rat was always placed in the apparatus facing the wall at the middle of the front: (transparent) segment. After the first exploration period the rat was put back in its home cage. After a delay interval, the rat was put back in the apparatus for the second trial (T2), but now with dissimilar objects , a familiar one and a novel one. The duration of exploring each object at TI and T2 was recorded manually with a personal computer. Exploration was defined as follows: directing the nose to the object at a distance of no more than $2 \mathrm{~cm}$ and/or touching the object with the nose. Sitting on the object was not considered as exploratory behavior. In order to avoid the presence of olfactory trails, the objects were always thoroughly cleaned. Moreover, each object was available in triplicate so none of the two objects from the first trial had to be used as the familiar object in the second trial. In addition, all combinations and locations of objects were used in a balanced manner to reduce potential biases due to preferences for particular locations or objects.

The basic measures were the total exploration time of both objects during TI and $T 2, e l$ and $e 2$, respectively. The discrimination index $[d 2=($ exploration novel object - exploration familiar object)/e2] is a relative measure of discrimination that corrects for the total exploration activity in the second trial. Performance at baseline level was assessed using a I-h delay, i.e., a time interval where object discrimination is expected, and a 24-h delay, i.e., a time interval where Wistar rats no longer can discriminate the novel object from the object that they previously explored. When using a 24-h delay, two sessions were given every week, one session comprised Monday and Tuesday and the other one comprised Thursday and Friday. Since Ro4368554 and metrifonate were expected to improve baseline memory performance. we used a 24-h delay at which no discrimination between the objects occurs. In contrast, a 1 -h delay was used for drug testing in animals treated with scopolamine and the protein-carbohydrate mixture

\section{Statistical analysis}

Since no difference in performance was observed between. similar treatment condition (comparison within conditions tested with a t-test: t's $<0.85, \mathrm{n} . \mathrm{s}$.), the data of the $d 2$ values were pooled by dose condition across the sessions. Subsequently, for each subject the mean of each variable was calculated. Furthermore, the data of both the vehicle-vehicle and the scopolaminevehicle condition were pooled over the metrifonate and the Ro4368554 study. The same was done for the TRP + and the TRP- conditions.

Overall comparisons of exploration times ( $e /$ and $e 2)$ between the different 
dose conditions of each treatment were analyzed with a one-factorial ANOVA. Apparent effects were evaluated in more detail with a Dunnett posthoc analysis (two-sided, $\mathrm{p}<0.05$ ) by comparing the results of each condition to those of a control group (e.g. vehicle, scopolamine or TRP+ group).

To evaluate the discrimination performance, we compared the $d 2$ values between the different treatment conditions using an ANOVA with a Dunnet post hoc test. In addition, we compared the $d 2$ values of the different doses with a virtual group, which was formed on basis of seven vehicle sessions from previous experiments in which animals were tested on a 24-h delay interval, i.e., a condition where there is no recognition (see Sik et al. 2003). This virtual group had a mean $d 2$ of zero and an SEM of 0.07. Comparisons with these groups evaluate more reliably whether discrimination performance differs from zero in a certain test condition. In addition, natural fluctuation in control conditions (in this case 24-h delay, scopolamine, TRP-) may be either slightly higher or lower than zero. This may lead to underestimation or overestimation of drug effects, respectively. Comparisons between the $d 2$ of the different dose conditions and the virtual group were assessed by an analysis of variance (ANOVA). In case of a statistically reliable dose effect. c omparisons between the different doses and the virtual group were analyzed in more detail using a one-sided Dunnett post-hoc test. Since by definition the memory performance cannot be negative $12(d 2<0)$, a one-sided test was used. Thus, no memory means $d 2=0$ whereas memory for objects represents a $d 2>0$.

To examine to possible differences in the route of scopolamine administration (i.p. or s.c.) on discrimination performance, the data of scopolamine treatment were analyzed with a two-factorial (Injection by Dose) analysis of variance with the factor Dose as repeated measures.

\section{Results}

\section{Base-line performance}

\section{Time-dependent forgetting}

In the first trial of the 1-h interval condition, the rats spent a total time of 21 (2.15) s [mean (SEM)] exploring both identical objects, while in the second trial they explored the objects over a period of $28(2.0) \mathrm{s}$. In the 24-h delay condition, the animals explored the objects for $26(1.6) \mathrm{s}$ and $30(2.0) \mathrm{s}$ 
during $\mathrm{Tl}$ and $\mathrm{T} 2$, respectively. The exploration times in both trials did not differ between the $\mathrm{I}-\mathrm{h}$ and 24 -h conditions [t(46)'s, n.s.]. However, an increase in activity from $\mathrm{Tl}$ to $\mathrm{T} 2$ was found in the $1-\mathrm{h}$ and the 24-h delay condition $[t(46) ' \mathrm{~s}>3.10, p<0.01]$.

The discrimination index at the 1 -h delay differed from the virtual control group $[d 2=0.36(0.03), t(46)=3.54, p<0.001]$, indicating that the rat spent more time investigating the novel object. However, the discrimination index was low after a 24 -h delay $[d 2=0.05(0.05)]$, and the $d 2$ value was not different from virtual control group $(t(46)=0.34$, n.s. $)$.

\section{Scopolamine}

Scopolamine did not affect the exploration time in T1 [Dose: $F(3,120)=0.46$, n.s.; see Table 2] and was similar in both routes of administration [Injection: $F(1,40)=0.02$, n.s.]. Scopolamine affected the activity in T2 [Dose: $F(3,120)=$ 4.57; $p<0.01]$. Although the effects on exploration times in $\mathrm{T} 2$ were dependent on the injection method used $[F(1.40)=8.62, p<0.01]$, no interaction occurred between the two factors [Injection x Dose: $F(3,120)=0.45$, n.s.]. A dose effect was found on the relative discrimination index after treatment with scopolamine $[F(3,120)=3.49, p<0.05$; see Fig. I]. In contrast to the vehicle condition, rats treated with scopolamine at a dose of 0.1 and $0.3 \mathrm{mg} / \mathrm{kg}$ did not discriminate between the objects: for both doses, the $d 2$ values were not different from those of the virtual control group. Furthermore, the effects on the relative discrimination index did not depend on the route of injection $[F(1,40)=0.02$, n.s.] and no interaction effect was found [Injection $x$ Dose: $F(3,120)=0.36$, n.s.]. The minimal effective dose was $0.1 \mathrm{mg} / \mathrm{kg}$ s.c. (see Fig. 1). Since the route of administration did not affect the memory performance the i.p. and s.c. data were pooled for the evaluation of drug effects.

Table 2. Effects of scopolamine on exploration times in the object recognition task. using a 1 -h interval. Rats received injections of scopolamine hydrobromide at doses of $0.03,0.1$ and 0.3 $\mathrm{mg} / \mathrm{kg} .30$ minutes before T1. Scopolamine injection was given s.c. at a volume of $2 \mathrm{ml} / \mathrm{kg}$ or i p: at a volume of $1 \mathrm{ml} / \mathrm{kg}$. Mean values $( \pm$ SEM) of total exploration time (s) during the first ( $\theta 1)$ and the second trial $(e 2)$ are presented. Differences from vehicle condition: $\ddagger p<0.05$

Scopolamine (s.c., $2 \mathrm{ml} / \mathrm{kg}$ )

$\begin{array}{lll}\text { dose } & \text { et } & \text { e2 } \\ 0 \mathrm{mg} / \mathrm{kg} & 30(2.2) & 30(1.9) \\ 0.03 \mathrm{mg} / \mathrm{kg} & 28(2.0) & 23(1.9) \\ 0.1 \mathrm{mg} / \mathrm{kg} & 24(2.0) & 28(2.4) \\ 0.3 \mathrm{mg} / \mathrm{kg} & 31(2.5) & 33(2.7)\end{array}$

Scopolamine (i.p., $1 \mathrm{ml} / \mathbf{k g}$ )

$\begin{array}{lll}\text { dose } & e 1 & e Z \\ 0 \mathrm{mg} / \mathrm{kg} & 26(2.1) & 34(2.1) \\ 0.03 \mathrm{mg} / \mathrm{kg} & 29(2.0) & 31(2.4) \\ 0.1 \mathrm{mg} / \mathrm{kg} & 30(2.2) & 34(1.7) \\ 0.3 \mathrm{mg} / \mathrm{kg} & 28(27) & 37(2.8)\end{array}$




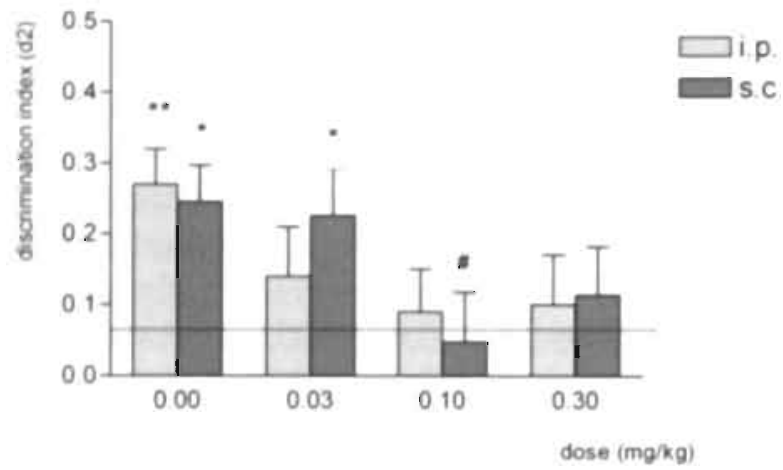

Fig. 1. Effects of scopolamine-Hbr on the discrimination performance in an object recognition task in adult male Wistar rats using a 1-h delay (mean + SEM). In the vehicle session, rats were treated with saline. In the drug session, rats were treated with doses of $0.03,0.1$ and $0.3 \mathrm{mg} / \mathrm{kg}$ s. c. $2 \mathrm{ml} / \mathrm{kg}$ and i.p. $1 \mathrm{ml} / \mathrm{kg}$. Differences from virtual group (indicated by the dotted line): * $p<0.05, \cdots p<0.01$. Differences from vehicle group: \#p<0.05.

\section{Acule TRP depletion (data not shown)}

In both trials ( $\mathrm{T} 1$ and $\mathrm{T} 2$ ), no differences in exploration times were found between the TRP $+[35(2.5) \mathrm{s}$ and $44(3.5) \mathrm{s}$, respectively] and the TRP- [38 (2.6) s and $46(2.9) \mathrm{s}$, respectively] group [t(44)'s, n.s.]. A treatment effect was found on the relative discrimination index $[r(44)=2.52, p<0.01]$. While in the TRP + condition, the rats could discriminate between objects in the second trial $\mid d 2=0.37(0.04)$; significantly different from virtual control group, $p<0.001]$. the $d 2$ value was reduced to chance level in the TRP-condition $[(d 2=0.07(0,04)]$ and post-hoc analysis did not reveal a difference between the TRP- and the virtual group.

\section{Effects of Ro4368554}

\section{Time-dependent forgetting}

Exploration levels in $\mathrm{Tl}$ were affected by treatment with Ro4368554 $[F(3,85)=6.20, p<0.05 ;$ see Table $3 \mathrm{~A}]$, although post-hoc analysis did not reveal differences between Ro4368554-treated groups and the vehicle-treated group. The exploration times in $\mathrm{T} 2$ were not affected by treatment with Ro4368554 [F(3,85) $=0.43$, n.s.]. After treatment with Ro4368554, the rats did not discriminate between the novel object and the familiar object equally during $\mathrm{T} 2[F(3,85)=0.74$, n.s.; see Fig. 2]. 
Table 3: Effects of Ro4368554 and metrifonate treatment on exploration times in the object recognition task. Rats received injections of Ro4368554 at doses of 1.3 and $10 \mathrm{mg} / \mathrm{kg}$ (i.p., 1 $\mathrm{m} / \mathrm{kg}$ ) and metrifonate at doses of 1, 3, 10 and $30 \mathrm{mg} / \mathrm{kg}$ (p.o., $1 \mathrm{~mL} / \mathrm{kg}), 60$ and 30 minutes before $T 1$, respectively. Mean values ( \pm SEM) of total exploration time ( $(s)$ during the first (e1) and the second trial $(e 2)$ are presented: $(A)$ after a $24-h$ delay. $(B)$ treatment of scopolamine and $(C)$ treatment of a TRP-free, protein-carbohydrate mixture. Differences from control group in each condition: $\ddagger p<0.05$

Ro4368554

\section{(A) Time-dependent forgetting}

$\begin{array}{lll}\text { dose } & \text { ef } & \text { e2 } \\ 0 \mathrm{mg} / \mathrm{kg} & 13(1.9) & 12(1.2) \\ 1 \mathrm{mg} / \mathrm{kg} & 18(2.1) & 13(1.0) \\ 3 \mathrm{mg} / \mathrm{kg} & 11(1.1) & 14(1.6) \\ 10 \mathrm{mg} / \mathrm{kg} & 8.5(1.1) & 12(1.1)\end{array}$

\section{(B) Scopolamine}

$\begin{array}{lll}\text { dose } & \text { e1 } & \text { e2 } \\ \text { Vehicle } & 25(1.6) & 29(1.3) \\ 0 \mathrm{mg} / \mathrm{kg} & 25(1.2) & 32(1.6) \\ 1 \mathrm{mg} / \mathrm{kg} & 18(1.3) \ddagger & 25(1.4) \\ 3 \mathrm{mg} / \mathrm{kg} & 32(2.0) \ddagger & 34(2.5) \\ 10 \mathrm{mg} / \mathrm{kg} & 21(1.9) & 23(2.1)\end{array}$

\section{(C) Acute TRP depletion}

$\begin{array}{lll}\text { TRP/dose } & e 1 & e 2 \\ \text { TRP }+/ 0 & 28(2.3) & 30(1.6) \\ \text { TRP-/0 } & 29(1.8) & 29(1.8) \\ \text { TRP }-11 & 27(1.8) & 27(2.0) \\ \text { TRP-/3 } & 21(1.4) & 29(2.3) \\ \text { TRP }-110 & 24(1.7) & 29(2.2)\end{array}$

\section{metrifonate}

$\begin{array}{lll}\text { dose } & \text { e1 } & \text { e2 } \\ 0 \mathrm{mg} / \mathrm{kg} & 25(1.5) & 27(2.0) \\ 3 \mathrm{mg} / \mathrm{kg} & 25(2.5) & 27(1.8) \\ 10 \mathrm{mg} / \mathrm{kg} & 23(1.5) & 32(2.1) \\ 30 \mathrm{mg} / \mathrm{kg} & 26(1.9) & 28(2.3)\end{array}$

$\begin{array}{lll}\text { dose } & \text { o1 } & \text { e2 } \\ \text { Vehicle } & 25(1.6) & 29(1.3) \\ 0 \mathrm{mg} / \mathrm{kg} & 25(1.2) & 32(1.6) \\ 3 \mathrm{mg} / \mathrm{kg} & 28(1.3) & 33(2.0) \\ 10 \mathrm{mg} / \mathrm{kg} & 29(1.8) & 31(2.0) \\ 30 \mathrm{mg} / \mathrm{kg} & 34(2.7) \mp & 32(2.1)\end{array}$

$\begin{array}{lll}\text { TRP/dose } & e 1 & \theta 2 \\ \text { TRP }+10 & 28(2.3) & 30(1.6) \\ \text { TRP-/0 } & 29(1.8) & 29(1.8) \\ \text { TRP-11 } & 20(1.4) & 27(2.6) \\ \text { TRP-/3 } & 22(1.7) & 32(3.5) \\ \text { TRP-/10 } & 20(1.7) & 25(21)\end{array}$




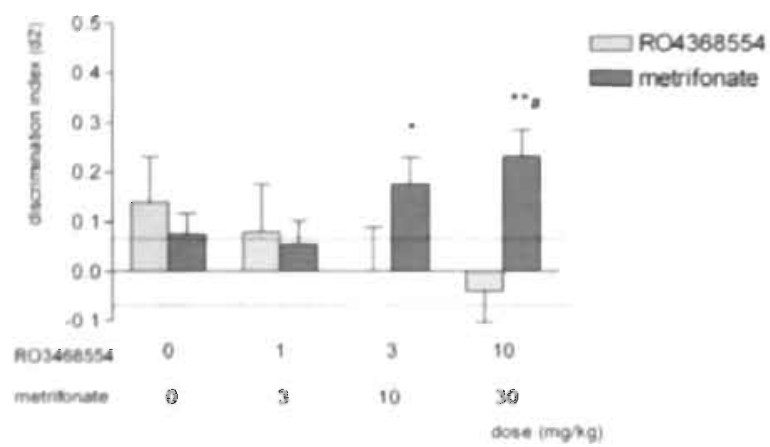

Fig. 2. Effects of Ro4368554 and metrifonate on the discrimination performance in an object recognition task using a 24-h delay (mean + SEM). In the vehicle session, rats were treated with saline. In the drug session, rats were treated with doses of 1.3 and $10 \mathrm{mg} / \mathrm{kg}$ of Ro4368554 or with doses of 3,10 and $30 \mathrm{mg} / \mathrm{kg}$ of metrifonate. Differences from virtual control group (indicated by the dotted line): " $p<0.05$ and $" p<0.01$. Differences from vehicle group: $\# p<0.05$.

\section{Scopolamine}

In both trials, explorative behavior was affected by combined treatment with scopolamine and Ro4368554 [F $>5.09, p<0.01$; see Table 3B]. As compared with the vehicle-treated group, $e l$ values were lower in the group treated with $1 \mathrm{mg} / \mathrm{kg}$ Ro4368554 and higher in the group treated with $3 \mathrm{mg} / \mathrm{kg}$ Ro4368554. Treatment with Ro4368554 reversed the scopolamine-induced object discrimination deficit $[F(4,160)=5.62, p<0.01$; see Fig. 3]. Post-hoc analysis revealed that the $d 2$ value of the 3 and $10 \mathrm{mg} / \mathrm{kg}$ was different from both the scopolamine-treated and the virtual group.

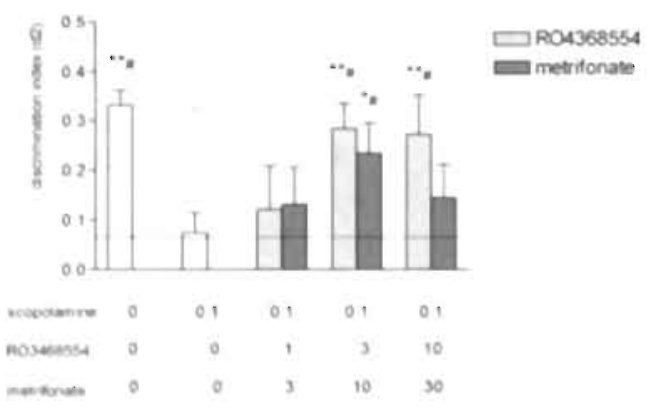

xas rapos

Fig. 3. Effects of Ro4368554, and metrifonate after treatment of scopolamine-Hbr on the discrimtnation performance in an object recognition task in adult male Wistar rats (mean * SEM). A 1-h interval was used between trials In the vehicle session, rats. were treated with saline. In the drug session, rats were treated with đoses of 1,3 and $10 \mathrm{mg} / \mathrm{kg}$ of Ro4368554 and with doses of 3.10 and $30 \mathrm{mg} / \mathrm{kg}$ of metrifonate. Differences from virtual control group (indicated by the dotted line) * $p<0.05$ and ${ }^{*} p<0.01$. Differences from scopolamine-vehicle group: $\# p<0.05$. 


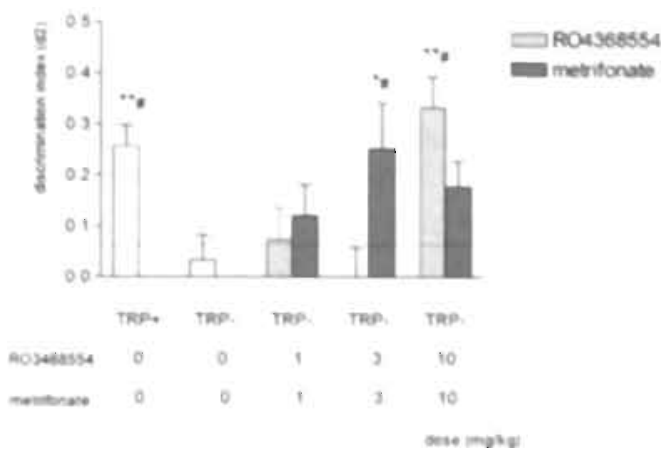

Fig. 4 : Effects of Ro4368554 and metrifonate after TRP-free, protein-carbohydrate meal on the discrimination performance in an object recognition task in adult male Wistar rats (mean + SEM). A t-h interval was used between trials. In the control session of the acute TRP depletion, rats were treated with the same meal with an addition amount of TRP (TRP+) In the vehicle session, rats were treated with saline. In the drug session, rats were treated the TRP-free, protein-carbohydrate meals and with doses of 1.3 and $10 \mathrm{mg} / \mathrm{kg}$ of Ro4368554 or metrifonate. Differences from zero in virtual control group (indicated by the dotted line) ${ }^{*} p<0.05$; ${ }^{*} p<0.01$ Differences from TRP-/vehicle group: \# $p<0.05$

\section{Acute TRP depletion}

No treatment effects in explorative behavior were found in $\mathrm{Tl}$ and $\mathrm{T} 2$ $[F(4,126)<2.28$, n.s.; see Table $3 C]$. Treatment with Ro4368554 reversed the acute TRP depletion-induced deficit on the discrimination performance $[F(4,126)=7.22, p<0.01]$. Fig. 4 shows no effect of I and $3 \mathrm{mg} / \mathrm{kg}$, and the discrimination index did not differ from the virtual group. Treatment with 10 $\mathrm{mg} / \mathrm{kg}$ Ro4368554 improved object recognition in the TRP- condition as compared with the vehicle and virtual control group.

\section{Effects of metrifonate}

Time-dependent forgetting

The exploration times for $e l$ and $e 2$ were not affected by treatment with metrifonate $[F(3,91)<1.32$, n.s.; see Table $3 \mathrm{~A}]$, but explorative behavior tended to be higher for $e 2$. Treatment with metrifonate improved object discrimination at a 24 -h retention interval $[F(3,91)=2.96, p<0.05$; see Fig. 2]. Post hoc analysis showed that 10 and $30 \mathrm{mg} / \mathrm{kg}$ metrifonate improved the memory performance when compared with the virtual group.

\section{Scopolamine}

Exploration time for el was, affected by treatment $[F(4,162)=3.95, p<0.01$; see Table 3B]. Fost hoc analysis showed that rats were more active in the group treated with $30 \mathrm{mg} / \mathrm{kg}$ metrifonate. No treatment effect on explorative 
behavior in $\mathrm{T} 2$ was found $[F(4,162)=0.88$, n.s.]. The $d 2$ value was affected by metrifonate $[F(4,162)=5.37, p<0.01$; see Fig. 3]. Post hoc analysis indicated that only $10 \mathrm{mg} / \mathrm{kg}$ metrifonate reversed the scopolamine-induced memory deficit.

\section{Acute TRP depletion}

Metrifonate treatment affected the $e l$ values in TRP depleted rats $[F(4,100)=$ 3.14. $p<0.05$; see Table 3C]. Exploration levels in T2 were not affected by TRP depletion or metrifonate treatment $[F(4,100)=0.94$, n.s.]. An increase in. explorative behavior between $e l$ and $e 2$ values was found in most dose conditions. Treatment with metrifonate affected the relative discrimination index. after TRP depletion $[F(4,100)=3.79, p<0.01$; see Fig.4]. The $d 2$ value in the TRP-/vehicle treated group was markedly reduced compared to the TRP+/vehicle treated group. Post hoc analysis revealled that the TRP depletion deficit in object recognition was significantly reversed by metrifonate at a dose of $3 \mathrm{mg} / \mathrm{kg}$.

\section{Discussion}

The aim of the present study was to investigate the cognitive-enhancing propertics of the 5-HT, antagonist RO4368554, and to compare its effects with those of the $A C h E I$ metrilonate in an object recognition task using different models of memory deficiency in adult male Wistar rats. RO4368554 and metrifonate both reversed the memory-deficit induced by scopolamine and acute TRP depletion, whereas metrifonate, but not RO4368554, enhanced memory performance when a 24-h delay was interposed between both trials.

\section{Impairment in object recognition}

The discrimination performance in the object recognition test was dependent on the duration of the interval between $\mathrm{T} 1$ and $\mathrm{T} 2$. Consistent with results from other studies, rats accurately discriminated between the novel and the familiar object at a retention interval of $1 \mathrm{~h}$, but not after a 24 -h delay (Ennaceur and Meliani, 1992). The 24-h delay was subsequently used for lime-dependent forgetling studies, whereas the 1-h delay was used for druginduced deficiency models: scopolamine and acute TRP depletion-induced. disruption of object recognition.

Treatment of scopolamine is frequently used in experimental studies to induce amnesia including novelty detection (Ennaceur and Meliani. 1992: Dodart et al., 1997: Pitsikas et al.. 2001). Our data confirm the disruptive effects of 
scopolamine on object recognition and a dose of $0.1 \mathrm{mg} / \mathrm{kg}$ was selected for reversal studies with Ro4368554 and metrifonate. Although reversal effects of a scopolamine-induced deficit is typically interpreted in terms of an effect on cognitive function, it has been suggested that scopolamine may primarily affect sensory/attention processes rather than inducing a direct and selective effect on learning and memory processes (Blokland, 1995: Sarter et al., 2003). Since the present. study did not address attentional or motivational functions, the possibility of attentional or sensorimotor effects cannot be completely ruled out. It is unlikely that nonspecific effects on motor behavior confounded the effects of scopolamine on novel object discrimination as no reduction was found in el values after scopolamine treatment, and the total exploration time in T2 in fact gradually increased with dose. Consistent with our findings with a $0.1 \mathrm{mg} / \mathrm{kg}$ scopolamine, treatment with scopolamine at doses below $1 \mathrm{mg} / \mathrm{kg} \mathrm{s.c}$. have been reported to not affect motor functions (Besheer et al., 2001).

Recently, we found that $4 \mathrm{~h}$ after treating adult rats with a TRP-free, proteincarbohydrate mixture, plasma TRP levels were substantially reduced ( $65 \%$ ) and consequently this resulted in decreased concentrations of 5 -HT $(-40 \%)$ in different brain structures (Lieben et al., 2004a). Moreover, it was found that plasma TRP depletion in rats caused an impaired performance in object recognition without changing affective behavior (Lieben et al., 2004b). This finding was in accordance with an impairment in delayed recognition several hours after a TRP-free amino acid was given to healthy humans (Riedel et al., 1999; Rubinsztein et al., 2001). These authors concluded that this effect was probably related to changes in the consolidation process when the levels of TRP were acutely reduced. In our studies, rats depleted of TRP could no longer discriminate a novel object from a familiar object they had seen I h before, i.e., at a time interval when TRP levels were expected to be low. Based on these findings, the acute TRP depletion method was included as a 5-Htergic deficit model for testing the effects of Ro4368554 and metrifonate on object recognition memory.

The exploration values were different in the different experiments and were sometimes affected by drug treatment. Especially, the exploration levels in the time-dependent forgetting test with Ro3438554 were relatively low. This variation in exploration levels could be related to different batches of rats, and or scoring between experiments. However, in a previous study with mice we showed that the discrimination performance based on the measure $d 2$ is. not dependent on the exploration level (Sik et al., 2004). It was suggested that. exploration levels lower than $10 \mathrm{~s}$ may affect the reliability of the $d 2$ measure. In this study most values were clearly higher than $10 \mathrm{~s}$ indicating that the discrimination measure could be measured reliably in all testing conditions. 


\section{Effects of RO4368554}

The treatment with Ro4368554 did not improve object recognition in a time-dependent forgetting protocol, but reversed the impairment in object discrimination induced by treatment with scopolamine and the memory deficit induced by TRP depletion. These data further support the notion that $5-\mathrm{HT}_{6}$ receptor antagonists have cognition enhancing properties (Rogers and Hagan, 2001; Woolley et al., 2001; Woolley et al., 2004). Comparing the dose-related effects of Ro4368554 across both drug-induced deficit models revealed a similar pattern. At the highest dose, Ro4368554 enhanced memory performance in both scopolamine-treated and TRP-depleted rats. However, the medium dose was only effective in reversing the scopolamineinduced effect, indicating a wider active dose range in the cholinergic deficit model. It therefore appears that the dose response curve has shifted somewhat towards the right in the TRP depletion model as compared to the scopolamine model, suggesting that the cholinergic deficit model is more sensitive to the effects of Ro4368554. However, higher doses of Ro4368554 need to be tested to confirm this conclusion.

The present data are consistent with those reported witn Ro4368554 in a social recognition task. That is, Ro4368554 did not improve a timedependent retention deficit but ameliorated a scopolamine-induced impairment of social memory (Szczepanski et al., 2002). On the other hand, a recent study showed that two $5-\mathrm{HT}_{6}$ antagonists reversed a time-dependent forgetting when injected $20 \mathrm{~min}$ before or directly after T1 in a novel object. discrimination task (King et al., 2004). It is likely that differences in rat strain (Wistar vs Lister hooded) and delay interval ( $24 \mathrm{~h} \mathrm{vs} 4 \mathrm{~h}$ ) may account for these diflerences. These findings suggest that the effects of $5-\mathrm{HT}_{6}$ antagonists on delay-dependent forgetting are less robust than the effects in a scopolamine deficit model.

\section{Effects of metrifonate}

In contrast 1o Ro4368554. metrifonate reversed retention deficits induced by a $24-\mathrm{h}$ delay at the highest dose of $30 \mathrm{mg} / \mathrm{kg}$. Furthermore, the scopolamineinduced deficit on object recognition was enhanced at a medium dose of 10 $\mathrm{mg} / \mathrm{kg}$.

Our data are consistent with the metrifonate-induced amelioration of memory performance in a wide variety of behavioral tests at doses of 10 and 30 $\mathrm{mg} / \mathrm{kg}$ (Blokland et al., 1995; Riekkinen et al.. 1996; van der Staay et al.. 1996a: Dachir et al., 1997: Scali et al., 1997: Prickaerts et al., 1999). Furthermore, at the dose of $3 \mathrm{mg} / \mathrm{kg}$, metrifonate reversed the retention deficit 
after TRP depletion to a level comparable with the TRP+ group. Since metrifonate reversed the memory deficit induced by acute TRP depletion at lower dose than the reversal of a scopolamine-induced memory deficit, the effects of metrifonate seem to be somewhat more potent when tested in a 5-HT mediated deficiency model. The effects of metrifonate at low doses may involve another mechanism since the minimal effective dose for reversal of the TRP-depletion deficit in object recognition $(3 \mathrm{mg} / \mathrm{kg}, \mathrm{p} . \mathrm{o}$.$) is around$ 1.0-fold lower than the reported minimal effective dose for inhibition of AChE activity (van der Staay et al., 1996b). Indeed it was suggested that the cognition enhancing effects of metrifonate may involve non-cholinergic mechanism (van der Staay et al., 1996b), for example inhibition of acylpeptide hydroxylase (Richards et al., 1999; Richards et al., 2000).

\section{Neurochemical mechanisms involved in the effects of $5-\mathrm{HT}_{0}$ antagonists on cognition}

There is only a limited number of studies in which the neurochemical effects of $5-\mathrm{HT}_{0}$ antagonism have been investigated. The present data suggests that it may involve an increase in cholinergic transmission (Shirazi-Southall et al., 2002: Riemer et al., 2003). Previous behavioral studies indicated such an enhanced cholinergic neurotransmission after administration with a $5-\mathrm{HT}_{6}$ antagonist (Bentley et al. 1999). The present finding that Ro4368554 reversed a scopolamine-induced deficit in novel object recognition, corroborates other studies showing scopolamine reversal in cognition tasks (Meneses, 2001; Woolley et al., 2003; Foley et. al., 2004). These data strongly support the notion that the cognition enhancing effects of $5-\mathrm{HT}^{*}$ antagonists are mediated via a cholinergic mechanism. Although the effects seem to be mediated via a cholinergic mechanism, microdialysis studies have shown that the $5-\mathrm{HT}_{6}$ antagonist. SB-271046 increases levels of glutamate and aspartate in the frontal cortex and hippocampus (Dawson et al., 2001). It was suggested that this effect may be mediated via an indirect effect of blockade of 5- $\mathrm{HT}_{6}$ receptors on GABAergic interneurons (see also Woolley et al., 2004). Since glutamate is critically involved in long-term potentiation (Bliss and Collongridge, 1993), this effect on excitatory amino acids may be involved in the improved memory performance by $5-\mathrm{HT}_{6}$ antagonists, including Ro4368554. This notion is supported by a recent finding showing that glutamate is involved in the enhanced object memory performance by the 5-HT, antagonist. Ro046790 (King et al., 2004). Our studies in TRP-depleted animals suggest that a 5-HTergic mechanism may also contribute to the cognitive-enhancing effects of Ro4368554. However. microdialysis experiments showed that. 5-HT, antagonism did not change 5-HT levels in various brain areas (Dawson et al., 
2001; Lacroix et al., 2004). At least two possible alternative explanations can be offered to explain the effects of Ro4368554 in the TRP model. First, acute TRP depletion decreased levels of the amino acid citruline without affecting arginine levels (Lieben et al., 2004a). It has been suggested that this effect may reflect a decrease in the nitric oxide synthase activity, and concomitantly in reduced nitric oxide levels. Since glutamate and nitric oxide are closely linked in pathways associated with long-term potentiation (Bliss and Collingridge, 1993), this might be a potential mechanism underlying cognitive deficits in a TRP deficiency model. As mentioned earlier, 5- $\mathrm{HT}_{6}$ antagonists seem to increase excitatory neurotransmission (Dawson et al., 2001). Consequently, if the effects of TRP depletion were mediated via a nitric oxide mechanism, the effects of Ro4368554 in the TRP depletion model might be mediated via the nitric oxide-glutamatergic pathway. A second explanation involves an indirect effect on 5-HT. A recent study showed that the 5- $\mathrm{HT}_{6}$ antagonist SB-271046 augmented the effects of amphetamine on 5-HT (and dopamine) release (Dawson et al., 2003). These data suggested that 5- $\mathrm{HT}_{6}$ antagonism may have a modulatory - rather than a direct - effect on 5-HT neurotransmission. In the TRP model the 5-HT system is compromised and Ro4368554 could modulate these effects. Thus, a relative increase in 5-HT neurotransmission could be established by Ro4368554 after acute TRP depletion. Preliminary data (Dr. D. Bonhaus) indeed support this speculative explanation and showed that Ro4368554 increased hippocampal 5-HT levels in TRP depleted rats. To fully understand the mechanisms by which $5-11 T_{6}$ antagonists exert their effects on cognition more studies are needed to scrutinize the effects of these drugs on the modulation of neurotransmitter release.

\section{5-HT/ACh and menory}

The 5-HTergic system is implicated in learning and memory processes although its precise function is still a matter of debate. In vitro (Gillet et al.. 1985: Maura et al.. 1989) and in vivo (Robinson, 1983: Leonard and Llinas. 1994) studies suggest that an increase of serotonergic activity leads an inhibition of cholinergic activity. Accordingly, it would be expected that TRP depletion would result in a increase in cholinergic activity and a subsequently improvement in object recognition (cf. Prickaerts et al., in press). But since TRP depletion induced a memory deficit, the effects of TRP depletion on baseline performance in the novel object recognition might not be mediated via a cholinergic component. Our behavioral data suggest that $5-\mathrm{HT}$ and $\mathrm{ACh}$ are not inversely related in object memory, and that both neurotransmitters may affect independent processes in object memory (Steckler and Sahgal. 
1995). This may also apply for Ro4368554. This drug seems to reverse the cholinergic induced memory deficit via a cholinergic and/or glutamatergic mechanism. Conversely, the reversal of 5-HTergic memory deficit by Ro4368554 might be mediated via a 5-Htergic mechanism and/or glutamatergic mechanism.

In conclusion, both the serotonergic and cholinergic system may independently affect object memory in different manners. The TRP depletion method can be used to test the effects of other potential cognitive enhancers in order to increase our understanding of the role of 5-HT, and its interactions with other neurotransmitter systems, in processes of learning and memory. The present data provide further support for the notion that $5-\mathrm{HT}_{6}$ antagonists may mediate memory performance via different neurochemical mechanisms.

\section{Acknowledgements}

The authors gratefully acknowledge the helpful suggestions of Dr. Doug Bonhaus and Dr. Marie Woolley.

\section{References}

Barnes, J.M., Barnes, N.M. and Cooper, S.J. (1992) Behavioural pharmacology of 5-HT3 receptor ligands. Neurosci Biobehav Rev: 16: 107-13.

Becker, R.E., Colliver, J.A.. Markwell, S.J., Moriearty. P.L.. Unni. L.K and Vicari. S. (1998) Effects of metrifonate on cognitive decline in Alzheimer disease: a double-blind, placebo-controlled. 6-month study. Alzheimer Dis Assoc Disord 12:54-7.

Besheer, J., Short, K.R. and Bevins, R.A. (2001) Dopaminengic and cholinergic antagonism in a novel-object detection task with rats. Behav Brain Res. 126: 211-7.

Bliss, T.V and Collingridge, Ci. (1993) A synaptic model of memory: long-term potentiation in the hippocampus. Nature $361: 31-9$

Blokland, A. (1995) Acetylcholine: a neurotransmitter for learning and memory? Brain Research Reviews 21: 285-300.
Blokland, A. Hinz, V, and Schmidt, B. (I095) Effects of metrifonate and tacrine in the spatial Morris task and modified Irwin test evaluation of the efficacy/safety profile in rats. Drug Dev. Res. 36: $166-179$

Bonhaus, D.W., Martin. R., Brothers, J., Novakovic, S., Lew, R., Schwab, D, and Clark, R (2002) RO4368554, a high aflinity, selective, CNS penetrating 5-HT6 receptor antagonist. Society for Neuroscience 844.5

Bos, M.. Sleight. A.J. Godel. T., Martin, J R. Riemer, C and Stadler, H. (2001) 5-HT(6) receptor antagonists: lead optimisation and biological evaluation of $\mathrm{N}$-aryl and $\mathrm{N}$-heteroaryl 4-amino-benrene sulfonamides, Eur J Med (hem 36; 165-78

Bourson. A., Boess, F. G. Bos, M and Sleight, A.J. (1998) Involvement of 5-HT6 receptors in nigrostriatal function in rodents. Br I Pharmaral. 125 $1562-6$ 
Bromidge, S.M., Brown, A.M., Clarke, S.E. Dodgson, K., Gager, T., Grassam, H.L., Jeffrey, P.M., Joiner, G.F., King, F.D., Middlemiss, D.N. Moss, S.F., Newman, H., Riley, G., Routledge, C. and Wyman, P. (1999) 5-Chloro-N-(4-methoxy-3piperazin-1-y!- pheny!)-3-methyl-2-benzothiophenesulfon- amide (SB-271046): a potent, selective, and orally bioavailable 5-HT6 receptor antagonist. I Med Chem. 42:202-5.

Buhot, M.C., Martin, S. and Segu, L. (2000) Role of serotonin in memory impairment. Ann Med. 32 . $2|0-2|$

Cummings, J.L. Cyrus, P.A., Bieber, F., Mas, J. Orazem, J. and Gulanski, B. (1998) Metrifonate treatment of the çognitive deficits of Alzhẹimer's disease. Metrifonate Study Group. Neumology. 50: $|2| 4-2 \mid$

Dachur, S., Schmodt, B. and I evy, A (1907) Effects of metrifonate on radial arm maze acquisition in middle-aged rats. Brain Res $777: 251+4$

Dawson, L.A. Nguyen, H.Q. and L., P. (2000) In vivo effects of the 5-HT(6) antagonist SB-271046 on striatal and frontal cortex extracellular coneentrations of noradrenaline, dopamine, 5-H I, glutamate and asparate. Br J Pharmacol, 130: 23-6.

Dawson, L. A., Nguyen, H.Q and Li. P. (2001) The 5-117(6) receptor antagonist $\mathrm{SB}-271046$ selectively enhances exchtatory neurotransmission in the rat frontal cortex and happocanpus. Neuropsichopharmacology: 25: 662-8.

Dawson, I.A. Nguyen, H.Q. and Li. P. (2003) Polentiation of mphemanine-induced changes in dopaminc and $5-H T$ by a $5-11 T_{6}$, receptor antagonist. Brain Res Bull. 59; 513-521.

Dodart, J.C.. Mathis, C. and Ungerer, A. (1997) Scopolamine-induced deficits in a wo-trial object recogniton task in mice. Neturoncort. 8: 1173-8.

Ennaceur. A. and Delacour. J. (1988) A new onetral test for neurobiological studies of memory in rats. 1: Behavioral data. Behar Brain Res 31:47-59.

Ennaceur, A and Melian, K. (1002) Effects of physostigmine and scopolamine on rats' performances in object-recognition and radial-maze tests. Psichopharmacologr (Berl). 109:321-30

Foles, A.G. Murphy, K.J. Hirst, W.D. Gallagher.
H.C., Hagan, J.J. Upton, N., Walsh, F.S. and Regan, C.M. (2004) The 5-HT, receptor antagonist SB-271046 reverses scopolamine-disrupted consolidation of a passive avoidance task and ameliorates spatial task deficits in aged rats. Neuropsychopharmacology 29: 93-100.

Gerard, C., Martes, M.P., Lefevre, K., Miquel. M.C., Verge, D., Lanfumey, L., Doucet, E. Hamon, M. and el Mestikawy, S. (1997) Immunolocalization of serotonin 5-HT6 receptor-like material in the rat central nervous system. Brain Res 746: $207 \cdot 19$

Gillet, G. Ammor, S. and Fillion, Gi. (1985) Serotonin inhibits acetylcholine release from rar striatum slices: evidence for a presynaptic receptor-mediated effect. I Neurochem. 45: 1687-91.

Golighily, K.L., Lloyd, J.A., Hobson, J.E. Gallagher, P., Mercer, Ge and Young, A.H. (2001 Acute tryptophan depletion in schizophrenia Pruchol Med. 31: 75-84

Itoh, A., Nita, A., Katono, Y., Usui, M., Naruhashi, K., lida, R., Hasegawa, T and Nabeshima, T (1997) Effects of metrifonate on memory impairment and cholinergic dystunction in rats. Eur I Pharmacol. 322: 11-9.

King, M.V., Slẹight, A.J., Woolley, M. L.. Topham. I.A. Marsden, C.A and Fone, K.C. (2004). 5. HT(6) receptor antagonists reverse delay-dependeat deficits in novel object discrimination by enhancing consolidation- an effect sensitive to NMI B receptor antagonism. Neteropharmacology 47: 195-204.

Lacroix. L.P., Dawson, L.A.. Hagan. J.J. and Heidbreder. C.A. (2004) 5-HT6 receptor antagonist SB-27!046 enhances extracellular levels of monoammes in the rat medial prefrontal cortex. Synapse. 51: 158-64.

Leonard, C.S. and Llinas, R. (1994), Serotonergic and cholinergic inhibition of mesopontine cholinergic neurons controlling REM sleep: an in sitro electrophysiological study. Neruroscience. 59: 309-30.

Lieben. C.K., Blokland. A., Westerink, B. and Deutz. N.E. (2004a) Acute tryptophan and serotonin depletion using an optimized tryptophan-free protein-carhohydrate mixture in the adult rat. Neunchem Int, 44:9-16. 
Lieben. C.K. Oorsouw, K.. Deutz, N.E. and Blokland, A. (2004b) Acute tryptophan depletion induced by a gelatin-based mixture impairs object memory but not affective behavior and spatial learning in the rat. Behav Brain Res. 151: 53-64.

Lindner, M.D., Hodges, D.B., Jr. Hogan, J.B.. Orie, A.F. Corsa, J.A., Barten, D.M. Polson, C.. Robertson, B.J., Guss, V.L., Gillman, K.W.. Starret1, J.E., Jr. and Gribkoff, V.K. (2003): An assessment of the effects of serotonin 6 (5-HT6) receptor antagonists in rodent models of learning. $J$ Pharmacel Exp Ther 307: 682-91.

Maura, G. Fedele, E. and Raster, M. (1989) Acetylcholine release from rat hippocampal slices is modulated by 5-hydroxytryptamine. Eur J Pharmacol 165: 173-9

MeEntee, W.J. and Crook, T.H. (1991) Serotonin. memory, and the aging hrain. Psichopharmacology $103: 143-9$.

Meneses, A (1999) 5-HT system and cognifion. Neurosci Biobehav Rev. 23: 1111-25.

Meneses, A. (2001) Role of 5-HT(6) receptors in memory formation. Drug News Perspect 14:396400 .

Myhrer, T. (2003) Neurotransmitter systems involved in learning and memory in the rat: a metaanalysis based on studies of four behavioral tasks. Brain Res Brain Res Res, 41: 268-87.

Park, S.B. Coull, J.T. McShane, R.H., Young. A.H.. Sahakian, B.J., Robbins, T.W. and Cowen, P.J. (1994) Tryptophan Depletion in Normal Voluntecrs Produces Selective Imparments in Leaming and Memory. Neumopharmacology. 33: 575.588

Pitsıkas, N., Rigamonti. A.E., Cella, S.G. Locatellr, V. Sala, M. and Muller. E.E. (2001) Effects of molsidomine on scopolamine-induced. amnesna and hypermotility in the rat. Eur \& Pharmacol, 426: 193-200.

Porter, R.J. Lunn, B.S. and O'Brien, J.T. (2003) Effects of acute tryptophan depletion on cognutive function in Alzheimer's discase and in the healthy elderly. Psuchol Med 33:41-9

Prickacrts, J., Honig, W., Schmidt, B.H and Blokland, A. (1999) Metrifonate impros es working but not reference memony performance in a spatial cone ficld task. Eur J Pharmacol. 380: 61-5.

Prickacrts, J.,Sik, A., van der Staay, F.J., de Vente, J. and Blokland, A. (in press) Dissociable effects of acetylcholinesterase inhibitors and phosphodiesterase type 5 inhibitors on object recognition memory: acquistion versus consolidation. Psuchopharmacology

Richards, P., Johnson, M. Ray, D, and Walker, C. (1999) Novel protem targets for organophosphorus compounds. Chem Btol Interact. 119-120: 503-11.

Richards, P.G, Johnson, M.K. and Ray, D.E. (2000) Identification of acylpeptide hydrolase as a sensituve site for reaction with organophosphorus compounds and a potential target for cognitive enhancing drugs. Mol Pharmacol 58: 577.83 .

Riedel, W.J., Klaassen, T., Deut/, N.E., van Someren. A. and van Praag. H.M. (1099) Tryptophan depletion in normal voluntecrs produces selective impairment in memory consolidation. Psychopharmacology (Berl) 141:362-9.

Riedel, W.J., Klaassen, T and Schmitt, J.A. (2002) Tryptophan, mood, and cognitive function. Brain Behav Immun. 16:581-9.

Rickkinen, P., Jr., Schmidt, B., Stefanski, R., Kuitunen, J, and Riekkinen, M. (1996) Metrifonate improves spatial navigation and avoidance behavtor in scopolamine-treated, medial septum-festoned and aged rats. Eur J Pharmacol 309: 121-30.

Riemer, C.. Borroni, E., Levet-Trafit, B, Martin. J.R., Poli. S., Porter, R.H. and Bos, M. (2003) Influence of the 5-HT6 receptor on acetylcholine release in the cortex: pharmacological characterization of 4-(2-bromo-6-pyrrolidin-1-ylpyridine-4sulfonyliphenylamine, a potent and selective 5 H. T6 receptor antagonust. J Med Chem. 46: 1273-6.

Ringman, J.M and (ummings, J.I. (1999) Metrifonate: update on a new antidementra agent. $J$ Clin Psychialry 60: 776-82.

Rohbins. I.W (1998). Homology in behav poura! pharmacology: an approach to animal models of human cognition. Behav Pharmacol 9.509.19

Roberts, J C. Reavill, (., Fast, S.Z. Harrison, PJ Patel. S. Routledge, ( and Leshe, R.A. 12002) The distribution of 5 - HT(6) receptors in rat bram. 
an autoradiographic binding study using the radiolabelled 5-HT(6) receptor antagonist [(125)I]SB258585. Brain Res. 934: 49-57.

Robinson, S.E. (1983) Effect of specific serotonergic lesions on cholinergic neurons in the hippocampus, cortex and striatum. Life Sci. 32: 345-53.

Rogers, D.C. and Hagan, J.J. (2001) 5-HT6 receptor antagonists enhance retention of a water maze task in the rat. Psychopharmacology (Berl). 158: $114-9$

Ruat, M., Traiffort, E., Arrang. J.M., TardivelLacombe, J., Diaz, J. Leurs, R. and Schwartz, J.C. (1993) A novel rat serotonin (5-HT6) receptor: molecular cloning. localization and stimulation of cAMP accumulation. Biochem Biophys Res Commun. 193:268-76

Rubinsztein, J.S., Rogers, R.D., Riedel, W.J.. Mehta, M.A., Robbins, T.W. and Sahakian, B.J. (2001) Acute dietary tryptophan depletion impairs maintenance of "affective set" and delayed visual recognition in healthy volunteers. Psvehopharmacology (Berl), 154: 319-26.

Russell, M.(i, and Dias, R. (2002) Memories are made of this (perhaps): a review of serotonin 5 . IT(6) receptor ligands and their biological funclioms. Curr Top Med Chem. 2: 643-54.

Sarter. M., Bruno, J.P and Givens, B. (2003) Attentonal functions of cortical cholinergic inputs: what does it mean for learning and memory? Neurobiol Learn Mem. 80: 245-56.

Scali, C., Ciiovannini, M.G, Bartolini, L., Prosperi, C.. Hisz, V. Schmidt, B. and Pepeu, G. (1997) Eflect of metrifonate on extracellular brain acetylcholine and object recognition in aged rats. Eur $y$ Pharmaiol 325. 173-80.

Shirazi-Southal!. S., Rodriguez, D.E. and Nomikos, Gici (2002) Effects of typical and atypical antipsychotics and receptor selective compounds on acetylcholine efllux in the hippocampus of the at. Aeuropsochopharmacology: 26. 583-94.

Sik, A., van Nicuwchuyzen. P.. Prickacrts, J. and Blokland, A. (2003) Performance of different mouse strains in an object recognition task. Behav. Brain Res. 147: 49-54.
Sleight, A.J., Boess, F.G., Bos, M. and Bourson, A. (1998) The putative 5-ht6 receptor: localization and function. Ann N Y Acad Sci. 861: 91-6.

Sobczak, S., Riedel. W.J., Booij, I., Aan Het Rot, M., Deuc, N.E. and Honig, A. (2002) Cognition following acute tryptophan depletion: difference between first-degree relatives of bipolar disorder patients and matched healthy control volunteers. Psychol Med. 32: 503-15.

Steckler, T. and Sahgal, A. (!995) The role of serotonergic-cholinergic interactions in the mediation of cognitive behaviour. Behav Brain Res. 67: 165-99.

Szczepanski, K., Vivian, J.A., Dorsch, K., Blokland, A., Hedley, L., Lieben, C., Martin, J.R., Morcau, J.L.. Secchi, R.L., Sik, A., Sung, E. and Schreiber, R. (2002) Procognitive effects of the 5 . HT6 receptor antagonist RO4368554. Society of Neuroscience. 290.20.

van der Staay, F.J., Hinz, V.C. and Schmidt, B.H. (1996a) Effects of metrifonate on escape and avoudance learning in young and aged rats, Behav Pharmacol. 7: 56-64.

van der Staay, F.J., Hinz, V.C. and Schmidt, B.H. (1996b) Effects of metrifonate. its transformation product dichlorios, and other organophosphorus and reference cholinesterase inhibitors on Morris water escape behavior in young-adult rats. J Pharmacol Exp Ther: 278: 697-708.

Woolley, M.L.. Bentley, J.C., Sleight, A.J., Marsden, C.A. and Fone, K.C. (2001) A role for 5-ht6 receptors in retention of spatial leaming in the Norris water maze. Neuropharmacology, 41: 210-9.

Woolley, M.L., Marsden, C.A.. Sleight, A.J. and Fone, K.C. (2003) Reversal of a cholinergicinduced deficit in a rodent model of recognition memory by the selective 5-HT(6) receptor antagonist, Ro 04-6790. Psychopharmacology (Berl). 170: $358-67$.

Woolley, M.L. Marsden. C.A. and Fone K.C. (2004) 5-HT6 receptors. Current Drug Targets. CNS \& Veurobiological Disonders. 3: 59.79 


\section{CHAPTER}

9

\section{General discussion}


Over the last half century, the emphasis on the role of the 5-HT synthesis in the pathogenesis of neuropsychiatric disorders (e.g. depression, anxiety, schizophrenia, autism, impulsive disorders, neurodegenarative disorders, eating disorders, alcoholism and substance abuse) has grown substantially. Many of the clinical drugs developed as atypical antipsychotics, antidepressants, anxiolytics or anorectic agents interact with 5-HT receptors. However, in most cases the precise working mechanism of these drugs on the 5-HT system remains unclear. In order to develop selective ligands with a high efficacy and low side effects, it is in our opinion of great importance to investigate how exactly $5-\mathrm{HT}$ is related to behavioral functions and disorders. Animal studies have generated a wealth of information about the possible neurobiological basis of 5-HT in affective and cognitive dysfunctions. However, substantial controversy has arisen from these studies, in particular in terms of identifying certain anatomical brain structures and/or neurochemical pathways involved in these functions.

For the studies in this thesis, the method of acute TRP depletion was selected as the main approach to reduce central 5-HT levels in rats. This method was applied to investigate whether the behavioral effects induced by a reduction in plasma TRP levels reflect a change in the affective or cognitive state of the animal.

\section{The method of acute TRP depletion as a model of depression?}

Animal models are mostly developed for a better understanding of the brain circuitry in disorders frequently found in humans and are often used as research tools. However, in order to be considered as an adequate simulation of a disorder, an animal model should ideally fulfill three criteria: construct validity (homology and similarity of underlying neurobiological mechanisms), face validity (isomorphism) and predictive validity (pharmacological correlation) (D'Mello and Steckler, 1996; Willner and Mitchell, 2002).

\section{Effects of an acute TRP depletion on the 5-HT system}

Construct validity indicates how well the measures of a process reflect the theoretical rationale underlying the process of interest. In this case. the criterion requires that the etiology and neurobiology of depression is similar in depressed humans and in animal undergoing an acute TRP depletion. 
As illustrated in the introduction, depression is a complex disorder consisting of various symptoms of different nature. Nevertheless, important biological aspects of the disorder are a dysfunctional 5-HT system, i.e. a decrease in 5-HT levels and activity (Meltzer, 1989; Mann, 1999) and a disturbed HPA system which results in higher cortisol levels in depressed patients (McAllister-Williams et al., 1998; Nestler et al., 2002).

Application of a TRP-free amino acid mixture has frequently demonstrated to be suitable to reduce plasma TRP levels in humans. Even more direct indicators of central 5-HT (e.g. plasma TRP/LLNAA ratio and CSF 5-HIAA) were affected by this treatment (Reilly et al., 1997; Williams et al., 1999; Booij et al., 2003). An advantage of animal studies is that the treatment effects can be investigated in more detail by investigating changes in the central nervous system. Earlier animal studies showed that the treatment with a TRP-free amino acid mixture substantially $(-75 \%)$ reduced plasma TRP levels (Biggio et al., 1974; Gessa et al., 1974). In our first study (Chapter 2), we tried to replicate these findings by using a TRP-lacking amino acid mixture similar in composition to those used in humans. However, after a 5 h-delay, only a moderate reduction in plasma and central TRP levels occurred. Although contrary to earlier animal studies, our findings were in line with other studies showing rather moderate effects of this TRP-lacking mixture on centra! 5- -HT tissue concentrations and 5-HT dialysate (Bel and Artigas, 1996; Brown et al., 1998). Nevertheless, several remarks are in place, which can contribute to these apparent contradicting effects. Besides the composition of the mixture (varying in the use of amino acids with or without additional substances such as vitamins or sucrose), the amount of mixture administered or the interval used between treatment and measurement may all be of crucial importance for the outcomes. Besides, we noticed that the majority of animal studies on acute TRP depletion were performed on juvenile rats instead of adult male rats used in our studies. Since younger animals have a higher metabolic level in protein synthesis and a higher need for TRP compared to more adult animals, also helps to explain the contrasting effects in the level of plasma TRP reduction. However, due to this discrepancy in the degree of TRP depletion, we could not generalize the behavioral effects of this TRP-free amino acid mixture in rats to those found in humans.

Consequently, we decided to develop an alternative way to substantially deplete plasma TRP levels in rats, that would be comparable to those in humans. The data of Chapter $\mathbf{3}$ and $\mathbf{4}$ revealed that a gelatin-based protein mixture combined with carbohydrate can induce substantial reductions $(65-75 \%)$ in plasma TRP levels in adult rats. This was made possible since 
gelatin can be defined as a protein which consists of a high variety of amino acids with additional substances, except for TRP (Djagny et al., 2001) and therefore this mixture is assumed to be more comparable to a normal nutritional diet. Furthermore, this TRP-free protein-carbohydrate mixture also affected the central 5-HT concentrations in diverse areas of the rat's brain. Additionally, the experiment described in Chapter $\mathbf{4}$ pays attention to the specificity of the treatment. Irrespectively from the TRP reduction, administration of this protein-carbohydrate mixture increases the levels of several amino acids, which might affect the physical or mental condition of the animals. Furthermore, we found that administration of this proteincarbohydrate mixture induces a marked reduction in plasma TYR. Initially, this was found to be an unfavorable effect that could bias the selectivity of the treatment. However, this reduction in plasma TYR did not affect central DA concentrations. Although both 5-HT and DA are directly dependent on the level of their precursors (TRP and TYR, respectively), there is a difference in how the transmitters are synthesized. Within the dopaminergic system, the TYR hydroxylase (the rate-limiting enzyme) is about $75 \%$ saturated with TYR while, within the serotonergic system. TRP hydroxvlase is half saturated with TRP (Westerink and De Vries, 1991). Therefore, DA concentrations are less susceptible to variation of TYR levels in plasma or brain.

A moderate reduction in central TRP levels (Chapter 2 ) or a severe depletion 5-HT neurons of the DRN (Chapter 6), did not affect resting corticosterone levels nor did these treatments change the corticosterone response to a physiological stressful condition. This indicates that lowering the 5-HT synthesis does not have a direct effect on the HPA regulation.

\section{Implications of an acute TRP depletion on behavioral functions}

Face validity refers to a similarity between the effects of the model and the expression of the disorder being modeled. This implies that the response observed in the animal model should show a resemblance to the symptoms in humans with the disorder.

The occurrence of depression can be defined by a broad spectrum of symptoms. However feelings of hopelessness and a decreased interest in pleasurable stimuli (anhedonia) are the main symptoms observed in depressed patients. It was exactly on these symptoms that animal tests (i.e. the forced swimming test and sucrose preference tests, respectively) are developed. Since signs of anxiety often go together with symptoms of depression. we have tried to enlarge our insight of a 5-HT depletion on affective behavior by assessing the treatment effects both on anxiety-and depression-related behavior. 
By moderately reducing plasma TRP levels (Chapter 2), the animals appeared to react more anxious in a novel situation. It was found that the TRP depleted animals displayed less explorative behavior and remained more time in the saver areas of an open field. Additionally, the TRP depleted rats were less mobile in the FST indicating that the rats were found in a more depressive-like state than the group that received a TRP-enriched amino acid mixture. However, by increasing the extent of plasma TRP depletion (Chapter 5), these changes in affective behavior completely disappeared.

Albeit that the substantial TRP depletion was induced by a different type of mixture (gelatin-based protein in stead of amino acids), the data indicated that the appearance of affective behavior might depend on the degree of TRP/5-HT reduction. Indeed one has to be very cautious with making interexperimental comparisons, but the results from Chapter $\mathbf{6}$ are in favor of this hypothesis. Here, it was found that lesioning the 5-HT neurons in the DRN did not cause a change in affective behavior. Other researchers have made assumptions along this line. Treatment with a low dose of 5,7-DHIT induced anxiety-like behavior in rats which could no longer be detected when the dose of this neurotoxin was increased (Hall et al., 1999). Anxiogenic behavior also appeared after PCA treatment moderately decreased 5-HT levels. At this same time, this treatment also induced depressive-like behavior (Harro et al., 2001). Another theory holds that in case depression is related to a dysfunctional 5-HT system, there is a high probability that it is preceded by symptoms of anxiety and/or aggression (van Praag, 1996). It was suggested that the relationship between the 5-HT metabolism and mood changes is negatively orientated. Moreover, a threshold theory has been suggested indicating that the occurrence of depressive relapse can be expected in remitted treated patients whose plasma TRP levels have been reduced to approximately $60 \%$ or more (Van der Does, 2001)

Since depressed patients often display cognitive dysfunctions, we included learning and memory-related tasks in most of our studies. Moderate plasma TRP reduction induced by an amino acid mixture, did not change spatial performance related to working and reference memory (Chapter 2). Spatial learning and memory functions were neither affected by a substantial decrease in TRP levels (Chapter 5). However, it was found that this TRPlacking protein-carbohydrate mixture severely impaired the rat's performance to discriminate between objects after a short delay. These results indicated that TRP depletion selectively affected recognition memory. The findings that a substantial decrease in plasma TRP levels affected memory function without changing mood-related behavior is in agreement with human findings (Riedel et al.. 1999) and therefore increase the value of face validity. 


\section{Effectiveness of cognitive-enhancers after acute tryptophan depletion}

With respect to the cognitive impairment induced by the gelatin-based protein mixture, it was investigated whether these effects on recognition memory could be challenged by pharmacological memory-enhancers. Although it was shown that citalopram can facilitate long-term memory processes (Harmer et al., 2002) in humans, our preference went out to two compounds which are able to increase the cholinergic activity. The memory-related effects of Ro4368554, a 5-HT, antagonist, were tested in TRP depleted rats and these were compared with those of metrifonate (MTF), a cholinesterase innibitor (Chapter 8). The data revealed that both Ro4368554 and MTF reversed the impairment in object discrimination induced by scopolamine (a muscarinic receptor antagonist), as could be expected on basis of the cholinergic mechanism of action of both drugs. Remarkably, both drugs appeared to reverse the effects of an acute TRP depletion on recognition memory. This can imply that these memory-enhancing effects were accomplished through a change in cholinergic activity independently from action of the 5-HT system. However, these results might also refer to a $5-\mathrm{HT} / \mathrm{ACh}$ interaction. The underlying mechanism of these effects remains unclear since we do not know whether an acute TRP depletion can actually affect the cholinergic activity. The pathogenesis of most psychiatric disorder does not exclusively dependent on the deregulation of one particular transmitter system but is mostly the outcome of a disturbed pattern of integrated neurotransmitter systems. Accordingly, one would expect the function of 5-HT in memory processes to be more complex than that representing a simple imbalance. However the exact relationship between 5-HT and other neurotransmitters in not well known. For example it has been stated that 5-HT neurons interacts with ACh-containing neurons in an inhibitory manner (Robinson, 1983; Leonard and Llinas, 1994). This might explain how antagonizing the $5-\mathrm{HT}_{6}$ receptor type may enhance memory functions through stimulating the ACh. release. In contrast, application of this theory would predict the occurrence of memory deficits to be a result of a 5 -HT increase rather than the consequence of a 5-HT reduction as found in our studies. 


\section{Concluding remarks: acute tryptophan depletion as a potential model for memory deficiency}

Several studies presented in this thesis have demonstrated severe impairment in ability to recognize an object after a short delay when plasma TRP levels were reduced in rats. The performance in object discrimination is determined based on the spontaneous preference for investigating novel rather than familiar objects (Ennaceur and Delacour, 1988). This means that performance does not depend on a specific rule or is influenced by a reward. Interestingly, we did not find evidence that an acute lowering in TRP levels impaired spatial memory. Although we have not looked at the function of 5-HT in other memory paradigms, the present data suggest that a 5-HT depletion may generate specific memory effects.

Moreover, the fact that this impairment in recognition memory occurred under the condition that the stimuli were presented at the time TRP levels were severely reduced, is in agreement with human studies where it was implied that this recognition effect was caused by a change in the process of consolidation rather than retrieval (Riedel et al., 1999: Schmitt et al., 2000). The task of object recognition is considered as a measure of working memory in which the hippocampal region (i.e. perirhinal cortex, parahippocampal cortex, entorhinal cortex and hippocampus) plays a prominent role. Animal studies have demonstrated that lesioning these medial temporal lobe structures (e.g. rhinal cortex) selectively disrupted the ability to discriminate between objects (Ennaceur et al., 1996). The effect on recognition memory was also demonstrated in patients with damage restricted to the hippocampal region (Manns et al., 2003). Recognition memory is considered to have a episodic and a familiarity component (Brown and Aggleton, 200 l).

The effect of reduced plasma TRP levels on object recognition was consistently found in our lab (Chapter $\mathbf{5}$ and 8) and elsewhere (Chapter 7). Although it has been shown that this TRP-free protein-carbohydrate mixture reduces central levels of $5-\mathrm{HT}$, it still remains questionable whether this treatment also changes the transmission of 5-HT (i.e. 5-HT release) and whether the functional changes (recognition memory) are directly mediated by a change in the $5-\mathrm{HT}$ system or rather through the interference of other systems? As described above, the finding that dysfunction in object discrimination in TRP depleted rats could be reversed by cholinergic-related compounds (i.e. MTF and Ro4368554) led to the speculation of other transmitter systems (e.g. ACh or GABA) being involved in the memory impairments after an acute TRP depletion. Additionally, the involvement of 
two alternative systems could possibly account for these effects on object memory. Looking in detail at the biochemical effect of the TRP-free proteincarbohydrate mixture revealed a decrease in central levels of citrulline (CIT) that is presumably related to the TRP depletion since this did not occur in the other groups. Because arginine (ARG) is converted in the same metabolic rout to CIT and nitric oxide (NO) (Dawson and Dawson, 1996), central NO levels might also be affected by the TRP-lacking treatment. If so, this might have marked consequences for synaptic plasticity and learning and memory functions through its involvement in long-term potential (LTP) (Prast and Philippu, 2001). Animal studies have illustrated the effects of the NO system on object discrimination (Blokland et al., 1998; Pitsikas et al., 2003). Secondly, besides the synthesis of 5-HT, TRP is also involved in the production of kynurenine (KYN). In regard to memory functions, the metabolic pathway of TRP-KYN could be interesting. It was namely found that two of the metabolites (K.YNA and QUINA) are related to NMDA receptors which play a crucial role in the formation of LTP (Stone, 2001).

Nevertheiess treatment with 5.7-DHT increased our insight in the role of 5-HT in cognitive functions (Chapter 6), revealing that chronic depletion of 5-HT impaired object memory in a similar way as acute 5-HT depletion. The fact that treatment of 5,7-DHT destroys the 5-HT containing neurons in the DRN, thereby leaving the TRP levels intact, suggests that the cognitive deficit is mediated by 5-HT rather than by other metabolic mechanisms. However, we cannot exclude the interaction of 5-HT with other transmitter system related to memory processes (e.g.. ACh or NO). Changes in these systems may consequently contribute to the memory impairment displayed after reducing central 5-HT levels. Nevertheless, a similar memory-related effect in one particular task (i.e. object recognition) was found in two different models of 5-HT depletion supports the prominent role of 5-HT in recognition memory. Furthermore, inspired by the threshold theory (i.e. TRP levels as determinant. in the onset of affective dysfunctions), we hypothesized that performance in recognition memory could be related to the degree of TRP/5-HT reduction. This suggestion was confirmed by the results in Chapter 7 . It was found that varying the amount of the gelatin-based protein affected the degree in plasma TRP reduction. Moreover, the gradual decline in plasma TRP appeared to be related to the memory performance in object discrimination. These data strongly support the role of TRP 5 -HT in object memory and that a threshold for TRP-dependent memory performance can be assumed. The data suggest that the threshold lies somewhere around a $50 \%$ reduction of plasma TRP. with more severe impairment in object memory at more a pronounced TRP depletion. 


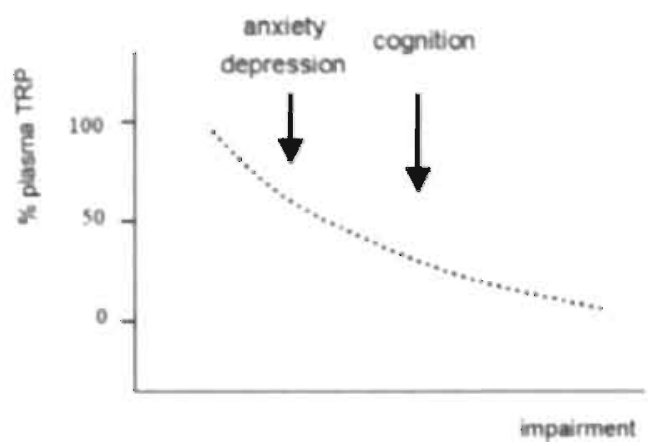

\section{Directions for further research}

Taken together, the results lead more towards the direction of applying this TRP-free protein-carbohydrate mixture as an animal model of memory deficiency rather than a model of anxiety or depression. However, more elaborate studies are recommendable to investigate the biochemical and functional effects of depleting 5-HT by means of reducing the levels of TRP. At first, more intense research is required to exclude or detect the involvement of other biological systems which could contribute to the dysfunctions induced by the TRP-free protein-carbohydrate mixture. The line of research for this purpose can differ in many ways. At the moment it is very difficult to decide whether the effects in recognition memory in TRP depleted rats are only/directly related to a change in 5-HT activity. However, a micro-dialysis study investigating the 5-HT release after treatment thereby making a time curve where the effects of central TRP levels are compared to those of 5-HT will give a better insight on the relation between the 5-HT synthesis and functional behavior. Other experiments can elaborate on the involvement of alternative systems such as ACh, NO or K.YN with reduced TRP levels and investigate whether they interact with 5 -HT. More challenge studies with 5-HT-related (e.g. SSRIs or 5-HT specific ligands) and 5-HT non-related compounds (e.g. NMDA agonists, NO donors, GABA antagonists) can contribute to improve our knowledge in the mechanism of cognitive impairment induced by an acute TRP depletion. Moreover, this gelatin-base protein can also be applied in chronic studies where it is used as a diet rather than as a mixture and thereby reducing plasma TRP levels and central 5-HT levels over longer periods. Once validated, a comparison on biochemical and functional effects of an acute versus a chronic reduction of TRP levels can be investigated. 
Based on the anxiogenic and depressive-like behavior after a moderate, but not a more substantial TRP depletion, and on the threshold theory, it would be interesting to investigate whether dose-dependent effects occur with respect of anxiety- and depression-related behavior when using this TRP-free protein-carbohydrate mixture. In line with the theory proposed by van Praag (1996), 5-HT related memory dysfunctions might be driven by anxiety and/or depressive symptoms.

An ongoing research is studying the effects of the gelatin-based protein mixture in humans to validate the treatment effects on plasma TRP levels. This way, inter-species comparisons can be made to further enhance our insight of 5-HT on functional behavior.

The indications that mood lowering effects are more frequently induced by a TRP depletion in subject with a predisposition for depression (e.g. females, family history of mood disorders, history of recurrent depressive episodes) could form the base of several animal studies in which the consequences of a biological sensitivity to depression are studied by investigating gender or strain (e.g. genetically modified or selectively bred animals, see: Overstreet et al., 2003) differences.

\section{References}

Bel, N, and Artigas, F. (1996) Reduclion of serolonergic function in rat braun by tryptophan deplelion: effects in comfol and flusoramine-treated rats. I Nezowethem. 67:669-76.

Biggie, (i. Fadda, F., Fanni, P.. Tagliamonte, A. and Gessa, (i.l. (1974) Rapid depletion of serum trypophan, brain tryptophan. serotonin and 5 hydroxyindoletic acid by a iryptophan-free diet. life Sitences, 14: 132!-1329.

Blokland, A., Prickacrts, J. Honig, W. and de Vente, I. (1998) State-dependent imparment in object recogntion atter hippocampal NOS inhibilion. Neuroneport. 9: 4205-8.

Booij, L., Van der Does. A.J and Riedel, W.J. (2003) Monoamine depletion in psychiatric and healthy populations: review. Mol Psychary: 8: $951-73$

Brown. C.M. Fetcher, PJ. and Cuscina, D.V. (1998) Acute amino acid loads that deplete brain serotonin fail to alter behavior. Pharmacol Biochem Behow: 54: 115-21.
Brown, M.W. and Aggleton. J.P. (2001) Recognition memory: what are the roles of the perirhnal cortex, and hippocampus? Nat Ret: Nemosci. 2: 51-6!

Dawson, V.L. and Dawson, T.M. (1996) Nitric oxide actions in neurochemistry. Neurochem $\operatorname{lnt}$. 29: $97-110$

Djagny, V.B. Wang, Z and Xu, S. (2001) Gelatin. a valuable protein for food and pharmaceutical industries: review. Crit Rev Food Sci Nutr. 41 : $481-92$.

D'Mello, GiD. and Steckler, T. (1996) Animal models in cognitive behavioural pharmacology: an overview, Brain Res Cogn Braun Res. 3: $345-52$.

Ennaceur, A. and Delacour, J. (1988) A new onetrial test for neurobiological studies of memory in rats. I: Behavioral data. Behav Brain Res. 31:47-59.

Ennaceur. A... Neave, N. and Aggleton. J.P. (1996) Neurotoxic lestons of the perirhinal cortex do not mimic the behavioural effects of fornix transection in the rat. Behar Brain Res 80: 9-25. 
Gessa, GL. Biggio, G. Fadda, F., Corsini, GU and Tagliamonte, A. (1974) Effect of the oral administration of tryptophan-free amino acid mixtures on serum tryptophan, brain tryptophan and scrotonin metabolism. J Neunochem. 22; 869-70.

Hall, F.S. Devries, A.C., Fong, GiW. Huang. S and Pert. A. (1999) Effects of 5.7-dihydroxytryptamine depletion of tissue serotonm levels on extracellular serotonin in the striatum assessed with in vivo microdialysis: relationship to behavior. Sinapse. 33: 16-25.

Harmer, C.J. Bhagwagar, Z. Cowen, PJ and Goodwin, GM. (2002) Acute administration of citalopram facilitates memory consolidation in bealthy volunteers. Prychopharmacology (Berl). 163: $106-10$

Harro, J., Tonissaar, M., Eller, M., Kask, A. and Oreland, L. (2001) Chronic variable stress and partial 5-HT denervation by parachloroamphetamine treatment in the rat: effects on behavior and monoamine neurochemistry. Brain Res, 899: 227. 39

Leonard. C.S. and L.linas, R. (1994) Serotonergic and cholinergic inhibition of mesopontine cholinergic neurons controlling REM slẹp: an in vitro electrophysiological study. Neuroscience, 59: 309. 30.

Mann, J J. (1999) Role of the serotonergic system In the pathogenesis of major depression and suici. dal behavior. Neuropsychopharmacology: 21: 99S. $105 \mathrm{~S}$.

Manns, J.R., Hop̣kins, R.O., Reed, J.M.. Kitchener, E. . and Squire, L.R. (2003) Recognition memory and the human hippocampus. Neuron. $37: 171-80$.

McAllister-Williams, R.H., Ferrier, I.N. and Young. A.H. (1998) Mood and neuropsychological function in depression : the role of corticosteroids and serotonin. Psichological medicine. 28: 573. 584.

Melver, H. (1989) Serotonergic dysfunction in depression. Br I Psychatry Suppl 155 (Suppl X): 25-31.

Nestler, E.J., Barrot. M., DiLeone, R J Eisch, A J.. Gold, S.J. and Monteggra, L.M. (2002) Veurobiology of depression. Neuran. 34: 13-25
Overstreet, D.H., Commıssaris, R.C., De La Giarza. R., 2nd, File, S.E., Knapp, D.J. and Seiden, L.S. (2003) Involvement of 5-HT I A receptors in animal tests of anxiety and depression: evidence from genetic models. Strexs. 6: 101-10.

Pitsikas, N., Rigamonti, A.E., Cella, S.Gi and Muller. E.E. (2003) The GABAB receptor and recognition memory: possible modulation of its behavioral effects by the nutrergic system. Neuruscience. 118: 1121-7.

Prast. H. and Philippu, A. $(2001) \mathrm{i}$ Nitric oxide as modulator of neuronal function. Prog Neurobiol $64: 51-68$.

Reilly; J.G, McTavish, S.F.B. and Young. A.H. (1997) Rapid depletion of plasma tryptophan: a review of studies and experimental methodology. Journal of Psuchopharmacology: I1: 381-392.

Riedel, W.J., Klaassen, T., Deut/, N.E., van Someren. A. and van Praag. H.M. (1999) Tryptophan depletion in normal voluntecrs produces selective imparment in memory consolidation. Psychopharmacology (Berl). 141: 362-9.

Robinson, S.E. (1983) Effect of specific serotonergic lesions on cholinergic neurons in the hippocampus, cortex and striatum. Life Sel. $32: 345$. 53.

Sehmitt, J.A., Jorissen, B.L., Sobczak, S., van Boxtel, M.P., Hogervorst, E.. Deut. N.E and Riedef, W.J. (2000) Tryptophan depletion umpain memory consolidation but improves focussed attention in healthy young volunteers. Jesurnal of Psuchopharmacology 14:21-29

Stone. T.W. (2001) Kynurenines in the CNS: from endogenous obscurity to therapeutic importance. Prog Necurobiol 64: 185-218.

Van der Does, A.J.W. (2001) The mood-lowering effect of tryptophan depletion: possible explanation for discrepant findings. Archuves of General Psichatr: $58 \cdot 200-202$.

van Praag, H.M. (1996) Serotonin-related, anxiety/aggression-driven, stressor-precipitated depression. A psycho-biological hypothesis. Eur Pruchiatri 11.57-67. 
Westerink, B.H. and De Vries, J.B. (1991) Effect of precursor loading on the synthesis rate and release of dopamine and serotonin in the striatum: a microdialysis study in conscious rats. J Neurochem. 56: 228-33.

Williams, W.A., Shoaf, S.E., Hommer, D. Rawlings, R. and Linnoila, M. (1999) Effects of acute tryptophan depletion on plasma and cerebrospinal fluid tryptophan and 5-hydroxyindoleacetic acid in normal volunteers. $J$ Neurochem. 72: $1641-7$.
Willner, P. and Mitchell, P.J. (2002) The validity of animal models of predisposition to depression. Behav Pharmacol. 13: 169-88. 


\section{Summary}

An imbalance in central serotonin (5-hydroxytryptamine; 5-HT) synthesis is presumed to play a prominent role in the etiology of several psychiatric disorders such as anxiety disorders, depression and neurodegenerative disorders. The main objective of this thesis is to investigate the function of 5-HT in affective and cognitive behavior in rats.

Due to the rate-limiting function of tryptophan-hydroxylase, a change in tryptophan (TRP; 5-HT precursor) levels will result in a similar change in concentrations of 5-HT. Based on this parallel mechanism of the 5-HT synthesis, the method of acute TRP depletion was selected to reduce brain 5 -HT concentrations in rodents. Consequently, it was evaluated whether the administration of a nutritional TRP-lacking mixture could induce behavioral effects related to anxiety, depression and cognition.

So, by means of lowering 5-HT synthesis, we tried to integrate both biochemical and functional findings in order to investigate how exactly $5-\mathrm{HT}$ could contribute to certain neuropsychological functions.

Chapter 1 provides a general introduction on 5-HT synthesis and a concise overview of methods applied in animal studies to reduce serotonergic activity. In this chapter, functions such as mood, depression and cognition are discussed. This is followed by a review of widely used animal models, 5-HTrelated theories and treatments of these neuropsychological functions. Furthermore, biological and psychological consequences of acute plasma TRP depletion in humans and animals are evaluated. Finally, this chapter outlines the aims and scientific questions which form the base of the different studies presented in this thesis.

Chapter 2 presents the behavioral effects of a study in which adult rats received a TRP-free amino acid mixture, similar to that previously used in human studies. The results revealed anxiogenic and depressive-like bẹavior at a moderate reduction $(34 \%)$ in plasma TRP levels. However, this moderate reduction in plasma TRP levels did not affect cognitive functions, such as spatial working and reference memory, nor did it change sustained attention. Furthermore, corticosterone levels (prior and post stress-induced exposure) were not affected. Besides a reduction in plasma TRP levels, the TRP-free amino acid mixture also reduced central TRP levels in the hippocampus $(33 \%)$. The TRP depletion seems to be less pronounced in rats when compared to humans. The different levels of TRP depletion between this study (moderate) and human studies (marked), hampers comparison of behavioral effects between rat and man. 
Clearly, development of a novel method, leading to a more substantial TRP depletion in rats, would facilitate comparison with results from human studies. This was the aim of the studies described in the next chapters.

Chapter 3 reports the effects of a gelatin-based protein mixture on plasma TRP levels and methodological procedures are investigated in detail. Within two hours after a single administration, the TRP-free protein-carbohydrate mixture caused a considerable reduction $(43 \%)$ in plasma TRP levels. Multiple administrations of this mixture resulted in an even more pronounced and prolonged depletion. A substantial reduction of $73 \%$ in plasma TRP levels occurred less then $4 \mathrm{~h}$ after the first administration was given. Compared to the TRP-free amino acid mixture, the gelatin-based protein mixture induced a higher reduction in plasma TRP levels, which mimicked more closely the degree of TRP depletion in humans. In addition, the effects were reversible since plasma TRP levels increased back to normal levels within several hours. Finally, it was shown that this TRP-free protein-carbohydrate mixture can be balanced for plasma TRP levels by enriching the mixture with an additional amount of TRP.

Chapter 4 provides a more detailed evaluation of the biochemical effects of a TRP-free protein-carbohydrate mixture in rats. Except for TRP and TYR, the gelatin-based protein mixture increased the plasma levels of the most

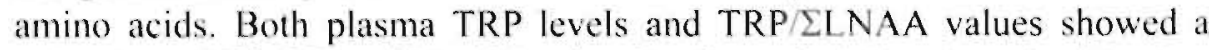
reduction of $75-78 \%$ within $4 \mathrm{~h}$ after the first administration. At this time point, the TRP depleted rats displayed a $50 \%$ reduction in central 5 -HT concentration. As in plasma, the TRP levels in the brain could be balanced by an additional amount of TRP. The TRP-lacking treatment also affected TYR (i.e. precursor of DA) levels. Nevertheless, these effects appeared to be specifically related to TYR and not to DA concentrations in the brain. Based on these data, this treatment was selected as a tool to further examine the role of $5=11 \mathrm{~T}$ in aflective and cognilive behavior.

The aim of the study presented in Chapter $\mathbf{5}$ was to investigate whether an acute reduction in plasma TRP levels could induce a change in affective and cognitive behavior of adult rats. It was found that, $4 \mathrm{~h}$ after administration, a TRP-free protein-carbohydrate mixture substantially reduced plasma TRP levels but did not cause anxiety-related or depressive-like behavior. Although TRP depleted rats were not affected in spatial learning and memory functions, object memory was severely impaired after treatment. It was concluded that a substantial 5-HT depletion caused a selective effect on object recognition. 
Furthermore, the data revealed that enriching the gelatin-based mixture with TRP functioned as a good control condition for both biochemical and behavioral aspects.

Chapter 6 reports long-term consequences of a 5-HT depletion on affective and cognitive behavior. Injection of the neurotoxin 5,7-DHT in the dorsal raphe nucleus caused a permanent damage in 5-HT neurons which prevented further transmission of 5-HT. Although the treatment with 5,7-DHT did not induce anxiety-related or depressive-like behavior, it generated a severe impairment in object recognition. Furthermore, the corticosterone response to a stress-induced situation was not affected by a chronic 5-HT depletion. These results are consistent with a previous study in which it was found that an acute reduction of plasma TRP levels did not affect corticosterone response to a stressor. This suggests that a depletion in 5-HT synthesis is not involved in the deregulation of the HPA-axis as often observed in depressed patients. The results of this study further support the hypothesis that 5-HT mediates cognitive processes. The findings from this study presented a great similarity with the behavioral effects observed after a substantial reduction in plasma TRP levels and this suggests that the effects on recognition memory are associated with the availability of 5-HT.

Based on a threshold-theory, it was speculated that cognitive performance is be related to the concentration of 5-HT. The notion that the performance in an object recognition task may depend on the degree of TRP/5-HT depletion is investigated in Chapter 7. A gradual reduction in plasma TRP levels was accomplished by varying the amount of gelatin-based protein used in the carbohydrate mixture. In the control (TRP+) and lower doses, the animals could still recognize the objects which they had previously explored. Indications of impaired recognition memory were found at higher doses. In the dose condition where the amount of TRP-lacking protein was similar as in previous studies, the rats failed to discriminate the familiar object from the novel object. It was concluded that a relationship exists between plasma TRP and recognition memory: a reduction in plasma TRP levels of about $50 \%$ or higher leading to an impairment in object memory.

Hence, the method of acute TRP depletion can be considered as a model of memory deficiency. The aim of Chapter $\mathbf{8}$ was to investigate potential memory-enhancing effects of a 5- $\mathrm{HT}_{0}$ receptor antagonist (Ro4368554). The effect of Ro4368554 on recognition memory was assessed in memorydeficient paradigms of time-dependent forgetting, treatment with scopolamine (an ACh muscarinic antagonist) and acute TRP depletion. The 
effect of Ro4368554 was compared with that of metrifonate (a cholinesterase inhibitor) in the three memory deficiency models. Unlike Ro4368554, treatment with metrifonate improved the performance in object recognition at a 24-h delay. Both Ro4368554 and metrifonate reversed the memory deficit after treatment with scopolamine and the TRP-free protein-carbohydrate mixture. The interaction between 5-HT and ACh neurotransmitter systems is discussed with regard to the memory effects induced by an reduction in plasma TRP levels.

Finally, Chapter 9 provides a general discussion where concluding remarks are given concerning the involvement of 5-HT in behavioral functions such as anxiety, depression and cognition. The use of a gelatin-based proteincarbohydrate mixture is evaluated as a powerful tool to induce a reduction in central 5-HT concentrations. Although no change in affective behavior was found after reducing 5-HT levels (method of acute TRP depletion and 5,7-DHT lesion), object memory was severely impaired. The decrease in performance in the object recognition task when gradualiy lowering plasma TRP levels indicates the relationship between plasma TRP levels and the object memory. It is further discussed how exactly this method of acute TRP depletion can be applied to further investigate the neuropsychological function of 5-HT in both animals and humans. Consequently, several suggestions are given for further experimental research which might benefit our insight on the relationship between 5-HT and behavioral functions.

$\Lambda$ subsequent study, described in Appendix 1, was concerned with the effects of an acute TRP depletion on the metabolism of kynurenine. Besides its involvement in the TRP/5-HT pathways, a high amount of TRP also serves for the synthesis of kynurenine. Therefore it was hypothesized that administration of a gelatin-based protein-carbohydrate mixture would reduce the levels of kynurenine and its metabolites (kynurenine acid and quinolinic acid). Since these metabolites are related to glutamatergic activity through the NMDA receptors (i.e. associated with learning and memory processes), a change in the concentration of kynurenine acid or quinolinic acid could underly the deficit in object memory induced by an acute TRP depletion. Although a moderate peripheral reduction in the levels of kynurenine and the metabolites occurred in the TRP depleted animals, this treatment did not reduce the synthesis of kynurenine in the brain. Therefore, it was concluded that an acute reduction in plasma TRP levels may not have affected recognition memory by a reduction in central kynurenine levels. 


\section{Samenvatting}

Een uit evenwicht geraakte synthese van serotonine (5-hydroxytyptamine; 5 -HT) in het brein wordt aanschouwd als een voorname factor in de etiologie van diverse psychiatrische stoornissen. zoals angst, depressie en neurodegeneratieve stoornissen. Het hoofddoel van deze thesis bestaat erin de betrokkenheid van 5 -HT in affectief en cognitief gedrag in ratten te onderzoeken.

Omwille van de snelheid-beperkende functie van tryptofaan-hydroxylase, resulteert een verandering in tryptofaan (TRP; precursor van 5-HT) waarden op gelijke wijze in een verandering in 5-HT concentraties. Op basis van dit parallel mechanisme in de 5-HT synthese, werd de methode van acute TRP depletie geselecteerd om centrale 5-HT concentraties in ratten te verlagen. Vervolgens werd er onderzocht of een toediening van een voedzaam mengsel, waarbij TRP ontbreekt, gedragseffecten kon induceren die verwant zijn met angst, depressie en cognitie.

Door middel van een verlaging in de 5-HT synthese, hebben we getracht biochemische en gedragsmatige bevindingen met elkaar te integreren. Aan de hand hiervan werd getracht conclusies te vormen omtrent de relevantie van 5 -HT bij bepaalde neuropsychologische functies.

Hoofdstuk 1 bevat een algemene inleiding ontrent het mechanisme onderliggend aan de 5-HT synthese en geeft en beknopte overzicht van de verschillende methodes die bij dierstudies gehanteerd worden om de serotonerge activiteit te reduceren. Dit hoofdstuk geeft uitleg over stemming, depressie en cognitie. Vervolgens is er een weergave van de meest voorkomende diermodellen, 5-HT gerelateerde theorieën en behandelingen ontwikkeld voor deze neuropsychologische functies. Verder worden biologische en psychologische gevolgen van een acute verlaging in plasma TRP geëvalueerd bij zowe! mensen als dieren. Tenslotte schetst dit hoofdstuk de doelstellingen en de wetenschappelijke vraagstellingen onderliggend aan de verschillende studies die in dit proefschrift worden voorgesteld.

Hoofdstuk 2 omschrijft de gedragseffecten van een studie waarin volwassen ratten behandeld met een TRP-vrij aminozuren mengsel, gelijkend op wat voorheen gebruikt werd in humane studies. De resultaten tonen angstig en depressie-gerelateerd gedrag aan bij een matige verlaging in plasma TRP $(34 \%)$ waarden. Deze matig plasma TRP depletie had geen effect op cognitieve functies zoals spatieel werk- en referentie geheugen, noch veranderde het volgehouden aandacht. Verder waren de corticosterone 
waarden (voor en na blootstelling aan een stressvolle situatie) niet aangetast door de acute verlaging in plasma TRP waarden. Naast de verlaging in plasma TRP, verminderd het TRP-vrij aminozuur mengsel ook de hippocampale waarden van TRP (33\%). Maar, bij ratten bleek de TRP depletie minder uitgesproken te zijn dan bij mensen. Het verschil in TRP depletie niveaus in deze studie (matig) en humane studies (ernstig), belemmert de vergelijking van gedragseffecten tussen rat en mens.

De ontwikkeling van een nieuwe methode, die leidt tot een substantiëlere TRP depletie in ratten, zal weliswaar het vergelijk met de resultaten uit humane studies vergemakkelijken. Dit was het doel van de studies die worden weergegeven in de volgende hoofdstukken.

Hoofdstuk 3 rapporteert de effecten van een op gelatine gebaseerd eiwit mengsel waarbij de methodologische aspecten omtrent deze behandeling in detail worden bestudeerd. Een enkelvoudige toediening van het TRP-vrij eiwit-koolhydraten mengsel veroorzaakt, binnen twee uur, een aanzienlijke verlaging in plasma TRP waarden $(43 \%)$. Meervoudige toedieningen van het mengsel resulteerde in een meer uitgesproken plasma TRP depletie die tevens langer aanhoud over tijd. Een substantiële verlaging (73\%) in plasma TRP waarden trad op bij een interval van minder dan 4 uur na de eerste toediening. Vergeleken met het TRP-vrij aminozuur mengsel, werd er bij dit op gelatine gebaseerd eiwit mengsel een meer substantiëlere verlaging in plasma TRP waarden gevonden, dat meer gelijkend was op de mate van depletie zoals gevonden bij mensen. Bovendien zijn de effecten omkeerbaar omdat de plasma TRP waarden terug toenemen binnen een tijdspan van enkele uren. Als laatste werd er bewijs geleverd dat dit TRP-vrij eiwit-koolhydraten mengsel gebalanceerd kan worden voor plasma TRP levels door het mengsel te verrijken met een aanvullende hoeveelheid TRP.

Hoofdstuk 4 voorziet een meer gedetailleerde evaluatie van de biochemische effecten van het TRP-vrij eiwit-koolhydraten mengsel bij ratten. Het op gelatine gebaseerd mengsel verhoogde de plasma waarden van de meeste aminozuren, behalve die van TRP en TYR. Zowel de waarden van TRP als de waarden van TRP/ LLNAA in plasma vertoonden een $75-78 \%$ reductie, 4 uur na de eerste toediening. Op dit tijdsstip, lieten de TRP gedepleteerde ratten een $50 \%$ verlaging zien in centrale 5 -HT concentraties. Zoals in het plasma. konden de effecten in het brein gebalanceerd worden door een aanvullende hoeveelheid TRP. Ofschoon de behandeling ook de TYR (precursor van DA) waarden beïnvloedde, bleken deze effecten zich specifiek voor te doen bij 
TYR en niet voor DA waarden in het brein. Gebaseerd op deze data, werd de behandeling geselecteerd als een middel om de rol van 5-HT op affectief en cognitief gedrag verder te onderzoeken.

Het doel van de studie in Hoofdstuk $\mathbf{5}$ was vast te stellen of een kortdurende verlaging in plasma TRP waarden een verandering kon teweeg brengen in affectief en cognitief gedrag bij volwassen ratten. Er werd aangetoond dat, 4 uur na de toediening van het TRP-vrij eiwit-koolhydraten mengsel, plasma TRP waarden aanzienlijk verlaagd waren. Nochtans veroorzaakte de behandeling geen angst of depressie gerelateerd gedrag bij de dieren. Ofschoon geen veranderingen in ruimtelijke leer- en geheugen functies werden waargenomen, vertoonden de TRP gedepleteerde ratten een verslechtte prestatie in object discriminatie. Daaruit werd geconcludeerd dat een aanzienlijke 5-HT depletie een selectief effect veroorzaakt op object herkenning. Vervolgens bleek dat het met TRP verrijkt mengsel een goede controle conditie was voor zowel biochemisch als gedragsmatig aspecten.

Hoofdstuk 6 rapporteert de lange termijn gevolgen van een 5-HT depletie op stemming en cognitief gedrag. Injectie van de neurotoxische stof 5,7-DHT in de dorsale raphe kern veroorzaakt een permanente beschadiging in de 5-HT neuronen dat verdere overdracht van 5-HT voorkomt. Ofschoon deze behandeling met 5,7-DHT het gedrag gerelateerd aan angst en depressie niet aantastte, leidde het wel tot ernstige stoornissen in object herkenning. Verder werd de corticosterone response bij blootstelling aan een stress situatie, niet beïnvloed door de chronische 5-HT depletie. Deze resultaten zijn overeenkomstig met die van een eerdere studie waarin werd aangetoond dat een acute verlaging in plasma TRP waarden geen effect heeft op de response van corticosterone bij blootstelling aan een stressfactor. Dit suggereert dat een verlaging in de synthesis van 5-HT niet betrokken is bij de verstoorde HPA-as zoals vaak voorkomend bij depressieve patiënten. De resultaten van deze studie ondersteunen de hypothese dat 5-HT een belangrijke rol speelt bij cognitieve processen. De gedragsmatige bevindingen van deze studie zijn gelijkend aan de effecten van een substantiële verlaging in plasma TRP waarden. Dit suggereert dat de effecten op object geheugen geassocieerd zijn met een verandering in $5-\mathrm{HT}$.

Op basis van een theorie over drempel waarden, werd er gespeculeerd of cognitieve prestaties gerelateerd kunnen worden aan 5-HT waarden. Het idee dat de de prestatie van object herkenning kan afhangen van de mate van TRP/5-HT depletie werd onderzocht in Hoofdstuk 7. Een geleidelijke 
verlaging in plasma TRP waarden werd bekomen door de hoeveelheid van het op gelatine gebaseerd eiwit in het koolhydraten mengsel te variëren. In de controle (TRP + ) en de lage dosis condities herkenden de dieren nog steeds het object dat ze kort voorheen verkend hadden. Indicaties in de richting van een verstoring in object herkenning werden gevonden bij hogere doseringen. In de conditie waarbij de hoeveelheid op gelatine gebaseerd eiwit gelijk is aan die van voorheen uitgevoerde studies, konden de ratten het nieuwe object niet meer onderscheiden van het bekende object. Daaruit volgend, bleek er een relatie te bestaan tussen plasma TRP waarden en herkenning geheugen, aantonend dat bij een plasma TRP daling van meer dan $50 \%$, de prestatie in object herkenning afzwakt.

Hieruit volgde dat de methode van acute TRP depletie aanschouwd kan worden als een model voor geheugen verstoring. De opzet van Hoofdstuk 8 was om de potentiële geheugen verbeteringseffecten van $5-\mathrm{HT}_{6}$ receptor antagonist (Ro4368554) te onderzoeken in drie modellen van geheugenstoornis. Het effect van Ro4368554 op object herkenning werd getest in de geheugenverstorende paradigma's van tijdsgerelateerd vergeten, behandeling met scopolamine (een $\mathrm{ACh}$ muscarine antagonist) en na een acute TRP depletie. Het effect van Ro4368554 werd in ieder model vergeleken met dat van metrifonaat (een cholinesterase inhibitor). In tegenstelling tot Ro438554, verbeterde de behandeling met metrifonaat de prestatie in object herkenning na een 24-uur interval. Zowel RO4368554 als metrifonaat konden de geheugenverstoring bij behandeling van scopolamine en van het TRP-vrij eiwit-koolhydraten mengsel opheffen. De interactie tussen 5-HT en ACh neurotransmitter systemen wordt bediscussieerd met betrekking tot de geheugeneffecten bekomen door een verlaging in plasma TRP waarden.

Als laatste voorziet Hoofdstuk 9 ons van een algemene discussie waarin besluitende opmerkingen worden gemaakt over de betrokkenheid van 5-HT op gedragsfuncties zoals angst, depressie en cognitie. Het gebruik van het op gelatine gebaseerd eiwit-koolhydraten mengsel wordt als een middel bediscussicerd om een verlaging in 5-HT concentraties te bewerkstelligen. Ofschoon er zich geen verandering voordeed in affectief gedrag na een verlaging in 5-HT waarden (door acute TRP depletie en 5,7-DHT), trad er wel een verstoring op in het object geheugen. De verminderde prestaties in the object herkenningstaak bij geleidelijke daling in plasma TRP waarden wijst op de relatie tussen plasma TRP waarden en object geheugen. De manier warop deze methode van acute TRP depletie kan dienen als middel om neuropsychologische functies van $5-\mathrm{HT}$ bij zowel dieren als mensen te 
bestuderen, wordt verder besproken. Dit wordt opgevolgd door enkele suggesties voor verder experimenteel onderzoek dat ons kennis betreffende de betrokkenheid van 5-HT op gedragsfuncties kan bevorderen.

Een latere studie, zoals beschreven in Appendix 1, handelt over de effecten van een acute TRP depletie op het metabolisme van kynurenine. Sinds de meerderheid van TRP wordt omgezet in kynurenine, luidt de hypothese dat de toediening van een op gelatine gebaseerd eiwit-koolhydraten mengsel leidt tot een verlaging in de waarden van kynurenine en zijn metabolieten (kynurenine zuur en quinoline zuur). Deze metabolieten staan in relatie tot glutamaterge activiteit door middel van de NMDA receptoren (betrokken bij leer en geheugen processen). Hierdoor kan een concentratie verandering van het kynurenine zuur of het quinoline zuur een onderliggende factor zijn bij de stoornis in object geheugen na een acute TRP depletie. Ofschoon er een matige perifere verlaging optrad in kynurenine en de metabolieten bij de TRP gedepleteerde dieren, deden er zich geen centrale effecten voor in de synthese van kynurenine. Daaruit werd geconcludeerd dat een acute verlaging van TRP waarden niet in relatie stond met centrale waarden van kynurenine. 



\section{APPENDIX}

\section{Effects of an acute \\ tryptophan depletion on the kynurenine pathway}

C.K.J. Lieben, R. Schwarcz, P. Guidetti and A. Blokland. 


\section{Abstract}

Besides its involvement in the biosynthesis of serotonin, the degradation of Iryptophan (TRP) is mostly concerned with the metabolism of kynurenine $(K Y N)$. The metabolites kynurenic acid (KYNA) and quinolinic acid' (QUINA) may be associated with immunological and neurological diseases through their involvement on NMDA receptors (Stone, 2001b). Nevertheless a NMDA receptor-mediated change in glutamaterigic activity may also act on cognitive functions, and KYNA also affects a7 nicotinic acetylcholine receptors at low concentrations (Hilmas et al., 2001). Therefore "a shift in the synthesis of $K Y N$ or its metabolites, might participate in the cognitive impairment found after deterioration of the 5-HT synthesis induced by an acute TRP depletion.

The present study was designed to evaluate potential changes in the KYN pathway after acute TRP depletion in rats. Four hours after the rats were administrated with a TRP-free protein-carbohydrate mixture, the levels of TRP, KYN, KYNA and QUINA were determined in liver, serum and brain samples. Concentrations of the metabolites showed a moderate decrease in the liver of the TRP depleted rats. In serum samples, a decrease was fouma in KYN and QUINA concentrations. The TRP-free protein carbohydrate mixture reduced central TRP levels while the treatment did not affect central levels of KYN. KYNA and QUINA. This indicated that KYN metabolites are not likely to the cognitive impairment induced by an acute reduction of plasma TRP levels.

\section{Introduction}

It was recently found that an acute reduction in TRP levels, induced by a nutritional mixture lacking TRP. can impair memory-specific processes (i.e. consolidation of newly learned information). In humans, delayed recognition of words and pictures were worse when TRP levels were acutely reduced (Schmitt et al., 2000: Rubinsztein et al., 2001; Sobezak et al., 2002: Booij et al. 2003). Comparable to humans, a substantial depletion in plasma TRP levels impaired performance in object recognition (Lieben et al., 2004b). This cognitive dysfunction was believed to be mediated through a dysregulation of the 5-hydroxytyptamine (5-HT: serotonin) system since it was found that within $4 \mathrm{~h}$ after administration, this TRP-free protein-carbohydrate mixture decreased plasma TRP levels over $60 \%$ and resulted in a reduction of central 
5-HT levels by about. $40 \%$ (Lieben et al., 2004a). Moreover, a similar impairment in object recognition was found in 5-HT-lesioned rats indicating that this cognitive effect might indeed be 5-HT related (Lieben et al., 2003).

Under normal circumstances, the proportion of ingested TRP used for the production. of $5-\mathrm{HT}$ is estimated at $1-2 \%$ (Twarog and Page, 1953). The vast majority of TRP is utilized for protein synthesis in which TRP is determined for the metabolism of the kynurenine (KYN).

Therefore, KYN is the primary major degradation product of TRP and is further converted, directly or indirectly, to several metabolites, such as KYNA (KYNA) and quinolinic acid (QUINA; see Fig. 1) (Moroni. 1999). Independent of each other, both metabolites are connected with $\mathrm{N}$-methyl-Daspartate (NMDA) receptors (Stone and Perkins, 1981).

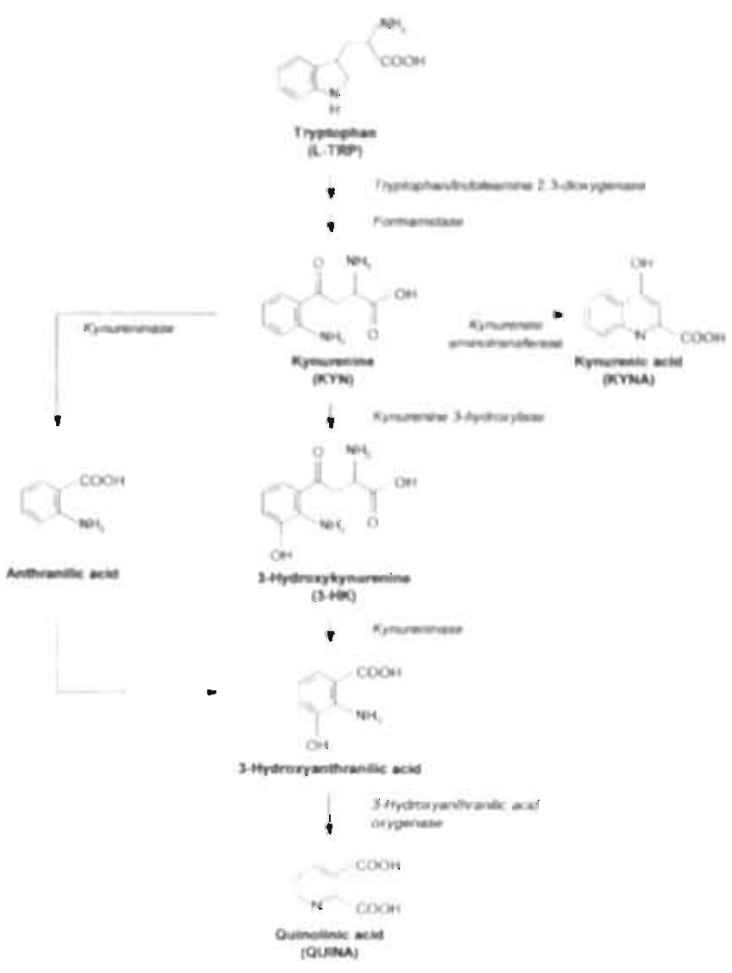

Fig. 1. Synthesis of kynurenine

KYNA has a neuroprotective function through its antagonizing mechanism on glutamatergic NMDA receptor. In contrast, QUiNA has a excitatory function of this glutamatergic system. QUINA can result in an overstimulation of NMDA receptors and give rise to a neurotoxic function wich can account for neuronal damage as been seen in hypoxia, ischaemia (Schwarcz et al., 1983: Stone, 2001a):

Besides this, NMDA receptors are often linked to cognitive functions. NMDA receptor activity results in a $\mathrm{Ca}^{2+}$ efflux which induces a state of long-term potention (LTP), assumed to be a potential molecular model of synaptic plasticity as part of learning and memory processes (Wang et al., 1997). It has been shown that NMDA receptor antagonists can inhibit LTP (Collingridge, 1987: Bohme et al., 1993) and leads to memory impairments (Harder and Ridley, 2000). This and the fact that KYN metabolites act on NMDA 
receptors, led to the idea that changes in the KYN pathway might affect cognitive functions. Indication have been found that cognitive functions are believed to be established by the working mechanism of KYNA on glycine-2 dite on the NMDA receptor (Birch et al., 1988). However, conflicting results have been found showing that KYNA interferes with working memory (Steele and Stewart, 1993) while on the otherhand, KYNA is found to improve recognition memory (Hlinak and Krejci, 1995). On the other hand, it also has been shown that treatment of QUINA can induce memory deficits (Jhamandas et al., 1994; Misztal et al., 1996).

We hypothesized that the KYN pathway was affected by the method of acute TRP depletion, thereby decreasing the amount of $\mathrm{KYN}$, and that changes in the metabolites (i.e. KYNA and QUINA) could contribute to the cognive impairment seen after treatment with a TRP-free mixture. In the present study, rats were treated with a TRP-free protein-carbohydrate mixture and after a 4h-delay, concentrations of TRP, KYN, KYNA and QUINA were determined in liver, serum and brain samples. These data were compared to those of rats treated with a TRP-enriched protein-carbohydrate mixture.

\section{Materials and methods}

\section{Animals}

Subjects were ten 4-month-old male Wistar rats (Charles River. The Netherlands), weighing between 315 and $395 \mathrm{~g}$ at their arrival. The rats were housed two per cage in standard Makrolon cages on sawdust bediding in an air-conditioned room $\left( \pm 20^{\circ} \mathrm{C}\right)$. The animals had free access to water. They were kept under a reversed 12/12-h light/dark cycle. The lights were on from $06.00-18.00 \mathrm{~h}$. A radio, which was playing softly, provided background noise.

\section{Drugs and chenicals}

The Gelatin hydrolysate (Solugel $C^{x}$ ) was obtained from PB Gelatins (Tessenderlo, Belgium). Glucodry 200 was obtained from the Amylumgroup (Koog aan de Zaan, The Netherlands). L-tryptophan, L-tyrosine and L-norvaline were from Sigma (Zwijndrecht, The Netherlands). Potasiumchloride $(\mathrm{KCl})$, calciumchloride-dihydrate $\left(\mathrm{CaCl}_{2} \cdot 2 \mathrm{H}_{2} \mathrm{O}\right)$ and 5-sulfosalicylic acid dihydrate were purchased from Merck (Darmstadt. Germany): 


\section{Treatment}

During a period of one week preceding the experiment, the rats were handled and habituated to oral injections with normal tap water $(10 \mathrm{~mL} / \mathrm{kg})$. Afterwards, they were randomly assigned to one of the two experimental groups $(\mathrm{n}=5$ /group) and were orally treated with a protein-carbohydrate mixture containing TRP (TRP+ group) or lacking TRP (TRP- group). The composition of the nutritional mixture is shown in Table 1.

To minimize the availability of TRP from food, the rats were deprived from food $14 \mathrm{~h}$ prior treatment until the experiment was completed. On this experimental day, the animals were orally injected twice, with a $90 \mathrm{~min}$ interval. Each administration consisted of $4 \mathrm{~g}$ Solugel $\mathrm{C}$ and $2 \mathrm{~g}$ Glucodry in a volume of $10 \mathrm{ml} / \mathrm{kg}$. Four hours after the first oral administration, the rats were decapitated. Immediately thereafter, trunk blood samples were collected in heparinic tubes and kept on ice. The whole liver and the brain were dissected and stored in $-80^{\circ} \mathrm{C}$ for further analysis.

Table 1: Composition of the nutritional TRP-free proteincarbohydrate mixture $(\mathrm{g})$.

\begin{tabular}{|l|c}
\hline Protein (Solugel C) in $100 \mathrm{ml}$ tap water & 100 \\
Carbohydrate (Glucodry 200) in $80 \mathrm{ml}$ tap water & 50 \\
$\mathrm{KCl}$ & 0.094 \\
$\mathrm{CaCl}_{2}-2 \mathrm{H}_{2} \mathrm{O}$ & 2.32 \\
$\mathrm{~L}-$ tryptophan (TRP-group) & 0 \\
L-tryptophan (TRP+ group) & 0.28 \\
\hline
\end{tabular}

\section{Measuring kynurenine}

Brain and liver tissue were homogenized $(1: 10, \mathrm{w} / \mathrm{v})$, and plasma was diluted $(1: 10, v / v)$, in ultrapure water. For the determination of TRP, KYN and QUINA, tissue homogenates and diluted plasma were furthẹ diluted $(1: 2.5$, $\mathrm{v} / \mathrm{v})$ with ultrapure water. Fifty $\mu \mathrm{l}$ of internal standard $(100 \mathrm{nM}$ 3,5 -pyridinedicarboxylic acid and $200 \mathrm{nM}$ homophenylalanine) were then added to $50 \mu \mathrm{l}$ aliquots of homogenates and plasma, respectively. To this mixture, $25 \mu \mathrm{l}$ of $5 \mathrm{~N} \mathrm{HCl}$ and $100 \mu \mathrm{l}$ of chloroform were added to precipitate proteins and to remove fatty acids. The samples were centrifuged $(12,000 \times \mathrm{g})$, and $100 \mu \mathrm{l}$ of the supernatant were added to glass tubes containing $50 \mu \mathrm{l}$ of $62.5 \mathrm{mM}$ tetrabutylammonium hydrogen sulfate and lyophilized overnight. The samples were then reacted with $25 \mu \mathrm{l}$ of methylene chloride containing $7.5 \%$ of diisopropylethylamine and $3 \%$ pentafluorobenzyl bromide (PFB-Br) at $60-65^{\circ} \mathrm{C}$ for $15 \mathrm{~min}$. Subsequently. $50 \mu \mathrm{l}$ of decane and $750 \mu \mathrm{I}$ of water were added. The samples were: 
thoroughly mixed, and the decane phase was removed. The gas chromatography $(\mathrm{GC})$ and the electron capture negative ionization mass spectrometry (MS) system (ThermoFinnigan, San Jose, CA) was a Trace GC coupled with a Trace MS quadrupole mass spectrometer. Chromatographic separation and $\mathrm{GC} / \mathrm{MS}$ analysis was achieved using a $30 \mathrm{~m}$ Rtx-5MS capillary column $(0.25$ $\mathrm{mm}$ i.d., $0.25 \mu \mathrm{m}$ film thickness, Restek Corp., Bellefonte, PA) with helium as a carrier gas. A split/splitless injection port ( $1 \mu \mathrm{l}$ injection volume) was used at $220^{\circ} \mathrm{C}$. The temperature program was as follows: $155^{\circ} \mathrm{C}$ for 1.25 $\min , 40{ }^{\circ} \mathrm{C} / \mathrm{min}$ to $275^{\circ} \mathrm{C}, 10^{\circ} \mathrm{C} / \mathrm{min}$ to $320^{\circ} \mathrm{C}, 1 \mathrm{~min}$ at $320^{\circ} \mathrm{C}$. The ion. source temperature was $220^{\circ} \mathrm{C}$. Selected ion monitoring was performed by recording the signal of the characteristic derivatives. For TRP, KYN and QUINA, the characteristic (M-PFB)-ions are di-PFB derivatives with a $\mathrm{m} / \mathrm{z}$ ratio of 346, 387 and 383, respectively (Naritsin et al., 1995). For the measurement of KYNA, the liver homogenate was further diluted $(1: 5, \mathrm{v} / \mathrm{v})$ with ultra pure water. To precipitate proteins, $25 \mu \mathrm{l}$ of $6 \%$ perchloric acid were added to $100 \mu \mathrm{l}$ of the tissue homogenates or diluted plasma, and the denatured proteins were removed by centrifugation $(12,000 \mathrm{xg})$. One hundred $\mu \mathrm{l}$ of the supernatant were further diluted with $150 \mu \mathrm{l}$ of ultra pure water, and $200 \mu \mathrm{l}$ of the mixture were subjected to HPLC analyses. Chromatographic separation was obtained on a $C_{18}$ reverse phase column (HR-80, esa, Chelmsford, MA) using a $200 \mathrm{mM}$ zinc acetate solution ( $\mathrm{pH}$ 6.2) containing $3.5 \%$ of acetonitrile as the mobile phase. HPLC was performed at a flow rate of $1 \mathrm{ml} / \mathrm{min}$, and KYNA was determined fluorimetrically in the eluate (excitation: $344 \mathrm{~nm}$; emission: $398 \mathrm{~nm}$; Perkin-Elmer LC 240 fluorescence detector, Beaconsfield, UK). The retention time of KYNA was approximately $5 \mathrm{~min}$.

\section{Statistic analysis}

Mean concentrations (+ SEM) of TRP, KYN, KYNA and QUINA were calculated in the liver, serum and brain samples for each group separately. The data were lirst submitted to a normality test (Kolmogorov-Smirnov) and extreme values were excluded from the statistical analysis. To study treatment effects, differences in concentrations were analyzed with a one-way (t-test) ANOVA. Treatment effects were regarded as statistically significant if $p<0.05$ 


\section{Results}

Four hours after the first administration of a TRP-free protein-carbohydrate mixture, serum TRP levels decreased by $60 \%$ when compared to the TRP+ group $[t(7)=-3.77, p<0.01$; see Fig. $2 \mathrm{~A}]$. Consequently, this resulted in a $31 \%$ reduction of central TRP levels $[t(7)=-4.08, p<0.01]$. As presented in Fig. 2B, the higest levels of KYN were found in the liver. Although TRP depletion did not affect KYN levels in the liver, this TRP-free mixture reduced KYN levels in serum samples $[r(7)=-3.41, p<0.05]$, without further changing central KYN levels, Notwithstanding the lack of significance, Fig, 2C shows a general decrease in the KYNA levels independent of the type of sample. Although, central KYNA levels were decrease by $33 \%$ in the TRP-depleted animals, this was found not to be statistatically different from those of the TRP+ group. Levels of QUINA were at the highest in the liver samples and treatment with the TRP-free mixture reduced QUINA concentrations with $42 \%$ in the liver $[t(8)=-2.70, p<0.05$; see Fig. 2D]. The TRP depleted rats showed a more subsided reduction $(15 \%)$ in the serum concentration of QUINA. And in the brain samples, the central QUINA levels of the TRPgroup was similar to those of the rats treated with the TRP-enriched mixture.

(A)

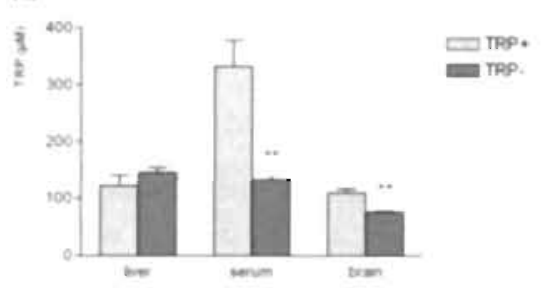

(C)

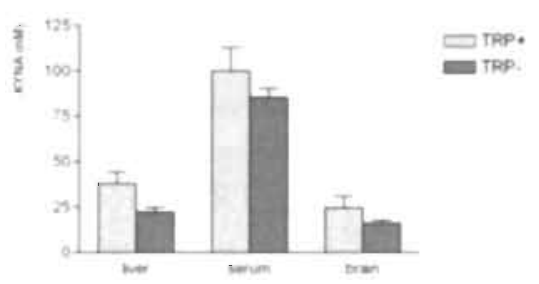

(B)

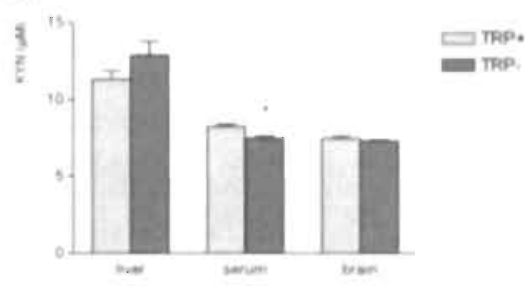

(D)

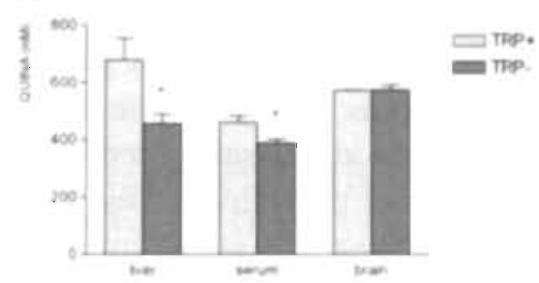

Fig. 2: Effects of an acute TRP depletion on the metabolism of kynurenine Varues are mean (+ SEM) concentrations of TRP (A), KYN (B), KYNA (C) and QUINA (D) in liver, serum and brain samples of rats administered with a protein-carbohydrate mixture with. (TRP+) or without TRP (TRP-). " $p<0.05$ and $\cdots p<0.01$ 


\section{Discussion}

After nutritional consumption, proteins are broken down in the stomach, ingested in the liver and uptaken into the bloodstream from which the amino acids can be transported into the brain to further support the metabolism of central transmitter systems. In the present study the effects of an acute TRP depletion on the KYN metabolism were investigated in these stages of nutritional absorption (i.e. liver, peripheral and central).

Independent of treatment, it. was found that the highest concentrations of KYN and QUINA were found in the liver wherease TRP and KYNA levels were more present in the blood samples. The only effect a TRP depletion caused in the liver was a decrease of QUINA concentrations. However, treatment with TRP-free protein-carbohydrate mixture peripherally reduced plasma TRP levels $1060 \%$ within $4 \mathrm{~h}$ after administration. Additionally, this cause a reduction in the serum levels of KYN and QUINA. The serum TRP depletion induced a central reduction of $30 \%$ in TRP levels. However, no change occurred in central level of the KYN pathway. Although not significantly different from the TRP+ group, a $33 \%$ reduction was found in the central KYNA levels of the TRP-group. These data do not support the hypothesis that functional effects after TRP depletion could be mediated through the KYN pathway, as the data reported no central change in KYN or its metabolites.

However, some conciderations and remarks have to be mentioned. This experiment has to be considered as a pilot study to investigate whether changes could be expected in the metabolic function of $\mathrm{KYN}$ after reducing TRP levels. Therefore, one has to concider the rather low amount of samples obtained within each treament condition and has to be careful with drawing conclusions. Nevertheless. the TRP-free protein carbohydrate mixture depleted the peripheral TRP levels to a similar extent as found in a previous study (Lieben et al., 2004b). One could argue that a control group (treatment with tap water or physiologic salt water 'saline') should have been included in this study to investigate potential effects of the protein-carbohydrate mixture. However, we previously found that plasma TRP levels in the TRP + group was similar to those of a saline group. As a result, the saline group was concidered excessive, although this saline group would have been recommendable to compare the effects of the protein-carbohydrate mixture on KYN levels. 
Furthermore, investigating the effects of an acute TRP depletion on the metabolites of KYN was interesting in terms of the memory deficiency in object recognition found after an acute depletion in plasma TRP levels, since both metabolites (KYNA and QUINA) have opposite functions on NMDA receptors. We wanted to see whether a change in the balance between both metabolites occurred in respect to glutamaterige activity. For example, one might expect a TRP depletion to reduce KYN levels and consequently reduce the excitatory function of QUINA on the glutamatergic activity, thereby inhibiting the function of LTP to acquire and process new information. However, no change in the central levels of QUINA occurred after acutely reducing TRP levels. Instead a non-significant central decrease occurred in the KYNA levels. Unfortunately we did not specify the effect of this acute TRP depletion on different brain structures. However, it would have been recommendable to further investigate area-specific treatment effects within this TRP-KYN pathway. This would espcially have been interesting with respect to brain structures (e.g. hippocampus or enthorinal cortex)which are associated to recognition memory (Brown and Aggleton, 2001).

The method of an acute TRP depletion may not be sufficient to induce a change in the TRP-KYN pathways since it requires a longer time to change the synthesis of KYN. Nevertheless, some indications of KYN involvement in the degradation of TRP were found after this acute effect on TRP levels (Schwarz et al., 2002). Besides a pattern of lowered central KYNA levels, it appears as if the treatment effect on QUINA levels gradually declined over the sample types, showing high significant effect on liver samples but no change in central QUINA levels. Switching over to a more chronic model of TRP depletion might further clarify the involvement of TRP on the KYN pathway. This way, TRP levels could be depeleted over a longer period resulting in chronic models of TRP depletion. This similar method has been previously applied to substantially reduce 5 -HT levels over days (Fadda et al., 2000). However this method is yet to be applied for investigating the effects on chronic TRP reduction on the metabolism. of $\mathrm{KYN}$ on learning and memory processes.

Nevertheless if this TRP.KYN pathway is involved in cogntive functions, one would expect to find acute effects in this pathway of TRP-KYN. However, since no significant changes occurred in central KYN pathway, we can not confirm the deficit in object memory after acute TRP depletion to be caused by the mechanism of KYN but rather can be interpreted to be 5-HT related. 


\section{References}

Birch, P.J., Grossman, CJ. and Hayes, A.G. (1988) Kynurenic acid antagonises responses to NMDA via an action at the strychnine-insensitive glycine receptor. Eur J Pharmacol. 154: 85-7.

Bohme, G.A., Bon, C., Lemaire, M., Reibaud, M.. Piot, O., Sturzmann. J.M.. Doble, A. and Blanchard, J.C. (1993) Altered synaptic plasticity and memory formation in nitric oxide synthase inhibitor-treated rats. Proc Nall Acad Sci U/SA. 90: $9191-4$

Booij, L., Van der Does, A.J. and Riedel, WJ. (2003) Monoamine depletion in psychiatric and healthy populations: review. Mol Psuchatry 8: 951-73.

Brown, M.W. and Aggleton, J.P. (200I) Recognition memory: what are the roles of the perirhinal cortex and hippocampus? Nat Rev Neuresct 2: 51.61

Collingridge. G (1987) Synapuc plasticily. The role of NMDA recepiors in learning and memory. Nature 330: 604-5.

Fadda, F., Coces, S. and Stancampiano, R. (2000) A physiological method to selectively decrease brain serotonun release. Brain Res Brain Res Protoc, 5: 219-22.

Harder, I.A. and Ridley, R.M. (2000) The 5-HTIA antagonist. WAY 100635 , alleviates cognitive imparments induced by dizocilpine (MK-801) in monkeys. Neuropharmacology. 39: 547-52.

Hilmas, C., Percira, E.F. Alkondon, M.. Rassoulpour, A.. Schwarcz. R. and Albuquerquec, E.X. (2001) The brain metabolite kynurenic acid inhibits alpha7 nicotinic receptor activity and increases non-alpha7 nicotinic receptor expression: physiopathological implications. I Neurosci. 2! $7463-73$

Hlinak, Z. and Krejci, I. (1995) Kynurenic acid and 5,7-dichlorokynurenic acids improve social and object recognition in male rats. Pswchopharmacologe $(B e r l)$. 120:463-9

Jhamandas, K.H. Boegman, R.J. and Beninger. R.J. (1994), The [993. Upjohn Award Lecture. Quinslinic acid induced hrain neurotransmitter deficits: modulation by endogenous excitotoxin antagonists. Can J Physiol Pharmacol. 72: 1473. 82.

Lieben, C., Steinbusch, H. and Blokland, A. (2003) Comparable effects of acute and chronic 5-HT depletion: Impaired object recognition but no effects on forced swimming hehavior in the rat. Society for Neuroscience. 835.19.

Lieben, C.K., Blokland, A., Westerink, B. and Deutz. N.E. (2004a) Acute tryptophan and seroconin depletion using an optimized tryptophan-free protein-carbohydrate mixture in the adult rat. Neurochem Int, 44: 9-16.

Lieben, C.K., Oorsouw, K., Deut, N.E. and Blokland. A. (2004b) Acute tryptophan depletion induced by a gelatin-based mixture tmpairs object memory but not affective behavior and spatial learning in the rat. Behov Brain Res. 151: 53-64.

Mistal, M., Skangiel-Kramska, J., Niewiadomska, G. and Danysz. W. (1996) Subchronic intraventricular infusion of quinolinic acid produces working memory imparment-a model of progressive excitoloxicity. Neuropharmacology. 35: 449-58.

Moroni, F. (1999) Tryptophan metabolism and brain function: focus on kynurenine and other indole metabolites. Eur . Pharmacol. 375: 87-100.

Naritsin, D. B., Boni. R.L. and Markey, S.P. (1995) Pentafluorobenzylation method for quantification. of acidic tryptophan metabolites using electron capture negative ion mass spectrometry. Anal Chem. 67: 863-70.

Rubinszrein, J.S., Rogers, R.D.. Riedel, W.J., Mehta. M.A., Robbins, T.W. and Sahakian, B.J. (2001) Acute dietary tryptophan depletion impairs maintenance of "affective set" and delayed visual recognition in healthy volunteers. Psuchopharmacology (Berl). 154: 319-26.

Schmitt. J.A., Jorissen, B.L.. Sobczak. S.. van Boxtel, M.P. Hogervorst, E., Deut, N.E. and Rredel. W.J. (2000) Tryptophan depletion impairs memory consolidation but improves focussed attention in healthy young voluntecrs. Journal of Psuchopharmacologi: 14:21-29. 
Schwarcz, R., Whetsell, W.O., Ir and Mangano, R.M. (1983) Quinolinic acid: an endogenous metabolite that produces axon-sparing lesions in rat brain. Science. 219: 316-8.

Schwarz, M.J., Offenbaccher, M., Neumeister, A. Ewert, T., Willeit, M., Praschak-Rieder, N., Zach. J., Zacherl, M., Lossau, K., Weisser, R., Stuckı, Gi and Ackenheil, M. (2002) Evidence for an altered tryptophan metabolism in fibromyalgia. Neurobiol Dis. 11: 434-42.

Sobczak, S., Riedel, W.J., Booij. I., Aan Het Rot, M. Deutz. N.E. and Honig. A. (2002) Cognition following acute tryptophan depletion: difference between first-degree relatives of bipolar disorder patients and matched healthy control volunteers Psychol Med. 32: 503-15.

Steele, R.J. and Stewart, M.G. (1993) 7-Chlorokynurenate, an antagonist of the glycine binding site on the NMDA receptor, inhibits memory formation in day-old chicks (Gallus domesticus). Behav Neural Biol. 60: 89-92.
Stone: T.W. (2001a) Endogenous neurotoxins from tryptuphan. Taxicon, 39:61-73.

Stone, T.W. (200Ib) Kynurenines in the CNS: from endogenous obscurity to therapeutic importance. Prog Neurobiol. 64: 185-218.

Stone, T.W. and Perkins, M.N. (1981) Quinolinic acid: a potent endogenous excitant at amino acid receptors in CNS. Eur J Pharmacol. 72: 411-2

Twarog. B.M. and Page, I.H. (1953) Serotonin content of some mammalian tissues and urine and a method for its determination. Am J Phoriol. 175 |57-6].

Wang, J.H. Ko, G.Y, and Kelly, P.T (1997) Cellular and molecular bases of memory: synaptic and neuronal plasticity. I Clin Neurophsiol. 14: 264.93. 



\section{Dankwoord}

Ik geloof ten stelligste dat een goede verstandhouding tussen mensen gebaseerd is op het principe van 'geven en nemen'. Zoals bij vele dingen, is het uitvoeren van een onderzoek zeker geen solotrip. Het is moeilijk om iedereen, die op directe of indirecte wijze betrokken is bij de totstandkoming van dit boekje, te vermelden. Toch wil ik een aantal mensen uitdrukkelijk bedanken. Ik heb erg genoten van jullie medewerking en vriendschap en hoop dat het genoegen ook wederzijds is.

Als eerste wil ik Dr. Arjan Blokland bedanken. Na mijn studie bood je mij de mogelijkheid onderzoek te verrichten en uiteindelijk te promoveren bij de vakgroep Psychiatrie en Neuorpsychologie. Jouw suggesties zorgde voor heel wat variatie in het werk. De oplossing voor jouw vele ideeën: 'meten is weten'. Arjan, ik wil je verder bedanken voor het vertrouwen dat je in me gesteld hebt. Je stond me altijd bij in raad en daad. Zonder jouw steun en begeleiding was het allemaal niet zo soepel verlopen. Veel dank hiervoor.

Ik wil mijn promotor Prof. dr. Harry Steinbusch bedanken voor de vrijheid, die hij me al die jaren gegeven heeft.

Dr. Jos Prickaerts en Wiel Honing waren de eerste mensen waarmee in contact kwam binnen de afdeling. Ze hebben me zowat alles wat ik weet over het omgaan en testen van dieren bijgebracht. Jos, jouw enthousiasme voor de neurowetenschappen heb ik als zeer motiverend ervaren. Hopelijk dat onze gemeenschappelijke interesse in het vak in de toekomst tot een publicatie zal leiden. Wiel, als de spanning hoog werd, kwam je er nog een schepje bovenop doen, kwestie van de spanning te doorbreken. Maar toch kon ik meestal wel bij jou terecht voor het oplossen van praktische problemen als ik er niet zeker van was of, hetgeen wat ik in gedachte had, wel 'zou gaan gaan'.

Het delen van een werkruimte met Gunther Kenis, resulteerde meteen in het 'belgen'-plekje binnen de afdeling, waarbij we elkaar aanspraken met 'ge' en waar een mok een tas werd en een balpen, een stylo. Nadien mocht ik een werkruimte delen met Ayhan Sik en deze werd meteen een van de gezelligste kamers binnen de afdeling. Ayhan, je was een zeer leuke collega die de betekenis van teamwerk echt wel tot zijn recht laat komen. Ik ben vereerd om jou als paranimf te hebben. 
Psychologen in een lab, dat is zeker niet evident. Daar kunnen Hellen Steinbusch en Marjanne Markerink wel van meepraten. Leren pipetteren, het maken van buffers bij een sucrose oplossing, het kleuren en insluiten van coupes, het waren allemaal aspecten waarbij jullie hulp zeer van pas kwam. Onze talkie-talkies samen met Lilian Swaen, Nicole Senden en Akke Spauwen, verlichtte vaak mijn isolement in de mannengemeenschap.

Tevens dank ik Kim van Oorsouw, Miriam Nijholt, Isabelle Bauer, Eric Croes en Kris Rutten. Jullie waren destijds nog studenten toen we elkaar leerden kennen. Ik heb veel van jullie geleerd en hoop dat jullie ook iets van mij hebben opgestoken. Allen veel succes toegewenst met jullie carrières. Verder alle (oud-)collega's bedankt voor de gezellige werksfeer. Jullie vormde een leuke en interessante groep.

De grondslag van dit proefschrift is mede terug te vinden bij dr. Nicolaas (alias Mick) Deutz. Niet enkele is Mick co-promotor van dit proefschrift maar hij is weliswaar de bedenker van het TRP-vrije eiwit dieet. Bij Mick kon ik altijd wel terecht voor een open gesprek en zijn medewerkers Gabrie ten Have en dr. Hans van Eijk hebben me steeds bijgestaan bij het opwerken en de concentratiebepaling van samples. Het was telkens benieuwd uitkijken naar wat de resultaten van een pilot of experiment. leder bezoek aan de afdeling van Algemene Heelkunde bracht telkens weer iets spannends met zich mee, variërend van nieuwe bevindingen tot nieuwe ideeën en onderzoeken. Ik voelde me allijd zeer welkom bij jullie, dank voor alles.

Mede dank aan dr. Jeroen Schmitt. Tessa Kilkens en Lisbeth Evers, samen hebben we de eerste pogingen ondernomen on de effecten van het mengsel ook bij mensen te valideren. Tessa, het verzamelen van darmbiopten en hersenstructuren bij 80 muizen leverde onvergetelijke momenten op. Jammer toch dat deze resultaten niet tot een publicatie hebben geleid.

Mede dank aan dr. Rudy Schreiber en zijn lieftallige echtgenote Ineke Groeneveld. Jullic opvang tijdens mijn verblijf in the Bay area, heb ik zeer gewaardeerd. Rudy, ik heb naar mijn gevoel veel opgestoken van jouw professionele aanpak, de waarúevolle adviezen en de tijdelijke betrokkenheid in het reilen en zeilen binnen een farmaceutisch bedrijf. Mocht je beslissen ooit de 'Golden State' te verlaten voor 'de Lage Landen' sta ik als eerste in rij voor een sollicitatiegesprek. 
Anja, mijn best vriendin/ oud kamergenoot/ collega/ getuige/ paranimf/... Ook jij hebt de afgelopen jaren bergen verzet om bepaalde doelen te bereiken. Voor mij blijf je iemand om naar op te kijken. Ofschoon we vaak weinig of geen woorden nodig hebben om hetzelfde te denken, kunnen we ook uren kwebbelen. Bij jou pogingen om iemand te doorgronden, zijn jouw spontane gedragingen en uitspaken kostelijk om te zien en horen. Dank dat je ook nu weer aan mijn zijde wil staan. Natuurlijk wil ik ook Peter, Kurt, An, Maarten, Gerda en den Dave bedanken voor de vriendschap die ik bij jullie vind. Onze jaarlijks verhuis naar Werchter zal waarschijnlijk vervangen worden door een bezoek aan Plopsa-land of een optreden van K3. Zullen we daar dan ook de tent, de barbecue en de sofa meenemen? Verder dank ik alle leden van de families Geelen, Lieben, Peters en Punie.

Natuurlijk wil ik ook mijn ouders, Maria en Luciën, vermelden. Ik ben er fier om jullie dochter te zijn. Jullie hebben me altijd voorzien van een stabiele thuisbasis. Hopelijk dat het pakket van waarden me op lange termijn ook iets oplevert, maar toch goed dat ik ze van thuis uit heb meegekregen. Wat er ook gebeurde, bij juilie kon ik altijd terecht voor een luisterend oor en verkreeg de daaropvolgende steun zonder er om te moeten vragen. Daarom is dit werk ook een beetje van/voor jullie. Bedankt voor alles.

Tot slot, Krist, in de afgelopen jaren hebben we onze portie van vanalles gehad, van vreugde en kabaal tot verdriet en stilte. Maar goed dat jij de rustige van ons twee bent en het geduld kan opbrengen om me zo nu en dan te laten uitrazen. Nu Lena er is, het boekje af is en het huisje bijna bewoonbaar is, moeten we stilletjes uitkijken naar een nieuwe uitdaging of zullen we het eens rustig aan doen?. Moge het nieuwe huis ons ook een gelukkige 'thuis' bieden. En toch ben ik fier op 'ons'.

Cindy 



\section{Curriculum Vitae}

Cindy Lieben is geboren op 3 oktober 1975 te Genk en groeide op in Beverst. In 1994 behaalde zij haar diploma aan het Sint-Lambertus college te Bilzen. Aan de Universiteit Maastricht beëindigde ze in 2000 haar studie Psychologie, afstudeerrichting Neuropsychologie. Inmiddels werkte ze als onderzoeksassistent bij de vakgroep Psychiatrie en Neuropsychologie waar ze reeds als stagaire werkzaam was. In opdracht van het farmaceutisch bedrijf BAYER AG (CNS-Research) verrichtte ze onderzoek naar geheugeneffecten van fosfodiesterase remmers. Haar interesse in onderzoek was gewekt en om haar promotiewerk te vervolledigen startte ze in 2002 als assistent in opleiding binnen het onderzoeksinstituut Hersenen \& Gedrag aan de Universiteit Maastricht, onder supervisie van dr. A. Blokland. In datzelfde jaar voerde ze gedurende enkele maanden onderzoek uit in samenwerking met dr. R. Schreiber binnen ROCHE Pharmaceuticals, Palo Alto, CA, USA. Tijdens de afgelopen jaren heeft ze de gegevens voor de in dit proefschrift gepresenteerde studies verzameld. Intussen is ze getrouwd en onlangs moeder geworden van een flinke dochter. 



\section{Publications}

\section{Articles}

Blokland, A., Lieben, C. and Deutz, N.E. (2002) Anxiogenic and depressivelike effects, but no cognitive deficits, after repeated moderate tryptophan depletion in the rat. J Psychopharmacol. 16: 39-49.

Lieben, C.K., Blokland, A., Westerink, B. and Deutz, N.E. (2004) Acute tryptophan and serotonin depletion using an optimized tryptophan-free protein-carbohydrate mixture in the adult rat. Neurochem Int. 44:9-16.

Lieben, C.K., van Oorsouw, K., Deutz, N.E. and Blokland, A. (2004) Acute tryptophan depletion induced by a gelatin-based mixture impairs object $\mathrm{m}$ emory but not affective behavior and spatial learning in the rat. Behav Brain Res. 151: 53-64.

Evers, E.A.T., Tillie, D.E., van der Veen, F.M., Lieben, C.K., Jolles, J., Deutz, N.E.P. and Schmitt, J.A.J. (2004) Effects of a novel method of acute tryptophan depletion on plasma iryptophan and cognitive performance in healthy volunteers. Psychopharmacology, accepted for publication.

Blokland, A., Lieben, C., Deutz, N.E.P. and Schmitt, J.A.J. (2004) Acute tryptophan depletion: comparing the effects of an amino acid mixture with a gelatine-based protein in man and rats. Current Topics in Nutraceutical Research 2: 161-169.

Lieben, C.K.J.. Blokland, A., Sik, A., Sung, E., van Nieuwenhuizen, P. and Schreiber, R. (submitted). Cognition-enhancing effects of the selective 5-HT, receptor antagonist Ro4368554 in cholinergic and serotonergic models of memory deficiency in the rat. 


\section{Abstracts}

Lieben, C.K.J. and Blokland, A. The effects of acute tryptophan depletion on open field behaviour in rats. Proceedings of the 19th Low Countries Meeting. Nijmegen (1999), p 33.

Lieben, C.K.J. and Blokland, A. Acute tryptophan depletion affects anxiety and depressive-like behavior, but not cognition in rats. 4th Dutch EndoNeuro Meeting, Doorwerth (2000), p 131.

Lieben, C.K.J. and Blokland, A. Acute myocardial infaretion size is related to corticosterone levels, but not anxiety and depressive-like behavior in rats. Proceedings of the 20th Low Countries Meeting, Antwerp (2000), p 20.

Lieben, C.K.J., Blokland, A., Westerink, B. and Deutz, N.E.P. A new method for acute tryptophan depletion to affect serotonin synthesis in the rat. 5th Dutch EndoNeuro Meeting, Doorwerth (2001), p 131.

van Oorsouw, K.I.M., Lieben, C.K.J. and Blokland, A. Substantial tryptophan depletion does not affect anxiety-or depression-related behavior, but impairs object memory in the rat. 5th Dutch EndoNeuro Meeting, Doorwerth (2001), p 151 .

Nijholt, M.M., I.ieben, C.K.J.. Sik, A. and Blokland, A. Rate dependency of dopaminergic and serotonergic drugs in animal models of impulsivity. 5th Dutch EndoNeuro Meeting, Doorwerth (2001), p 147.

L.ieben, C.K.J., van Oorsouw, K.I.M., Deutz, N.E.P. and Blokland, A. Substantial tryptophan depletion does not affect anxiety- or depressionrelated behavior, but impairs object memory in the rat. The first joint meeting of EBBS-EBPS, Marseille (2001), p S60.

Szezepanski, K., Vivian. J.A.. Dorsch, K., Blokland, A., Hedley, L., Lieben, C., Martin, J.R., Moreau, J.L., Secchi, R.L., Sik, A., Sung, E. and Schreiber, R. Procognitive effects of the 5-HT, receptor antagonist RO4368554. Society of Neuroscience. Orlando (2002), 290.20. 
Lieben, C.K.J., Blokland, A., Sung, E., Sik, A. and Schreiber, R. Cognitive effect of the acetylcholinesterase inhibitor metrifonate and the 5- $\mathrm{HT}_{\text {o }}$ antagonist RO4368554 in several rat models of memory deficiency in the object recognition test. The 10th biennal meeting of EBPS, Antwerp (2003), p S31.

Lieben, C.K.J. and Blokland, A. Comparable effects of acute and chronic 5-HT depletion: impaired object recognition but no effects on forced swimming behavior in rats. Society for Neuroscience, New Orleans (2003), 835.19 . 
